\title{
Documented Safety Analysis for the Waste Storage Facilities
}

\author{
Danny T. Laycak
}

March 2010 


\section{Weapons and Complex Integration \\ Radioactive and Hazardous Waste Management Division}

\section{DISCLAIMER}

This document was prepared as an account of work sponsored by an agency of the United States government. Neither the United States government, nor Lawrence Livermore National Security, LLC, nor any of their employees makes any warranty, expressed or implied, or assumes any legal liability or responsibility for the accuracy, completeness, or usefulness of any information, apparatus, product, or process disclosed, or represents that its use would not infringe privately owned rights. Reference herein to any specific commercial product, process, or service by trade name, trademark, manufacturer, or otherwise does not necessarily constitute or imply its endorsement, recommendation, or favoring by the United States government or Lawrence Livermore National Security, LLC. The views and opinions of authors expressed herein do not necessarily state or reflect those of the United States government or Lawrence Livermore National Security, LLC, and shall not be used for advertising or product endorsement purposes.

This work performed under the auspices of the U.S. Department of Energy by Lawrence Livermore National Laboratory under Contract DE-AC52-07NA27344. 


\title{
Documented Safety Analysis for the Waste Storage Facilities
}

\author{
March 2010
}

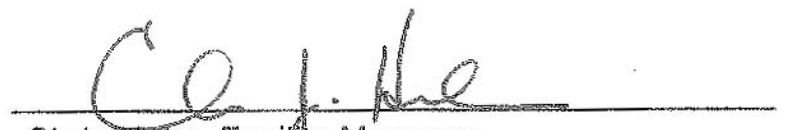

Chris Hôm, Facily Manager

Waste Storage Facilities

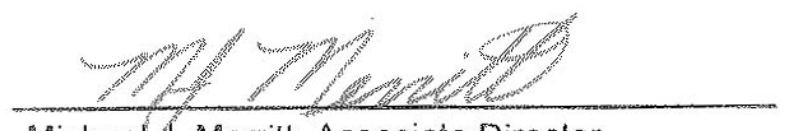

Michael/. Merritt, Associate Director

Nuclear Operations Directorate

Approved By:

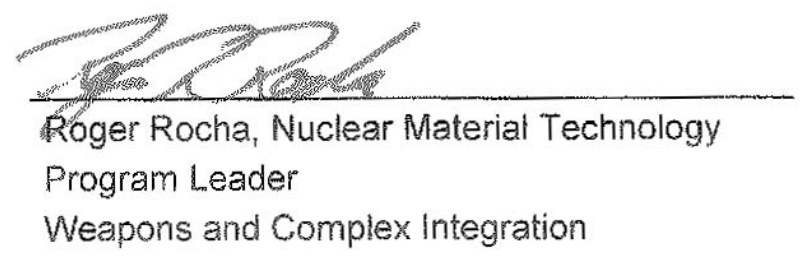

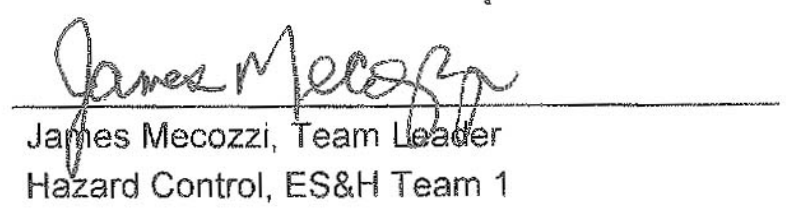




\section{Weapons and Complex Integration}

Radioactive and Hazardous Waste Management Division

This page intentionally left blank. 


\section{Table of Contents}

\section{Chapter 1 - Site Characteristics}

1.1 Introduction........................................................................................ 1

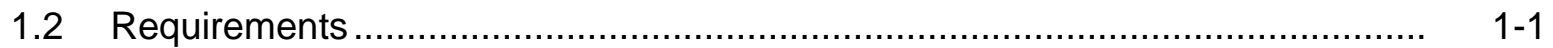

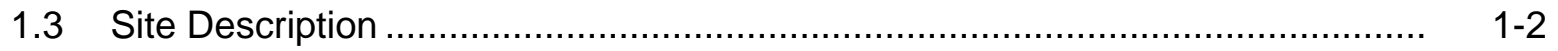

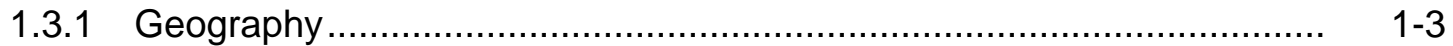

1.3.2 Demography ……............................................................... $1-3$

1.4 Environmental Description ...................................................................... $1-3$

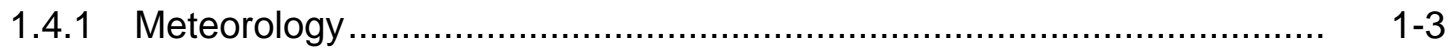

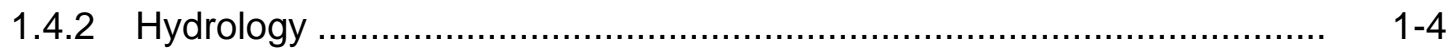

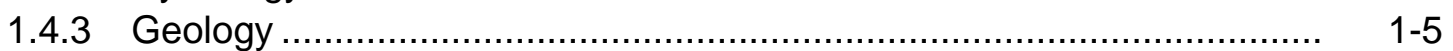

1.5 Natural Phenomena Threats ................................................................... 1-6

1.5.1 Earthquakes …….................................................................. $1-6$

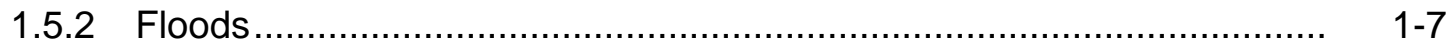

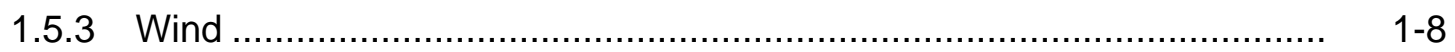

1.5.4 Lightning ……....................................................................... $1-8$

1.6 External Man-made Threats ................................................................. 1-8

1.7 Nearby Facilities ..................................................................................... $1-8$

1.8 Validity of Existing Environmental Analyses.................................................. 1-9

1.9 References .................................................................................

\section{Chapter 2 - Facility Description}

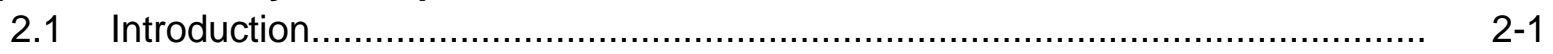

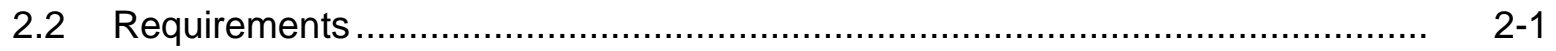

$2.3 \quad$ Facility Overview ................................................................................ 2-4

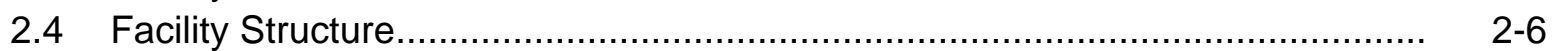

2.4.1 List of Facilities and Areas............................................................ 2-6

2.4.2 Basic Floor Plans of Facilities............................................................. 2- 2-7

2.4.3 Dimensions Significant to Hazard and Accident Analysis .................... 2-11

2.4.4 Construction Material................................................................... 2-12

2.4.5 Facility Performance Categorization.................................................... 2-13

2.4.6 Underground Tanks.................................................................... 2-13

2.5 Process Description ...................................................................... 2-14

2.5.1 Storage Operations .................................................................. 2- 2-14

2.5.2 Trailer-mounted Nondestructive Assay (NDA) System ....................... 2-19

2.5.3 Real-time Radiography (RTR) System ............................................. 2-19

$\begin{array}{ll}2.5 .4 \text { Headspace gas sampling (HSGS) System and Thermal } & 2-19\end{array}$

2.5.5 TRUPACT-II Loading/Unloading …............................................. 2-20

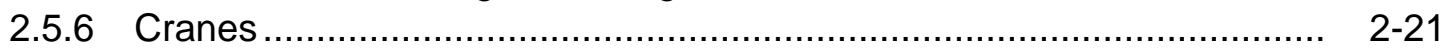

2.5.7 Maintenance Activities......................................................... 2-22 
2.6 Confinement, Containment and Ventilation Systems ................................ 2-22

2.6.1 Waste Containers ...................................................................... $2-22$

2.6 .2 Floors...................................................................................... $2-22$

2.6.3 Freezer Storage ................................................................. $2-22$

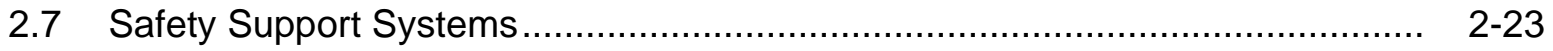

2.7.1 Fire Protection .......................................................................... $2-23$

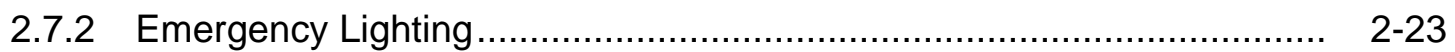

2.7.3 Emergency Evacuation/Alarm ...................................................... 2-23

2.7.4 Radiation Protection and Warning System ....................................... 2-23

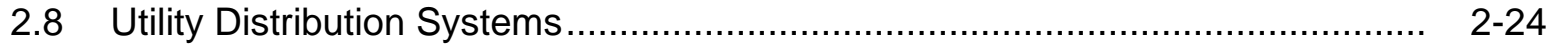

2.9 Auxiliary Systems and Support Facilities ............................................... $2-24$

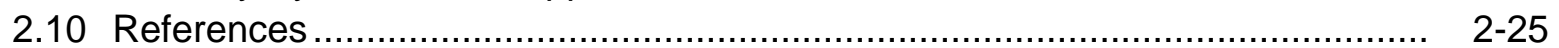

\section{Chapter 3 - Hazard And Accident Analyses}

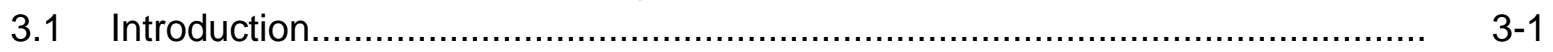

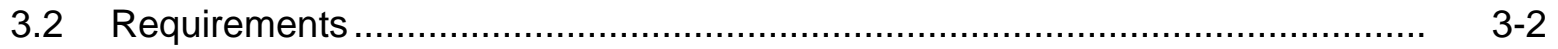

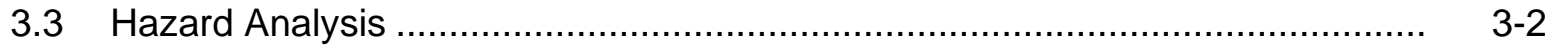

3.3.1 Methodology ........................................................................... 3

3.3.2 Hazard Analysis Results....................................................... $3-11$

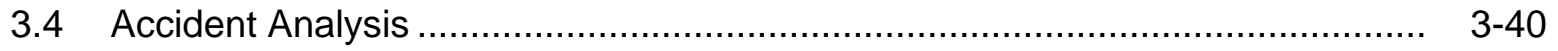

3.4.1 Methodology ...................................................................... $3-40$

3.4.2 Design Basis Accidents ............................................................ $3-43$

3.4.3 Beyond Design Basis Accidents ........................................... 3-60

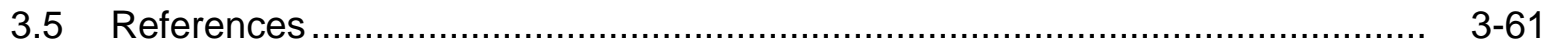

Chapter 4 - Safety Structures, Systems, and Components

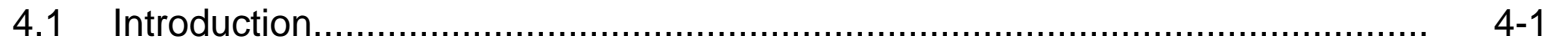

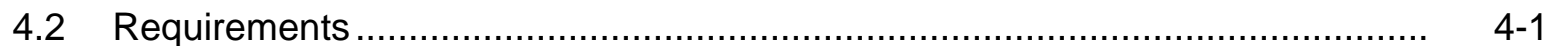

4.3 Safety-Class Structures, Systems, and Components ................................... $4-2$

4.4 Safety-Significant Structures, Systems, and Components ............................. $4-2$

4.4.1 Approved TRU Waste Containers .................................................. 4-3

4.4.2 B625 and B696R Structural Systems ............................................ $4-5$

4.4.3 B696S/B696R Partition............................................................... 4-7

4.5 Specific Administrative Controls (SACs) .......................................... $4-9$

4.5.1 TRU Waste Inventory Limits ...................................................... 4

4.5.2 Fissile Material Container Limit ................................................... $4-10$

4.5.3 Tritium Container Limit ........................................................... $4-11$

4.5.4 TRU Waste Staging Limits ...................................................... $4-12$

4.5.5 Authorized TRU Waste Storage Locations ...................................... 4-13

4.5.6 Storage in Approved TRU Waste Containers ..................................... 4-14

4.5.7 Approved TRU Waste Container Stacking Limits............................. $4-14$

4.5.8 Approved TRU Waste Container Lids ........................................ 4-15

4.5.9 Approved TRU Waste Container Staging Locations .......................... 4-16

4.5.10 Use of Metal Containers and Pallets for Waste in TRU Waste

Storage Areas........................................................................... 4-17

4.5.11 Combustible Loading Limit ................................................. $4-18$

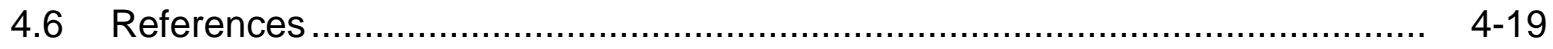




\section{Chapter 5 - Derivation of Technical Safety Requirements}

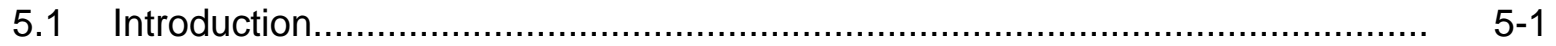

5.2 Requirements ............................................................................. 5

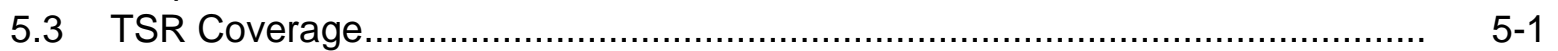

5.3.1 Important Defense in Depth requiring TSR coverage........................... 5-2

5.3.2 Worker Safety ................................................................... $5-2$

5.3.3 Safety-Class SSCs .................................................................. $5-4$

5.3.4 Safety-Significant SSCs ............................................................ $5-4$

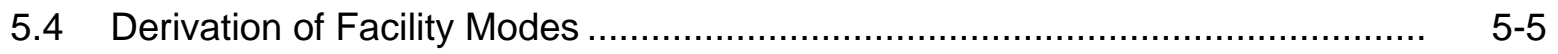

5.5 TSR Derivation ................................................................................ 5

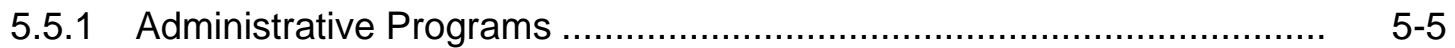

5.5.2 Specific Inventory Limits........................................................... $5-12$

5.5.3 Specific Container Handling and Storage Provisions ……………....... 5-13

5.6 Design Features ............................................................................. $\quad 5-15$

5.6.1 Equipment Important to Safety ................................................ $\quad 5-15$

5.7 Interface with TSRs from Other Facilities ...................................................... 5-16

5.8 References ................................................................................... $5-16$

CHAPTER 6 - Prevention of Inadvertent Criticality

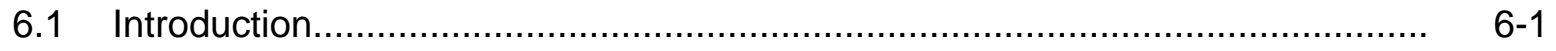

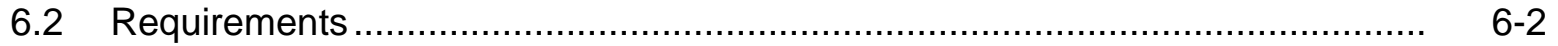

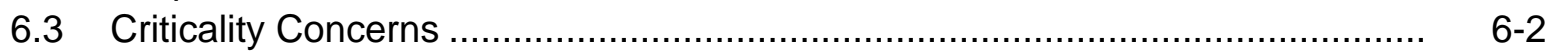

6.4 Criticality Safety Controls ............................................................................ $6-3$

6.4.1 Engineering Controls ................................................................. $6-3$

6.4.2 Administrative Controls................................................................ 6-3

6.4.3 Application of Double Contingency Principle ..................................... 6. 6-4

6.5 Criticality Protection Program ...................................................................... $6-4$

6.5.1 Criticality Safety Organization ………………….......................... $6-4$

6.5.2 Criticality Safety Plans and Procedures .......................................... $6-5$

6.5.3 Criticality Safety Training ............................................................ 6

6.5.4 Determination of Operational Nuclear Criticality Limits ........................ 6 6 6

6.5.5 Criticality Safety Inspections/Audits................................................ 6- 6 6

6.5.6 Criticality Infraction Reporting and Follow-Up …………………........ 6 6-6

6.6 Criticality Instrumentation ................................................................. 6

6.7 References ..............................................................................

\section{Chapter 7 - Radiation Protection}

7.1 Introduction......................................................................................

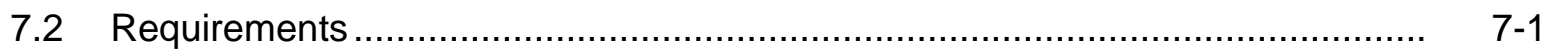

7.3 Radiation Protection Program and Organization ............................................. $\quad$ 7-1

7.4 ALARA Policy and Program .....................................................................

7.5 Radiological Protection Training.................................................................. $\quad 7-3$

7.6 Radiation Exposure Control ………………........................................

7.6.1 Administrative Limits............................................................... $\quad$ 7-3

7.6.2 Radiological Practices ............................................................... $\quad 7-4$

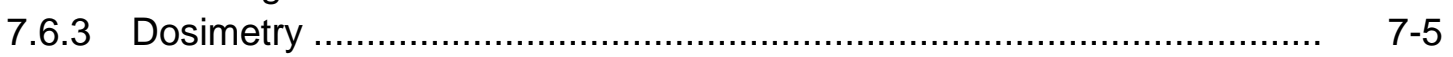

7.6.4 Respiratory Protection .............................................................. $\quad$ 7-5 


\section{Documented Safety Analysis for the Waste Storage Facilities}

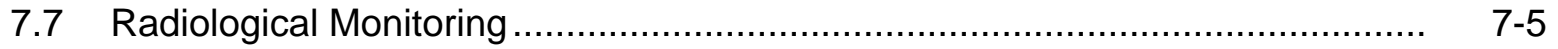

7.8 Radiological Protection Instrumentation ................................................... $\quad 7-5$

7.9 Radiological Protection Record-Keeping................................................. $\quad 7-6$

7.10 Occupational Radiation Exposures …...................................................... $\quad 7-6$

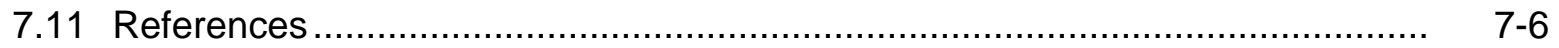

\section{Chapter 8 - Hazardous Material Protection}

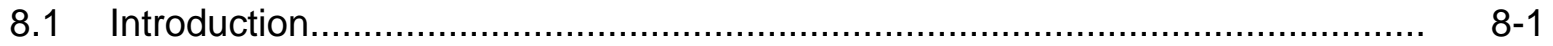

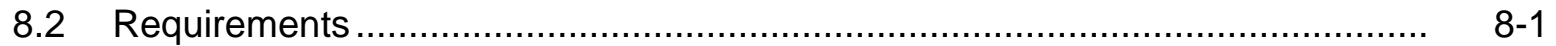

8.3 Hazardous Material Protection Program and Organization .............................. 8-1

8.4 ALARA Policy and Program ................................................................. 8

8.5 Hazardous Material Training ..................................................................

8.6 Hazardous Material Exposure Control ...................................................... 8-3

8.6.1 Hazardous Material Identification Program …................................... 8

8.6.2 Administrative Limits............................................................... 8 8-3

8.6.3 Occupational Medical Programs................................................. $8-4$

8.6.4 Respiratory Protection ............................................................ 8

8.7 Hazardous Material Monitoring …........................................................... 8

8.8 Hazardous Material Protection Instrumentation .............................................

8.9 Hazardous Material Protection Record-Keeping ...................................... $8-5$

8.10 Hazard Communication Program ........................................................... 8-6

8.11 Occupational Chemical Exposures .............................................................

8.12 References ....................................................................................

Chapter 9 - Radioactive and Hazardous Waste Management

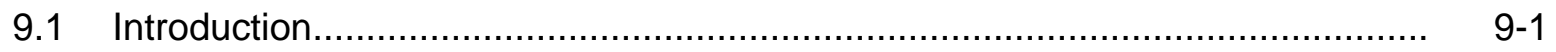

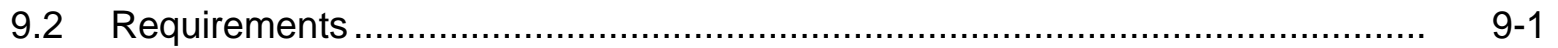

9.3 Radioactive and Hazardous Waste Management Program and

Organization ........................................................................................ 9

9.3.1 Program and Policies ........................................................... $9-2$

9.3.2 Organizational Structure ......................................................... $9-2$

9.3.3 Training ............................................................................................

9.3.4 Plans and Procedures .............................................................. 9-3

9.4 Radioactive and Hazardous Waste Streams or Sources ............................... 9-3

9.4.1 Waste Management Process ...................................................... 9-3

9.4.2 Waste Sources and Characteristics ................................................. 9 9-4

9.4.3 Waste-Handling or Waste-Treatment Systems ............................... $9-4$

9.5 References ............................................................................. $9-4$

Chapter 10 Initial Testing, In-Service Surveillance, and Maintenance

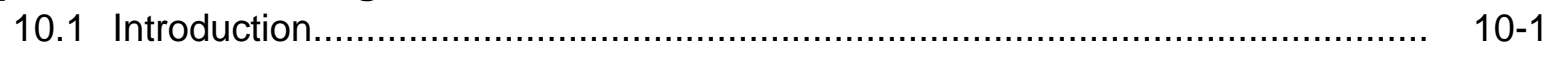

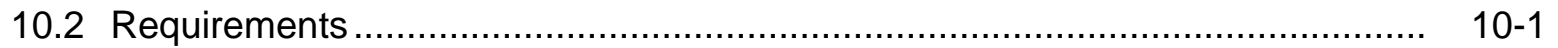

10.3 Initial Testing Program .......................................................................... $10-1$

10.4 In-Service Inspection \& Test Program............................................. $10-1$

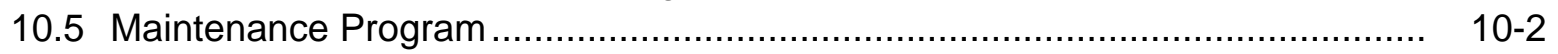

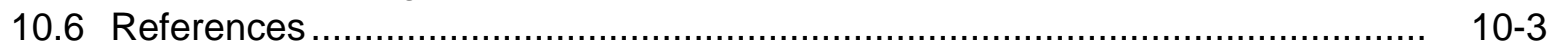




\section{Chapter 11 - Operational Safety}

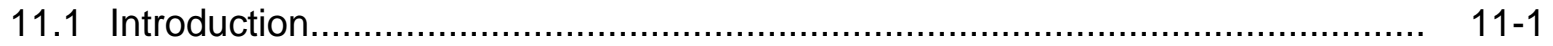

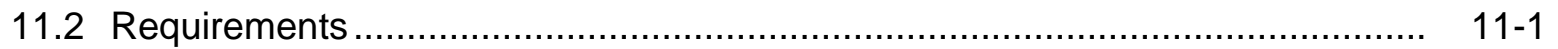

11.3 Conduct of Operations …............................................................... $11-2$

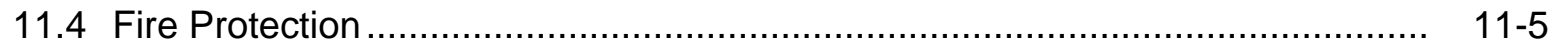

11.4.1 Fire Hazards .......................................................................... 11-5

11.4.2 Fire Protection Program and Organization ................................. 11-8

11.4.3 Combustible-Loading Control ...................................................... 11-9

11.4.4 Fire Fighting Capabilities ......................................................... 11-10

11.4.5 Fire-Fighting-Readiness Assurance ............................................ 11-13

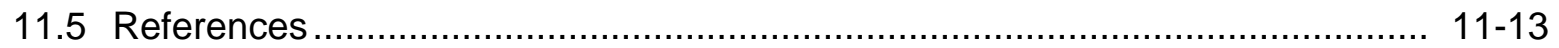

\section{Chapter 12 - Procedures and Training}

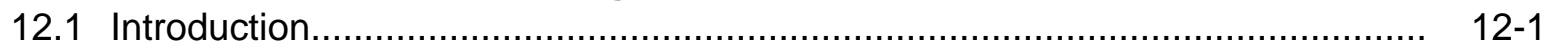

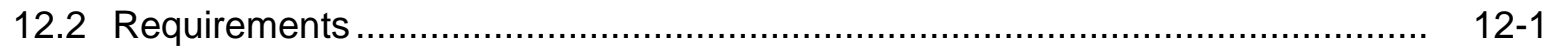

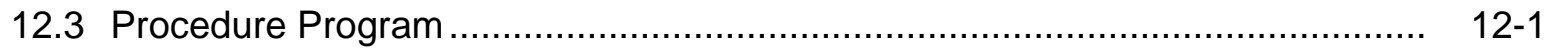

12.3.1 Development of Procedures ......................................................... $12-2$

12.3.2 Maintenance of Procedures............................................................ $12-2$

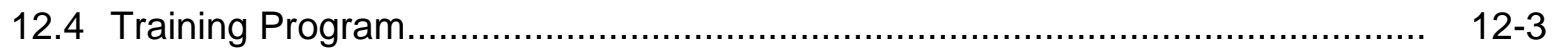

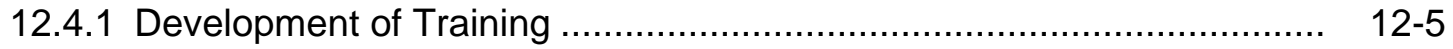

12.4.2 Maintenance of Training ........................................................... $12-5$

12.4.3 Modification of Training Materials ............................................ $12-5$

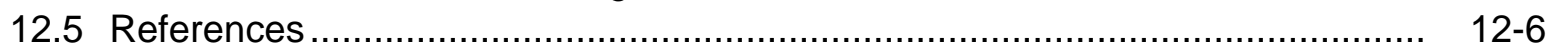

\section{Chapter 13 - Human Factors}

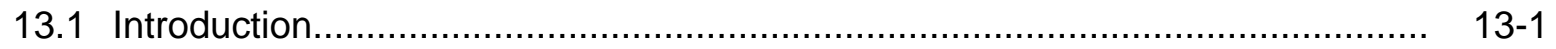

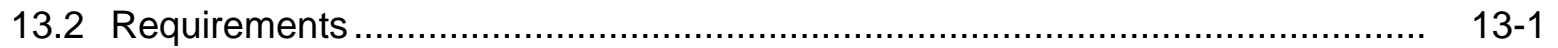

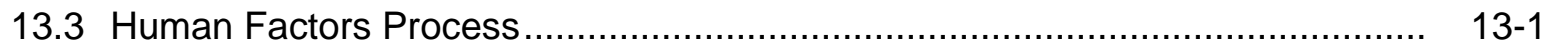

13.4 Identification of Human-Machine Interfaces ............................................... 13-1

13.5 Optimization of Human-Machine Interfaces ...................................... $13-2$

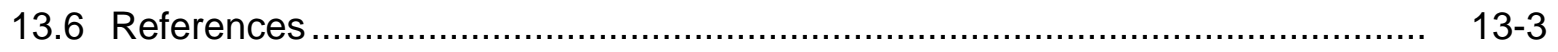

\section{Chapter 14 - Quality Assurance}

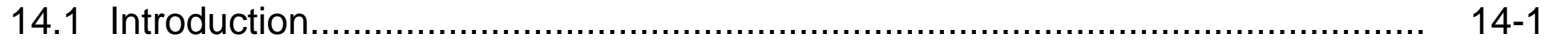

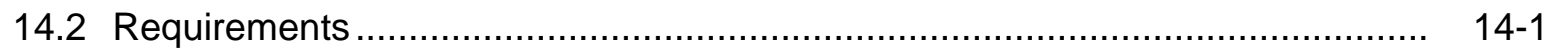

14.3 Quality Assurance Program and Organization ...................................... 14-1

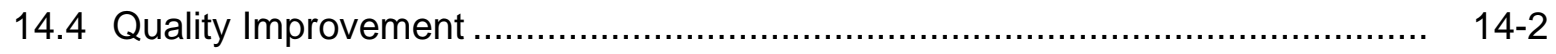

14.5 Documents and Records ................................................................... $14-2$

14.6 Quality Assurance Performance ......................................................... $14-2$

14.6.1 Work Processes ......................................................................... 14-2

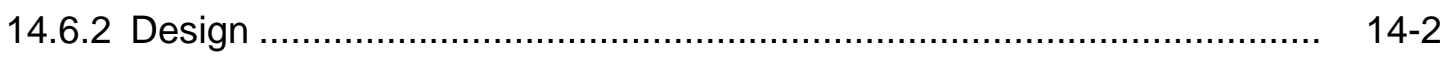

14.6.3 Procurement ............................................................................. 14-3

14.6.4 Inspecting and Testing for Acceptance ......................................... 14-3

14.6.5 Independent Assessment ..................................................... 14-3

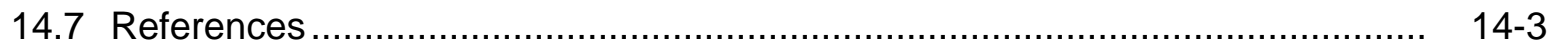


Chapter 15 - Emergency Preparedness Program

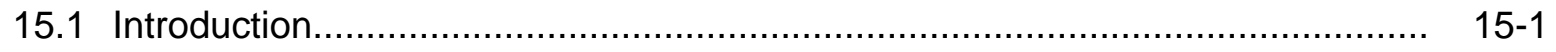

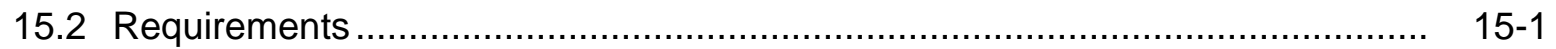

15.3 Scope of Emergency Preparedness.................................................... $15-1$

15.4 Emergency Preparedness Planning .................................................... $15-3$

15.4.1 Emergency Response Organization........................................... 15-3

15.4.2 Assessment Actions ................................................................ 15-4

15.4.3 Notification ............................................................................ 15-6

15.4.4 Emergency Facilities and Equipment ........................................ 15-6

15.4.5 Protective Actions .................................................................. 15-7

15.4.6 Training and Exercises ........................................................ 15-8

15.4.7 Recovery and Reentry ............................................................ 15-9

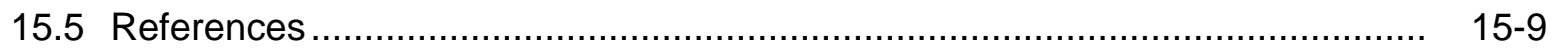

Chapter 16 - Provisions for Decontamination and Decommissioning

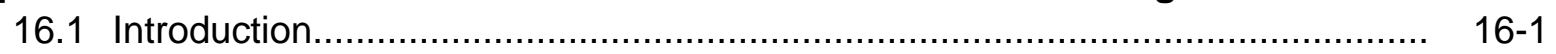

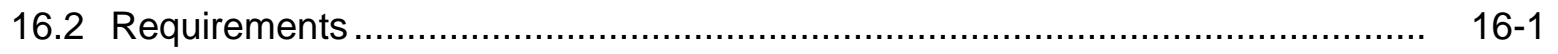

16.3 Description of Conceptual Plan .................................................... $16-2$

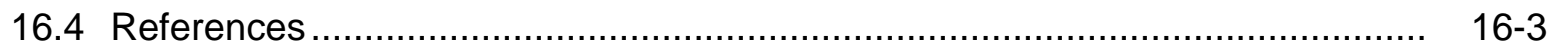

Chapter 17 - Management, Organization, and Institutional Safety Provisions

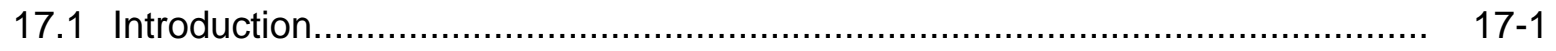

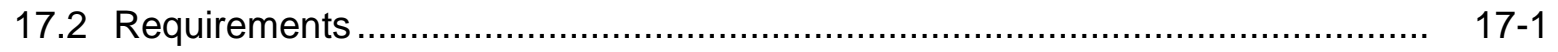

17.3 Organizational Structure, Responsibilities, and Interfaces ......................... $17-2$

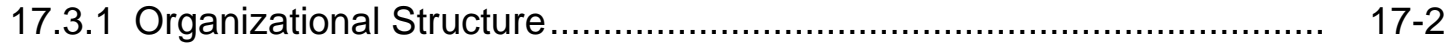

17.3.2 Organizational Responsibilities ............................................ 17-2

17.3.3 Staffing and Qualifications .................................................... 17-5

17.4 Safety Management Policies and Programs ......................................... $17-5$

17.4.1 Safety Review and Performance Assessment ................................ 17-5

17.4.2 Configuration Management and Document Control ........................... 17-6

17.4.3 Occurrence Reporting ........................................................ $17-6$

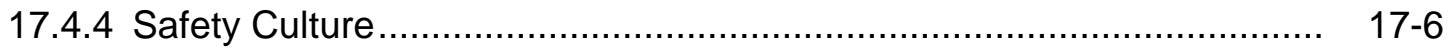

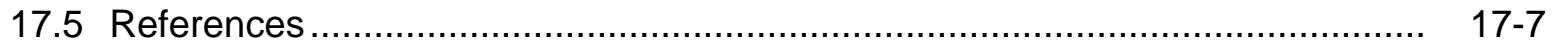

\section{Appendices}

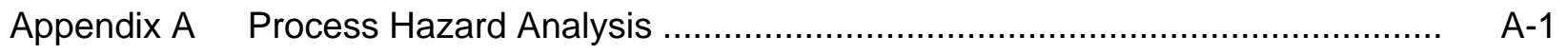

Appendix B $\quad$ Aircraft Crash Analysis ............................................................ B-1

Appendix C Segmentation Justification from the B695 segment ............................ C-1 


\section{Figures}

Figure 2-1. Area 625 Facilities .................................................................... $2-2$

Figure 2-2. DWTF Storage Area in the DWTF Complex..................................... $2-3$

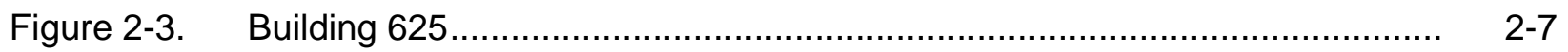

Figure 2-4. Area 612 Tank Trailer Storage ............................................................

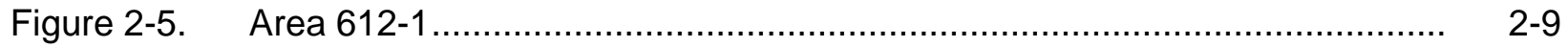

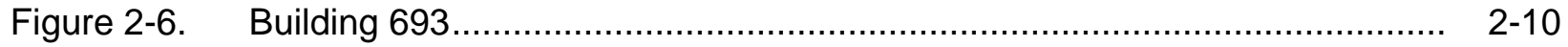

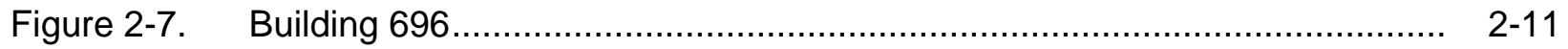

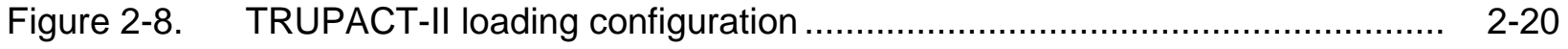

\section{Tables}

Table 2-1. $\quad$ Summary of Allowable Waste Types .................................................. $2-6$

Table 2-2. Building Dimensions ..................................................................... $2-11$

Table 2-3. $\quad$ Construction Material used in Waste Storage Facilities .......................... 2-12

Table 2-4. Facility Performance ...................................................................... $2-13$

Table 3-1. Qualitative Frequency of Occurrence of Postulated Events ..................... 3-6

Table 3-2. Severity Levels and Criteria ................................................... $3-8$

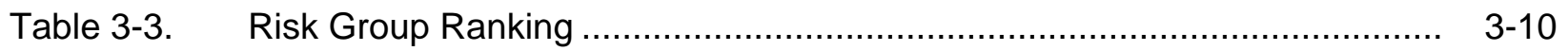

Table 3-4. $\quad$ Waste Storage Facilities Hazard Source List ..................................... $3-12$

Table 3-5. $\quad$ Representative Radionuclides for a Typical Waste Storage Facility ........... 3-13

Table 3-6. Dose Consequence Values from Ground Release of Non-Buoyant Plume .......................................................................................... $3-43$

Table 3-7. Dose Consequence Values from Ground Release of Buoyant Plume ........ 3-43

Table 5-1. Design Features Requiring TSR Coverage .......................................... $5-2$

Table 5-2. Control Features and Associated Assumptions................................... $\quad$ 5-3

Table 5-3. Minimum Staffing Requirements ...................................................... 5 



\section{Acronyms}

ACGIH American Conference of Governmental Industrial Hygienists

ALARA As low as reasonably achievable

ARF Airborne Release Fraction

CCR California Code of Regulations

CED Committed Effective Dose

CERCLA Comprehensive Environmental Response, Compensation, and Liability Act

CFR Code of Federal Regulations

$\mathrm{CM} \quad$ Configuration Management

CSE Criticality Safety Evaluation

D\&D Decontamination and Decommissioning

DBA Design Basis Accident

DBE Design Basis Earthquake

DBFL Design Basis Flood

DBW Design Basis Wind

DOE Department of Energy

DOT Department of Transportation

DR Damage Ratio

DSA Documented Safety Analysis

DTSC Department of Toxic Substances Control

DWTF Decontamination and Waste Treatment Facility

EBA Evaluation Basis Accident

EG Evaluation Guideline 


\begin{tabular}{|c|c|}
\hline EIS & Environmental Impact Statement \\
\hline EPA & Environmental Protection Agency \\
\hline ERO & Emergency Response Organization \\
\hline ERPG & Emergency Response Planning Guideline \\
\hline ES\&H & Environment, Safety, and Health \\
\hline EVA & Emergency Voice Alarm \\
\hline FFA & Federal Facilities Agreement \\
\hline FFCA & Federal Facilities Compliance Act \\
\hline FGE & Fissile Gram Equivalent \\
\hline $\mathrm{FHA}$ & Fire Hazard Analysis \\
\hline FSP & Facility Safety Plan \\
\hline $\mathrm{HC}$ & Hazard Category \\
\hline HDPE & High Density Polyethylene \\
\hline HWCL & Hazardous Waste Control Law \\
\hline IDLH & Immediately Dangerous to Life or Health \\
\hline ISM & Integrated Safety Management \\
\hline IWS & Integration Work Sheet \\
\hline LCO & Limiting Condition for Operation \\
\hline LLNL & Lawrence Livermore National Laboratory \\
\hline LLNS & Lawrence Livermore National Security \\
\hline LLW & Low-Level Waste \\
\hline LPF & Leak Path Factor \\
\hline LPG & Liquified Propane Gas \\
\hline MAR & Material at Risk \\
\hline
\end{tabular}




\begin{tabular}{|c|c|}
\hline MOI & Maximally-exposed Offsite Individual \\
\hline MUSD & Maintenance Utility Services Depertment \\
\hline NDA & Nondestructive Assay \\
\hline NFPA & National Fire Protection Association \\
\hline $\mathrm{NPH}$ & Natural Phenomena Hazard \\
\hline OEL & Occupational Exposure Limit \\
\hline OSHA & Occupational Safety and Health Administration \\
\hline PC & Performance Category \\
\hline PE-Ci & ${ }^{239} \mathrm{Pu}$-equivalent Curies \\
\hline PEL & Permissible Exposure Limit \\
\hline PPE & Personal Protective Equipment \\
\hline PrHA & Process Hazard Analysis \\
\hline QA & Quality Assurance \\
\hline QAMP & Quality Assurance Management Plan \\
\hline QAP & Quality Assurance Plan \\
\hline RCRA & Resource Conservation and Recovery Act \\
\hline RF & Respirable Fraction \\
\hline RHWM & Radioactive and Hazardous Waste Management \\
\hline RQ & Reportable Quantity \\
\hline RWQCB & Regional Water Quality Control Board \\
\hline RWSA & Radioactive Waste Storage Area \\
\hline SC & Safety Class \\
\hline SCIL & Single Container Inventory Limit \\
\hline $\mathrm{SIH}$ & tandard Industrial Hazard \\
\hline
\end{tabular}




\begin{tabular}{|c|c|}
\hline SMP & Safety Management Program \\
\hline SP & Safety Plan \\
\hline SS & Safety Significant \\
\hline SSC & Structure, System, or Component \\
\hline ST & Source Term \\
\hline SWB & Standard Waste Box \\
\hline SWPA & Solid Waste Processing Area \\
\hline TEDE & Total Effective Dose Equivalent \\
\hline TIM & Training Implementation Matrix \\
\hline TLV & Threshold Limit Value \\
\hline TQ & Threshold Quantity \\
\hline TRU & Transuranic \\
\hline TRUW & Transuranic Waste \\
\hline TSCA & Toxic Substances Control Act \\
\hline TSR & Technical Safety Requirement \\
\hline UBC & Uniform Building Code \\
\hline USQ & Unreviewed Safety Question \\
\hline $\mathrm{WCl}$ & Weapons and Complex Integration \\
\hline WAC & Waste Acceptance Criteria \\
\hline WDR & Waste Disposal Requisition \\
\hline WIPP & Waste Isolation Pilot Plant \\
\hline
\end{tabular}




\section{EXECUTIVE SUMMARY}

\section{E.1 FACILITY BACKGROUND AND MISSION}

This Documented Safety Analysis (DSA) for the Waste Storage Facilities was developed in accordance with 10 CFR 830, Subpart B, "Safety Basis Requirements," and utilizes the methodology outlined in DOE-STD-3009-94, Change Notice 3.

The Waste Storage Facilities consist of Area 625 (A625) and the Decontamination and Waste Treatment Facility (DWTF) Storage Area portion of the DWTF complex. These two areas are combined into a single DSA, as their functions as storage for radioactive and hazardous waste are essentially identical. The B695 Segment of DWTF is addressed under a separate DSA. This DSA provides a description of the Waste Storage Facilities and the operations conducted therein; identification of hazards; analyses of the hazards, including inventories, bounding releases, consequences, and conclusions; and programmatic elements that describe the current capacity for safe operations.

The mission of the Waste Storage Facilities is to safely handle, store, and treat hazardous waste, transuranic (TRU) waste, low-level waste (LLW), mixed waste, combined waste, nonhazardous industrial waste, and conditionally accepted waste generated at LLNL (as well as small amounts from other DOE facilities).

\section{E.2 FACILITY OVERVIEW}

The Waste Storage Facilities are located in two portions of the LLNL Main Site (Site 200), as shown in Figure Ex-1. A625 is located in the southeast quadrant of LLNL. The DWTF Storage Area, which includes Building 693 (B693), Building 696 Radioactive Waste Storage Area (B696R), and associated yard areas and storage areas within the yard, is located in the northeast quadrant of LLNL in the DWTF complex. A625 and the DWTF Storage Area are subdivided into various facilities and storage areas, consisting of buildings, tents, other structures, and open areas. Utilities are provided as part of the LLNL infrastructure. LLNL has an onsite Fire Department, as well as a Health Services Department for medical support. 


\section{Documented Safety Analysis for the Waste Storage Facilities}

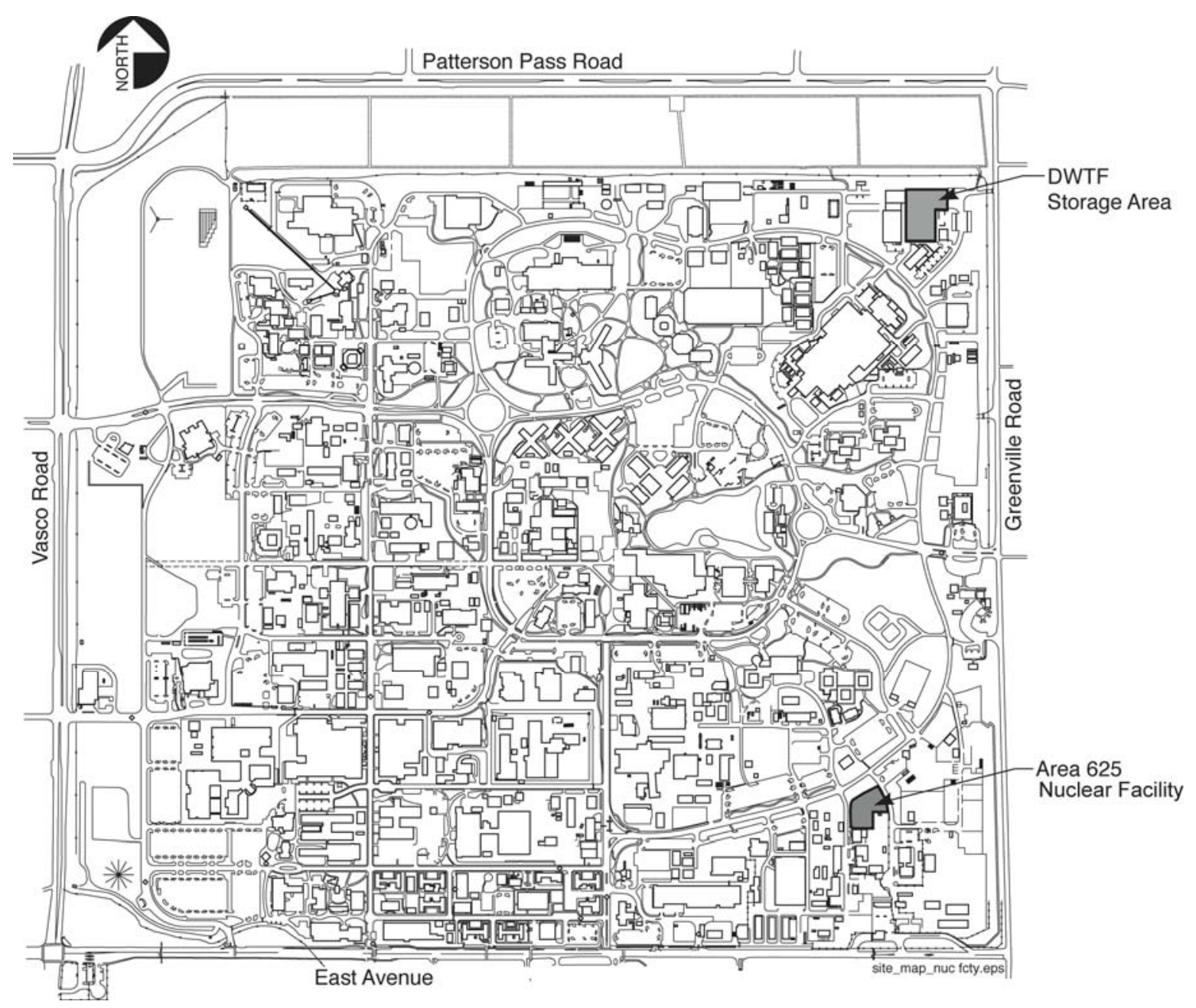

Figure Ex-1. Waste Storage Facilities at LLNL

\section{E.3 FACILITY HAZARD CLASSIFICATION}

The Waste Storage Facilities are Hazard Category 2 nuclear facilities. This categorization was determined by comparing the facility inventory of radionuclides with threshold values for the various hazard-classification levels in accordance with Section 3 of DOE-STD-1027-92, Change Notice 1, Hazard Categorization and Accident Analysis Techniques for Compliance with DOE Order 5480.23, Nuclear Safety Analysis Reports. The hazard classification defines the required level of safety documentation and the DOE orders governing the safety analysis.

The chemical hazard classification of low-hazard was determined by a comparison of chemical inventories with published threshold values. 


\section{E.4 SAFETY ANALYSIS OVERVIEW}

This section provides an overview of the Waste Storage Facilities operations and the results of the safety analysis.

- These facilities are primarily used for handling and storing containerized waste. The types of waste include hazardous waste, TRU waste, LLW, mixed waste, combined waste, nonhazardous industrial waste, and conditionally accepted waste. Operations and activities include (but are not limited to) moving containerized waste, maintaining integrity of waste containers, bulking, overpacking, surveying and assaying, lab packing, and sampling waste.

- The A625 and DWTF Storage Area facilities are consolidated into one DSA in order to standardize the safety provisions for all RHWM waste storage facilities and to reduce the administrative burden for document preparation and approval.

- The Hazard Analysis evaluated both radiological and chemical hazards, and concluded that the hazard of primary concern associated with the Waste Storage Facilities is TRU waste. A number of radiological release scenarios were, therefore, brought forward for Accident Analysis. The design basis accidents (DBAs) are:

- Deflagration in an approved TRU waste container.

- A spill involving multiple approved TRU waste containers being staged outside of a building.

- A fire involving multiple approved TRU waste containers stored inside a building.

- A fire involving multiple LLW containers containing tritium stored inside a building.

- A spill and fire involving multiple approved TRU waste containers being staged outside of a building.

- An aircraft crash into a TRU waste storage building.

- It is concluded from the Hazard and Accident Analyses that no passive or active system, structure, or component (SSC) should be classified as safety class. The following passive SSCs have been identified as safety significant: approved TRU waste containers; the B625 and B696R structural systems; and the B696S/B696R partition. The Technical Safety Requirements for the Waste Storage Facilities will include: the safety significant SSCs as design features, a number of specific administrative controls relating to inventory limits and waste container handling and storage, and programmatic administrative controls. 


\section{E.5 ORGANIZATIONS}

The Radioactive and Hazardous Waste Management (RHWM) Division of Weapons and Complex Integration (WCI) at LLNL is responsible for maintenance and operation of the Waste Storage Facilities. Facility safety is the joint responsibility of the Nuclear Operations Directorate, the RHWM Division, and LLNL Hazard Control Department Environment, Safety, and Health Team 1. This DSA was prepared by RHWM personnel with facility personnel information.

\section{E.6 SAFETY ANALYSIS CONCLUSIONS}

Facility risk is a measure of the effectiveness of the design and administrative controls in reducing the probability of operational hazards impacting workers, the public, and the environment. In this DSA, it is concluded that for the accidents analyzed, the overall risk to workers, the public, and the environment during the operation of the Waste Storage Facilities is adequately analyzed and appropriate controls have been developed. The safety analysis shows that the mitigated risk to workers and the public for all facility operations is low or negligible.

\section{E.7 DSA ORGANIZATION}

This DSA was developed in accordance with the 10 CFR 830 "Safe Harbor" methodology outlined in DOE-STD-3009-94, Change Notice 3. 


\section{CHAPTER 1 SITE CHARACTERISTICS}

\section{$1.1 \quad$ INTRODUCTION}

This chapter provides an overview of the site characteristics of the LLNL Main Site (Site 200) and the Radioactive and Hazardous Waste Management (RHWM) Waste Storage Facilities, which includes Area 625 (A625) and the Decontamination and Waste Treatment Facility (DWTF) Storage Area, that are necessary for understanding these facilities and their operations. The remainder of the DWTF complex, consisting of the B695 Segment of DWTF, is addressed under a separate DSA. All references to the LLNL site in this document will be to the Main Site. The Site 300 waste storage facility is covered by a different safety basis document.

The RHWM Waste Storage Facilities are low chemical-hazard facilities. Based on the inventory of transuranic (TRU) waste, these facilities are Hazard Category 2 nuclear facilities. The information presented herein provides support for the assumptions in the hazard and accident analyses used to identify and analyze potential external and natural phenomena accidents. Sections on site description (geography, demography), environmental description (meteorology, hydrology, geology), natural phenomena threats, external threats, nearby facilities, and validity of existing environmental analyses provide this support information. Complete discussions of the LLNL site geology, seismology, demography, local and regional meteorology, climatology, regional land and water use patterns, and hydrology are presented in the LLNL Environmental Impact Statement (EIS) (DOE 2005).

\subsection{REQUIREMENTS}

This section contains the directives in effect as of February 2009 as implemented in the Lawrence Livermore National Security, LLC, Contract No. DE-AC52-07NA27344 (NNSA/LLNS 2009). Specific sections of these directives are relevant to the content of this chapter. This section also contains the codes, standards, regulations, and DOE orders specific to this chapter and required to establish the safety basis of the facility.

\section{U.S. Department of Energy}

DOE O 420.1B, Facility Safety (2005)

DOE-STD-1020-94, Change Notice 1, Natural Phenomena Hazards Design and Evaluation Criteria for Department of Energy Facilities (1996)

DOE-STD-1020-2002, Natural Phenomena Hazards Design and Evaluation Criteria for Department of Energy Facilities (2002)

DOE-STD-1021-93, Change Notice 1, reaffirmed 2002, Natural Phenomena Hazards Performance Categorization Guidelines for Structures, Systems, and Components (2002)

DOE-STD-1022-94, Change Notice 1, reaffirmed 2002, Natural Phenomena Hazards Characterization Criteria (2002) 
DOE-STD-1023-95, Change Notice 1, reaffirmed 2002, Natural Phenomena Hazards Assessment Criteria (2002)

DOE-STD-3009-94, Change Notice 3, Preparation Guide for U.S. Department of Energy Nonreactor Nuclear Facility Safety Analysis Reports (2006)

\section{Code of Federal Regulations}

10 CFR 830, Subpart B, Safety Basis Requirements (2001)

\subsection{SITE DESCRIPTION}

The RHWM Waste Storage Facilities are located in two portions of LLNL, as shown in Figure 1-1. A625 is located in the southeast quadrant of LLNL. The A625 fenceline is approximately $225 \mathrm{~m}$ west of Greenville Road. The DWTF Storage Area, which includes Building 693 (B693), Building 696 Radioactive Waste Storage Area (B696R), and associated yard areas and storage areas within the yard, is located in the northeast quadrant of LLNL in the DWTF complex. The DWTF Storage Area fenceline is approximately $90 \mathrm{~m}$ west of Greenville Road. Chapter 2 describes the layout of the two areas.

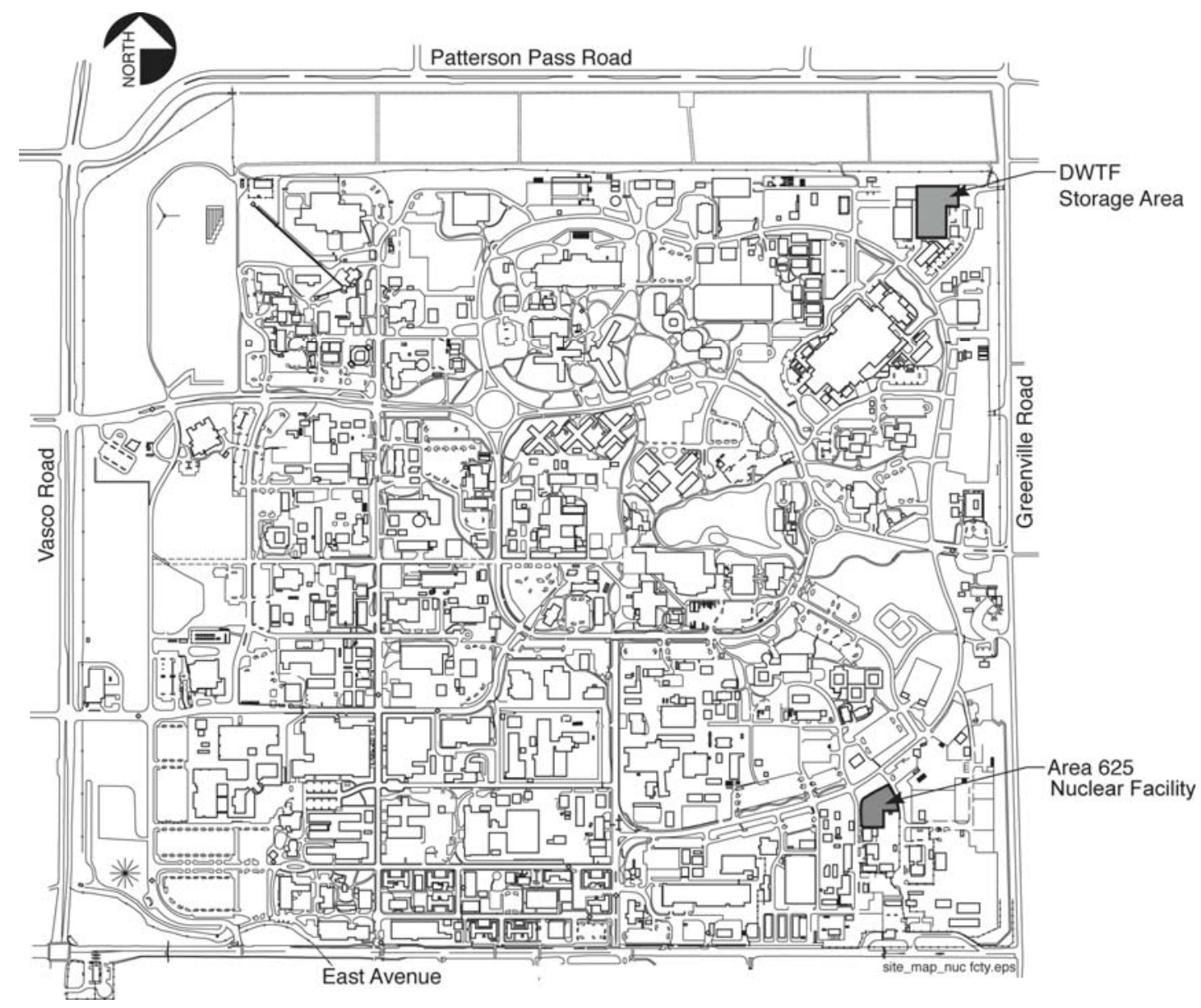

Figure 1-1. Waste Storage Facilities at LLNL 


\subsubsection{GEOGRAPHY}

LLNL occupies an area of approximately 1.3 square miles approximately 40 miles east of San Francisco at the southeast end of the Livermore Valley in Alameda County, California. The Livermore Valley is surrounded by hills that define the region and open space around the development on the valley floor. The terrain in the vicinity of the LLNL site ranges from relatively flat land to gently rolling hills. The hills east and south of LLNL gradually become steeper as they trend eastward to form the Altamont Hills of the Diablo Range.

The topographic surface at LLNL is of low relief and slopes gently to the northwest. Site elevation is 675 feet above sea level at the highest point in the southeast corner. Slopes or grades of the surrounding area range from $1 \%$ to $3.4 \%$, except for the few stream banks or the sides of drainage ditches, where slopes or grades average $50 \%$.

Significant man-made features include an earthfill embankment on the Arroyo del Valle forming the Del Valle Reservoir 7 miles southwest of the site. Livermore Municipal airport is located 6.5 miles west of the site.

\subsubsection{DEMOGRAPHY}

The city of Livermore's central business district is located approximately 3 miles to the west of LLNL. The site is bordered on the east by Greenville Road, on the north by Patterson Pass Road, on the west by Vasco Road, and on the south by East Avenue. East Avenue is closed to through traffic between Vasco and Greenville Roads. Rural residences and grazing land are the primary land uses to the east of the site. Sandia National Laboratory is located to the south. The rural character continues to the southwest, where large vineyards are located. Residential areas of the city of Livermore extend to LLNL's site boundary on the west. The nearest residential area to LLNL is located $0.04 \mathrm{~km}$ from the west perimeter. The nearest residential area to LLNL is located $0.04 \mathrm{~km}$ from the west perimeter. The area extending north from LLNL to Interstate 580 is industrial and includes research, business, and industrial sites. Primary features in this area are one- and two-story industrial buildings, business parks, and a railroad line that traverses the area.

The population in Alameda County in the year 2000 was 1,443,741; of these, 73,345 lived within the City of Livermore (2000 Census).

\subsection{ENVIRONMENTAL DESCRIPTION}

\subsubsection{METEOROLOGY}

The mean annual temperature at LLNL for the 30-year period from 1951 through 1980 was $58^{\circ} \mathrm{F}$.

The Livermore Valley has mild, rainy winters and warm, dry summers. Most rainfall occurs between October and April. The highest and lowest annual rainfalls on record were 30.6 inches (1982-83) and 6.1 inches (1975-76 and 1976-77), with a 25-year average of 13.3 inches (Thorpe 1990). 
During the summer months, winds are predominantly from the south or southwest, as a result of sea breeze. During the winter months, winds are more evenly distributed because of the passage of winter storms and because of the smaller temperature differential between the land surface and ocean water. The wind speeds measured at the 10-m meteorological tower located at the LLNL site range from calm winds (0 to $1 \mathrm{~m} / \mathrm{sec}$ ) to more than $10.8 \mathrm{~m} / \mathrm{sec}$. The frequency of wind speed greater than $10.8 \mathrm{~m} / \mathrm{sec}$ is $0.07 \%$ of the time. The frequency of wind speeds ranging from 0 to $1.3 \mathrm{~m} / \mathrm{sec}$ is $39 \%$ of the time, due to the typically calm nights. Table 1-1 (Gouveia 1989) shows atmospheric stability data.

Table 1-1. Meteorological Data for LLNL

\begin{tabular}{|l|c|c|c|c|c|c|c|}
\hline \multicolumn{1}{|c|}{ Stability Class } & A & B & C & D-Day & D-Night & E & F \\
\hline \hline Annual Frequency (\%) & 10.8 & 5.8 & 11.7 & 14.7 & 25.2 & 12.8 & 19.0 \\
\hline $\begin{array}{l}Z_{\mathrm{m}}-(\text { height of the inversion } \\
\text { layer, m) }\end{array}$ & 1200 & 1050 & 900 & 750 & 700 & 570 & 400 \\
\hline
\end{tabular}

\subsubsection{HYDROLOGY}

LLNL is located at the eastern end of the Livermore Valley groundwater basin. Recharge to the basin is largely from arroyos that originate in the foothills, including Arroyo Seco and Arroyo Las Positas, which cross the LLNL site. Waste storage areas are not located within the 100-year flood plain. To the north of the DWTF, a chain link fence crosses the Arroyo Las Positas with approximately 8-in clearance above the bottom of the channel. This fence has a locked flap gate used for security purposes. Water height is monitored constantly during storms. No springs are identified on the topographic map (USGS 1981) within 1 mile of LLNL. Components of the public water supply system within 1 mile of LLNL include the South Bay Aqueduct and the Patterson Pass Reservoir and Water Treatment Plant.

Within the Livermore Valley, uppermost-saturated sediments are commonly unconfined. Interbeds and interlenses of low-conductivity sediments within the saturated zone act as local aquitards, which tend to confine the deeper water-bearing zones (Thorpe 1990). The two most important formations that contain groundwater are Quaternary alluvial deposits and the Plio-Pleistocene Livermore Formation. The Livermore Formation is generally of lower permeability than the overlying deposits, but it commonly contains significant water-bearing zones. The LLNL area groundwater locally recharges by percolation through the valley alluvium and by infiltration via Arroyo Seco and Arroyo Las Positas as well as from unlined drainage ditches. A recharge basin (located south of LLNL) is a significant source of groundwater recharge. The basin receives treated groundwater from the southwest portion of LLNL. An artificially constructed drainage retention basin (located near the center of LLNL) has been lined to prevent the infiltration of storm water and treated groundwater discharge to the basin. 
In general, groundwater flows toward the east-west longitudinal axis of the Livermore Valley and then in a westward direction to the gravel pit mines and the municipal water supply wells near Livermore and Pleasanton. Vertical movement of water between the lower member of the Livermore Formation and the overlying alluvial sediments is restricted by permeability differences and by internal stratification within these sedimentary units. At LLNL, the upper 15 feet to 60 feet of the lower member of the Livermore Formation is known to act as an aquitard (Thorpe 1990). Under LLNL, the contact between distinctively colored units in the lower member of the Livermore Formation generally dips to the west and is found between approximately 25 feet and 400 feet below the ground surface.

\subsubsection{GEOLOGY}

LLNL lies in the California Coastal Range province between the San Francisco Bay to the west and the northern San Joaquin Valley to the east. The Livermore Valley is generally of low relief, but contains scattered groups of hills that rise to 150 feet above the valley floor. The valley is surrounded by the Tassajara Hills and Mount Diablo to the north, the Altamont Hills to the east, the Diablo Range to the south, and the Hayward Hills to the west.

The Livermore Valley is an east-west-trending synclinal structure composed primarily of gently deformed alluvial deposits overlying complexly deformed Cenozoic and Mesozoic rocks. The California Coast Range in the Livermore region consists of north-to-northwest-trending mountain ranges and valleys bounded by faults. Most of the faults in the region are right-lateral strike-slip faults associated with the San Andreas Fault system. The Calaveras Fault to the west, and the Greenville Fault to the east border the Livermore Valley.

The oldest rock units exposed in the Livermore area consist of the highly deformed sedimentary, igneous, and metamorphic rocks of the Jurassic-Cretaceous Franciscan Assemblage. The Cretaceous Great Valley Sequence, consisting of alternating beds of sandstone, siltstone, and shale, structurally overlies these rocks. Both of these units are intricately folded and faulted in the mountains surrounding the Livermore Valley. More gently folded Tertiary sedimentary and igneous rocks overlie the Franciscan Assemblage and the Great Valley Sequence.

In the Livermore Valley, valley fill deposits are composed of as much as 4000 feet of Late Tertiary to Holocene fluvial and lacustrine sediments according to the California Department of Water Resources (CDWR 1974). The oldest Livermore Valley fill deposit is the Plio-Pleistocene Livermore Formation, which has been divided into two members based on lithology and depositional environment. The lower member of the Livermore Formation consists of a poorly cemented pebble conglomerate, sandstone, and greenish-gray claystone of late Pliocene age (Dibblee 1980). The upper member consists of light reddish-gray, cobble-pebble gravel with varying amounts of claystone of Pleistocene age (Dibblee 1980). 


\section{Documented Safety Analysis for the Waste Storage Facilities}

\section{$1.5 \quad$ NATURAL PHENOMENA THREATS}

This section identifies specific natural phenomena events, such as design-basis earthquakes (DBEs) considered to be potential accident initiators. The natural phenomena threats used in the evaluation of the Waste Storage Facilities are supported by information contained in Chapter 3, "Hazard and Accident Analyses."

\subsubsection{EARTHQUAKES}

The 2005 LLNL EIS (DOE 2005) provides details of the local and regional faults as well as historic earthquake data. The potential for seismic hazards at the Livermore Site are presented in the 2005 LLNL EIS and summarized below.

Strong earthquake ground motion is responsible for producing almost all of the damaging effects of earthquakes, except for surface-fault rupture. The intensity of ground motion or shaking that could occur at LLNL as a result of an earthquake is related to the size of the earthquake, its distance from LLNL, and the response of the geologic materials beneath LLNL. Ground shaking generally causes the most widespread effects, not only because it propagates considerable distances from the earthquake source, but also because it may trigger secondary effects from ground failure and water inundation. Potential sources for future ground motion at the LLNL Main Site include the major regional faults, as well as the local faults.

A recent U.S. Geological Survey (USGS) study of the likelihood of major earthquakes in the San Francisco Bay Area (Working Group on California Earthquake Probabilities 1990) has determined that there is a 62 percent probability of one or more earthquakes with a magnitude of 6.7 on the Richter Scale or greater occurring within the next 30 years. The study concluded that the probability of these earthquakes occurring along the Calaveras and Greenville faults, and the Mt. Diablo Thrust Fault within the next 30 years was 11 percent, 3 percent, and 3 percent, respectively. The study calculated that there was a 50 percent chance of the Livermore area exceeding a ground shaking of Modified Mercalli (MM) intensity VII to VIII. The Association of Bay Area Governments has mapped the distribution of ground-shaking intensity. A large earthquake on the Greenville Fault is projected to produce the maximum ground-shaking intensities in the Livermore area with intensity ranging from strong (MM VII) to very violent (MM X). The MM IX level is associated with damage to buried pipelines and partial collapse of poorly built structures.

Seismic hazard analyses have been performed for the LLNL Main Site to quantify the hazard. The analyses identify the probability of exceeding a given peak ground acceleration. The frequency of the DBE for the Waste Storage Facilities required by DOE-STD-1020-94, Change Notice 1 (DOE 1996) is $1 \times 10^{-3} / \mathrm{yr}$. The maximum horizontal peak ground acceleration at the Livermore Site for return periods of 1,000 years is $0.57 \mathrm{~g}$ (DOE 1996). DOE-STD-1020-2002 (DOE 2002) modified the criteria for PC-1 and PC-2 evaluations compared to DOE-STD-1020-94, Change Notice 1 (DOE 1996). The new criteria are based on the 2000 IBC rather than the 1997 UBC. The differences in the two building codes are minor (Coats 2004). Executive Order 12941, "Seismic Safety of Existing Federally Owned or Leased Buildings," references the 2000 IBC, and requires reevaluation of structural integrity under certain circumstances. Based on a seismic screening and evaluation of conditions 
conducted as required by Executive Order 12941, and the minor changes to the code, none of the RHWM facilities meet the criteria requiring reevaluation (Coats 2004). The potential for surface faulting within the LLNL Main Site is very low, although the potential for surface faulting does exist south of the LLNL Main Site. Based on the fairly deep groundwater levels, the uniformly distributed, poorly sorted sediments beneath the site, and a relatively high degree of sediment compaction, the potential for damage from liquefaction (saturated soil behaves like a fluid from shaking) at the LLNL Main is quite low. Insignificant potential for seismically induced landslides exists at the Livermore Site because of the relatively flat land surface.

\subsubsection{FLOODS}

The Waste Storage Facilities are located above the 100-yr flood plain (DOE 2005). The design-basis flood (DBFL) for a performance category 2 (PC-2) facility at LLNL has a return period of 2000 years (DOE 2002). The two sources of flooding at LLNL are from the Arroyo Las Positas and the Arroyo Seco.

The Arroyo Las Positas approaches LLNL from the east and travels around the site along the eastern and northern borders. A storm flood study was conducted for the DWTF based on historical data and the local surrounding area (Lin 1998). The overflow of this Arroyo during a 2,000 year flooding event has been estimated to impact the DWTF with floodwater approximately nine inches above the existing grade of the DWTF site. The conclusions show no major flood damage to buildings within the DWTF from a 2,000 year frequency precipitation event.

The Arroyo Seco drains the foothills to the southeast and is present for about 900 linear feet in the far southwest corner of the Livermore Site. A Flood Hazard Analysis was conducted for Building 231 Vault (Majumdar 2001). B231 is a PC-2 structure located closer to Arroyo Seco than A625 and is also at a lower elevation than A625. The analysis concludes that a 2,000-year flooding event will not impact the B231 facility safety or operational safety. Therefore, A625 is also expected to have no major flood damage to buildings from a 2000 -year flood.

If failure of the Del Valle Dam were to occur at the same time a landslide results in closure of the Arroyo de la Laguna Canyon at the western end of the Livermore Valley, floodwaters would flow to and collect at the western end of the Livermore Valley. The total surface area of the valley below the $120 \mathrm{~m}$ contour line is approximately $65 \mathrm{~km} 2$; the elevation at the western end is about $100 \mathrm{~m}$ above mean sea level or lower. Because the maximum capacity of the reservoir is $9.5 \times 107 \mathrm{m3}$ (77,100 acre-ft) and the lowest LLNL elevation is approximately $174 \mathrm{~m}$ above mean sea level, the site would not be in the floodplain of water released from postulated failure of the dam (McCann 1988). 


\subsubsection{WIND}

The design-basis wind (DBW) for a PC-2 facility at LLNL is $72 \mathrm{mph}$ at $10 \mathrm{~m}$ above ground (DOE 1996). Buildings in the DWTF Storage Area and B625 in A625 are designed and constructed to withstand the effects of a PC-2, 72-mph fastest mile wind at $10 \mathrm{~m}$ above ground (DOE 1996). DOE-STD-1020-2002 (DOE 2002) modified the wind criterion for PC-1 and PC-2 evaluations. The new criterion is based on a "peak gust" condition rather than "fastest mile" condition. Codes and standards have been changed to reflect the use of "peak gust" wind speeds with the intent of keeping design loads essentially the same (Coats 2004). In addition, the total seismic loads are typically significantly greater than the wind loads for structures in the Waste Storage Facilities.

Data evaluated from September 1996 through April 2008 showed that the highest peak wind gust observed at the Livermore site was in January 2008: $27.5 \mathrm{~m} / \mathrm{s}(61.4 \mathrm{mph})$ at $10 \mathrm{~m}$ and 29.7 $\mathrm{m} / \mathrm{s}$ (66.3 mph) from the elevated instruments (35 m or $52 \mathrm{~m}$ ) (Spencer 2008).

\subsubsection{LIGHTNING}

The Livermore Valley rarely experiences severe weather. Thunderstorms occur fewer than 10 days per year and are typically not intense. Over a 10 year period (1991 to 2000), only four lightning strikes were recorded within a 2 mile radius of LLNL. There were no recorded instances of lightning strikes within the boundaries of LLNL during this 10 year period.

\subsection{EXTERNAL MAN-MADE THREATS}

As noted in Section 1.3.1, the nearest public airport to LLNL is the Livermore Municipal Airport, which is located 6.5 miles west of the site. The airport primarily services single-engine aircraft, with some use by twin-engine aircraft and corporate jets. Accordingly, Chapter 3 must address the issue of a small aircraft crash into the Waste Storage Facilities. High voltage power lines run overhead across the A625 yard. This hazard is analyzed in Chapter 3.

\subsection{NEARBY FACILITIES}

Nearby facilities considered in the hazard analysis include the National Ignition Facility, located approximately 800 feet to the south of the DWTF Storage Area, and B691, located 600 feet to the southeast. Also, the B697 consolidated waste accumulation area/Chemical Exchange Warehouse and the B695 Segment are near the DWTF Storage Area. The facilities located near A625 are Area 612 (A612) to the south, fueling stations to the east, construction equipment and material storage to the south and west, and an office building to the north. The fueling stations (e.g., ethanol, compressed natural gas) are analyzed in Chapter 3. None of the other facilities listed or other facilities at LLNL are likely to impact the Waste Storage Facilities. 


\section{$1.8 \quad$ VALIDITY OF EXISTING ENVIRONMENTAL ANALYSES}

No significant discrepancies exist or indicate the need to revise the Livermore Site Hazardous Waste Facility Permit (LLNL latest revision). Variations exist in the DSA hazard and accident analysis assumptions for radioactive waste relative to the assumptions used in the $2005 \mathrm{LLNL}$ EIS (DOE 2005) for which a Record of Decision was signed in November 2005 (FR 2005). The Facility Safety Plans will control operations to be consistent with the assumptions used in the DSA and TSR.

\subsection{REFERENCES}

CDWR (1974), Evaluation of Ground Water Resources: Livermore and Sunol Valleys (from Appendix A: Geology 1966). California Department of Water Resources, Sacramento, CA. (CDWR Bulletin 118-2, in cooperation with Alameda County Flood Control and Water Conservation District, Zone 7).

CFR (2001), Title 10, Code of Federal Regulations, Part 830, Nuclear Safety Management, Federal Register, Volume 66, Number 7, January 10, 2001.

Census (2000), U.S. Census Bureau, Census 2000 Summary File 1, Matrices PCT12 and P13, 2000.

Coats, D. (2004), Memo to Lothar Westfall from Dave Coats, "Impact of DOE-STD-1020-2002 On Building 332," Lawrence Livermore National Laboratory, Livermore, CA, July 20, 2004.

Dibblee, T. W., Jr. (1980), Geologic Map of the Altamont Quadrangle, Alameda County, CA, U.S. Geological Survey, Washington, DC, 1980, (USGS Open File Report 80-538).

McCann, Jr, M. W. and A. C. Boissonnade, Natural Hazards Modeling Project: Preliminary Flood Hazard Estimates for Screening Department of Energy Sites, Albuquerque Operations Office, Albuquerque, NM, UCRL-21045 (May 1988).

DOE (1996), Natural Phenomena Hazards Design and Evaluation Criteria for Department of Energy Facilities, DOE-STD-1020-94, Change Notice 1, U.S. Department of Energy, Washington, DC, June 1996.

DOE (2002), Natural Phenomena Hazards Design and Evaluation Criteria for Department of Energy Facilities, DOE-STD-1020-2002, U.S. Department of Energy, Washington, DC, January 2002.

DOE (2005), Final Site-wide Environmental Impact Statement for Continued Operation of Lawrence Livermore National Laboratory and Supplemental Stockpile Stewardship and Management Programmatic Environmental Impact Statement, DOE/EIS-0348, DOE/EIS-0236-S3, March 2005.

DOE (2006), Preparation Guide for U.S. Department of Energy Nonreactor Nuclear Facility Safety Analysis Reports. DOE-STD-3009-94, Change Notice 3. U.S. Department of Energy, Washington, DC, March 2006. 
FR (2005), Record of Decision of the Final Site-Wide Environmental Impact Statement for Continued Operation of Lawrence Livermore National Laboratory and Supplemental Stockpile Stewardship and Management Programmatic Environmental Impact Statement, November 29, 2005, (Federal Register/Vol. 70, No. 228).

Gouveia, F. J; and K. R. Chapman (1989), Climatology of Lawrence Livermore National Laboratory, Lawrence Livermore National Laboratory, Livermore, CA. UCID-21686, 1989.

Lin, A. (1998), Flood Study for the Decontamination and Waste Treatment Facility, Parsons Infrastructure and Technology Group, Inc. May 3, 1998.

Majumdar (2001), Building 231 Vault (B 231) Flood Hazard Analysis, Lawrence Livermore National Laboratory, Livermore, CA, UCRL-ID-146099, September 28, 2001.

NNSA/LLNS (2009), Management and Operating Contract between The US Department of Energy/National Nuclear Security Administration and Lawrence Livermore National Security, No. DE-AC52-07NA27344, February 27, 2009.

Spencer, D. K., Wind Speeds at LLNL from September 1996 through April 2008, Calculation AB-B331-08-007, Lawrence Livermore National Laboratory, Livermore, CA (September 2, 2008).

Thorpe, R. K., W. F. Isherwood, M. D. Dresen, and C. P. Webster-Scholten (eds) (1990), CERCLA Remedial Investigations Report for the LLNL Livermore Site, Lawrence Livermore National Laboratory, Livermore, CA, (UCAR-10299, Predecisional Final, 5 volumes), 1990.

USGS (1981), Altamont Quadrangle - California, Alameda County 7.5 minute series (topographic map). U.S. Geological Survey, Washington, DC, 1981.

Working Group on California Earthquake Probabilities (1990), Probabilities of Large Earthquakes in the San Francisco Bay Region, California, U.S. Geological Survey, Washington, DC, 1990, (USGS Circular 1053, 51 pp). 


\section{CHAPTER 2 FACILITY DESCRIPTION}

\section{$2.1 \quad$ INTRODUCTION}

Regional access to LLNL is primarily from Interstate 580 by the Vasco Road interchange. The LLNL site is accessed by security gates along Vasco Road (West Gate), East Avenue (South Gate), and Greenville Road (East Gate).

This chapter describes the structures, operations, confinement systems, safety support systems, utility distribution systems, and auxiliary systems for the Radioactive and Hazardous Waste Management Division's (RHWM) waste storage facilities located at the Lawrence Livermore National Laboratory (LLNL) Main Site (Site 200). The information will also be used to evaluate potential accidents associated with operations, natural phenomena, and external events related to the RHWM Waste Storage Facilities.

The RHWM Waste Storage Facilities are located in two portions of LLNL. A625 is located in the southeast quadrant of LLNL and includes B625, two tents, and associated yard areas. The DWTF Storage Area, which includes Building 693 (B693), Building 696 Radioactive Waste Storage Area (B696R), and associated yard areas and storage areas within the yard, is located in the northeast quadrant of LLNL in the DWTF complex.

These facilities are used by RHWM to handle and store hazardous waste, transuranic (TRU) waste, low-level waste (LLW), mixed waste, combined waste, nonhazardous industrial waste, and conditionally accepted waste generated at LLNL.

Figure 2-1 shows the A625 footprint and identifies the facilities located in this area. Figure 2-2 shows the DWTF Storage Area footprint and identifies the facilities located in this area. Section 2.4 describes each of the storage facilities and includes major systems and design criteria.

\subsection{REQUIREMENTS}

This section contains the directives in effect as of February 2009 as implemented in the Lawrence Livermore National Security, LLC, Contract No. DE-AC52-07NA27344 (NNSA/LLNS 2009). Specific sections of these directives are relevant to the content of this chapter. This section also contains the codes, standards, regulations, and DOE orders specific to this chapter and required to establish the safety basis of the facility. 


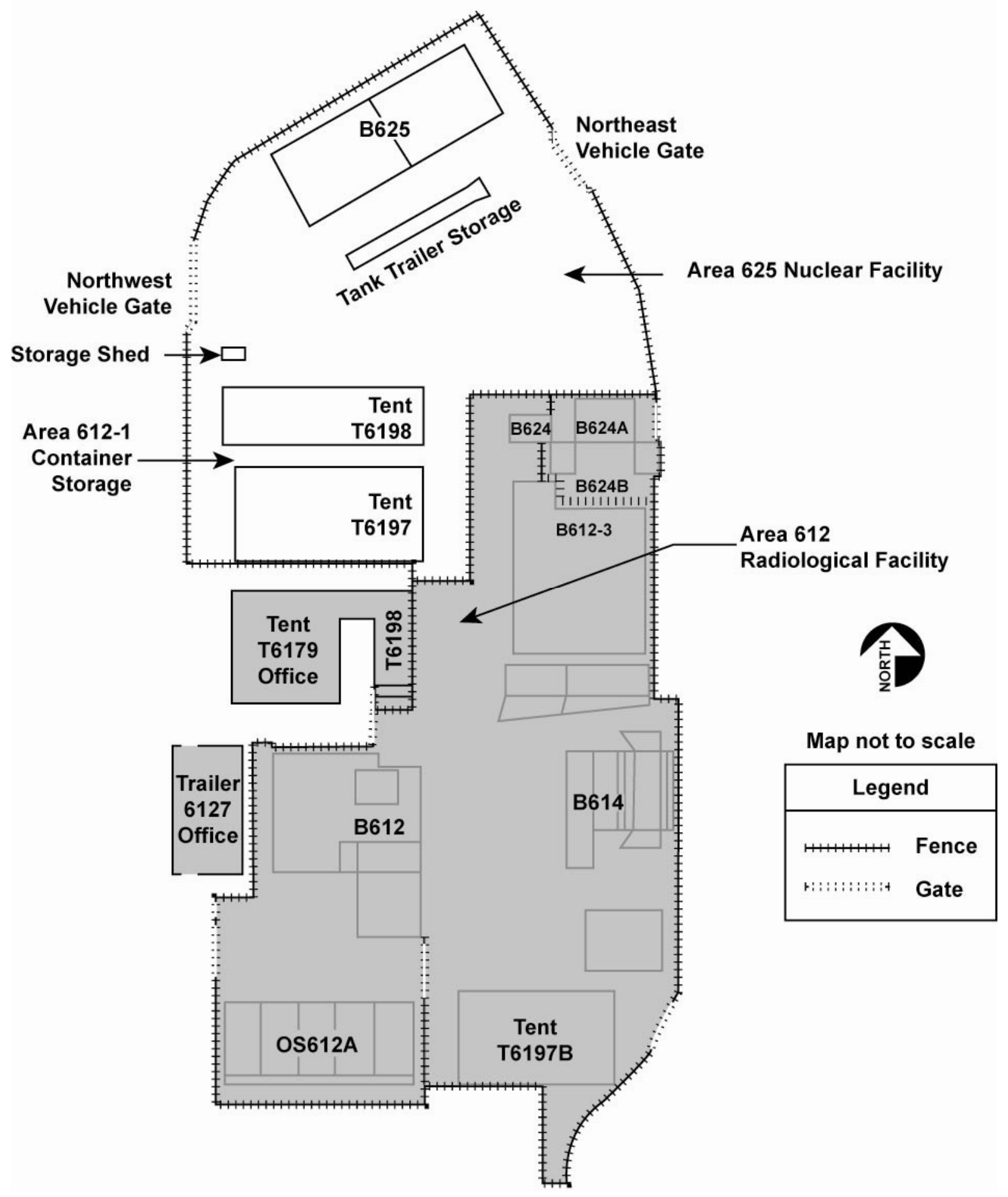

Figure 2-1. Area 625 Facilities 


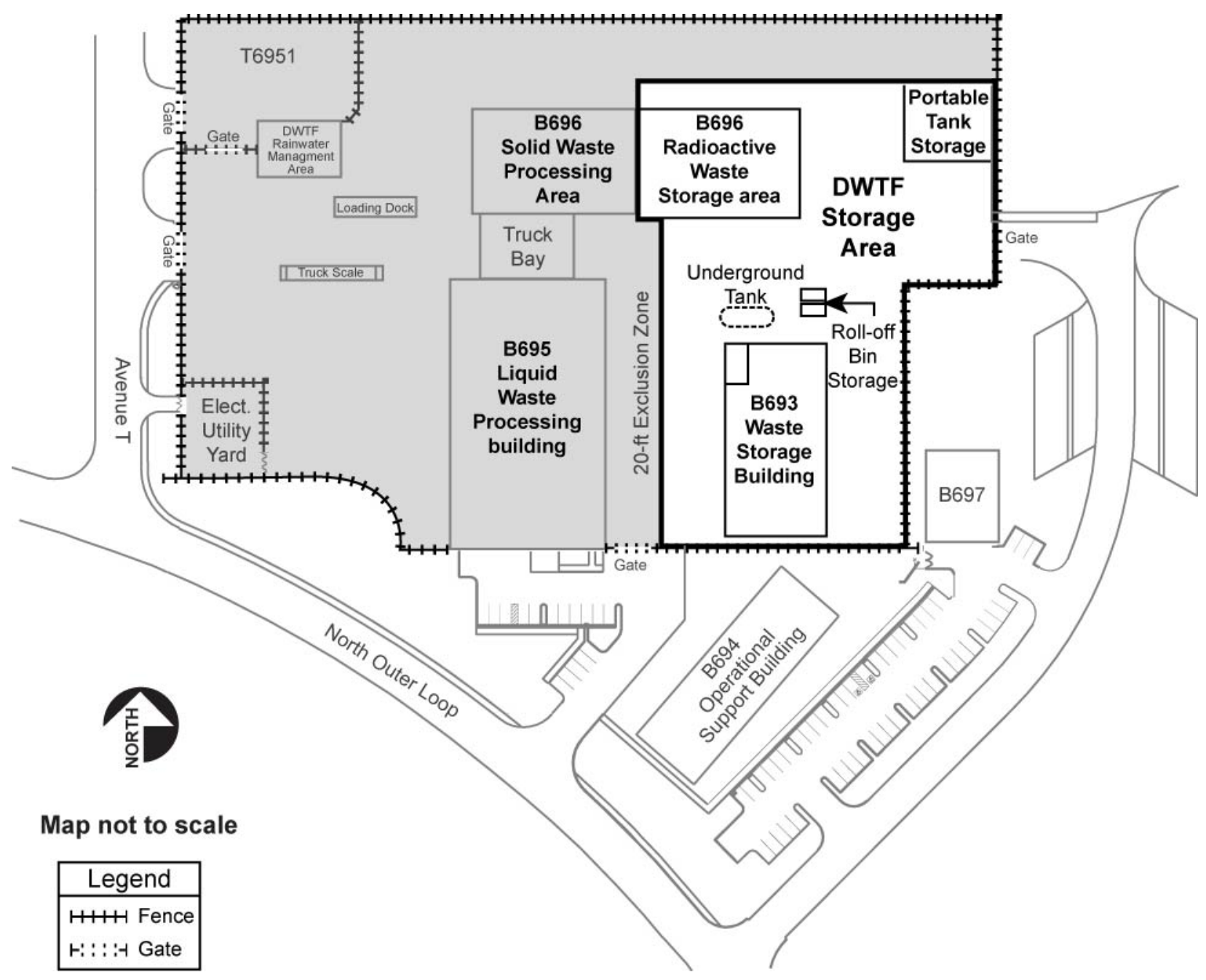

Figure 2-2. DWTF Storage Area in the DWTF Complex

\section{U.S. Department of Energy}

DOE O 5400.5, Change Notice 2, Radiation Protection of the Public and the Environment (1993)

DOE O 5480.19, Change Notice 2, Conduct of Operations Requirements for DOE Facilities (2001)

DOE O 5480.20A, Personnel Selection, Qualification, and Training Requirements for DOE Nuclear Facilities (2001)

DOE O 435.1, Change Notice 1, Radioactive Waste Management (2001)

DOE O 420.1B, Facility Safety (2005)

DOE-STD-1020-94, Change Notice 1, Natural Phenomena Hazards Design and Evaluation Criteria for Department of Energy Facilities (1996) 
DOE-STD-1020-2002, Natural Phenomena Hazards Design and Evaluation Criteria for Department of Energy Facilities (2002a)

DOE-STD-1021-93, Change Notice 1, reaffirmed 2002, Natural Phenomena Hazards Performance Categorization Guidelines for Structures, Systems, and Components (2002b)

DOE-STD-1022-94, Change Notice 1, reaffirmed 2002, Natural Phenomena Hazards Characterization Criteria (2002)

DOE-STD-1023-95, Change Notice 1, reaffirmed 2002, Natural Phenomena Hazards Assessment Criteria (2002)

\section{Code of Federal Regulations}

10 CFR 820, Procedural Rules for DOE Nuclear Activities (10CFR820)

10 CFR 830, Subpart A

10 CFR 830, Subpart B, Quality Assurance Requirements (10CFR830A)

Safety Basis Requirements

10 CFR 835, Occupational Radiation Protection (10CFR835)

10 CFR 850, Chronic Beryllium Disease Prevention Program (10CFR850)

10 CFR 851, Worker Safety and Health Program (10CFR851)

40 CFR 264, Standards For Owners and Operators of Hazardous Waste Treatment, Storage and Disposal Facilities

\section{California Code of Regulations}

22 CCR 66264, Standards for Owners and Operators of Hazardous Waste Transfer, Treatment, Storage, and Disposal Facilities

\section{California Environmental Protection Agency}

Permit Number 99-NC-006, Hazardous Waste Facility Permit for Lawrence Livermore National Laboratory (Main Site)

\subsection{FACILITY OVERVIEW}

As briefly described in Section 2.1 above, the RHWM Waste Storage Facilities are in two locations at LLNL. The locations are designated A625 and the DWTF Storage Area. Each of these locations is further subdivided into facilities and storage areas, which consist of buildings, tents, other structures, and open areas. 


\section{Documented Safety Analysis for the Waste Storage Facilities}

\section{Current and Historical Use of Facilities}

All of the facilities and areas covered by this DSA are used for storage of containerized waste typically generated at LLNL. The types of waste include hazardous waste, TRU waste, TRU mixed waste, LLW, mixed waste, combined waste, nonhazardous industrial waste, and conditionally accepted waste (e.g., special packaging, animal research, pharmaceutical, and medical waste). Some TRU wastes may contain materials considered hazardous by California, but these containers are labeled and stored the same as regular TRU waste and will not be differentiated in this document. The California Environmental Protection Agency Department of Toxic Substances Control (DTSC) under the Resource Conservation and Recovery Act (RCRA) permits portions of these facilities for storage of hazardous and mixed waste (DTSC 1999).

The LLNL site was farmland. During World War II, it was used as a Navy airbase for training. Operations as a nuclear weapons research lab began in 1952. A625 has been used for waste storage since approximately 1962. Building 693 of the DWTF Storage Area has been used for waste storage since approximately 1993. Building 696R of the DWTF Storage Area has been used for waste storage since 2002.

\section{Projected Future Use of Facilities}

The facilities and areas covered by this DSA will continue for the foreseeable future to be used for the storage of containerized waste generated at LLNL, as well as small amounts generated at other facilities.

\section{Basic Processes Performed in Facilities and Areas}

As stated earlier, the facilities and areas in A625 and the DWTF Storage Area are predominately used for the storage of containerized waste generated at LLNL. All facilities and areas are permitted by DTSC to store and treat hazardous and mixed waste. Some facilities are appropriate only for solid waste; others can store both solid and liquid waste. Table 2-1 provides an overview of the types and forms of waste stored in the various facilities and areas of the RHWM Waste Storage Facilities. Some facilities are broken down to the room level because of different waste types allowed within the facility.

Waste is accepted into the RHWM Waste Storage Facilities based on information provided by the generators. Waste must satisfy waste acceptance criteria established by RHWM that reflect the criteria provided by disposal sites. Some portion of waste, excluding TRU and mixed TRU, is sampled and analyzed to verify generator knowledge. In order to ensure that the Waste Isolation Pilot Plant (WIPP) waste acceptance criteria (WAC) are satisfied, TRU and mixed TRU will be analyzed using noninvasive (e.g., radiography, radioassay) techniques prior to shipment to WIPP as necessary. It is recognized that due to changing WIPP WAC requirements, waste that predated the WIPP WAC requirements and waste verification activities, some stored TRU waste may deviate from the current WAC requirements. These deviations from the WAC do not represent an increased risk over that postulated in the bounding accident. 
Table 2-1. Summary of Allowable Waste Types ${ }^{1}$

\begin{tabular}{|l|c|c|c|c|c|c|c|}
\hline \multicolumn{1}{|c|}{$\begin{array}{c}\text { Waste Type } \\
\text { Facility }\end{array}$} & Haz. & $\begin{array}{c}\text { Mixed } \\
\text { LLW }\end{array}$ & TRU & $\begin{array}{c}\text { Mixed } \\
\text { TRU }\end{array}$ & Liquid & Solid & $\begin{array}{c}\text { Flam. } \\
\text { Liquid }\end{array}$ \\
\hline \hline B625 & $\mathrm{X}$ & $\mathrm{X}$ & $\mathrm{X}$ & $\mathrm{X}$ & $\mathrm{X}$ & $\mathrm{X}$ & \\
\hline A612 Tank Trailer Storage & $\mathrm{X}$ & $\mathrm{X}$ & & & $\mathrm{X}$ & & \\
\hline A612-1 including T6197 \& T6198 & $\mathrm{X}$ & $\mathrm{X}$ & & & & $\mathrm{X}$ & \\
\hline B693, Room 1000 & $\mathrm{X}$ & $\mathrm{X}$ & & & $\mathrm{X}$ & $\mathrm{X}$ & $\mathrm{X}$ \\
\hline $\begin{array}{l}\text { B693, Rooms 1004, 1008, 1012, } \\
\text { 1014 }\end{array}$ & $\mathrm{X}$ & $\mathrm{X}$ & & & $\mathrm{X}$ & $\mathrm{X}$ & \\
\hline B693 Freezer (Room 1016) & $\mathrm{X}$ & $\mathrm{X}$ & & & $\mathrm{X}$ & $\mathrm{X}$ & \\
\hline B693 Roll-off Bin Storage & $\mathrm{X}$ & & & & & $\mathrm{X}$ & \\
\hline DWTF Portable Tank Storage & $\mathrm{X}$ & $\mathrm{X}$ & & & $\mathrm{X}$ & $\mathrm{X}$ & $\mathrm{X}$ \\
\hline B696R & $\mathrm{X}$ & $\mathrm{X}$ & $\mathrm{X}$ & $\mathrm{X}$ & $\mathrm{X}$ & $\mathrm{X}$ & \\
\hline
\end{tabular}

1 Any area within the Waste Storage Facilities fencelines can be used to store non-hazardous (industrial), low-level radioactive, and combined (low-level plus California-only hazardous) waste.

2 May be used to store non-infectious, non-hazardous biological material such as animal cadavers and medical waste.

Haz. Hazardous waste (gaseous waste can be stored in any facility permitted to be used for hazardous waste).

Flam. Flammable liquid waste.

X Commonly stored or allowed for this waste type.

\section{$2.4 \quad$ FACILITY STRUCTURE}

This section provides an overview of the buildings, structures, and areas in the RHWM Waste Storage Facilities, including construction details such as basic floor plans, equipment layout, construction materials and structural dimensions. Pertinent information related to the structure and the general arrangement of the facilities are extracted for the hazard and accident analysis. Although an effort has been made to use consistent terminology for describing facilities and areas, there are alternate names that have been used primarily in the Operation Plan (RCRA Permit). Many of the storage areas are known as Container Storage Units (CSUs) in the Operation Plan. In general, this DSA does not use this nomenclature.

\subsubsection{LIST OF FACILITIES AND AREAS}

Following is a list of the storage facilities covered by this DSA:

\section{Area 625}

1. Building 625 (Figure 2-3)

2. Area 612 Tank Trailer Storage (Figure 2-4) 
3. Area 625 (outside south of B625)

4. Area 612-1 (Figure 2-5)
a. Tent 6197
b. Tent 6198
c. Asphalt pad

\section{DWTF Storage Area}

1. Building 693 (Figure 2-6)

2. B693 Roll-off Bin Storage Unit (Figure 2-2)

3. DWTF Portable Tank Storage Unit (Figure 2-2)

4. DWTF Underground Tank (Figure 2-2)

5. Building 696 Radioactive Waste Storage Area (B696WSA) portion of B696 (Figure 2-7)

\subsubsection{BASIC FLOOR PLANS OF FACILITIES}

Following are floor and plot plans for the facilities and areas covered by this DSA. Where appropriate, equipment footprints are located within the floor plans. Key dimensions are included on the floor plans.

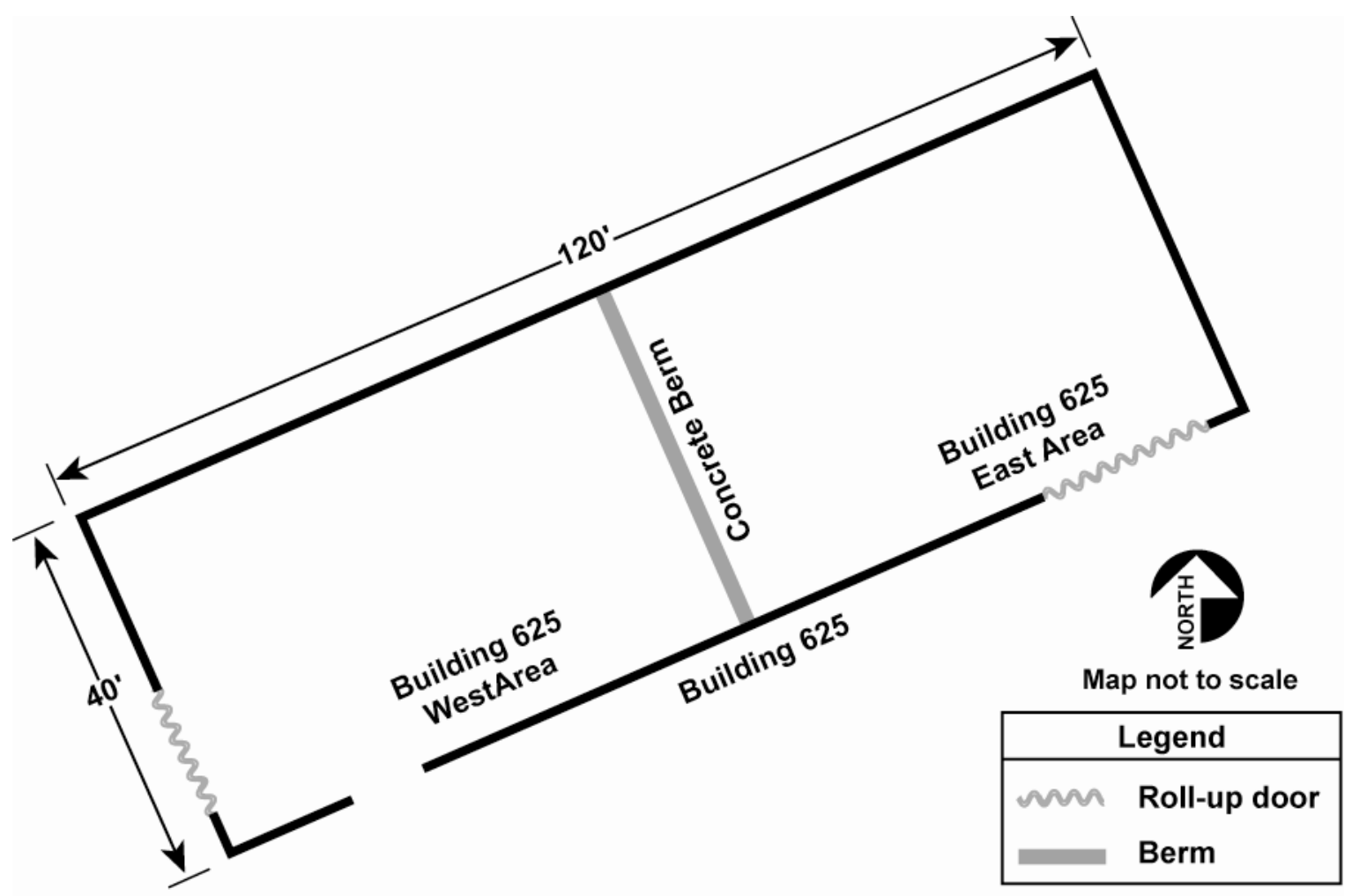

Figure 2-3. Building 625 


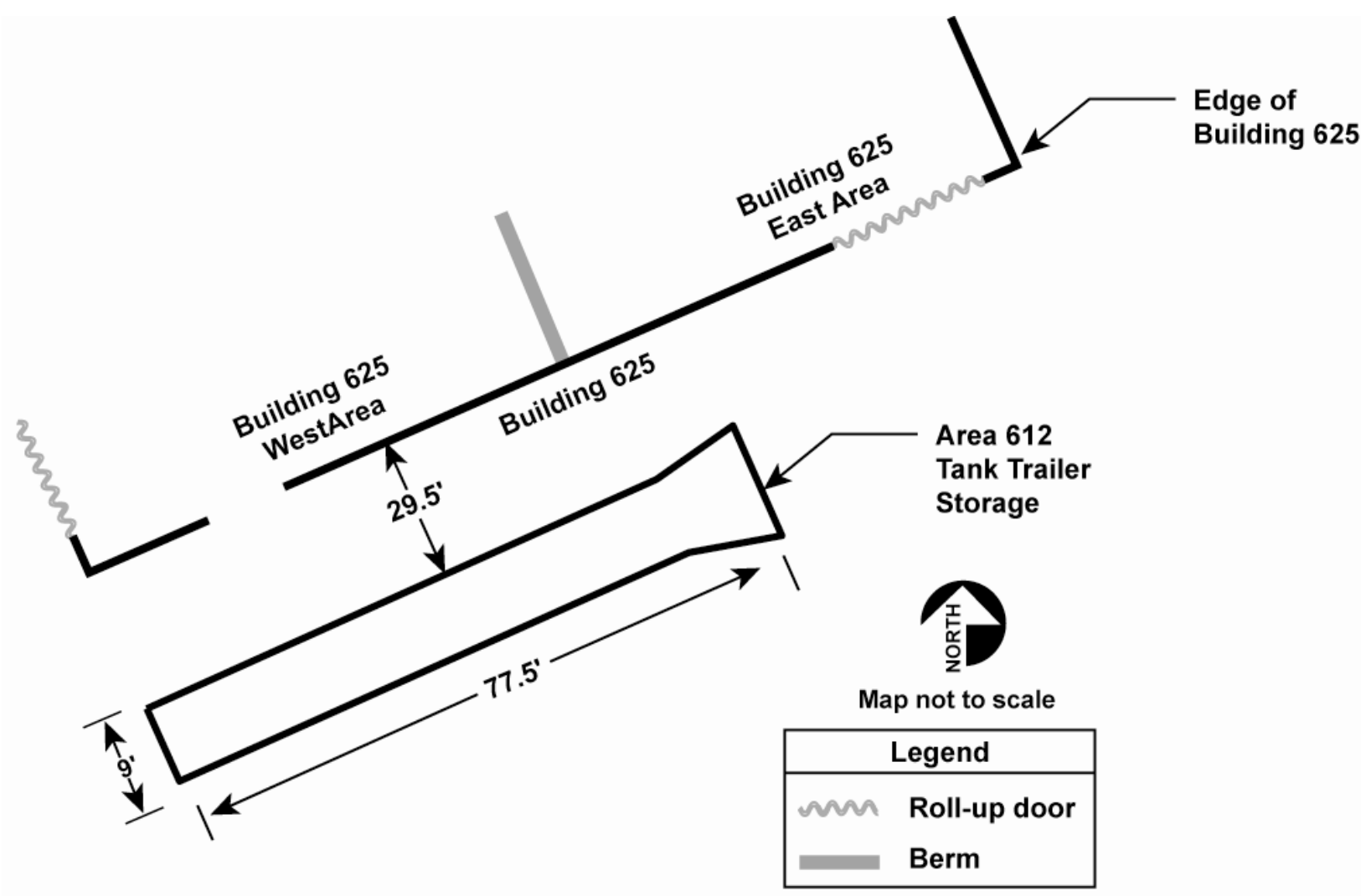

Figure 2-4. Area 612 Tank Trailer Storage 


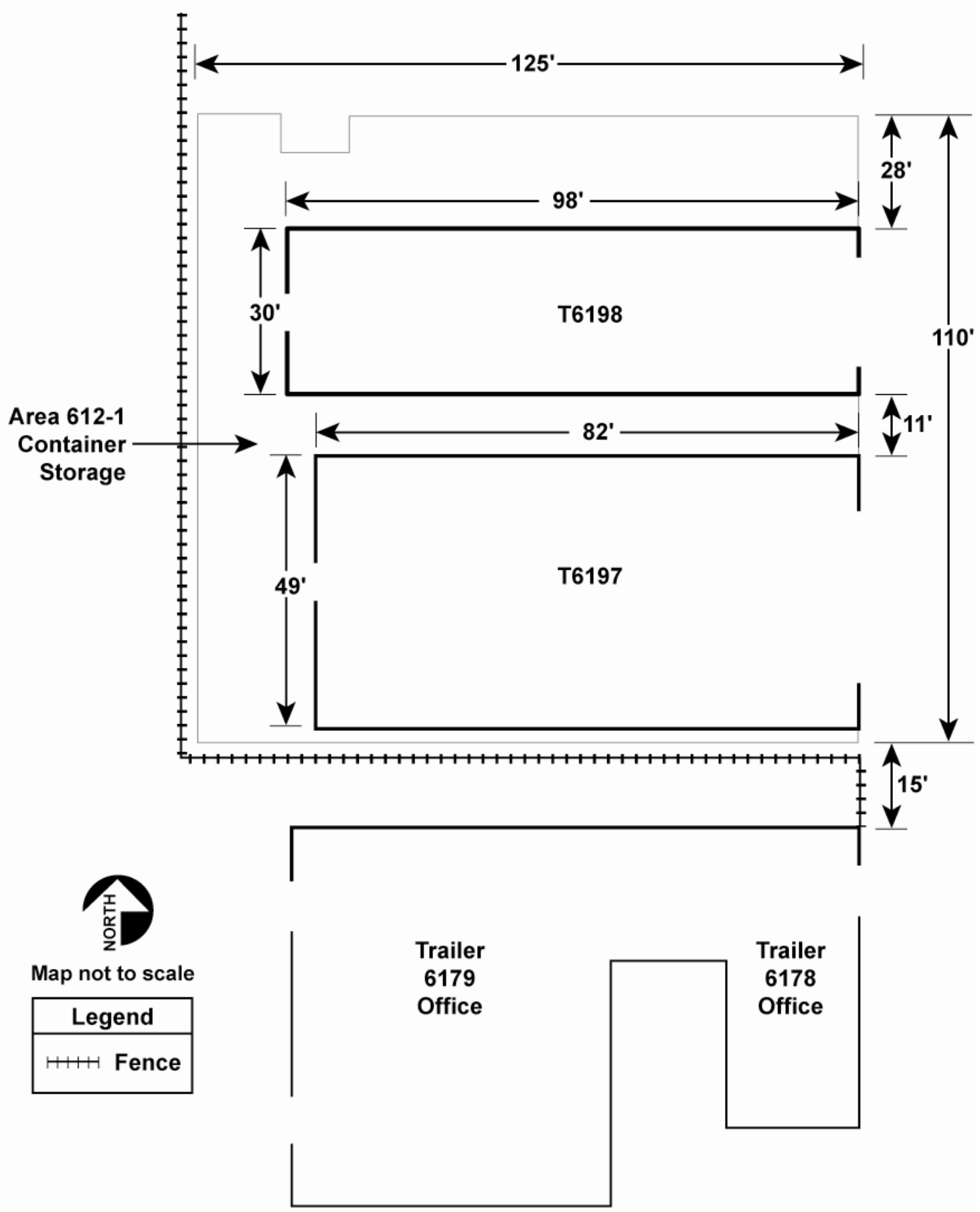

Figure 2-5. Area 612-1 
Documented Safety Analysis for the Waste Storage Facilities

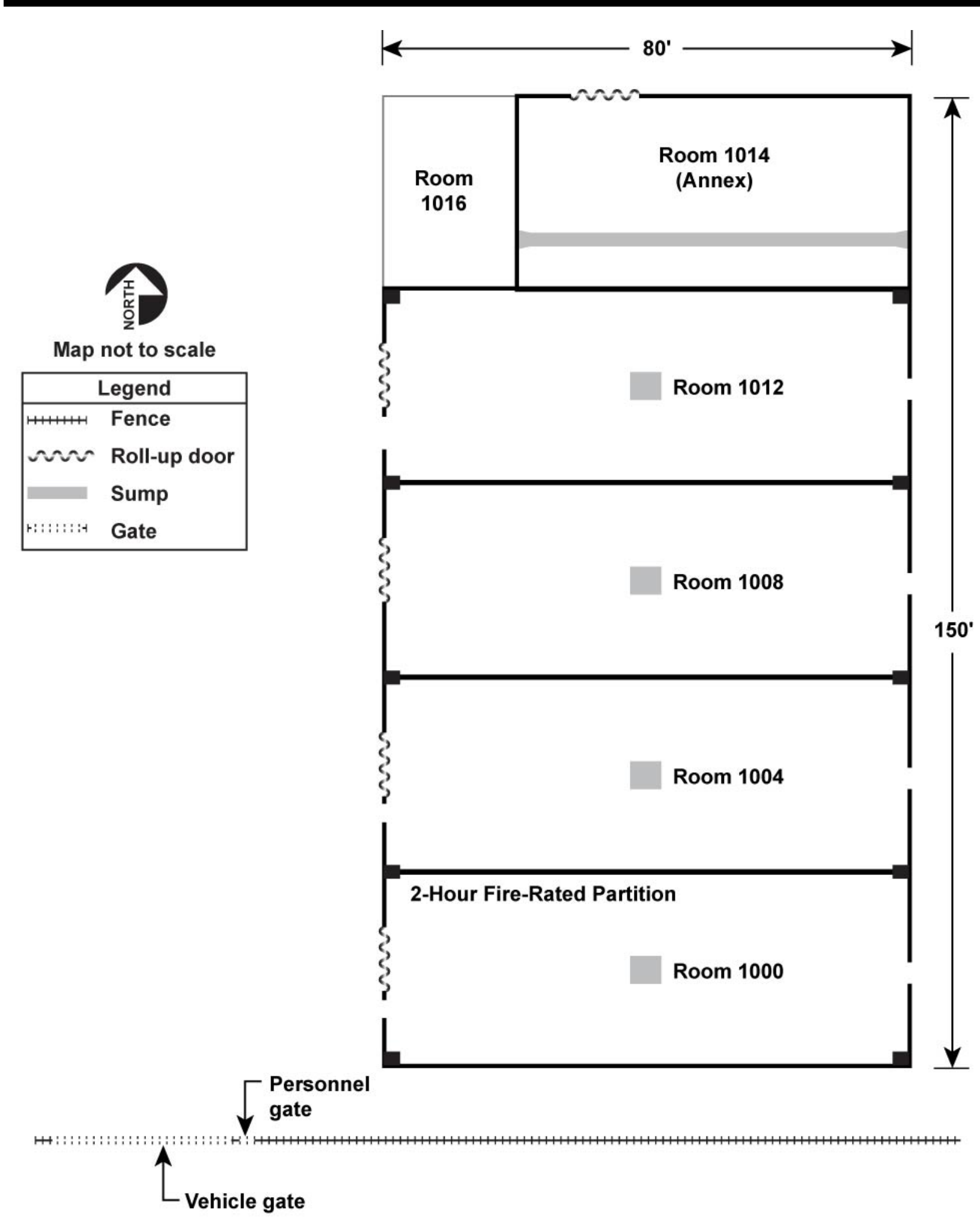

Figure 2-6. Building 693 


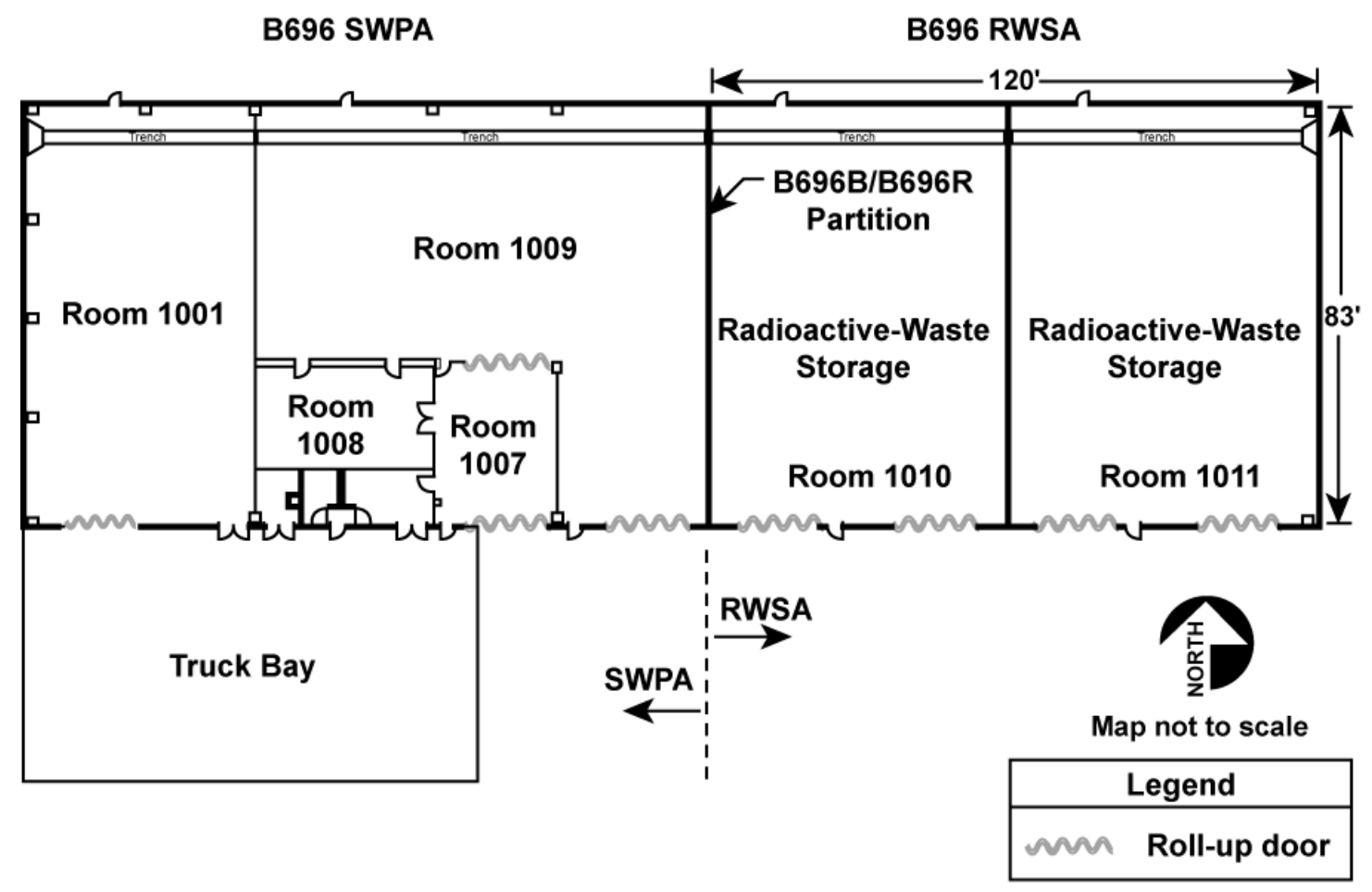

Figure 2-7. Building 696

\subsubsection{DIMENSIONS SIGNIFICANT TO HAZARD AND ACCIDENT ANALYSIS}

The dimensions most significant to hazard and accident analysis activities are the distance from the facility to the nearest LLNL site fenceline and the overall size of the facility (applicable to roofed facilities). Dimensions of tents are not included. The closest fenceline in all cases is the Greenville Road fenceline, to the east. Table 2-2 provides these distances.

Table 2-2. Building Dimensions

\begin{tabular}{|l|c|c|c|c|}
\hline \multicolumn{1}{|c|}{ Facility } & $\begin{array}{c}\text { Distance to } \\
\text { fenceline, } \mathbf{m}\end{array}$ & Height, ft & Width, ft & Depth, ft \\
\hline B625 & 250 & 24 & 120 & 40 \\
\hline A612 Tank Trailer Storage & 260 & NA & 77.5 & 9 \\
\hline A612-1 including T6197 \& T6198 & 260 & NA & NA & NA \\
\hline A625 Yard Area & 225 & NA & NA & NA \\
\hline B693 & 130 & 16 & 150 & 80 \\
\hline B693 Roll-off Bin Storage & 130 & NA & NA & NA \\
\hline DWTF Portable Tank Storage & 90 & NA & NA & NA \\
\hline B696R & 140 & 23 & 120 & 80 \\
\hline
\end{tabular}


Facility boundary fence nearest site fenceline (E. of B693)

90

NA

NA

NA

\subsubsection{CONSTRUCTION MATERIAL}

Some of the facilities are built to meet PC-2 requirements, designed to protect the waste from being seriously damaged in an earthquake or high wind, as will be described in a subsequent section. The structural systems that are important for maintaining the PC-2 rating for the B625 and B696R facilities consist of the following:

Foundations

Columns

Beams directly connected to the columns

Lateral bracing

Crane support/restraints (for B625 only)

Roof deck

Table 2-3 provides a summary of construction materials employed in the facilities covered by this DSA.

Table 2-3. Construction Material used in Waste Storage Facilities

\begin{tabular}{|l|c|c|c|c|c|c|}
\hline \multicolumn{1}{|c|}{ Facility } & Roof & Ext. walls & Int. wall(s) & Floor & $\begin{array}{c}\text { Floor } \\
\text { covering }\end{array}$ & Berms \\
\hline B625 & metal & metal & none & concrete & epoxy & concrete \\
\hline $\begin{array}{l}\text { A612 Tank Trailer } \\
\text { Storage }\end{array}$ & none & concrete & none & concrete & epoxy & concrete \\
\hline Tents 6197 and 6198 & $\begin{array}{c}\text { PVC-coated } \\
\text { polyester }\end{array}$ & $\begin{array}{c}\text { PVC-coated } \\
\text { polyester }\end{array}$ & none & asphalt & none & asphalt \\
\hline B693 & metal & $\begin{array}{c}\text { concrete } \\
\text { block \& } \\
\text { metal }\end{array}$ & gypsum & concrete & epoxy & concrete \\
\hline $\begin{array}{l}\text { B693 Freezer Pad } \\
\text { (Room 1016) }\end{array}$ & metal & none & none & concrete & none & none \\
\hline $\begin{array}{l}\text { B693 Roll-off Bin } \\
\text { Storage Unit }\end{array}$ & none & none & none & concrete & none & none \\
\hline $\begin{array}{l}\text { DWTF Portable Tank } \\
\text { Storage Unit }\end{array}$ & none & none & none & concrete & epoxy & concrete \\
\hline B696R & metal & metal & gypsum & concrete & epoxy & concrete \\
\hline Yard areas & none & none & none & asphalt & none & none \\
\hline
\end{tabular}


Note: In all cases where concrete is specified, including concrete block, it is steel-reinforced concrete

\subsubsection{FACILITY PERFORMANCE CATEGORIZATION}

The RHWM Waste Storage Facilities were built over many years. Some facilities have been upgraded or retrofitted to improve the seismic integrity. All of the facilities were built to meet or exceed the building codes and DOE Orders that were in place at the time of construction or upgrade. The most likely natural phenomena hazard that might affect these structures is an earthquake. Seismic evaluations have been performed to verify that the facilities satisfy the requirements for a PC-2 facility, as defined in DOE-STD-1020-94, Change Notice 1 (DOE 1996). The results of these reviews are summarized in Table 2-4. None of the RHWM facilities require seismic reevaluation based on DOE-STD-1020-2002 criteria (see Section 1.5.1).

Seismic forces typically generate the governing structural loads, so facilities that meet seismic requirements typically exceed wind criteria. California is not known for hurricanes or tornados and DOE-STD-1020-2002 does not require tornado design consideration for PC-2 facilities. Most buildings have calculations specific to maximum wind speed.

Water damage is possible but would not be expected to be severe at LLNL. LLNL is located near some minor arroyos, and no rivers are located within the valley. Flash floods are not expected. Table 2-4 summarizes information on the facilities.

Table 2-4. Facility Performance

\begin{tabular}{|l|c|c|c|c|c|}
\hline \multicolumn{1}{|c|}{ Facility } & $\begin{array}{c}\text { UBC } \\
\text { Year }\end{array}$ & $\begin{array}{c}\text { Seismic/Wind } \\
\text { Reference }\end{array}$ & $\begin{array}{c}\text { Meets PC-2 } \\
\text { Seismic }\end{array}$ & $\begin{array}{c}\text { Meets PC-2 } \\
\text { Wind }\end{array}$ & $\begin{array}{c}\text { Meets PC-2 } \\
\text { Flood }\end{array}$ \\
\hline \hline B625 & 1997 & LLNL 2000 & Yes & Yes & Yes \\
\hline B693, Rooms 1000-1012 & 1988 & LLNL 1991a & Yes & Yes & Yes \\
\hline $\begin{array}{l}\text { B693, Rooms 1014 \& } \\
\text { 1016 }\end{array}$ & 1997 & LLNL 1995 & Yes & Yes & Yes \\
\hline B696R & 1994 & LLNL 1995 & Yes & Yes & Yes \\
\hline
\end{tabular}

1. UBC in effect when building was designed or when seismic review was performed.

\subsubsection{UNDERGROUND TANKS}

\section{DWTF Underground Tank}

The 20,000-gal fiberglass-reinforced plastic (FRP) single walled underground tank provides containment for fire sprinkler water from B693 Room 1014, the DWTF Truck Bay, B695 Reactive Waste Storage Rooms, and B697. It will handle approximately 30 minutes worth of fire sprinkler water discharge, depending on the building involved. The tank has a 4-in. pump-out connection for removing contents via an extraction truck, a level switch and transmitter, and 2 -in. vent. The tank is also equipped with a 30 -in. access way that is accessible via a steelcovered entry hole in a concrete pad. Mounted on the exterior south wall of B696R is the monitoring station to monitor the tank level. 


\subsection{PROCESS DESCRIPTION}

This section provides descriptions of the processes to support assumptions used in the hazard and accident analyses. These descriptions focus on major process features necessary to understand the hazard analysis and accident analysis.

\subsubsection{STORAGE OPERATIONS}

The facilities covered by this DSA handle the following types of materials:

- Nonhazardous industrial waste

- Hazardous waste

- Transuranic (TRU) waste

- $\quad$ Low-level waste (LLW)

- Tritiated items (e.g., 40,000 Ci of phone dials)

- $\quad$ Tritiated waste

- $\quad$ Mixed waste

- Combined waste (LLW that contains California-only regulated hazardous constituents above the regulatory limit)

- Conditionally accepted waste (e.g., special packaging, animal research, pharmaceutical)

The following summarizes general storage operation and material handling activities occurring in these facilities:

- Moving, staging, or storing containerized waste.

- Moving, staging, or storing containerized tritium items.

- Segregating waste according to compatibility.

- Removing the lids of containers of waste, except TRU waste or mixed TRU waste, for activities such as inspection, sampling, sorting, segregating, or repackaging.

Removing filter vents of approved TRU waste containers is allowed.

- Opening containers of tritium items for activities such as inspection, sampling, sorting, segregating, or repackaging.

- Sampling activities, including preserving samples, decontamination of nondisposable sampling equipment, $\mathrm{pH}$ and flashpoint testing.

- Overpacking or repackaging.

- Lab packing, overpacking, or repackaging tritium items. 
- Encapsulating, packing and otherwise preparing sealed sources for shipment.

- Surveying and assaying waste containers, e.g., gamma spectrometry, nondestructive assay (NDA) techniques, and headspace gas sampling (HSGS).

- Radiography (e.g., real-time radiography).

- Counting radioactive swipes samples.

- Inspecting integrity of containers and container storage areas (daily and weekly when-in-use inspections).

- $\quad$ Bulking and transferring waste, except TRU or mixed TRU.

- Container maintenance (e.g., painting, replacing gaskets on portable tanks, adding and removing labels, filter vent replacement).

- Relieving pressure from over-pressured drums except for TRU or mixed approved TRU waste containers.

- Decontamination of equipment except that equipment designated as TRU or mixed TRU.

- Dismantling and size reduction of equipment except equipment designated as TRU or mixed TRU.

- $\mathrm{pH}$ adjustment of aqueous non-hazardous waste for sewer discharge; discharge of waste effluent to the sanitary sewer.

- Transport of containers within the DWTF and A625 using vehicles, including trucks and forklifts, and manual means such as drum dollies.

- TRUPACT-II loading/unloading.

- Movement of containers within the buildings and other structures using forklifts and manual means such as drum dollies.

- Receiving containers from and shipping containers to facilities outside of DWTF and A625 using vehicles.

- $\quad$ Storing sealed sources, for example, plutonium and uranium standards, for use in calibration and testing of radioassay equipment; assembling and disassembling samples consisting of these standards placed into containers, such as drums; inventorying and leak testing them.

The discussion in this section focuses on the general storage operation and waste/tritium item handling activities that are common throughout the storage facilities covered by this DSA. Additional activity and process descriptions are provided in subsequent sub-sections for facilityspecific activities, such as the TRU Thermal Conditioning and the trailer-mounted NDA unit. 


\section{Documented Safety Analysis for the Waste Storage Facilities}

In general, the waste/tritium item containers used at LLNL range in size from $1 \mathrm{ml}$ to 20,000 gal and include cans, bags, vials, jars, bottles, drums, boxes, carboys, portable tanks, and tank trucks. Large containers such as transportainers and roll-off bins are used. All containers, portable tanks, liners, and over-packing material used at LLNL are selected for their compatibility with the contents. Liquid wastes are typically stored in metal, plastic, or glass containers. Solid waste and waste that does not contain free liquids can be stored in cellulose containers as well as metal, plastic, or glass containers. Metal cylinders are used to store gaseous waste or liquefied gas waste. Compatible containers are used to store flammable and combustible liquids in areas designated for such storage. Waste/tritium containers are staged and stored on metal, plastic, or wood pallets. TRU waste is stored on metal pallets only.

TRU waste is stored in approved TRU waste containers that satisfy the free drop test performance criteria for steel 7A Type A packaging [49 CFR 173.465(c)(1)].

Most approved TRU waste containers are vented with carbon-media filter vents to prevent the buildup of gases. The remaining approved TRU waste containers, specifically TRU Oversize Boxes, are not fitted with vents. However, the gasket area between the lid and the box may provide some venting of gases. Removing filter vents of approved TRU waste containers is done for maintenance, replacement and sampling activities. These activities simply support storage activities; there is no handling, repackaging, intrusive inspection, or characterization of the waste within the container. There are some steel Type A drums that were accepted as containing LLW but on assay reclassified as TRU (LLW/TRU conversions) that are unvented. The waste disposal requisition (WDR) for LLW/TRU conversions will be updated to reflect the change in waste characterization and the containers will be moved into an approved TRU storage area. These drums may be relocated to another facility to have a vented lid replacement or may be placed into a larger container with a vent. LLW is stored in a variety of containers, including, but not limited to, metal boxes and drums, plastic drums and bags, large metal transportainers, plastic tanks, wood crates, and fiber boxes.

Containers can arrive at the storage facilities either by truck or forklift, either from other RHWM facilities, other DOE facilities, or from the generator. The containers are secured to the vehicle using RHWM tie-down procedures when transported outside the fenced waste areas. Forklifts are generally used to move waste/tritium item containers from trucks to staging areas, storage areas, or into storage buildings. Forklifts may also be used to move waste/tritium items within the A625 or DWTF.

The transport of containers is performed in accordance with the LLNL Transportation Safety Document (LLNL 2007), which establish LLNL policy for the onsite transfers of hazardous and radioactive materials, substances, and wastes within LLNL. These documents provide requirements for the proper containment, communication, and controls for materials in transit. The topics covered by this manual that are relevant to waste/tritium item handling include:

- Responsibilities of RHWM Division personnel

- Securing containers during transportation

- Requirements for vehicles transporting radioactive or hazardous waste. 


\section{Documented Safety Analysis for the Waste Storage Facilities}

Containers are transported manually (e.g., carried, drum dolly) or by forklift. Drums and smaller containers moved by forklifts are handled using a forklift attachment or placed on pallets for moving a group of containers. Some containers, such as portable tanks and boxes, have skids that are designed to be transported by a forklift. Pickup and flatbed trucks are also used to transport containers. Containers and pallets are secured to the bed of the truck prior to transport. Operator training and traffic controls minimize the potential for spillage and accidents.

Approved TRU waste containers can be loaded into TRUPACT-II shipping casks with a crane.

Liquid waste is normally transported in containers, portable tanks, and tank trucks. All containerized liquid waste (including waste containing free liquids) is stored in secondary containment.

Containers are kept closed except when empty or when wastes/tritium items are being added or removed (not applicable to TRU waste) as in sampling, bulking, pH adjustment, repackaging, or lab packing operations. However, some waste containers may need to be vented to prevent pressure build-up and/or flammability hazards. Approved TRU waste containers are vented to allow for the dissipation of hydrogen gas resulting from the radiolysis of plastic waste materials. Removing filter vents is done for maintenance, replacement and sampling activities. Containers of hydrogen peroxide may be vented using plugs that prevent the escape of liquids. When required either to comply with air emission requirements (e.g., 40 CFR 264 Subpart CC) or to prevent other types of releases (e.g., radionuclides), such as required by the DOE Waste Isolation Pilot Plant Waste Acceptance Criteria (WAC), the container vents are fitted with carbon and/or high-efficiency particulate air (HEPA) filters.

Gas cylinders are stored in a manner that minimizes the likelihood of rupture should the cylinder be dropped, tipped, or hit by a heavy falling object. For example, a gas cylinder may be secured in an upright position, strapped to a pallet in a horizontal position, or overpacked in an approved container. When not in use, cylinders are firmly capped.

Different material types are often stored in the same facility. As an example, hazardous, mixed and TRU waste might be placed in a room together. In general in the Waste Storage Facilities, there may be differences in how the material is stored such as the pallets used (e.g., hazardous and low-level waste on metal and plastic pallets). However, in rooms storing TRU waste, only waste in metal containers and on metal pallets is allowed. Tritium items may be stored in Waste Storage Facilities yard area in the same vicinity as radioactive and hazardous waste container storage.

Waste staging involves placing containerized waste in the yard area (outside of a storage area), and is usually performed when waste is being received, moved from one location to another, or prepared for shipment. Waste may also be staged when maintenance is being performed in a storage area. Staging is temporary, and hazardous and mixed wastes are subject to time constraints described in the RCRA Operation Plan. Staged waste is posted as staged. Low-level radioactive waste may be stored in the same areas (any place inside the Waste Storage Facilities). 


\section{Documented Safety Analysis for the Waste Storage Facilities}

With the exception of TRU waste, containers can be opened for sampling or other waste/tritium item handling activities. The work authorization control program assures that either sampling procedures, processing plans, work permits, and/or integration worksheets are used to implement controls and monitoring when required. Chapter 9 discusses protocols for developing and implementing controls and monitoring of waste/tritium item handling activities.

Lab packing, overpacking, and repackaging activities are performed throughout the Waste Storage Facilities. TRU waste is not lab-packed or repackaged. Lab packing involves placing a number of small waste containers into one single container. Even though each waste remains in their small container, only compatible wastes may be lab packed together. Overpacking usually involves placing one container of waste into another larger container. However, numerous large containers of waste may be overpacked into a transportainer. Repackaging involves removing waste from its original container and placing it into another container. The repackaging of containers of tritiated materials is the same operation as standard repackaging.

Containerized wastes/tritium items are also subject to surveying, assaying, and radiography. Surveying determines the level of radiation at the container surface or some distance from the container using portable hand held equipment. Assaying determines the type and quantity of radionuclides in the waste. Portable or stationary equipment may be used. A Non-destructive Assay (NDA) unit is used in the facilities to measure containers. A Gamma Spectroscopy System is a portable assay unit that is also used in the storage areas covered by this DSA. A trailermounted NDA may be used to assay radioactive waste in either waste storage area. Headspace gas sampling (HSGS) is performed to measure and determine type and concentrations of vapors and gases in approved TRU waste containers. Radiography (e.g., real-time radiography) uses $x-$ rays to inspect the contents of waste containers. This is used to verify the physical form of the waste, ensure the waste matches the waste stream description, and identify prohibited items.

RHWM container storage areas are inspected on a routine basis to ensure that waste/tritium item containers are in good condition. Containers that are found to be damaged, deteriorated, or leaking are managed in accordance with applicable procedures. Visual inspections are used to determine if liquids have accumulated in any of the facility sumps. Equipment is used to remove accumulated liquids.

Unvented TRU Oversize Boxes and unvented TRU drums (LLW/TRU conversions) are visually inspected for bulging, an indicator of possible flammable gas buildup. Although some methane is produced from radiolysis of organics, the major product is hydrogen. Hydrogen also has the wider flammability range of the two and is thus used to bound accident scenarios.

Inspection results may indicate the need for container maintenance to be performed to ensure a container's integrity. Examples of container maintenance are painting, replacing gaskets on portable tanks, and adding/removing labels.

Waste effluent is discharged to the sanitary sewer through an access port in the A625 yard. Prior to the discharge of aqueous waste to the sanitary sewer, the $\mathrm{pH}$ may need to be adjusted to meet discharge requirements. If the $\mathrm{pH}$ adjustment does not constitute treatment (as defined by RCRA), this activity may occur anywhere in the A625 or DWTF yard. 
Equipment decontamination or dismantling may also be performed anywhere in the yard of A625 or the DWTF, as long as these activities do not constitute treatment as defined by RCRA. These activities may include use of manual, electric, and pneumatic tools, such as saws, shears grinders, and impact wrenches; flammable gas torches and plasma cutters; and other standard equipment used for such purposes.

\subsubsection{TRAILER-MOUNTED NONDESTRUCTIVE ASSAY (NDA) SYSTEM}

A trailer mounted NDA unit will be used in A625 and DWTF to quantify the radionuclides in waste containers. The trailer will be moved in by truck (tractor) and set up in a suitable location to keep from interfering with normal waste movement. The trailer-mounted NDA does not contain a radiation-generating device. Electrical connections will be made to supply the NDA equipment. Containers of waste are loaded and unloaded from the NDA trailer using forklifts.

\subsubsection{REAL-TIME RADIOGRAPHY (RTR) SYSTEM}

The RTR unit performs nondestructive examination of approved TRU waste containers (e.g., 55-gal drum) using a mobile RTR technique. The RTR system contains an x-ray tube, which operates in the range of $20 \mathrm{kV}$ to $420 \mathrm{kV}$. The high energy $\mathrm{x}$-rays penetrate through the approved TRU waste container onto an image intensifier. A high-resolution camera then records the image from the intensifier onto VHS tape and/ or digital media. Digital imaging of $100 \%$ of the approved TRU waste container provides a non-intrusive method for inspecting packages containing TRU and mixed TRU waste. The RTR equipment is designed to characterize only one approved TRU waste container at a time. Containers of waste are loaded and unloaded from the trailer using forklifts.

\subsubsection{HEADSPACE GAS SAMPLING (HSGS) SYSTEM AND THERMAL CONDITIONING}

HSGS of an approved TRU waste container (e.g., 55-gal drum) is performed in accordance with the WIPP requirements. TRU and mixed TRU waste is thermally conditioned prior to headspace gas sampling as part of the characterization process required to certify waste for shipment to the WIPP for disposal. Thermal conditioning involves maintaining containers at a minimum temperature of $65^{\circ} \mathrm{F}$ for an established period of time. Blanket heaters and box style heaters are used to thermally condition TRU and mixed TRU in B625 and B696R. These blankets are electrically heated and thermostatically controlled.

Once the approved TRU waste containers are selected, the containers are moved on a drum dolly or by forklift to a designated sampling area. The filter vent may need to be removed and replaced with a filter vent with a sampling port. A needle is inserted through the needle guide on the filter or through the carbon filter depending on the model of filters being used. If the carbon is punctured the filter will be replaced with a new filter. The headspace gas sample is collected through the needle into a gas canister. The gas canister is then taken to the analytical instrument (Gas Chromatography/Mass Spectrometry - GC/MS) where the gas is analyzed. The instruments may be set up in TRU storage areas. 


\subsubsection{TRUPACT-II LOADING/UNLOADING}

The TRUPACT II (TRansUranic PACkiging Transport, Number Two) is a Department of Transportation (DOT) Type B shipping cask on a tractor pulled trailer. Up to three casks can be placed on a single trailer for transportation. DOT Type B casks are designed to meet stringent performance standards under a variety of accident scenarios. The TRUPACT II casks are certified by the Nuclear Regulatory Commission (NRC) to meet the 10 CFR Part 71 requirements for a Type B shipping container (NRC 2001). The TRUPACT-II has been designed and licensed to transport contact-handled transuranic materials for the DOE. The TRUPACT-II cask consists of an Outer Containment Assembly (OCA), which provides a primary containment boundary and acts as an environmental barrier, and an Inner Containment Vessel (ICV), which provides a secondary containment boundary.

The payload for the TRUPACT-II consists of fourteen 55-gal approved TRU waste drums per cask. If shipping less than 14 loaded drums, empty dunnage drums must be used to form the payload. To load drums of waste into the TRUPACT II casks, the drums are bundled together into a single payload and lifted by a crane into the casks. Ten drum overpack and boxes are also accepted payload.

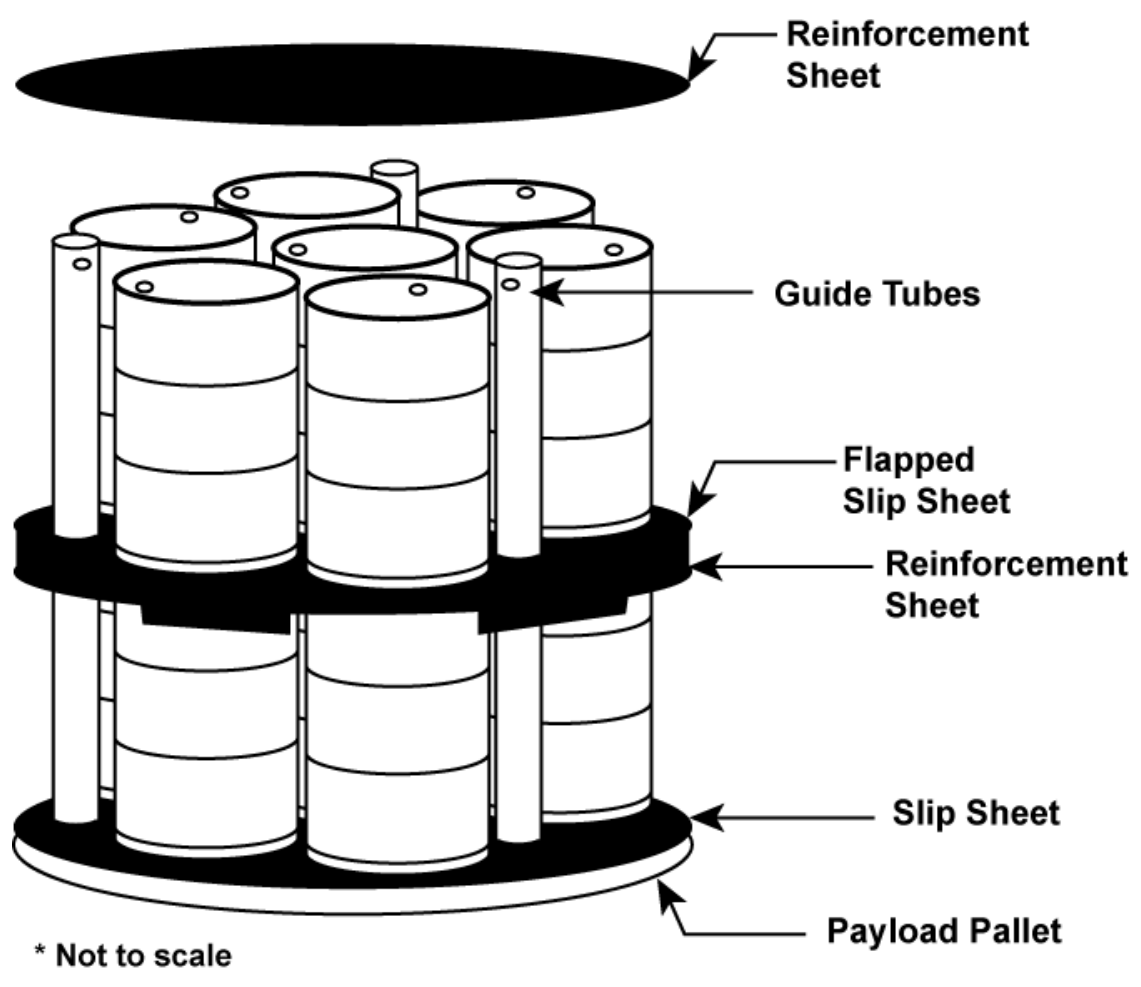

Figure 2-8. TRUPACT-II loading configuration

TRUPACT II loading/unloading is performed in the A625 yard or the yard area west of B693. 


\section{Documented Safety Analysis for the Waste Storage Facilities}

When loading, seven drums are positioned on a drum payload pallet. A slip-sheet is placed on top of the drums, and an additional seven drums are positioned on the top layer. Stretch wrap is applied around the drums multiple times, in accordance with WIPP requirements, during the payload assembly both before and after the second layer of drums is positioned. Another slipsheet is positioned on top of the drums. Guide tubes are inserted into the assembly, completing the payload assembly. The payload assembly is moved by forklift to the loading area, if necessary.

The TRUPACT II cask(s) is prepared for payload loading. This may be performed before, during, or after payload assembly. The casks may or may not be removed from the trailer for loading. The trailer may or may not be present during the TRUPACT-II loading and payload assembly. The OCA lid is removed from the cask and placed on a storage stand using the Adjustable Center of Gravity Lift Fixture (ACGLF) attached to the crane. The crane operator is certified. The ICV lid is removed following the same procedure as the OCA lid and also placed on a storage stand.

The ACGLF and the crane are used to lift the drum payload and place it in the ICV. The ICV lid is replaced, followed by the OCA lid. For loading/unloading the payload, operation of the crane meets the definition of a Critical Lift as defined in DOE-STD-1090-2007 and follows the implementation of this standard found in ES\&H Manual Document 15.3, "Crane, Hoist and Rigging Safety." Inspections, cleaning, surveys, and swipes of the TRUPACT-II vessels, lids, and drum payload assemblies are performed as necessary throughout the process.

In general, procedures for unloading the TRUPACT-II are the reverse of loading. Generally, the hazard is the same as for unloading, however, the procedures for inspections and preparation of the payload are typically more complex.

\subsubsection{CRANES}

A 3-ton overhead bridge crane system is located in B625. The B625 bridge crane is used for moving large waste containers, such as Standard Waste Boxes (SWBs), equipment or for picking containers from storage arrays. Personnel using the cranes are trained in their operation. The crane is comprised of a trolley assemblage, hand control unit, crane unit, crane girders, and 3-ton hoist. The unit spans about 40 feet in a north-south orientation. The crane unit travels the length of the building (in an east to west direction), and is controlled by a hand unit connected to the crane. The crane has been retrofitted with seismic restraints. The seismic restraints were designed to meet DOE-STD-1020-94 PC-2 criteria.

Mobile cranes are also used throughout the Waste Storage Facilities for activities such as moving waste containers, transportainers, and equipment and for maintenance. Hoisting and rigging is performed consistent with established LLNL practices by qualified crane operators. 


\subsubsection{MAINTENANCE ACTIVITIES}

Maintenance activities are performed in compliance with current DOE orders for maintenance of nuclear facilities where applicable. All maintenance is at least performed similarly to that found in industry using the graded approach. Maintenance activities are primarily performed by RHWM maintenance personnel, Maintenance Utility Services Department (MUSD), and Hazard Control. These activities are governed by and must comply with work authorization practices. Examples of maintenance activities include standard building maintenance, such as painting, resurfacing asphalt, re-epoxying floors, welding, filter replacement, and equipment maintenance (e.g., calibration, lubrication, re-builds, parts replacements). Fixed and portable ladders, man lifts, scaffolding and scissor lifts will be used for working at heights. The schedule and type of maintenance for facilities and process equipment is tailored to the facility and to the type of equipment, frequency of use, age, and performance requirements.

Maintenance requires the use of limited quantities of lubricants, solvents, and other combustible/flammable materials in the facility. Welding and other hot work may be performed using the LLNL Hot Work Permit Process. The RHWM Maintenance Program is discussed in Chapter 10.

\subsection{CONFINEMENT, CONTAINMENT AND VENTILATION SYSTEMS}

This section identifies and describes the set of structures, systems and components that perform confinement, containment and/or ventilation functions.

\subsubsection{WASTE CONTAINERS}

Waste containers provide primary confinement for waste material being stored, staged, or handled, thus preventing a significant release of radioactive or hazardous material. Approved waste containers provide the means to package contaminated waste for transport and handling, and are a layer in defense-in-depth to significant releases and to mitigate releases in the event of mechanical impacts or thermal stresses. TRU and mixed TRU waste are stored in approved TRU waste containers.

\subsubsection{FLOORS}

All facilities that store hazardous liquid waste have concrete floors with integral concrete berms with the exception of the freezer. Liquids stored in the freezer will be placed in secondary containment. The floors and berms are coated with a sealant to reduce the possibility of spilled liquids reaching the soil under the concrete. All other floors are concrete or asphalt.

\subsubsection{FREEZER STORAGE}

The freezer is located in B693 Room 1016 on the freezer pad. The industrial grade freezer primarily stores non-infectious, non-hazardous animal carcasses.. 


\subsection{SAFETY SUPPORT SYSTEMS}

No active Safety Systems have been identified. Therefore, there are no support systems on which a Safety System relies. The storage facilities covered by this DSA are typically simple structures with few active systems. There are no safety support systems built to a lower standard than the building or a safety significant system as described in DOE-STD-1021-93, Change Notice 1, reaffirmed 2002 (DOE 2002b).

\subsubsection{FIRE PROTECTION}

B625 and B696R have fire sprinkler systems meeting NFPA 13 for Ordinary Hazard occupancies. Both are wet pipe systems.

Building 693 has a fire sprinkler system meeting NFPA 13 for Ordinary Hazard Group 2, except that Room 1000 and 1014 (Annex) are hydraulically calculated to Extra Hazard Group 1. B693 Room 1000 has an automatic high-expansion foam fire extinguishing system that is the primary fire protection provided for flammable waste storage. This system is triggered either by rate compensated heat detectors, or by manual pull stations, and is designed to activate prior to the fire sprinklers, greatly reducing the quantity of water that might be discharged on a fire.

Fire extinguishers are located according to the requirements of NFPA 10, Standard for Portable Fire Extinguishers, and where specific fire hazards are present.

\subsubsection{EMERGENCY LIGHTING}

All fully enclosed storage buildings (no light from windows or openings) have battery operated egress lights. The egress lights become active when there is a power failure. RHWM also has a portable generator and lights.

\subsubsection{EMERGENCY EVACUATIONIALARM}

A625 and the DWTF are connected to the audible warning system operated by the LLNL Emergency Management System. Speakers adequate to cover the area are mounted both outside and inside facilities. In addition, in B696R a visual warning system is provided to notify personnel to evacuate the building.

\subsubsection{RADIATION PROTECTION AND WARNING SYSTEM}

When required, RHWM places portable continuous-air monitors (CAMs) or passive air samplers (PASs) in areas where individuals are performing operations involving opened radioactive-waste containers, such as for drum crushing of radiologically contaminated drums. CAMs and PASs are placed and used in accordance with 10 CFR 835.403, "Area Monitoring." 


\section{Documented Safety Analysis for the Waste Storage Facilities}

\section{$2.8 \quad$ UTILITY DISTRIBUTION SYSTEMS}

The storage facilities are simple structures with minimal, standard utilities. The utilities found in these facilities are electricity, telephones, water (cold domestic, hot domestic, and fire suppression), and compressed air. All facilities have emergency eyewash and shower stations. There are no utilities or attachments built to a lower standard than the building or a safety significant system, a potential concern described in DOE-STD-1021-93. Utilities are periodically modified to meet institutional and operational needs. There are electric heating systems in B693 Room 1014 and hot water space heating systems in B696R Rooms 1010 and 1011.

The availability of any of these utilities affects neither the storage function nor the operations carried out in these facilities. RHWM has portable generators and lights that can be employed if necessary.

The water to the automatic fire sprinkler systems is provided by a Laboratory-wide distribution system, with three possible sources. The water generally comes from tanks located high enough to provide adequate pressure based on gravity alone. A 12-in. asbestos-concrete water main traverses A625 in an east-west line, running along the southern edge of T6197. It is buried approximately 60 inches deep. A 10-in. asbestos-concrete water main tees from the 12-in. main east of B624 and runs north under OS624A south and OS624A north. It is approximately 60 inches deep.

High voltage (three phase $115 \mathrm{kV}$ ) transmission lines cross A625 in an east-west line, running along the southern edge of T6197. Lower voltage (three phase $13.8 \mathrm{kV}$ ) distribution lines cross A625 in an east-west line, running along the southern edge of T6179. B693 annex room 1014 has electric powered heating units.

There are underground natural gas pipes traversing both the DWTF Storage Area and A625. The pressure of gas in these lines is no greater than $60 \mathrm{psi}$, the pressure coming from the PG\&E main at East Avenue. A 3-in. carbon steel high-pressure gas line crosses in front of B694 and then under the DWTF Storage Area in a north-south line equidistant between B693 and B697 (east of B693). It is capped at depth at approximately $70 \mathrm{ft}$ north of the storage area fence. It is buried approximately 60 inches deep and does not come to the surface.

A 12-in. carbon steel high-pressure natural gas line crosses A625 in an east-west line, running along the southern edge of T6197. It is buried approximately 56 inches deep.

\section{$2.9 \quad$ AUXILIARY SYSTEMS AND SUPPORT FACILITIES}

The Waste Storage Facilities are part of the infrastructure of the LLNL Main Site. Thus, all of the auxiliary systems and support facilities expected at a large DOE research facility are available. In addition to the utilities described above, LLNL maintains a contract with Alameda County to provide emergency services on-site; deploying a fully equipped and staffed onsite Fire Department, including ambulances with trained paramedics. 
The DWTF complex is fully fenced. The area encompassing the A625 nuclear facility is fully fenced. Access is limited to trained RHWM workers, trained and authorized maintenance workers, trained and authorized Hazard Control personnel, and trained and authorized DOE personnel. Others must be under escort.

\subsection{REFERENCES}

DOE (1996), Natural Phenomena Hazards Design and Evaluation Criteria for Department of Energy Facilities, DOE-STD-1020-94, Change Notice 1, U.S. Department of Energy, Washington, DC, January 1996.

DOE (2002a), Natural Phenomena Hazards Design and Evaluation Criteria for Department of Energy Facilities, DOE-STD-1020-2002, U.S. Department of Energy, Washington, DC, January 2002.

DOE (2002b), Natural Phenomena Hazards Performance Categorization Guidelines For Structures, Systems, And Components, DOE-STD-1021-93, Change Notice 1, reaffirmed 2002, U.S. Department of Energy, Washington, DC, April 2002.

DTSC (1999), Hazardous Waste Facility Permit for Lawrence Livermore National Laboratory (Main Site), Permit Number 99-NC-006, Facility EPA ID No.: CA2890012584, effective November 19, 1999, expiration date November 19, 2009, and all other permits included by reference.

LLNL (1991a), Seismic Review Report for Chemical Waste Facility Building 693, Lawrence Livermore National Laboratory, Livermore, CA, October 25, 1991.

LLNL (1995), Decontamination and Waste Treatment Facility Project Design Criteria, ISR-0007, January 13, 1995.

LLNL (2000), Memo from Madhu Kamath, LLNL, to Erik Brown, LLNL, "Bldg. 625 Seismic/Wind Evaluation for PC-2 Criteria," Lawrence Livermore National Laboratory, Livermore, CA, June 30, 2000.

LLNL (2007), Transportation Safety Document, Lawrence Livermore National Laboratory, Livermore, CA, UCRL-MA-152462 Rev. 2, April 2007.

NNSA/LLNS (2009), Management and Operating Contract between The US Department of Energy/National Nuclear Security Administration and Lawrence Livermore National Security, No. DE-AC52-07NA27344, February 27, 2009.

NRC (2001), Certification of Compliance for Radioactive Material Packages, Certificate number 9218, Rev. 12, U.S. Nuclear Regulatory Commission, July 27, 2001. 
This page intentionally left blank. 


\section{CHAPTER 3 \\ HAZARD AND ACCIDENT ANALYSES}

\section{$3.1 \quad$ INTRODUCTION}

This chapter presents the Waste Storage Facilities hazard and accident analyses, which comprises an identification and assessment of hazards, a facility hazard categorization based both on radiological and chemical hazards, and an analysis of potential accidents that could impact the worker, public, and the environment. This analysis was prepared in accordance with DOE-STD-3009-94, Change Notice 3 (DOE 2006) with the primary objective of obtaining a better understanding of the hazards and risks associated with operation of the Waste Storage Facilities. This chapter provides an overview of the safety analysis methodology, a characterization of the hazards, the impacts of bounding accidents, the assessment of risk, and conclusions of the analyses.

Transuranic (TRU) waste, hazardous waste, mixed waste, low-level waste (LLW), mixed TRU waste, liquid waste, solid waste, flammable waste, and combined waste are allowed to be stored in these facilities. A list of California regulated hazardous wastes can be found in the CCR, Title 22. A list of hazardous wastes that may be accepted into the permitted facilities are contained in the RCRA permit and associated operational plan. The main California hazardous wastes stored in the facility are small amounts of solid corrosives, toxic waste containing metals or organics, and some listed wastes. In the first sections, the purpose of these analyses is discussed, and the hazard identification and evaluation methodologies are presented. These sections are followed by the identification of hazards and development of such hazards into hazardous events, assessment of preventive and mitigative features, and the hazard categorization analysis. Postulated hazardous events were evaluated in a qualitative risk assessment to identify important or high-consequence events. Once identified, these events were further analyzed against Evaluation Guidelines in the accident analysis.

The graded approach as applied to these analyses prescribes that an analysis technique be no more sophisticated or detailed than necessary to present a comprehensive examination of the hazards associated with a facility (DOE 2006). Therefore, the analyses presented here were conducted only to the level necessary to provide a technical basis that the facility can be operated safely, with minimal risk to workers, the public, and the environment. Consequently, the presentation largely takes the form of a qualitative analysis, with only the consequences of bounding accidents evaluated quantitatively as appropriate. Where U.S. Environmental Protection Agency (EPA) guidelines and DOE classification criteria could be met easily, the use of bounding assumptions and less-detailed physical modeling and accident analysis was appropriate. 
Based upon the analyses reported herein, the Waste Storage Facilities were determined to be Hazard Category 2 nuclear facilities for the radionuclide inventory in accordance with DOE STD-1027-92, Change Notice 1 (DOE 1997) and a low-hazard classification as supported by Appendix K of ES\&H Manual Document 3.1, "Nonnuclear Safety Basis Program," September 9, 2009 (LLNL 2009a). It was demonstrated that the design and operation of the Waste Storage Facilities does not adversely impact the health and safety of the workers and the public.

\subsection{REQUIREMENTS}

This section contains the directives in effect as of February 2009 as implemented in the Lawrence Livermore National Security, LLC, Contract No. DE-AC52-07NA27344 (NNSA/LLNS 2009). Specific sections of these directives are relevant to the content of this chapter. This section also contains the codes, standards, regulations, and DOE orders specific to this chapter and required to establish the safety basis of the facility.

DOE-STD-1027-92, Change Notice 1, Hazard Categorization and Accident Analysis Techniques for Compliance with DOE Order 5480.23, Nuclear Safety Analysis Reports (DOE 1997)

DOE-STD-3009-94, Change Notice 3, Preparation Guide for U.S. Department of Energy Nonreactor Nuclear Facility Safety Analysis (DOE 2006)

DOE-STD-3014-96, Accident Analysis for Aircraft Crash into Hazardous Facilities (DOE 1996b)

\subsection{HAZARD ANALYSIS}

This report is intended to provide the basis for operation of the Waste Storage Facilities. This is accomplished by means of a thorough hazard-identification and hazard-assessment process to evaluate potential process-related consequences resulting from internal, external, and natural phenomena events. The discussion of this hazard analysis includes the following:

Description of hazard analysis methodology

- Identification of hazard sources

- Identification of the radiological and chemical inventory by type, form, quantity, and location

- A radiological hazard categorization in accordance with DOE-STD-1027-92 by a comparison to the radionuclide inventory with threshold values

- A chemical hazard classification supported by Appendix K of ES\&H Manual Document 3.1, "Nonnuclear Safety Basis Program," September 9, 2009 (LLNL 2009a).

- Identification of potential hazardous events and their respective consequences 
- Identification of preventive and mitigative features

- Identification of significant worker-safety features

- Identification of defense-in-depth measures

- Assessment of a qualitative likelihood of occurrence of hazardous events in combination with potential consequences to estimate the risk associated with design and operation of the facility

Because the operations performed within the Waste Storage Facilities are not complex, e.g., the storage and handling of TRU waste, hazardous waste, LLW, and combined waste in containers, the graded-approach concept to hazards analysis is employed.

\subsubsection{METHODOLOGY}

The Process Hazard Analysis (PrHA) methodology was devised to identify and characterize hazards and to perform a systematic evaluation of hazardous events. This methodology is used to develop, based on the hazard analysis team's knowledge and experience with the area's systems and operations, accident scenarios involving the identified hazards. Application of the methodology does not require detailed system information or exhaustive development of accident sequences. Instead, facility equipment, material, environmental factors, and support systems are considered on a macroscopic level, and accidents that have occurred in the past are more easily researched. The PrHA is applicable for identifying potential accidents of relatively simple systems and procedures.

\subsubsection{Hazard Identification}

The hazard identification process involved identifying and inventorying hazardous materials and energy sources in terms of quantity, form, and location. Energy sources associated with the Waste Storage Facilities operations were also determined. The following conditions, which could impact the radioactive material inventory and potentially lead to a release, were investigated:

- Operational events (e.g., spills, fires, criticality, explosions)

- Natural phenomena (e.g., flooding, extreme winds, earthquakes, lightning)

- External events (e.g., accidents at nearby facilities, aircraft accidents)

A hazard was considered to be anything that could adversely affect workers, property, the public, or the environment. The hazard sources anticipated for the Waste Storage Facilities were determined through discussions with operations personnel, review of planned operations, design criteria, structural-design drawings, equipment specifications, and previous hazard analyses from similar RHWM operations. 
To facilitate the hazard-identification process, the following specific categories of hazards were selected for investigation:

- Radiation sources

- Toxic, corrosive, or reactive materials

- Chemical energy (in the form of flammable, or explosive materials)

- Electrical energy

- Kinetic energy

- Potential energy

Common industrial hazards that make up a large portion of basic Occupational Safety and Health Administration (OSHA) regulatory compliance were evaluated only to the extent of determining their ability to initiate or contribute to accidents; otherwise, such hazards are adequately covered by 29 CFR 1910 implementation programs. Additionally, hazards associated with the safe operation of electrical equipment are governed by documents such as the National Electrical Safety Code and the National Electrical Code and, thus, were not addressed in this analysis.

Standard industrial hazards (SIHs) are defined as materials or energy sources routinely encountered in general industry and construction and for which national consensus codes or standards (e.g., Occupational Safety and Health Administration [OSHA] and Department of Transportation [DOT] codes/standards) exist and are implemented in the facility to govern such hazards. SIHs such as radiography, welding, electrical short, cranes and hoists, and falling objects are evaluated to determine their ability to initiate or contribute to a radioactive or chemical release. Those SIHs that do are carried forward for hazard evaluation.

A coarse screening of events was performed during the hazard-identification process. A physical-possibility screen was applied to identify those operational events, natural phenomena, and external events not physically possible as a function of site location or characteristics of the facility. All screened events were eliminated from further analysis. For example, events such as seiche and avalanches were eliminated on this basis.

Included as part of the hazard-identification process was a facility hazard classification and categorization conducted in accordance with DOE-STD-1027-92, Change Notice 1 (DOE 1997) and supported by Appendix K of ES\&H Manual Document 3.1, "Nonnuclear Safety Basis Program," September 9, 2009 (LLNL 2009a). This classification and categorization are based on a comparison of the facility inventory with threshold quantities of chemicals and radionuclides. 


\subsubsection{Hazard Evaluation}

The methodology used to support the hazard analysis is a modification of the hazard analysis method described in the American Institute of Chemical Engineers, Guidelines for Hazard Evaluation Procedures, and is consistent with DOE-STD-3009-94, Change Notice 3. This methodology allows for consideration of potential effects on workers and the public, and is necessary to provide details for DSA accident analysis screening and updating.

The hazard analysis was conducted to ensure that all possible hazards were represented and considered. The focus of the hazard analysis is on potential accident conditions involving the hazards associated with the Waste Storage Facilities. Normal and abnormal conditions can also present hazards to the worker. However, these hazards are likely to involve minor exposures to contamination and other occupational hazards. These hazards are addressed in the facility description and the description of safety management programs (e.g., Radiation Protection Program) in Chapters 7 through 17 of this DSA.

In general, the hazard analysis consisted of a three-step process to:

- Systematically evaluate hazards, develop accident sequences, and identify administrative and engineered controls.

- Qualitatively assess frequency and consequence, for both unmitigated and mitigated accident sequences.

- Use the results to identify which controls should be preserved in the TSRs and the appropriate safety programs to effectively reduce the potential impact on the health and safety of the public and workers.

More specifically, based on the information acquired through the hazard-identification process, operations and systems in the Waste Storage Facilities were categorized into four types of scenarios: (1) Operations (waste storage, staging, handling, etc.); (2) Inadvertent Firearm Discharge; (3) External Events; (4) Natural Phenomenon Hazards.

The Hazard Tables are found in Appendix A of this DSA. The following information is provided for each scenario:

- Event ID No. Identifier to facilitate tracking of scenarios.

- Event/Hazard Summary and Material at Risk (MAR). A description of the accident type and an estimate of the inventory involved in the postulated scenario.

- Cause. Description of scenario, or family of scenarios, including identification of potential initiators. 
- Preventive/Mitigative Features. Appropriate preventive and mitigative safety features for eliminating, controlling, or mitigating the hazardous conditions. The controls identified fall within three groups:

- Initial conditions are used to develop a physically meaningful scenario per DOE-STD-3009-94, Change Notice 3, Appendix A

- Controls credited to reduce the frequency or consequence of the scenario.

- Controls not specifically credited to reduce the frequency or consequence of the scenario, but that serve as defense-in-depth.

- Frequency/Consequences/Risk. For a worker and the public, a qualitative estimate of the scenario frequency, potential consequences, and associated risk to determine the scenario risk profile before and after controls are credited

- Comments. Statements provided to clarify scenario development, hazard-evaluation assumptions, or other issues

The hazard analysis focused specifically on the worker (both facility and co-located) and the public. Site facility workers are typically protected by safety management programs. The impacts to the environment from the scenarios identified in the hazard analysis are considered less significant than the impacts to the public. As such, the controls identified in the hazard analysis are considered sufficient to address impacts to the environment.

The consequence and frequency ranking is combined to determine the risk ranking of each event. This process results in a relative risk ranking for each analyzed accident-family in the Waste Storage Facilities, based on its risk to the worker and the public. More information on the risk matrix development is presented subsequently.

\section{Frequency Category Estimates}

Each accident was assigned a frequency category based on the information in Table 3-1.

Table 3-1. Qualitative Frequency of Occurrence of Postulated Events

\begin{tabular}{|l|c|c|l|}
\hline \multicolumn{1}{|c|}{ Frequency level } & Acronym & Frequency & \multicolumn{1}{c|}{ Qualitative description } \\
\hline \hline Anticipated & A & $10^{-2} \leq \mathrm{f} \leq 10^{-1} / \mathrm{yr}$ & $\begin{array}{l}\text { Events that might occur several times } \\
\text { during the lifetime of the facility } \\
\text { (excluding normal operations) }\end{array}$ \\
\hline Unlikely & $\mathrm{U}$ & $10^{-4} \leq \mathrm{f}<10^{-2} / \mathrm{yr}$ & $\begin{array}{l}\text { Events not anticipated during the lifetime } \\
\text { of the facility }\end{array}$ \\
\hline $\begin{array}{l}\text { Extremely unlikely } \\
\text { Beyond extremely } \\
\text { unlikely }\end{array}$ & EU & $10^{-6} \leq \mathrm{f}<10^{-4} / \mathrm{yr}$ & $\begin{array}{l}\text { Events that will probably not occur during } \\
\text { the lifetime of the facility }\end{array}$ \\
\hline
\end{tabular}


Frequency estimation considered facility or industry data, if well known and readily available, estimates, or analyst's judgment. For all instances, the best information available was used. Making estimates consists of the following steps:

1. Identification of a rough initial estimate of scenario frequency

2. Identification of the following:

- Initiating-event frequency (per year)

- Independent or dependent probabilities for other failures (e.g., hardware, human error, conditional probability of fire)

- Number of repetitive operations over time

- Period or percentage of time material is present

- Combining all information to get final estimated scenario frequency.

- Frequency of occurrence is not meant to be an absolute number but, rather, to express an expected frequency range. Frequencies are assigned to both unmitigated accidents (before controls are applied) and mitigated accidents (after controls are applied).

The estimate for unmitigated frequency of occurrence for each accident scenario is based on the assumption that no controls are in place to lower the frequency. Such estimates are based on an interpretation of "unmitigated" to mean that no special controls are implemented above and beyond standard industrial practices, waste packaging, and assumed initial conditions. The frequency of an accident scenario is a function of the frequency of the initiating event and the frequency of enabling events. Enabling events are those that must occur following the initiating event to result in the postulated accident. For example, for a transportation accident that initiates a fire in a storage area, if the initiating event is vehicle equipment failure (e.g., brakes), the enabling event could be a fuel leak that is ignited and starts a fire.

Frequency estimates for mitigated accident scenarios take into account controls that lower the frequency of occurrence of both the initiating event and enabling events. For the example scenario, inspection and maintenance programs can reduce the relative frequency of the postulated brake failure. The same program can also lower the frequency estimate for the enabling event, thus minimizing the overall scenario frequency.

Mitigated frequencies, along with the consequence, are used for selecting safety related (safetyclass or safety-significant) and defense-in-depth controls. It is important to realize that the frequencies of occurrence used in the Process Hazard Analysis are not implied to be absolute numbers, but rather to express an expected frequency range of the postulated scenario. 


\section{Consequence Category Estimates}

Qualitative consequence severity categories are assigned to each of the postulated accident scenarios. For radiological materials, the categories consider inventory, material form, and energy of release. For toxic materials the categories consider toxicity, inventory, and volatility. Table 3-2 identifies the consequence severity levels, criteria used to establish them, and their impact. Public refers to the maximally exposed offsite individual (MOI) for releases of TRU waste that bounds releases of LLW. The nearest site boundary is located on Greenville Road, approximately 90 meters from the nearest storage area and $130 \mathrm{~m}$ from the nearest building in DWTF, and approximately $225 \mathrm{~m}$ from the nearest A625 boundary. The co-located worker is located not less than 100 meters from the point of release or the facility boundary, whichever is closer, or the point of highest dose is used for elevated releases or those involving plume lofting.

Table 3-2. Severity Levels and Criteria

\begin{tabular}{|c|c|c|c|c|}
\hline & & \multicolumn{3}{|c|}{ Receptors } \\
\hline & & Offsite Public & Worker & Site Facility Worker \\
\hline \multirow{3}{*}{ 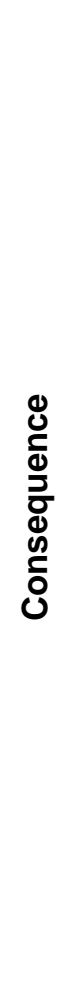 } & High & $\begin{array}{l}\text { Considerable off-site } \\
\text { impacts on people or the } \\
\text { environs. } \\
\text { >25 rem }{ }^{1} \text { TEDE or } \\
>\text { ERPG-2/TEEL-2 }\end{array}$ & $\begin{array}{l}\text { Considerable on-site } \\
\text { impacts on people or the } \\
\text { environs. } \\
\text { >100 rem TEDE or } \\
>\text { ERPG-3/TEEL-3 }\end{array}$ & $\begin{array}{l}{ }^{2} \text { Facility worker hazards are } \\
\text { typically protected with Safety } \\
\text { Management Programs. For } \\
\text { Safety Significant designation, } \\
\text { consequence levels such as } \\
\text { prompt death, serious injury, } \\
\text { or significant radiological and } \\
\text { chemical exposure, should be } \\
\text { considered. }\end{array}$ \\
\hline & Moderate & $\begin{array}{l}\text { Only minor off-site } \\
\text { impact on people or the } \\
\text { environs. } \\
\geq 1 \text { rem TEDE or >ERPG- } \\
1 / \text { TEEL- } 1\end{array}$ & $\begin{array}{l}\text { Considerable on-site } \\
\text { impact on people or the } \\
\text { environs. } \\
\geq 25 \text { rem TEDE or } \\
>\text { ERPG-2/TEEL-2 }\end{array}$ & \\
\hline & Low & $\begin{array}{l}\text { Negligible off-site impact } \\
\text { on people or the } \\
\text { environs. } \\
\\
<1 \text { rem or } \\
<\text { ERPG-1/TEEL-1 }\end{array}$ & $\begin{array}{l}\text { Minor on-site impact on } \\
\text { people or the environs. } \\
<25 \text { rem or } \\
<\text { ERPG-2/TEEL-2 }\end{array}$ & \\
\hline
\end{tabular}

\section{Notes:}

1 Offsite consequences $>25$ rem from operational accidents must be protected with Safety Class SSCs independent of frequency. Follow DOE-STD-3009 for manmade external and natural phenomenon events.

2 Occupational Radiation Protection; incidental exposures during normal operations are governed by 10 CFR 835 . 
The site facility worker refers to the worker involved within the facility boundary, for whom safety programs, including training, typically provide assurances for operational safety. Unmitigated potential site facility worker consequences are qualitatively developed based on estimated colocated worker consequences using engineering judgment. The resulting site facility worker qualitative consequences are compared to the site facility worker criteria and interpretations to determine the severity level. The greater of the co-located worker or site facility worker consequence severity level results are presented in Appendix A.

For the site facility worker, high consequence is interpreted as prompt worker fatality or an acute injury that is immediately life threatening or permanently disabling, or significant radiological or chemical exposures to workers. This would typically result from a radiological exposure to a large prompt dose (e.g., criticality level) or from a chemical exposure to sustained Immediately Dangerous to Life or Health (IDLH) levels (i.e., life-threatening or permanently disabling, as opposed to a brief peak exposure over ERPG-3 for a few minutes), where permanent effects may occur.

For the site facility worker, moderate consequence is interpreted as serious injury with hospitalization required, but no immediate loss of life and no permanent disabilities. This would typically result from a radiological exposure to a very energetic release to an occupied area (for alpha emitters); essentially a major accident destroying barriers as opposed to a confinement leak. A chemical exposure with moderate consequence would result in the worker being hospitalized with evident distress; with lingering physical effects in the hospital, though none permanent.

For the site facility worker, low consequence is interpreted as minor injuries, no loss of consciousness, with no hospitalization, to negligible impacts. This would generally result from a radiological exposure to a glovebox leak or small-scale confinement failure; and reflects the typical DOE complex occupational worker contamination or uptake. A chemical exposure with low consequence would result in short-term effects that dissipate quickly upon egress (e.g., eyes watering, cough) or no effects beyond irritation.

Unmitigated and mitigated public and worker consequences are estimated for each scenario in a semi-quantitative manner based on the material at risk, material form, and energy available. Mitigated consequences qualitatively estimate how effective the controls are in reducing the consequences from a release. The analysis identifies effective controls as candidates for consideration as Technical Safety Requirements (TSRs).

\section{Risk Rankings}

The frequency and consequence estimates, and the risk-ranking matrix in Table 3-3, are used to assign a risk rank to each accident scenario for workers and the public. Where the risk ranking is defined as: I - High, II - Moderate, III - Low, IV - Negligible. 
Table 3-3. Risk Group Ranking

\begin{tabular}{|c|c|c|c|c|c|}
\hline & \multicolumn{4}{|c|}{ Frequency } \\
\hline & & $\begin{array}{c}\text { Beyond Extremely } \\
\text { Unlikely } \\
\text { Below } 10^{-6} / y r\end{array}$ & $\begin{array}{l}\text { Extremely Unlikely } \\
10^{-4} \text { to } 10^{-6} / \mathrm{yr}\end{array}$ & $\begin{array}{c}\text { Unlikely } \\
10^{-2} \text { to } 10^{-4} / y r\end{array}$ & $\begin{array}{l}\text { Anticipated } \\
10^{-1} \text { to } 10^{-2} / \mathrm{yr}\end{array}$ \\
\hline \multirow{3}{*}{ 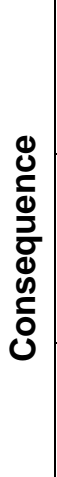 } & High & III & II & I & I \\
\hline & Moderate & IV & III & II & I \\
\hline & Low & IV & IV & III & III \\
\hline
\end{tabular}

Risk ranking I events must be protected with safety structures, systems, and components (SSC) and Technical Safety Requirements (TSR). For offsite public protection, Safety Class SSCs and TSRs are required for radiological events $>25$ rem TEDE in accordance with Appendix A of DOE-STD-3009. Events which challenge but do not exceed 25 rem TEDE should be considered in selection of Safety SSCs and/or TSRs. Operational events resulting in high offsite radiological consequences must be moved forward into accident analysis for determination of safety classification, without consideration of frequency.

Risk ranking II events must be considered for protection with TSRs and safety SSCs. The consideration of control(s) shall be based on the effectiveness and feasibility of the considered controls along with the identified features and layers of defense in depth (DID). Operational events resulting in high offsite radiological consequences must be moved forward into accident analysis for determination of safety classification, without consideration of frequency.

Risk ranking III events are generally protected by the safety management programs (SMPs). These events may be considered for defense in depth SSCs in unique cases.

Risk ranking IV events do not require additional measures. 


\section{Scenario Development}

The PrHAs focused on key scenarios for each operation that denote the unique and representative potential accidents. This approach only addressed the highest unmitigated worker consequences and the highest unmitigated public consequences. The intent is to ensure that an adequate review of controls can be developed for mitigated risks. A graded approach for this Category 2 nuclear facility adequately evaluates risk commensurate with the segment's category and complexity without superfluous information in the PrHA.

\section{Control Description}

Preventive and mitigative controls that apply to the subject scenario are listed in the PrHA in Appendix A. The process involved identifying existing controls for the Waste Storage Facilities activities and proposing new controls as necessary. The total list of controls for a scenario gives an indication of the defense-in-depth that is provided. In the PrHA, controls that are initial conditions, and controls credited for reducing risk, are identified with single asterisks and bold font, respectively.

Once the PrHA tables were completed, the results were evaluated to determine if the controls identified were adequate.

\subsubsection{HAZARD ANALYSIS RESULTS}

This section presents the results of the hazard identification, classification, and evaluation for the Waste Storage Facilities. Significant aspects of defense-in-depth and identification of any safety SSCs and other items potentially requiring TSR coverage are summarized.

\subsubsection{Hazard Identification}

This subsection presents the results of the hazard-identification activity. Attributes of the hazards identified here are the basis for subsequent hazard evaluation. The principal hazards in the Waste Storage Facilities are in the form of radioactive material.

\subsection{Identification of Hazards}

The hazards associated with the Waste Storage Facilities were identified through the use of a checklist and discussions with program personnel. Such hazards do not necessarily have a quantity or type associated with them, and they can exist in all locations throughout the segment. The hazards identified in Table 3-4 were considered while developing the PrHA. 
Table 3-4. Waste Storage Facilities Hazard Source List

\begin{tabular}{|c|c|}
\hline Source Category & Hazards List \\
\hline $\begin{array}{l}\text { Motion/ } \\
\text { Mechanical }\end{array}$ & $\begin{array}{l}\text { Vehicles, mass in motion, belts, gears, chains, sharp edges, pinch points, } \\
\text { push carts, forklifts }\end{array}$ \\
\hline Gravity-mass & $\begin{array}{l}\text { Falling, falling objects, roll-up doors, lifting, hoists, tripping, slipping, } \\
\text { earthquakes }\end{array}$ \\
\hline Static & Container rupture, overpressurization, negative pressure effects \\
\hline Natural Phenomena & Earthquake, wind, flood, lightning \\
\hline Cold & Ice, snow, wind, rain, cold surfaces, compressed gases, freezer \\
\hline Heat & Electrical equipment, hot surfaces, electricity, friction, solar, fire \\
\hline $\begin{array}{l}\text { Flammable materials and } \\
\text { fires }\end{array}$ & $\begin{array}{l}\text { Presence of flammable/combustible material—solid, liquid, gas } \\
\text { Presence of ignition source—engines, sparks }\end{array}$ \\
\hline Pressure & $\begin{array}{l}\text { Confined/compressed gases, pressurized liquids, objects propelled by } \\
\text { pressure, noise }\end{array}$ \\
\hline Electrical & $\begin{array}{l}\text { Static electricity, power supplies, power cables, transformers, wiring, } \\
\text { batteries, exposed conductors, other high-voltage sources, lightning }\end{array}$ \\
\hline Radiant & $\begin{array}{l}\text { Intense light (electric arc welding), RF fields, infrared radiation (welding), } \\
\text { solar, ionizing radiation, electromagnetic radiation, neutrons }\end{array}$ \\
\hline $\begin{array}{l}\text { Chemical (present, } \\
\text { combustion product, or } \\
\text { reaction product) }\end{array}$ & $\begin{array}{l}\text { Flammable/combustible materials (e.g., hydrogen from radiolytic } \\
\text { decomposition of materials), asphyxiants, carcinogenic materials, toxic } \\
\text { materials, reproductive hazards }\end{array}$ \\
\hline $\begin{array}{l}\text { Chemical reaction (non- } \\
\text { fire) }\end{array}$ & Corrosion, rust, and related hazards (e.g., heat and pressure) \\
\hline Criticality & $\begin{array}{l}\text { Although the average loading of fissionable materials in individual } \\
\text { containers is below levels that would cause any criticality concern, the total } \\
\text { fissionable material inventory in this facility exceeds the minimum critical } \\
\text { mass }\end{array}$ \\
\hline Biological & Non-infectious, non-hazardous biological material (animal cadavers) \\
\hline
\end{tabular}

\subsection{Identification of Radionuclide Inventories}

Waste Storage Facilities will serve as a storage repository for a variety of radioactive waste such as liquid and solid TRU waste, LLW, mixed waste, and combined waste. Waste generators are responsible for collecting, packaging, identifying, and labeling the wastes prior to transfer to the Waste Storage Facilities.

Typical TRU waste consists of contaminated wiping tissues, paper, plastic, chemistry glassware, ceramics, and metal. The storage of TRU with water-reactive materials, pyrophorics, and other reactives is not authorized. All TRU waste is packaged in approved TRU waste containers as described in Section 4.4.1.3. 
Table 3-5 summarizes the principal radionuclides and provides a historic quantity for each radionuclide for a typical waste storage facility that represents the facility containing the greatest quantity of TRU waste. This information is not a limit or a restriction on radionuclides, but is representative historical data provided only for information purposes. The inventory of radionuclides is entered into a database management system that is maintained by RHWM for recordkeeping and retrieval for each facility.

Table 3-5. Representative Radionuclides for a Typical Waste Storage Facility

\begin{tabular}{|l|c|}
\hline \multicolumn{1}{|c|}{ Radionuclide } & Historic Quantity (g) \\
\hline \hline Am-241 & 0.030 \\
\hline Am-243 & $1.6 \times 10^{-4}$ \\
\hline Cf-249 & $6.9 \times 10^{-9}$ \\
\hline Cm-243 & 0.010 \\
\hline Cm-244 & $4.9 \times 10^{-10}$ \\
\hline Co-60 & $7.0 \times 10^{-9}$ \\
\hline Cs-137 & $5.4 \times 10^{-6}$ \\
\hline Eu-154 & 0.16 \\
\hline H-3 & 2.3 \\
\hline Np-237 & 3.9 \\
\hline Pu-238 & 3,200 \\
\hline Pu-239 & 260 \\
\hline Pu-240 & 9.3 \\
\hline Pu-241 & 3.1 \\
\hline Pu-242 & 0.36 \\
\hline U-233 & $4.6 \times 10^{-4}$ \\
\hline U-234 & 220 \\
\hline U-235 & \\
\hline
\end{tabular}




\section{Documented Safety Analysis for the Waste Storage Facilities}

TRU waste is defined as waste contaminated with alpha-emitting transuranic radionuclides (with half-lives greater than 20 years) in excess of $100 \times 10^{-9} \mathrm{Ci} / \mathrm{g}$ or $100 \mathrm{nCi} / \mathrm{g}$. Therefore, LLW contains a maximum of $100 \mathrm{nCi} / \mathrm{g}$ of TRU isotopes, for radionuclides with half-lives greater than 20 years. Because of the allowable concentrations, the maximum radioactive inventory for these isotopes in a drum containing LLW is very small, as calculated below:

$$
M A R=100 \times 10^{-9} \mathrm{Ci} / \mathrm{g} \times 4.54 \times 10^{2} \mathrm{~g} / \mathrm{lb}=4.5 \times 10^{-5} \mathrm{Ci} \text { per } 1 \mathrm{lb} \text { of } \mathrm{LLW}
$$

A review of LLNL approved TRU waste drums identified that they contain a net mass of less than 1,000 pounds. This results in $0.05 \mathrm{Ci}$ per container of TRU isotopes, for radionuclides with half-lives greater than 20 years, when loaded to 1,000 pounds. The PE-Ci is calculated using Dose Conversion Factors (DCFs) that account for all radiation, not just alpha particles. Although there are a number of transuranic isotopes with half-lives less than 20 years, such as $\mathrm{Cm}-244$, these isotopes typically do not contribute significantly to the PE-Ci for LLW in the Waste Storage Facilities. All radioactive waste accepted by RHWM must be contact-handled waste so that the surface dose rate of a radioactive waste container may not exceed $200 \mathrm{mrem} / \mathrm{hr}$. Based on the LLW inventory in May 2004, the total combined PE-Ci for the over 3200 LLW containers in the Waste Storage Facilities was just over $1 \mathrm{PE}-\mathrm{Ci}$. The maximum PE-Ci in any single LLW container was $0.20 \mathrm{PE}-\mathrm{Ci}$, and only 15 of the over 3200 containers had greater than $0.01 \mathrm{PE}-\mathrm{Ci}$. Hence, a postulated accident involving drums containing LLW is bounded by that involving approved TRU waste containers. Consistent with the graded approach, a potential accident involving LLW other than tritium is not evaluated in Section 3.4.2.

\subsection{Identification of Chemical Inventories}

Although RHWM handles a large quantity of hazardous waste, the primary waste streams would be described as industrial hazardous waste such as dilute aqueous solutions, paint, oil, solvents, dilute corrosives, and fluorescent tubes. Before waste can be accepted, it goes through a series of reviews. One of these reviews is to verify if the waste meets the requirements of the Hazardous Materials Protection Program.

\subsubsection{Hazard Categorization}

This subsection presents the segmentation and classification of the Waste Storage Facilities from the remainder of the DWTF facilities, and the results of the Waste Storage Facilities final hazard classification activity outlined in DOE-STD-1027-92, Change Notice 1.

\subsection{Segmentation}

The DWTF Complex, shown in Figure 2-2, contains two nuclear facilities: the DWTF Storage Area and the B695 Segment of DWTF. The DWTF Storage Area is addressed in this DSA; the B695 Segment is addressed in a separate DSA (LLNL 2009b). Segmentation of the DWTF Storage Area from the B695 Segment was performed by considering future operations in the DWTF as well as existing operating facilities. The B695 Segment consists of B695, B696S, and the adjacent yard area, and is used primarily for waste treatment. 
Fire, earthquake, and aircraft crash are potentially the worst common-cause events identified in this DSA that could lead to uncontrolled radioactive release from several contiguous nuclear facilities. All buildings in the DWTF Complex are at least $48 \mathrm{ft}$ apart (B695 and B696 have a truck bay between them), and the area between them is covered with asphalt. This separation, in conjunction with each building's non-combustible, PC-2 construction, amply serves as a passive barrier in the form of a firebreak. In addition, RHWM will maintain a 20 -ft firebreak marked appropriately between the DWTF Storage Area and the B695 Segment of DWTF as part of the fire protection program.

It is shown in the segmentation justification provided in Appendix C that the B695 Segment of DWTF is sufficiently separated physically from the DWTF Storage Area and that passive barriers exist if the separation distance is not adequate as in the case of the partition separating B696R and B696S. As discussed in Appendix C, the combination of the B696S/B696R partition and the TSR combustible loading limits precludes a fire from propagating from one side of the partition to the other. In addition, independence of pertinent systems precludes the potential for concurrent release of materials from common cause or common mode failure in the DWTF Storage Area and the B695 Segment of DWTF from postulated aircraft crash, fire or earthquake. Therefore, segmentation of the DWTF Storage Area from the remainder of the DWTF complex is in accordance with the requirements of DOE-STD-1027-92, Change Notice 1 (DOE 1997).

\subsection{Radiological Hazard Categorization}

The Waste Storage Facilities contain TRU waste in excess of $56 \mathrm{PE}-\mathrm{Ci}$, the threshold quantity for HC-2 nuclear facilities in Table A-1 of DOE-STD-1027-92, Change Notice 1. Therefore, the Waste Storage Facilities are categorized as Hazard Category 2 nuclear facilities.

\subsection{Chemical Hazard Classification}

The Waste Storage Facilities are used to handle and store hazardous waste, TRU waste, LLW, mixed waste, combined waste, nonhazardous industrial waste, and conditionally accepted waste generated at LLNL. Although RHWM handles a large quantity of hazardous waste, the primary waste streams would be described as industrial hazardous waste such as dilute aqueous solutions, paint, oil, solvents, dilute corrosives, and fluorescent tubes.

Although nuclear facilities are not applicable to ES\&H Manual Document 3.1, "Nonnuclear Safety Basis Program," September 9, 2009 (LLNL 2009a), the discussion in Appendix K of Document 3.1 supports a Low chemical hazard classification for the Waste Storage Facilities.

\subsubsection{Hazard Evaluation}

This section provides the analysis of the Waste Storage Facilities operations. The analysis uses the graded-approach, which prescribes that an analysis technique be no more sophisticated or detailed than necessary to present a comprehensive examination of the hazards associated with a facility (DOE 2006). 
The generic hazards from energy sources, materials, and natural phenomena associated with the Waste Storage Facilities were identified in Table 3-4. These generic hazards were developed into hazard scenarios as documented in the PrHA in Appendix A using the methodology in Section 3.3.1.2.

The focus of the hazard analysis is on potential accident conditions involving the generic hazards associated with the Waste Storage Facilities. Normal and abnormal conditions can also present hazards to a worker. However, such hazards are likely to involve minor exposures and other occupational injuries. For the site facility worker, such hazards are typically addressed by the safety management programs (e.g., Radiation Protection Program) in Chapters 7 through 17 of this DSA. Initiating events involving the hazards discussed above are presented in the following sections.

\section{Waste-Storage/Staging/Handling Operations Evaluation}

Scenarios involving waste storage, staging, handling, or operations were identified and evaluated in the PrHA in this DSA for the DWTF and A625 Waste Storage Facilities. These include:

1. Scenarios involving forklifts or vehicles (e.g., trucks) that impact drums resulting in either a spill or fire,

2. Loading or unloading scenarios resulting in a spill,

3. Cylinder failure scenarios resulting in a spill,

4. Crane operations scenarios resulting in a spill,

5. Electrical failure or welding accident scenarios leading to a fire,

6. Container deflagration scenarios,

7. Criticality scenarios,

8. Tritium scenarios resulting in either a spill or fire,

9. Chemical release scenarios resulting in either a spill or fire that does not have a potential to release radioactive material

10. Container handling, maintenance, filter replacement, sampling, analysis, and radiography scenarios, and

11. TRUPACT-II loading/unloading accidents. 


\section{Forklift/Vehicle Scenarios Impacting TRU Waste (WH-1, WH-2, WH-8, WH-8A, WH-9)}

Scenarios involving forklift or vehicle accidents could result in the release of radioactive material due to a spill and/or fire. Credible initiators for such scenarios include personnel error in misjudging speed, container mishandling, and vehicle fires near stored containers. Although misjudging speed is considered to be an initiator for the accident scenarios, the hazard analysis assumes that speed is not a factor with respect to the consequences of the accident. For conservatism, the analysis assumes that the vehicle collides with staged containers resulting in a complete loss of waste to the facility floor or yard area. Physical layout of facilities prevents a vehicle from attaining speeds that can cause a high energy impact.

The unmitigated frequency of a spill following a forklift/vehicle accident is estimated in accordance with the general guidelines described in Section 3.3.1.2. Container spills caused by vehicle accidents are estimated to be "anticipated" for a minor spill (WH-1) and "unlikely" for a significant spill (WH-2).

For scenarios involving spill and fire following a forklift/vehicle accident $(\mathrm{WH}-8, \mathrm{WH}-8 \mathrm{a}$, and $\mathrm{WH}-$ 9) the unmitigated frequencies are lowered one bin (e.g., "unlikely" to "extremely unlikely") to account for the conditional probability of a fuel spill and ignition in a vehicle accident.

Site facility worker consequences are consistent with the co-located worker consequences. Workers closer to the point of release could receive higher exposure as compared to the exposures evaluated at the onsite receptor location (e.g., co-located worker). The estimation of consequence to the worker has a high degree of uncertainly due to the complexity of parameters involved with a worker close to the point of release. Worker consequences are qualitatively judged to have similar consequences as the co-located worker. It is reasonable to assume that the workers will observe the accident and leave the scene in a timely manner. Movement of TRU waste requires a minimum of two personnel, which further supports a reasonable detection and emergency response to any event.

The potential unmitigated consequences are estimated as "low" for the worker and the public for spills within A625 and for spills within the DWTF storage facilities involving both one drum and for significant spills involving pallets of drums.

The potential unmitigated consequences are estimated as "low" for the worker and the public for fires within A625 and DWTF storage facilities involving one drum, and are estimated as "low" for the worker and "moderate" for the public for fires within A625 and the DWTF storage facilities involving pallets of drums.

All scenarios involving forklift/vehicle accidents represent a "low" or "negligible" risk to the public and worker. 


\section{Documented Safety Analysis for the Waste Storage Facilities}

Forklifts and trucks powered by hydrocarbon fuels are potential sources of flammable materials. Generally, diesel and gasoline fuel tanks on forklifts are located on the side and are shielded with a 1/4-inch steel plate. Propane tanks are typically mounted at the rear at the elevated position of the operators. Due to these types of fuel tank configurations, the fuel tanks are not easily accessible to result in a breach of their integrity in a collision with other vehicles or internal building components or systems. Furthermore, the maximum speed attainable by a forklift is such that an impact is not anticipated to lead to a catastrophic fuel tank failure.

Trucks used by RHWM to transport waste are designed in accordance to national standards. For light trucks, the gross weight of which is less than $10,000 \mathrm{lb}$, Federal Motor Vehicle Safety Standards and Regulations (FMVSS) 301 issued by the National Highway Traffic Safety Administration (NHTSA) has criteria for allowable fuel spillage in the event of a 30-mph front end impact onto a fixed barrier. A front-end impact is considered the primary hazard of concern for trucks impacting staged waste. The amount spilled is based on the duration of time after impact but the criterion is in the range of just a few ounces of fuel spilled. Additionally, fixed barriers would cause the force of the impact to be absorbed mostly by the vehicle causing more damage, whereas a pallet of drums would be toppled or would move and little impact force would be transferred to the vehicle.

For heavy trucks, which exceed $10,000 \mathrm{lb}$ gross weight, the governing Department of Transportation (DOT) regulation is 49 CFR 393.67, Liquid Fuel Tanks. Section (e)(1) in 49 CFR 393.67 specifies that the acceptable leakage is no more than one ounce of water per minute for a 30-foot drop test involving a fuel tank filled with water dropped on one corner.

The consumption rate to sustain a large gasoline pool fire is $0.5 \mathrm{gpm}$ (64 ounces per minute) per $1 \mathrm{MW}$ (WM/FS-WSF-0404). The postulated 9-MW fire requires approximately $4.5 \mathrm{gpm}$ (576 ounces per minute) to sustain the fire. This is far in excess of ounces of fuel leakage allowed from a 30-mph impact.

\section{Loading or Unloading Scenarios (WH-3, WH-4)}

Scenarios during radioactive material container loading or unloading operations could result in the release of radioactive material due to a container breach and subsequent spill. Credible initiators for such scenarios include personnel error in positioning, container mishandling, or mechanical problems with loading equipment.

The unmitigated frequency of a spill due to a loading or unloading accident is estimated as "anticipated" for minor and one drum spills, and "unlikely" for significant spills.

Co-located worker consequences were estimated as "low" for these scenarios. Site facility worker consequences are consistent with the co-located worker consequences. Workers closer to the point of release could receive higher exposure as compared to the exposures evaluated at the onsite receptor location (e.g., co-located worker). The estimation of consequence to the worker has a high degree of uncertainly due to the complexity of parameters involved with a worker close to the point of release. Worker consequences are qualitatively judged to have similar consequences as the co-located worker. It is reasonable to assume that the workers will 


\section{Documented Safety Analysis for the Waste Storage Facilities}

observe the accident and leave the scene in a timely manner. Loading or unloading of TRU waste requires a minimum of two personnel, which further supports a reasonable detection and emergency response to any event. The public consequences were estimated as "low."

All scenarios involving loading or unloading accidents represent a "low" risk to the public and worker.

\section{Cylinder Failure Scenarios ( WH-5)}

Scenarios involving pressurized gas cylinder failure could result in the release of hazardous material or generate a projectile that could impact and breach an approved TRU waste container resulting in a radioactive material spill. Credible initiators for such scenarios include a structural failure of the cylinder or container mishandling that could result in cylinder failure.

The unmitigated frequency for a structural failure of the cylinder or a container mishandling event resulting in cylinder failure that could generate a projectile that could impact and breach an approved TRU waste container releasing radioactive material is estimated as "extremely unlikely." This frequency is based on both the estimated infrequency of activities that could cause the cylinder valve to shear off as well as the probability that such a projectile would impact TRU waste containers.

Co-located worker consequences were estimated as "low" for these scenarios. Site facility worker consequences are consistent with the co-located worker. Workers closer to the point of release could receive higher exposure as compared to the exposures evaluated at the onsite receptor location (e.g., co-located worker). The estimation of consequence to the worker has a high degree of uncertainly due to the complexity of parameters involved with a worker close to the point of release. Worker consequences are qualitatively judged to have similar consequences as the co-located worker. It is reasonable to assume that the projectile would not incapacitate a worker by direct impact within the normally unoccupied area and the workers will observe the accident and leave the scene in a timely manner.

The potential unmitigated consequences are estimated as "low" for the worker and the public for all cylinder failure scenarios.

The scenarios involving pressurized gas cylinder failure accidents represent a "negligible" risk to the public and worker.

\section{Crane Operation Scenarios (WH-17, WH-18)}

Scenarios involving crane operations could result in the release of radioactive material from impacting and breaching an approved TRU waste container with the load, impacting and breaching approved TRU waste containers with the crane boom, or dropping approved TRU waste containers during lifting. B625 has a 3-ton overhead bridge crane. Mobile cranes can be brought into DWTF or A625 to perform activities, such as maintenance or movement of transportainers. Credible initiators for such scenarios include operator error or failure of the hoisting and rigging. 


\section{Documented Safety Analysis for the Waste Storage Facilities}

The unmitigated frequency for a crane operation accident releasing radioactive material from a single approved TRU waste container load is estimated as "anticipated." The unmitigated frequency for a crane operation accident releasing radioactive material from multiple approved TRU waste containers is estimated as "unlikely." Crediting the use of certified crane operators (licensed and qualified per LLNL requirements) lowers the mitigated frequency by one frequency bin to "extremely unlikely."

Co-located worker consequences were estimated as "low" for these scenarios. Site facility worker consequences are consistent with the co-located worker consequences. Workers closer to the point of release could receive higher exposure as compared to the exposures evaluated at the onsite receptor location (e.g., co-located worker). The estimation of consequence to the worker has a high degree of uncertainly due to the complexity of parameters involved with a worker close to the point of release. Worker consequences are qualitatively judged to have similar consequences as the co-located worker. It is reasonable to assume that the workers will observe the accident and leave the scene in a timely manner. Crane operations require multiple personnel, which further supports a reasonable detection and emergency response to any event.

The potential unmitigated consequences from a crane operation accident are estimated as "low" for the worker and the public for all crane operation accident scenarios involving single approved TRU waste containers for the Waste Storage Facilities. The potential unmitigated consequences from a crane operation accident are estimated as "low" for the worker and "moderate" for the public for crane operation accident scenarios involving multiple approved TRU waste containers for the Waste Storage Facilities.

Scenarios involving crane operation accidents represent a "low" mitigated risk to the public and a "negligible" mitigated risk to the worker.

\section{Electrical Failure or Welding Accident Fire Scenarios (WH-10, WH-11)}

Initiation of a fire involving plastic pallets used for non-TRU waste storage, electrical cables, or equipment can potentially occur only from an electrical short or exposure fire and combustion of damaged or worn insulation. A fire will be sustained only if a significant decomposition of insulating materials has occurred, i.e., the $1 \%$ thermal decomposition is not sufficient for a large fire. The $1 \%$ thermal decomposition temperature of polyvinyl chloride, a typical insulation material, is $457^{\circ} \mathrm{K}\left(363^{\circ} \mathrm{F}\right.$ ) (SFPE 1995). Other energy sources in the vicinity of the electrical cables and equipment necessary to maintain high temperatures and cause significant thermal degradation are limited in the Waste Storage Facilities. 


\section{Documented Safety Analysis for the Waste Storage Facilities}

In addition, the limiting oxygen index (LOI) - a measure of the tendency for a material, once ignited, to continue burning after the ignition source is removed-is typically very high for the insulating materials. For polyvinyl chloride, the LOI is 47 compared to 20 for cotton (SFPE 1995). A high LOI indicates that wire insulation requires a relatively large exposure fire to become self-propagating; rather, it will stop burning once the ignition source is removed. Quantities of combustibles in proximity to the electrical cables and equipment are not sufficient for a large exposure fire in non-flammable storage areas. Hence, initiation and propagation of an electrical fire is not likely in the Waste Storage Facilities.

These scenarios require significant combustible material. Combustible loading in the Waste Storage Facilities TRU waste storage areas is consistent with the fire-resistive rating of partitions of Waste Storage Facilities buildings. The combustible loading limit is established to preclude the potential for fire propagation. The combustible loading per each half-hour fire-resistive rating is 5 psf. For example a one-hour fire rated partition, would be expected to resist a fire resulting from a combustible loading of 10 psf (Table 7-5A in Fire Protection Handbook, 18th edition). One hour is the minimum resistivity of rated walls in TRU storage areas. For conservatism in B696R and B625, a lower combustible loading limit of 7 psf is conservatively established, which is consistent with the definition of light fire loading discussed in NPFA 80A.

Occasional welding, using either electrical arc or hot flame (oxyacetylene or MAAP gas), may be required to maintain important building systems. In addition, equipment such as gas torches and plasma cutters may be used for activities such as size reduction. Before hot work could be performed, a Hot Work Permit must be issued by Emergency Management to ensure personnel who perform welding, soldering, and other hot-work operations with a high fire potential are aware of and protected from hazards.

Co-located worker consequences were estimated as "low" for these scenarios. Site facility worker consequences are consistent with the co-located worker consequences. Worker injuries would primarily be related to elevated temperature and smoke rather than the result of radioactive uptake. Workers closer to the point of release could receive higher exposure as compared to the exposures evaluated at the onsite receptor location (e.g., co-located worker). The estimation of consequence to the worker has a high degree of uncertainly due to the complexity of parameters involved with a worker close to the point of release. Worker consequences are qualitatively judged to have similar consequences as the co-located worker. It is reasonable to assume that the workers will observe the accident and leave the scene in a timely manner. An observer is required during operations involving hot work, which further supports a reasonable detection and emergency response to any event. In some scenarios, the public consequences were estimated as "moderate," while worker consequences were "low." This estimation follows from the relatively more conservative consequence severity levels for the public as identified in Table 3-2. In addition, the public would not be aware of the accident and could unknowingly remain in the vicinity.

A fire initiated by an electrical failure or other ignition source in conjunction with a flammable liquid spill is considered an "extremely unlikely" event and a welding accident (including flammable gases) is considered an "unlikely" event. For these scenarios, the unmitigated 


\section{Documented Safety Analysis for the Waste Storage Facilities}

consequence to the public is considered "moderate" and the unmitigated consequence to the worker is considered "low." An element of the combustible control program that requires all waste in TRU waste storage areas to be in metal containers and on metal pallets is credited for $\mathrm{WH}-11$ to reduce the frequency of such events. Combustible loading is identified as an initial condition for both events. These controls minimize available combustibles in the room, thereby reducing the likelihood of an ignition source finding combustibles to ignite resulting in a release of material. After controls are credited, the electrical failure/welding accident fires are a "low" mitigated risk to the public and "negligible" mitigated risk to the worker.

\section{Container Deflagration Scenarios (WH-14, WH-15)}

Two types of container deflagration scenarios are evaluated, vented and unvented. For unvented containers, the unmitigated frequency for a deflagration scenario is considered "unlikely."

Container bulging is a sign that pressure buildup is occurring. A periodic inspection of containers to detect bulging and to verify the container integrity would lower the mitigated frequency by one frequency bin. Crediting the container maintenance program (a portion of the In-service Inspection \& Test Program), a mitigated deflagration in an unvented container is considered "extremely unlikely." For vented containers, the unmitigated frequency is considered "extremely unlikely" and does not require a credited control. Incorporating the container maintenance program, the mitigated frequency would be considered "beyond extremely unlikely."

Co-located worker consequences were estimated as "low" for these scenarios. Site facility worker consequences are not consistent with the co-located worker consequences. Workers closer to the point of release could receive a higher dose as compared to the doses evaluated at the onsite receptor location; they are qualitatively judged to have the potential for higher consequences. The resulting radioactive uptake may result in serious injury, but it is not expected to be life threatening or permanently disabling. The primary concern for worker injuries would be physical trauma due to the pressurized release of the lid impacting the worker, which represents a standard industrial hazard. Thus, the site facility worker consequences were estimated as "moderate." For protection for the worker in the event of drum lid loss resulting from a deflagration, an additional control is included requiring use of drum lid restraining devices during transport of pressurized unvented TRU waste drums unless the drums are overpacked.

For the unmitigated case, the consequences to the worker and the public are considered "moderate" and "low," respectively, for A625 and the DWTF storage facilities.

After controls are credited, the mitigated container deflagration accidents are considered a "negligible" risk to the public and a "low" risk to the worker for A625 and the DWTF storage facilities.

Additionally, a fire following a hydrogen deflagration is not postulated due to thermal limitations. Based on HC/AB-B696-0202 and SFPE (1995), the temperature increase from a deflagration is not sufficient to reach the exothermic pyrolytic decomposition temperature of $280^{\circ} \mathrm{C}$. 


\section{Documented Safety Analysis for the Waste Storage Facilities}

\section{Criticality Scenarios (WH-16)}

Unmitigated criticality events are considered to be "extremely unlikely." With the criticality safety program in place, which limits the quantity of fissile materials, moderators, and reflectors, criticality events are considered "beyond extremely unlikely." The criticality safety program is discussed in Chapter 6, and includes a fissile material inventory limit per container of 200 Pu-239 fissile gram equivalents (FGE).

Co-located worker consequences were estimated as "low" for these scenarios. Site facility worker consequences are not consistent with the co-located worker consequences. Workers closer to the point of release could receive a prompt radiation dose that would have significantly higher consequences than exposure to the fission products generated. This could result in consequences that are life threatening or result in permanently disabling injuries for the site facility worker. Thus, the site facility worker has the potential for "high" consequences due to a criticality event.

Potential mitigated consequences to the worker are considered "high" and the mitigated consequences to the public are considered "low" for DWTF storage facilities and "low" for A625 storage facilities. The resulting risk to the public is considered "negligible" and the worker is considered "low" for the mitigated case.

\section{Tritium Release Scenarios ( WH-6, WH-12, WH-12A)}

Scenarios involving the release of tritium (either tritium waste or tritium items) are evaluated for a spill and for a fire. Tritium is released as either molecular tritium (HT or TT) or as tritiated water (HTO or T2O). Credible initiators for such scenarios include operator errors.

Co-located worker consequences were estimated as "low" for these scenarios. Site facility worker consequences are consistent with the co-located worker consequences. Workers closer to the point of release could receive higher exposure as compared to the exposures evaluated at the onsite receptor location (e.g., co-located worker). The estimation of consequence to the worker has a high degree of uncertainly due to the complexity of parameters involved with a worker close to the point of release. Worker consequences are qualitatively judged to have similar consequences as the co-located worker. The form of the tritium and nature of tritium does not readily support a locally sustained release.

The unmitigated frequency for a tritium accident releasing significant amounts of molecular or oxidized tritium is estimated as "unlikely" for a spill or a fire.

The potential unmitigated consequences from a tritium accident are estimated as "low" for the public and "low" for the worker for tritium accident scenarios.

Scenarios involving tritium accidents represent a "low" risk to the public and a "low" risk for the worker. 


\section{Documented Safety Analysis for the Waste Storage Facilities}

\section{Chemical Containing Waste Scenarios (WH-7, WH-7A, WH-7B, WH-13, WH-13A, WH-13B)}

Scenarios involving chemical containing waste accidents could result in the release of a hazardous chemical due to a spill or fire. Credible initiators for such scenarios include operator errors and system failures.

The probability of the hazardous chemical release events is dependent on the quantity of hazardous chemicals released during an accident. Typical releases are small spills that do not release the entire contents of a container. The unmitigated frequency for a chemical containing waste accident releasing small amounts of a hazardous chemical is estimated as "anticipated." Releases of the entire contents of a container will have a lower frequency. Chemical inventory reviews demonstrate that more than $99 \%$ of containers released could result in consequences $\leq$ TEEL 1 . The unmitigated frequency for a chemical containing waste accident releasing an entire container of a hazardous chemical significantly less than the SCIL is estimated as "unlikely." Chemical inventory reviews demonstrate that less than $1 \%$ of containers released could result in consequences >TEEL 1 and $\leq$ TEEL 2 . The unmitigated frequency for a chemical containing waste accident releasing an entire container of a hazardous chemical approaching or at the SCIL is estimated as "extremely unlikely." The unmitigated frequency of a chemical containing waste accident with a subsequent fire is estimated to be the same as the spill scenarios for the different quantities.

Co-located worker consequences were estimated as "low" for scenarios involving small releases and releases of greater quantities of waste but in amounts significantly less than the SCIL. Site facility worker consequences are consistent with the co-located worker consequences. Workers closer to the point of release could receive higher exposure as compared to the exposures evaluated at the onsite receptor location (e.g., co-located worker). The estimation of consequence to the worker has a high degree of uncertainly due to the complexity of parameters involved with a worker close to the point of release. Worker consequences are qualitatively judged to have similar consequences as the co-located worker. It is reasonable to assume that the workers will observe the accident and leave the scene in a timely manner.

Co-located worker consequences were estimated as "moderate" for scenarios involving releases of greater quantities of waste in amounts approaching or at the SCIL. Site facility worker consequences are consistent with the co-located worker consequences. Workers closer to the point of release could receive higher exposure as compared to the exposures evaluated at the onsite receptor location (e.g., co-located worker). The estimation of consequence to the worker has a high degree of uncertainly due to the complexity of parameters involved with a worker close to the point of release. Worker consequences are qualitatively judged to have similar consequences as the co-located worker. It is reasonable to assume that the workers will observe the accident and leave the scene in a timely manner. Waste operations require a minimum of two personnel, which further supports a reasonable detection and emergency response to the event. Worker injuries could result in serious injury, but it is not anticipated that site facility workers would receive a sustained exposure that would be immediately dangerous to life or health.

The potential unmitigated consequences from chemical containing waste accidents are estimated as "low" for the public and the worker for small releases and releases of greater 
quantities of waste but in amounts significantly less than the SCIL, and as "moderate" for the public and the worker for releases of greater quantities of waste in amounts approaching or at the SCIL. Scenarios involving chemical containing waste represent a "low" risk to the public and the worker.

The Hazardous Material Protection Program ensures the Waste Storage Facilities are Low Hazard facilities and provides protection of the public, the co-located worker, and the site facility worker from chemical releases. A portion of the Hazardous Material Protection Program that is unique to the Waste Storage Facilities is the SCIL Program, which is used to control the inventory of hazardous chemicals in waste. This program limits the quantity of a chemical that can be stored in any one container based on a series of criteria such as the toxicity and vapor pressure of the material. The SCIL limits the consequences to the public and the co-located worker. The Hazardous Material Protection Program and the SCIL Program are further discussed in Chapter 8.

\section{Container Handling, Maintenance, Filter Replacement, Sampling, Analysis, and Radiography Scenarios (WH-19, WH-20a, and WH-20b)}

Operator errors during TRU or LLW container handling activities (e.g., moving, maintenance, filter replacement, sampling, analysis, radiography, LLW packaging) are covered by the waste handling events $\mathrm{WH}-19$. The unmitigated frequency of release from RTR or NDA activities is estimated to be "anticipated." Site facility worker and public consequences were estimated as "low," for these scenarios.

Exposure to the direct beams of a radiation-generating device (e.g., RTR) is covered by the waste handling event $\mathrm{WH}-20 \mathrm{a}$. The unmitigated frequency is estimated to be "anticipated." This is a Standard Industrial Hazard (SIH) to the worker and public and the consequence is not applicable.

Scenarios involving headspace gas leak or worker's gloves breached during sampling that could result in worker's contamination are addressed in event $\mathrm{WH}-20 \mathrm{~b}$. Credible initiators for such scenarios include personnel error, equipment failure, and gloved penetrated by sharp implement. The unmitigated frequency of contamination following a headspace gas leak or a breached glove accident is estimated to be "anticipated." Site facility worker and public consequences were estimated as "low." Low is the minimum defined consequence rank. However, the consequence to the public are essentially negligible.

\section{TRUPACT-II Loading/Unloading Accidents (WH-1, WH-2, WH-3, WH-4, WH-8A WH-17, WH-18, WH-21)}

Staging and loading/unloading of open TRUPACT-II Type B casks with approved TRU waste containers are covered by the waste handling events $\mathrm{WH}-1, \mathrm{WH}-2, \mathrm{WH}-3, \mathrm{WH}-4, \mathrm{WH}-8 \mathrm{~A}$ $\mathrm{WH}-17, \mathrm{WH}-18$.

The loading/unloading of the closed TRUPACT-II Type B cask onto the truck is addressed in events $\mathrm{WH}-21$. Initiators include worker error and faulty crane lift fixture. The unmitigated 
frequency for such initiators is estimated to be "unlikely." Site facility worker and public unmitigated and mitigated consequences were estimated as "low."

\section{Waste-Storage/Staging/Handling Operations Preventive and Mitigative Features}

Candidate preventive and mitigative features for the operational events include the following:

- For each approved TRU waste container in B696R or B625, the amount of radioactive material shall be no greater than $50 \mathrm{PE}-\mathrm{Ci}$ based on Acceptable Knowledge. Drum loading and configuration shall be administratively controlled to remain consistent with the National Environmental Policy Act (NEPA) bounding consequence calculations.

- The amount of tritium in a waste container shall be no greater than 2,000 Ci based on Acceptable Knowledge.

- TRU waste arrays staged outside the building shall be limited to a maximum inventory of 200 PE-Ci and separated by a minimum of 10 feet.

- $\quad$ All TRU waste shall be stored in approved TRU waste containers.

- For each container, the fissile material inventory shall be no greater than 200 Pu-239 FGE.

- Traffic controls are established in the Waste Storage Facilities yards.

- Hazardous material protection program, including the SCIL program to control the inventory of hazardous chemicals in waste.

- Container maintenance program (a portion of the In-service Inspection \& Test Program).

- Only waste in metal containers and on metal pallets shall be allowed in TRU waste storage areas.

- Criticality safety program to ensure that the potential for an inadvertent criticality event is precluded.

- An emergency preparedness program for the Waste Storage Facilities to train employees on appropriate emergency response actions.

- A training program, including certification and qualification of forklift and crane operators

\section{INADVERTENT FIREARM DISCHARGE HAZARDS EVALUATION}

\section{Inadvertent Firearm Discharge (FA-1)}

For event FA-1 the PrHA accident frequencies that result from an inadvertent firearms discharge of security personnel that cause an uncontrolled release of hazardous material are "beyond extremely unlikely" as described in LLNL 2006a. For conservatism, the consequences for all 
uncontrolled releases of hazardous material resulting from the inadvertent discharge of a firearm are "high" for the worker and "moderate" for the public. Security controls are identified in the Livermore Site Office letter on April 15, 2009 (LSO 2009).

\section{EXTERNAL EVENTS HAZARDS EVALUATION}

Seven external event scenarios were deemed appropriate for analysis in this report for the DWTF Waste Storage Facilities. These scenarios include:

1. An aircraft crash resulting in a spill;

2. An aircraft crash at B696R or B693 resulting in a spill and fire;

3. An aircraft crash at B625 resulting in a spill and fire;

4. An external fire that impacts the segment;

5. An accident at a nearby facility that impacts the segment;

6. A natural gas line breach; and

7. A high voltage power line fire in A625 yard.

Other external events (e.g., nuclear test activity, strong radio transmissions, and structural interaction) were removed in the screening because of site characteristics. Still others were eliminated in the screening because they were not considered credible for affecting the waste containers in the facility.

\section{Aircraft Crash (EE-1, EE-2A, EE-2B)}

The unmitigated frequencies for aircraft crashes into Waste Storage Facilities structures or staging areas were conservatively estimated in consultation with LSO and DOE-STD-3014 (Appendix B). For DWTF, an aircraft crash into B696R yielding only a spill was estimated to be marginally "extremely unlikely." An aircraft crash with a significant post-crash fire was estimated to be "beyond extremely unlikely." An aircraft crash into B693 with a significant post-crash fire was historically estimated to be "extremely unlikely," but that is no longer a candidate event as authorization for TRU waste in B693 has been withdrawn in this DSA. For A625, a bounding aircraft crash into B625 was estimated to be "extremely unlikely."

The potential unmitigated consequences of an aircraft crash into any Waste Storage Facilities facility resulting in a spill only are estimated as "low" for the public and the worker. The potential unmitigated consequences are estimated as "moderate" for the public and the worker for an aircraft crash into Waste Storage Facilities facility resulting in a fire. Facility worker consequences were not estimated in the immediate proximity of the crash as the event itself and the subsequent fire would yield worker fatalities independent of any radiological release. Workers at some reasonable standoff distance would not experience "high" consequences from a radiological release. 
The unmitigated aircraft crash scenarios resulting in a spill represent a "negligible" risk to the public and worker in A625 and DWTF waste storage facilities. The unmitigated aircraft crash scenarios resulting in a fire represent a "low" risk to the public and the worker in A625 and a "negligible" risk at DWTF waste storage facilities.

Co-located worker consequences were estimated as "low" for aircraft spill scenarios. Site facility worker consequences are consistent with the co-located worker consequences. Worker injuries would primarily be related to impact trauma rather than the result of radioactive uptake. Workers closer to the point of release could receive higher exposure as compared to the exposures evaluated at the onsite receptor location (e.g., co-located worker). The estimation of consequence to the worker has a high degree of uncertainly due to the complexity of parameters involved with a worker close to the point of release. Worker consequences are qualitatively judged to have similar consequences as the co-located worker. It is reasonable to assume that the workers will observe the accident and leave the scene in a timely manner. The nature of an aircraft crash provides indication of the event, which further supports a reasonable detection and emergency response to any event.

Co-located worker consequences were estimated as "moderate" for aircraft fire scenarios. Site facility worker consequences are not consistent with the co-located worker consequences.

Worker injuries would primarily be related to heat, smoke, and physical trauma rather than the result of radioactive uptake. Workers closer to the point of release could receive a higher dose as compared to the doses evaluated at the onsite receptor location; however, this is qualitatively judged to have a minimal impact on potential consequences because the thermal input would tend to loft the plume reducing the potential exposure. The physical impacts and subsequent fire from the crash itself could result in non-radiological consequences that are life threatening or cause permanently disabling injuries for the site facility worker. However, this potential derives from an externally imposed initiator that is immune to any intervention by either facility management or DOE. It is thus outside the envelope of consequence ranking in an analysis performed to define facility controls. 


\section{Documented Safety Analysis for the Waste Storage Facilities}

\section{External Fire (EE-3)}

The frequency of an external fire occurring that could impact the DWTF or A625 Waste Storage Facilities is considered "extremely unlikely." The unmitigated consequences are estimated as "moderate" for the public and "low" for the co-located workers. Site facility worker consequences are consistent with the co-located worker consequences. The "moderate" public consequence estimation follows from the relatively more conservative consequence severity levels for the public as identified in Table 3-2. In addition, the public would not be aware of the accident and could unknowingly remain in the vicinity. Workers closer to the point of release could receive a higher dose as compared to the doses evaluated at the onsite receptor location; however, this is qualitatively judged to have a minimal impact on potential consequences because the thermal input would tend to loft the plume reducing the potential exposure and a worker would have to remain in the plume for an extended period of time (hours) in order to receive a significant exposure. It is reasonable to assume that the workers will observe the accident and leave the scene in a timely manner. The nature of an external fire provides indication of the event, which further supports a reasonable detection and emergency response to any event. The external fire scenario represents a "low" risk to the public and a "negligible" risk to workers. One potential source of an external event fire for the A625 facilities would be an accident at the nearby fueling stations (e.g., ethanol, compressed natural gas). B695 Segment of DWTF had no unique impact on the DWTF Storage Area facilities due to separation distances and the partition between B696S and B696R.

\section{Accident at Nearby Facility (EE-4)}

The frequency of an accident (e.g., explosion) occurring at a nearby facility releasing hazardous material or creating a projectile that could impact TRU waste stored at the DWTF or A625 Waste Storage Facilities is considered "extremely unlikely." The consequences to the co-located worker and public are considered "low." Site facility worker consequences are consistent with the co-located worker consequences. Workers closer to the point of release could receive higher exposure as compared to the exposures evaluated at the onsite receptor location (e.g., co-located worker). The estimation of consequence to the worker has a high degree of uncertainly due to the complexity of parameters involved with a worker close to the point of release. Worker consequences are qualitatively judged to have similar consequences as the colocated worker. It is reasonable to assume that the workers will observe the accident and leave the scene in a timely manner. The nature of an accident at a nearby facility provides indication of the event, which further supports a reasonable detection and emergency response to any event. This represents a "negligible" risk to the public and the worker.

\section{Natural Gas Line Breach (EE-5)}

The frequency of a capped off natural gas line breach and ignition causing a fire that impacts stored TRU waste in A625 Waste Storage Facilities is considered "extremely unlikely." The consequences are considered "low" for the co-located worker and "moderate" for the public. Site facility worker consequences are consistent with the co-located worker consequences. The "moderate" public consequence estimation follows from the relatively more conservative consequence severity levels for the public as identified in Table 3-2. In addition, the public 


\section{Documented Safety Analysis for the Waste Storage Facilities}

would not be aware of the accident and could unknowingly remain in the vicinity. Workers closer to the point of release could receive higher exposure as compared to the exposures evaluated at the onsite receptor location (e.g., co-located worker). The estimation of consequence to the worker has a high degree of uncertainly due to the complexity of parameters involved with a worker close to the point of release. Worker consequences are qualitatively judged to have similar consequences as the co-located worker. It is reasonable to assume that the workers will observe the accident and leave the scene in a timely manner. The inherent aromatic warning for piped natural gas leaks provides indication of the event, which further supports a reasonable detection and emergency response to any event. This represents a "low" risk to the public and a "negligible" risk to the worker.

\section{Overhead Power Line (EE-6)}

The frequency of an overhead high voltage power line dropping into the yard, remaining energized, and inducing a fire that impacts approved TRU waste containers in A625 Waste Storage Facilities is considered "extremely unlikely." The consequences to the worker are considered "low" and the public are considered "moderate." Site facility worker consequences are consistent with the co-located worker consequences. The "moderate" public consequence estimation follows from the relatively more conservative consequence severity levels for the public as identified in Table 3-2. In addition, the public would not be aware of the accident and could unknowingly remain in the vicinity. Worker injuries would primarily be the result of electrical trauma rather than the result of radioactive uptake. Workers closer to the point of release could receive higher exposure as compared to the exposures evaluated at the onsite receptor location (e.g., co-located worker). The estimation of consequence to the worker has a high degree of uncertainly due to the complexity of parameters involved with a worker close to the point of release. Worker consequences are qualitatively judged to have similar consequences as the co-located worker. It is reasonable to assume that the workers will observe the accident and leave the scene in a timely manner. The circuit cutoff for shorted power lines provides indication of the event, which further supports a reasonable detection and emergency response to any event. This represents a "low" risk to the public and a "negligible" risk to the worker.

\section{External Events Preventive and Mitigative Features}

Candidate preventive and mitigative features for the external events include the following:

- For each approved TRU waste container in B696R or B625, the amount of radioactive material shall be no greater than $50 \mathrm{PE}-\mathrm{Ci}$ based on Acceptable Knowledge. Drum loading and configuration shall be administratively controlled to remain consistent with the National Environmental Policy Act (NEPA) bounding consequence calculations.

- The amount of tritium in a waste container shall be no greater than 2,000 Ci based on Acceptable Knowledge. 
- TRU waste arrays staged outside the building shall be limited to a maximum inventory of 200 PE-Ci and separated by a minimum of 10 feet.

- $\quad$ All TRU waste shall be stored in approved TRU waste containers.

- 20-foot exclusion zone in DWTF yard (element of Fire Protection Program.

- B696S/B696R partition.

- B625 and B696R structural systems.

- An emergency preparedness program for the Waste Storage Facilities to train employees on appropriate emergency response actions.

\section{NATURAL PHENOMENA HAZARDS EVALUATION}

Seven natural phenomena hazard (NPH) events were evaluated in the PrHA for this DSA for the DWTF and A625 Waste Storage Facilities. These include:

1. A design basis wind scenario,

2. Two lightning scenarios,

3. A design basis flood scenario

4. Three design basis earthquake scenarios, and

\section{Design Basis Winds (NPH-1)}

The design basis wind for a PC-2 facility at LLNL is discussed in Chapter 1. In the case of a facility not rated to meet PC-2 wind criteria, the structure could collapse, crushing some containers; thus, TRU waste is not stored in non-PC-2 buildings. Design basis wind events impacting inventories in the building or the yard and causing stacked containers to breach and release radioactive material are considered "unlikely" in the PrHA for DWTF and A625 Waste Storage Facilities. The consequences to the co-located worker and public are considered "low" for DWTF and A625 Waste Storage Facilities. Site facility worker consequences are consistent with the co-located worker consequences. Workers closer to the point of release could receive higher exposure as compared to the exposures evaluated at the onsite receptor location (e.g., co-located worker). The estimation of consequence to the worker has a high degree of uncertainly due to the complexity of parameters involved with a worker close to the point of release. Worker consequences are qualitatively judged to have similar consequences as the colocated worker. It is reasonable to assume that the workers will observe the accident and leave the scene in a timely manner. A significant wind that results in the release of radioactive material provides an indication of the event, which further supports a reasonable detection and emergency response to any event. The resulting risk to the public and the worker is considered "low" for DWTF and A625 Waste Storage Facilities. 


\section{Documented Safety Analysis for the Waste Storage Facilities}

\section{Lightning Strike ( NPH-2, NPH-3)}

Lightning strike scenarios resulting in a facility fire or a yard fire impacting TRU waste inventories are both considered "extremely unlikely" for DWTF and A625 Waste Storage Facilities. Over a recent 10 year period, only four lightning strikes were recorded within a 2 mile radius of LLNL. There were no recorded instances of lightning strikes within the boundaries of LLNL during this 10 -year period. The consequences are considered "moderate" to the public and "low" to the collocated worker for DWTF and A625 Waste Storage Facilities. Site facility worker consequences are consistent with the co-located worker consequences. The "moderate" public consequence estimation follows from the relatively more conservative consequence severity levels for the public as identified in Table 3-2. In addition, the public would not be aware of the accident and could unknowingly remain in the vicinity. Worker injuries would primarily be the result of electrical trauma rather than the result of radioactive uptake. Workers closer to the point of release could receive higher exposure as compared to the exposures evaluated at the onsite receptor location (e.g., co-located worker). The estimation of consequence to the worker has a high degree of uncertainly due to the complexity of parameters involved with a worker close to the point of release. Worker consequences are qualitatively judged to have similar consequences as the co-located worker. It is reasonable to assume that the workers will observe the accident and leave the scene in a timely manner. A lightning strike in a nuclear segment provides an indication of the event, which further supports a reasonable detection and emergency response to any event. The resulting risk to the public is considered "low" and risk to the worker is considered "negligible" for DWTF and A625 Waste Storage Facilities.

\section{Design Basis Flood (NPH-4)}

The two sources of flooding at LLNL are from the Arroyo Las Positas and the Arroyo Seco. The DBFI for a PC-2 facility at LLNL, with a 2000-year return period, is considered "unlikely" for DWTF and A625 Waste Storage Facilities. The flood analysis for DWTF (Lin 1998) estimates the overflow of the Arroyo Las Positas during a 2,000 year flooding event to impact the DWTF with floodwater approximately nine inches above the existing grade of the DWTF site. The conclusions show no major flood damage to buildings within the DWTF from a 2,000 year frequency precipitation event. Based on the flood analysis for the B231 vault (Majumdar 2001), it is expected that B625 will have no major flood damage to buildings from a 2000-year flood. It is assessed that some degree of drum leakage could occur from a 2,000-year flooding event of the facility. This could result in the leaking of a portion of the drums' radioactive contents. The consequences to the co-located worker and the public are considered "low" for DWTF and A625 Waste Storage Facilities. Site facility worker consequences are consistent with the co-located worker consequences. Worker injuries would primarily be the result of consequences from a flood rather than the result of radioactive uptake. Workers closer to the point of release could receive a higher dose as compared to the doses evaluated at the onsite receptor location, they are qualitatively judged to have a minimal impact on potential consequences because flooding conditions significantly limit the potential for the release of airborne particles. It is reasonable to assume that the workers will observe the accident and leave the scene in a timely manner. A significant flood provides an indication of the event, which further supports a reasonable 
detection and emergency response to any event. The resulting risk to the public and worker is considered "low" for DWTF and A625 Waste Storage Facilities.

\section{Earthquake (NPH-5, NPH-5a, NPH-6)}

The design basis earthquake for a PC-2 facility at LLNL is $0.57 \mathrm{~g}$ with a 1000 -year return period (DOE 1996a), and is considered "unlikely" for DWTF and A625 Waste Storage Facilities. The most probable scenarios in a seismic event include: 1) the toppling of stacked containers resulting in a spill, and 2) the toppling of stacked containers resulting in a spill with a subsequent fire and buoyant release. All facilities that store TRU waste meet PC-2 seismic criteria. In addition, the B625 crane has seismic restraints. Unmitigated consequences for a spill and fire are considered "moderate" to the public and "low" to the co-located worker. These consequence estimates account for potential interactions between building utilities and other attachments with the containerized TRU waste inventories. Site facility worker consequences are consistent with the co-located worker consequences. The "moderate" public consequence estimation follows from the relatively more conservative consequence severity levels for the public as identified in Table 3-2. In addition, the public would not be aware of the accident and could unknowingly remain in the vicinity. Workers closer to the point of release could receive higher exposure as compared to the exposures evaluated at the onsite receptor location (e.g., co-located worker). The estimation of consequence to the worker has a high degree of uncertainly due to the complexity of parameters involved with a worker close to the point of release. Worker consequences are qualitatively judged to have similar consequences as the co-located worker. It is reasonable to assume that the workers will observe the accident and leave the scene in a timely manner. An earthquake provides an indication of the event, which further supports a reasonable detection and emergency response to any event. The potential mitigated risk due to the seismic accidents is considered "low" to the public and the worker after crediting that containers shall not be stacked more than two levels high and limiting waste containers and pallets in TRU waste storage areas to metal.

\section{Natural Phenomena Hazards Preventive and Mitigative Features}

Candidate preventive and mitigative features for the NPH events include the following:

- For each approved TRU waste container in B696R or B625, the amount of radioactive material shall be no greater than $50 \mathrm{PE}-\mathrm{Ci}$ based on Acceptable Knowledge. Drum loading and configuration shall be administratively controlled to remain consistent with the National Environmental Policy Act (NEPA) bounding consequence calculations.

- The amount of tritium in a waste container shall be no greater than 2,000 Ci based on Acceptable Knowledge.

- TRU waste arrays staged outside the building shall be limited to a maximum inventory of 200 PE-Ci and separated by a minimum of 10 feet.

- B625 and B696R structural systems 


\section{Documented Safety Analysis for the Waste Storage Facilities}

- TRU waste will be stored in approved TRU waste containers

- Approved TRU waste containers shall not be stacked more than two levels high. Approved TRU waste containers exceeding a nominal height of 4 -ft shall not be stacked.

- Combustible loading shall be limited to an average of 7 pounds of equivalent ordinary combustibles per square foot, excluding waste containerized in metal packaging, in B625 and B696R.

- Only waste in metal containers and on metal pallets shall be allowed in TRU waste storage areas.

Periodic structural inspection, seismic restraints on the crane, and post-natural phenomena inspection are additional mitigative provisions.

\subsection{Planned Design and Operational Safety Improvements}

No specific design or operational safety improvements were identified as a result of the hazard evaluation.

\subsection{Defense-in-Depth}

This section summarizes significant aspects of the defense-in-depth philosophy as implemented to provide safety at the Waste Storage Facilities. This section does not provide a comprehensive list of defense-in-depth items listed in the PrHA, but consists of both design features and safety management programs. Defense-in-depth includes safety-significant SSCs and ensures that the health and safety of the public and workers are not adversely impacted by the design and operation of the Waste Storage Facilities.

Safety programs described in Chapter 6 through Chapter 17 assure that the occupational exposures to hazardous and radioactive materials are maintained as low as reasonably achievable below the regulatory limit during normal operations and most abnormal conditions. In the event of an accident, safety-significant SSCs and specific administrative controls identified and maintained in the TSR assure that the potential dose consequences are mitigated to protect the environment and the health and safety of the public and the workers.

Thus, the defense in depth philosophy as implemented in the Waste Storage Facilities consists of safety programs, i.e., institutional safety provisions and organizational discipline, to assure operational safety and to maintain safety significant SSCs that protect the environment and the health and safety of the public and the workers in the unlikely event of an accident. Safety significant items are discussed further below. The defense in depth is commensurate with the potential hazards consistent with the graded approach.

Consistent with the defense in depth philosophy described above, fire suppression systems are installed in the Waste Storage Facilities to control the fire growth and, thus, to prevent fire propagation in the event of a fire. Although fire suppression systems are not specifically credited to reduce the risk for any potential fires in the PRHA, building fire suppression systems in TRU storage areas are considered to provide significant risk mitigation and are important defense in 
depth. Accordingly, as a part of the fire protection program, fire suppression systems are inspected, tested, and maintained in accordance with the applicable NFPA requirements.

The potential dose consequences associated with postulated accidents that have been identified for further evaluation in accordance with DOE-STD-3009-94, Change Notice 3, are analyzed in detail in Section 3.4.

In summary, defense-in-depth controls are engineered and administrative provisions, and they serve either a mitigative or preventive function. The control types given in the PrHA constitute initial conditions of scenario development, controls credited for reducing frequency or consequence, and other defense-in-depth controls that contribute to best management practices.

\section{Safety-Significant Structures, Systems, and Components}

On the basis of the PrHA, the following passive SSCs have been designated as safety significant:

- Approved TRU waste containers

- B625 and B696R structural systems

- B696S/B696R partition

Chapter 4 discusses the safety function for each of these safety significant SSCs.

\section{Technical Safety Requirements (TSRs)}

TSR coverage is required for design features and administrative controls that support the defense-in-depth concept. The design features are the PC-2 structural systems of the buildings that store TRU waste (B696R and B625), the B696S/B696R partition, and approved TRU waste containers for storage of TRU waste. The following are specific administrative controls at the Waste Storage Facilities:

- For each approved TRU waste container in B696R or B625, the amount of radioactive material shall be no greater than $50 \mathrm{PE}-\mathrm{Ci}$ based on Acceptable Knowledge. Drum loading and configuration shall be administratively controlled to remain consistent with the National Environmental Policy Act (NEPA) bounding consequence calculations.

- The amount of tritium in a waste container shall be no greater than 2,000 Ci based on Acceptable Knowledge.

- For each container, the fissile material inventory shall be no greater than 200 Pu-239 FGE.

- TRU waste arrays staged outside the building shall be limited to a maximum inventory of 200 PE-Ci and separated by a minimum of 10 feet. 


\section{Documented Safety Analysis for the Waste Storage Facilities}

- $\quad$ All TRU waste shall be stored in approved TRU waste containers.

- Approved TRU waste containers shall not be stacked more than two levels high. Ten drum overpacks and other approved TRU waste containers exceeding a nominal height of 4-ft shall not be stacked.

- The lids for approved TRU waste containers shall not be removed in the Waste Storage Facilities.

- Approved TRU waste containers shall not be staged less than $130 \mathrm{~m}$ from the Greenville Road fence line (east of the B693 structure).

- Only waste in metal containers and on metal pallets shall be allowed in TRU waste storage areas.

- $\quad$ TRU waste storage shall be limited to B696R and B625.

- Combustible loading shall be limited to an average of 7 pounds of equivalent ordinary combustibles per square foot, excluding waste containerized in metal packaging, in B625 and B696R.

The following list identifies key elements of Programmatic ACs that are either an initial condition, a credited control in the Hazards Analysis, or designated as requiring identification in the TSR based on management discretion:

- Chemical Inventory Control (e.g., SCIL) (element of Hazardous Material Protection Program).

- Vent Verification/Inspection (element of In-service Inspection \& Test, and Maintenance Program).

- Fissile material inventory controls (element of Criticality Safety Program).

- 20-foot exclusion zone in DWTF yard (element of Fire Protection Program).

- No trucks allowed in TRU storage areas (element of Fire Protection Program).

- No flammable fueled forklifts stored in TRU storage areas (element of Fire Protection Program).

Further TSR derivation information is provided in Chapter 5.

\subsection{Worker Safety}

The major features protecting workers from hazards associated with accidents occurring during facility operation are similar to those documented in the defense-in-depth section, Section 3.3.2.3.2. This includes the description of safety-significant SSCs and administrative controls requiring TSRs.

The hazards to the Waste Storage Facilities workers, associated with normal and abnormal conditions, include potential exposure to radionuclides, hazardous materials, and safety and health hazards. Radiation exposure can occur with radioactive materials within the waste 
containers or from exposure to contamination that may exist on the surfaces of waste containers or waste-handling equipment. The hazardous components of hazardous, mixed, and combined wastes include corrosives, metals, and organics. The sources of safety and health hazards include electrical hazards, motion hazards, gravity-mass hazards, and pressure, heat, and noise hazards.

RHWM implements and maintains a full set of safety management programs that are described further in Chapters 6 through 17. As stated previously, the focus of the hazards analysis is on potential accident conditions. From the list of safety management programs, the following were considered the most significant for worker safety. These are included in the TSRs and are described in later chapters of this DSA.

- Criticality Safety Program (DSA Chapter 6). Ensures that a criticality event is not credible by setting appropriate inventory limits.

- Radiation Protection Program (DSA Chapter 7). Ensures that workers are provided adequate protection from radiological hazards, including training and monitoring.

- Hazardous Material Protection Program (DSA Chapter 8). Ensures that workers are provided adequate protection from hazardous materials, including training.

- In-service Inspection \& Test and Maintenance Programs (DSA Chapter 10). Ensures the integrity of the Safety Significant SSCs. Inspections are performed by qualified personnel using documented procedures.

- Fire Protection Program (DSA Chapter 11). Ensures that the facility has provisions in place for combustible loading control and adequate fire fighting capabilities, and separation to protect segmentation.

- Traffic Control Program (DSA Chapter 11). Provides protection from vehicular traffic for TRU waste in the yard by limiting the speed of vehicles in the Waste Storage Facilities.

- RHWM Training Program (DSA Chapter 12). Ensures that operators are qualified to perform their specified duties and thereby minimize exposure to hazardous conditions.

- Emergency Preparedness Program (DSA Chapter 15). Ensures that workers are aware of the proper response actions in the event of an emergency.

- Configuration Management Program (DSA Chapter 17). Ensures protection of workers and the public by establishing the mechanisms for consistency between design requirements, physical configuration, and documentation of configuration items.

- Quality Assurance Program (DSA Chapter 14). Ensures appropriate level of planning, organization, direction, control, and support for activities and SSCs at the Waste Storage Facilities. 


\section{Documented Safety Analysis for the Waste Storage Facilities}

\subsection{Environment Protection}

Protection of the environment is the result of design and operational features that reduce the potential for large releases of radioactive waste to the environment. Impacts to the environment from the scenarios discussed in this chapter are considered less than the impacts to the public. Controls identified in the PrHA are considered sufficient to address the impacts to the environment.

\subsection{Accident Selection}

Accident selection identifies the unique and representative potential accidents that are included in the accident analysis. Representative accidents bound a number of similar accidents that typically have lower consequences or frequencies. The selection criteria are consistent with the Nuclear Safety Risk Ranking and Control Selection Guidelines provided by the DOE Safety Basis Special Project Team (Nelson 2003) as described in Section 3.3.1.2. Unique accidents are those that cannot be bounded by representative accidents due to the nature of the hazard or accident progression. A potential accident identified with a high or moderate risk ranking is either brought forward for accident analysis or is bounded by a representative accident identified for accident analysis. This designation is specifically identified in the comment field of the PrHA. No high risk mitigated accident scenarios were identified that released radioactive material.

From the hazard analysis, six scenarios were identified as the bounding accidents requiring further evaluation in Section 3.4, "Accident Analysis," as shown below. The selected accidents were of different accident types with the largest predicted dose consequences to the public. These accidents were selected irrespective of the qualitative assessment of the likelihood of occurrence and encompass the representative and unique accidents brought forward for accident analysis.

Deflagration of Approved TRU Waste Container (WH-14) - A deflagration involving one container postulated due to ignition of flammable gas in an unvented approved TRU waste container. This is analyzed in Section 3.4.2.1.

Spill of Approved TRU Waste Containers in Yard (WH-2) - Spill postulated to occur from high-speed vehicle accident impacting pallets of staged approved TRU waste containers. The postulated spill in the yard bounds the inside the facility spill scenarios. This is analyzed in Section 3.4.2.2.

Fire Involving Stored Approved TRU Waste Containers in Building (WH-10) - Fire postulated to occur from spilled flammable liquid in the building resulting in failure of multiple approved TRU waste containers. This is analyzed in Section 3.4.2.3.

Tritium Fire in Building (WH-12) - Although a tritium release is not the bounding radiological event, it is included because of the unique form of tritium (it can be released as a gas or a high vapor pressure liquid). Fire postulated to occur from spilled flammable liquid in a building resulting in failure of containers containing tritium. Tritium is released as either molecular tritium ( $\mathrm{HT}$ or $\mathrm{T}_{2}$ gas) or tritiated water $\left(\mathrm{HTO}\right.$ or $\mathrm{T}_{2} \mathrm{O}$ ) at a reasonably rapid rate only in a fire scenario. Thus, a fire bounds a spill. This is analyzed in Section 3.4.2.4. 
Large Fire Involving Staged Approved TRU Waste Containers in the Yard (WH-8A) - Spill with subsequent fire postulated to occur from high-speed vehicle accident impacting pallets of staged approved TRU waste containers. This is analyzed in Section 3.4.2.5.

Aircraft Crash in Building Storing TRU Waste (EE-2B) - A general aviation, fixed wing single engine aircraft crashes into a building resulting in a spill of approved TRU waste containers from the impact. A subsequent fire from aviation gasoline is also postulated to occur, impacting additional approved TRU waste containers within the building. This is analyzed in Section 3.4.2.6.

The remaining operational, external, and NPH events were qualitatively determined to be of lower consequence or lower risk or, if having equal consequence, as having lower risk because of lower likelihood of occurrence.

Of the potential events qualitatively evaluated in the hazard analysis, only one postulated mitigated operational accident involves multiple pallets of TRU containers. This is a compartment fire resulting in failure of multiple TRU containers leading to radioactive release. No operational event qualitatively analyzed in the hazard analysis has the potential to involve the entire facility inventory.

The number of failed TRU containers in the postulated compartment fire accident is established by the magnitude and the severity of the potential fire, i.e., the predicted worst temperature must exceed $600^{\circ} \mathrm{C}$ for catastrophic failure of some drums as shown experimentally in WHC-SD-WM-TRP-246. For the most severe case analyzed in Section 3.4.2.3, the predicted maximum temperature is less than $400^{\circ} \mathrm{C}$ for the postulated 4-MW fire involving a pool of flammable liquid. The total number of failed approved TRU waste containers is ten with an assumed radioactive inventory of $50 \mathrm{PE} \mathrm{Ci} \mathrm{each,} \mathrm{and} \mathrm{is} \mathrm{independent} \mathrm{of} \mathrm{a} \mathrm{specific} \mathrm{location} \mathrm{within}$ the Waste Storage Facilities. The results of the analysis demonstrated that the fire severity from the postulated fuel pool fire would not lead to failure of all approved TRU waste containers even within the same compartment for the smallest of compartments in the Waste Storage Facilities.

Operationally, because of spatial limitations, radioactive waste containers, e.g., 55-gal drums, occupy nearly all available storage space in the buildings. This restricts the quantity of transient combustibles in each building. While a conservative combustible loading limit is established in the TSR to preclude fire propagation to adjacent compartments the actual combustible loading in each building is significantly below the established limit. In addition, ignition sources are limited because types of operations are mostly related to storage. Therefore, a potential fire that involves the entire facility inventory is not credible.

Furthermore, the fire protection program as described in Chapter 11 minimizes the combustible loading and ignition sources. Fire suppression systems will limit the fire growth in the unlikely event of a catastrophic programmatic failure. Fire-rated partitions in a building preclude the potential for fire propagation. The programmatic provisions and SSCs in combination provide further assurance that radioactive release from potential fires is minimized. 


\section{Documented Safety Analysis for the Waste Storage Facilities}

Natural phenomena hazard and external event scenarios can only affect limited material at risk based on the physical aspects related to the initiating event and subsequent enabling events through the progression of the accident scenario. The unmitigated accident scenarios analyzed have their MAR established considering these basic physical properties for each accident scenario. Some of the basic physical properties include the capped off natural gas line, separation distance from potential hazards (e.g., refueling stations), and the physical limitation of how much material the hazard can affect (e.g., aircraft engine). In addition, facilities that may not withstand a design basis accident and areas designated for storage of flammable liquids will not be used for storage of TRU waste. Thus, external or natural phenomena events qualitatively analyzed in the hazard analysis can only affect limited MAR based on the physical aspects related to the initiating event and subsequent enabling events through the progression of the accident scenario.

Although mitigated chemical spill or fire release scenarios identified in the PrHA represent a "moderate" consequence to the public, these accidents have a "low" risk and are not selected for accident analysis. The SCIL Program, which is a portion of the Hazardous Material Protection Program, is used to control the inventory of hazardous chemicals in waste. The SCIL limits the consequences to the public and the co-located worker. The Hazardous Material Protection Program ensures the Waste Storage Facilities are Low Hazard facilities and provides adequate protection of the public, the co-located worker and the site facility worker from chemical releases. The Hazardous Material Protection Program and the SCIL Program are further discussed in Chapter 8.

\subsection{ACCIDENT ANALYSIS}

This section presents the analysis of the postulated accidents selected from the hazard analysis described in Section 3.3.2.3.5, "Accident Selection." An evaluation was performed to assess the relative risk for each postulated accident. The methodology to determine the dose consequences of the postulated accidents is discussed in Section 3.4.1. Analyses of the dominant accident scenarios, including controls credited in each accident scenario, are presented in Sections 3.4.2.1 through 3.4.2.6 3.4.2.5 and 3.4.3.3.

\subsubsection{METHODOLOGY}

The accident analysis methodology complies with the guidelines in DOE-STD-3009-94, Change Notice 3. For each bounding accident, the accident scenario is developed to enable characterization and quantification of the source term. The dose consequence analysis is based on the source term analysis and the results of the atmospheric diffusion analysis. The source term is calculated by:

$$
S T=M A R \times A R F \times R F \times D R \times L P F
$$

where MAR is the quantity of radioactive inventory at risk, $A R F$ and $R F$ are airborne release fraction and respirable fraction from DOE-HDBK-3010-94 (DOE 1994), respectively, DR is the damage ratio, and $L P F$ is the leakpath factor. For unmitigated cases, a value of unity is assumed for $L P F$. 


\section{Documented Safety Analysis for the Waste Storage Facilities}

The source term is then multiplied by the potential dose consequence for unit of radioactivity released to the environment yielded by the atmospheric diffusion analysis. For postulated accidents involving plume buoyancy, the atmospheric diffusion analysis was performed using the computational code MACCS2 (SAND97-0594) based on the site-specific meteorological data, conservative terrain conditions, and building dimensions to maximize the dose consequences. The analysis yielded dose consequences for a unit radioactive release as a function of distance and the plume sensible heat. MACCS2 was also used for postulated accidents not involving plume buoyancy.

Radiation dose consequences are the product of the source term and the dose to source term ratio. Dose consequences are expressed in total effective dose equivalent (TEDE), which consists of the effective dose (ED) for radiation exposure from external sources and the 50-year committed effective dose (CED) for radiation exposure from internal sources absorbed by inhalation and ingestion. Unmitigated and mitigated dose consequences are reported for the colocated worker (at $100 \mathrm{~m}$ ) and the maximally-exposed offsite individual (MOI) located at the nearest site boundary on Greenville Road. The potential consequences to the site facility workers were qualitatively evaluated in the hazard analysis in Section 3.3.

The accident analysis in this chapter has been simplified consistent with the graded approach. The following conservative and simplifying assumptions were used in the analysis:

- A leak-path factor (LPF) of unity is assumed for buildings. That is, the radioactive particulate entrained in the exhaust ventilation flow is not reduced even though the release that would occur from the buildings would result in reduction of the LPF by gravitational settling and agglomeration.

- The bounding ARF $\times$ RF (airborne release fraction $\times$ respirable fraction) from the DOE-HDBK-3010-94, "Airborne Release Fractions/Rates and Respirable Fractions for Non-Reactor Nuclear Facilities," is used for the postulated accidents for simplicity and conservatism. As an example, for burning of packaged contaminated waste, a combined value of $5 \times 10^{-4} \times 1$ is recommended as the bounding value for ARF $\times R F$ in DOE-HDBK-3010-94.

- Dose conversion factors (DCFs), whether in Federal Guidance Report (FGR) No. 11 (FGR 11) or International Commission on Radiological Protection (ICRP) 72 (ICRP 72), are based on a particle size distribution of $1 \mu \mathrm{m}$ AMAD (activity median aerodynamic diameter). The RF in DOE-HDBK-3010-94 is the portion of the airborne particulate with sizes less than $10 \mu \mathrm{m}$ AED (aerodynamic equivalent diameter).

MACCS2 uses inhalation DCFs in FGR 11. For $\mathrm{Pu}^{239}$, the CEDE DCF for inhalation class $\mathrm{Y}$, which is appropriate for the materials in the Waste Storage Facilities, is $3.08 \times 10^{8} \mathrm{rem} / \mathrm{Ci}$ in FGR 11. In comparison, the DCF in ICRP 71/72 (ICRP 71, ICRP 72) for Type S, equivalent to Class $Y$ in FGR 11 , is $1.6 \times 10^{-5} \mathrm{~Sv} / \mathrm{Bq}\left(5.9 \times 10^{7} \mathrm{rem} / \mathrm{Ci}\right)$ for $1 \mu \mathrm{m}$ AMAD. Data from ICRP 71/72 was issued by the U.S. EPA as Federal Guidance Report No. 13 (FGR 13) in September 1999. 


\section{Documented Safety Analysis for the Waste Storage Facilities}

The DCF is based on solubility of the chemical form of plutonium. Type $S$ in ICRP 72 (Solubility Class $Y$ in FGR 11) is assumed for all TRU waste scenarios since most of the contamination is expected to be plutonium oxide. Type M in ICRP 72 (Solubility Class W in FGR 11) is appropriate for nitrates or other soluble plutonium compounds, e.g., plutonium chloride, which have higher DCFs as discussed above. However, the amount of soluble plutonium contamination on most TRU wastes is expected to be minimal. Plutonium nitrate contamination from aqueous plutonium recovery processes is expected to oxidize over time from exposure to air; plutonium fluoride readily decomposes. Consequently, plutonium nitrate, plutonium chloride, and plutonium fluoride or other soluble plutonium compounds are not expected to be significant portions of the radioactive inventory.

Even if the particle size distribution is conservatively ignored, there is a reduction factor of 5.2 when ICRP 72 data are used for $\mathrm{Pu}^{239}$ relative to FGR 11. Based on the results from MACCS2 for $\mathrm{Pu}^{239}$, the estimated dose consequences are manually reduced by a factor of 5.2 in this analysis as a means to employ the DCFs in ICRP 72. There is a slight increase (factor of 1.04) when ICRP 72 data are used for tritium. Based on the results from MACCS2 for tritium, the estimated dose consequences are manually increased by a factor of 1.04 in this analysis as a means to employ the DCFs in ICRP 72. Based on the factors discussed, radiation dose consequences predicted in the accident analysis are conservative.

For the rare cases where $\mathrm{Am}^{241}$ may be loaded in drums, the dose conversion factors in ICRP 72, show that the predicted dose consequences from potential accidents involving $\mathrm{Am}^{241}$ would be nearly the same or lower than those involving $\mathrm{Pu}^{239}$. Therefore, no adjustment is needed to account for $\mathrm{Am}^{241}$. Based on the recent health physics data in ICRP 72, there would be no additional impact on the health and safety of the public and the workers from exposure to $\mathrm{Am}^{241}$.

In order to provide a bounding analysis, the MAR in each approved TRU waste container is assumed to be $50 \mathrm{PE}-\mathrm{Ci}$.

As described in Chapter 2, TRU waste may be staged and stored in a number of locations in the Waste Storage Facilities. Activities and operations occurring in the Waste Storage Facilities are sufficiently similar such that postulated accident scenarios do not change substantively based on the storage facility or staging location. B625 and B696R are the only buildings currently authorized for storing TRU waste. Although RHWM does not currently plan to store TRU waste at B693, B693 is the closest waste storage facility to the LLNL site boundary that is appropriate for storing TRU waste if authorized by the safety basis. In addition, approved TRU waste containers will not be staged less than $130 \mathrm{~m}$ from the LLNL site boundary (i.e., east of the B693 structure). As a result, dose consequences to the $\mathrm{MOI}$ from postulated accidents involving staged or stored containers occurring at B693 were found to bound those from other Waste Storage Facilities storing or staging TRU waste as shown in Tables 3-6 and 3-7. The accidents presented in Section 3.4.2 are, therefore, postulated to occur at B693 even though RHWM does not currently plan to store TRU waste in this building. 
Table 3-6. Dose Consequence Values from Ground Release of Non-Buoyant Plume

\begin{tabular}{|l|c|c|}
\hline \multicolumn{1}{|c|}{ Location } & $\begin{array}{c}\text { MOI Dose } \\
\text { (rem/PE-Ci) }\end{array}$ & $\begin{array}{c}\text { Co-located Worker Dose @100 m } \\
\text { (rem/PE-Ci) }\end{array}$ \\
\hline \hline B625 & 7.5 & 41 \\
\hline B693 & 22 & 41 \\
\hline B696R & 20 & 41 \\
\hline
\end{tabular}

From WM/FS-WSF-0402.

Table 3-7. Dose Consequence Values from Ground Release of Buoyant Plume

\begin{tabular}{|l|c|c|c|c|}
\hline \multicolumn{1}{|c|}{ Location } & \multicolumn{2}{c|}{$\begin{array}{c}\text { MOI Dose } \\
\text { (rem/PE-Ci) }\end{array}$} & \multicolumn{2}{c|}{$\begin{array}{c}\text { Co-located Worker Dose } \\
\text { @100 } \mathbf{~ m} \text { (rem/PE-Ci) }\end{array}$} \\
\hline \multicolumn{1}{|c|}{ Magnitude of Fire } & $\mathbf{9 ~ M W ~}^{\mathbf{a}}$ & $\mathbf{4 . 1} \mathbf{~ M W ~}^{\mathbf{b}}$ & $\mathbf{9 ~ M W ~}^{\mathbf{a}}$ & $\mathbf{4 . 1}^{\mathbf{~ M W}^{\mathbf{b}}}$ \\
\hline \hline B625 & 2.6 & 4.6 & 11 & 18 \\
\hline B693 & 3.9 & 6.6 & 5.8 & 10 \\
\hline B696R & 3.8 & 5.0 & 4.7 & 6.8 \\
\hline
\end{tabular}

a Data from HC/AB-B696-0203.

b Data from WM/FS-WSF-0404.

Dose consequences for co-located workers at $100 \mathrm{~m}$ for accident scenarios involving buoyant plumes are based on the bounding results from Table 3-7 (i.e., B625). The variation in the results for the $100 \mathrm{~m}$ data for buoyant plumes is due to the inclusion of building wake effects in the MACCS2 model, which is influenced by the plume sensible heat, building dimensions, and the meteorological condition. Non-buoyant plume dose consequence estimates for co-located workers at $100 \mathrm{~m}$ are independent of the location of the release since they are not impacted by building specific information.

\subsubsection{DESIGN BASIS ACCIDENTS}

The PrHA identified events with potential radiological consequences that require further analysis. The Accident Analysis requires a radiological analysis to determine the impact to the MOI.

This section analyzes design basis accidents to quantify consequences and compare them to the evaluation guideline. From the hazard analysis, six design basis accidents were identified as the bounding accidents requiring further evaluation in the accident analysis:

- A deflagration due to ignition of flammable gas in an unvented approved TRU waste container.

- A spill in the yard postulated to occur from a high-speed vehicle accident impacting pallets of staged approved TRU waste containers. The postulated spill in the yard bounds the inside the facility spill scenarios. 


\section{Documented Safety Analysis for the Waste Storage Facilities}

- A postulated fire involving spilled flammable liquid in the building resulting in failure of multiple approved TRU waste containers.

- A postulated fire involving spilled flammable liquid in the facility resulting in failure of containers containing tritium.

- A spill in the yard with subsequent fire postulated to occur from a high-speed vehicle accident impacting pallets of staged approved TRU waste containers.

- An aircraft crash into a TRU waste storage building causing a fire and resulting in failure of multiple approved TRU waste containers.

\subsubsection{Deflagration in Approved TRU Waste Container}

Container handling is a routine part of the operations in the Waste Storage Facilities. TRU waste is packaged in polyethylene bags and contained in approved TRU waste containers. A potential exists for the buildup of radiolytic hydrogen in sealed approved TRU waste containers.

Based on the results of the hazard analysis in Section 3.3, radiolytic hydrogen buildup and deflagration in approved TRU waste containers is identified as one of the scenarios to be analyzed in the accident analysis. Consequently, this section provides a bounding analysis of a deflagration scenario to ensure that the postulated event does not adversely impact the health and safety of the public and the workers.

\subsection{Scenario Development}

A deflagration of radiolytic hydrogen scenario can compromise the structural integrity of a drum and lead to an uncontrolled release of radioactive contaminant.

The duration to reach the lower flammability limit (LFL) of $4 \%$ hydrogen by volume is calculated as 1,480 hours assuming a $20 \%$ void space in a hermetically sealed 55 -gal drum containing $8 \mathrm{PE}-\mathrm{Ci}$ (HC/AB-B696-0202). Adjusting the equation in the referenced calculation to account for $50 \mathrm{PE}-\mathrm{Ci}$ drums, the duration to reach the LFL of $4 \%$ hydrogen by volume becomes approximately 237 hours. This is a conservative estimate because a larger container or a larger void space in a 55-gal drum would require a longer duration to reach the LFL. For a larger Standard Waste Box or a larger void volume in a 55-gal drum, the duration to reach LFL will increase linearly - again, only if the container is hermetically sealed. Based on the radioactive inventory in storage, and the required duration and conditions to reach LFL, the postulated radiolytic hydrogen deflagration involving a hydrogen concentration above LFL in one container with $50 \mathrm{PE}-\mathrm{Ci}$ is considered "unlikely" for unvented containers.

\subsection{Source Term Analysis}

The assumed container inventory of $50 \mathrm{PE}-\mathrm{Ci}$ is used as the MAR. The bounding airborne respirable fraction (ARF $\times R F$ ) of $1 \times 10^{-3} \times 1$ is recommended in Section 5.1 of DOE-HDBK-3010-94 for "venting of pressurized gases over contaminated, combustible waste." It is stated in the same section that ARF $\times$ RF of $1 \times 10^{-3} \times 1$ are "applicable only to the portion of waste surfaces that are actually exposed." 


\section{Documented Safety Analysis for the Waste Storage Facilities}

The potential combustion energy from a deflagration of a hydrogen-air mixture at LFL in the $20 \%$ void space is $20.2 \mathrm{~kJ}$ (19 Btu) (HC/AB-B696-0202). For a deflagration involving a stoichiometric hydrogen-air mixture $(29.6 \%$ by volume of hydrogen in air), there is no oxygen remaining in the drum to sustain combustion. At the stoichiometric concentration the potential combustion energy from a deflagration is $150 \mathrm{~kJ}$ (142 Btu). The temperature attained by an adiabatic heat transfer of the entire combustion energy, from a stoichiometric hydrogen-air mixture deflagration is not close to the exothermic pyrolytic decomposition temperature of $280^{\circ} \mathrm{C}$ the thermal degradation temperature of polyethylene.

There is a lower oxygen limit (LOL) of around $10 \%$ to $15 \%$, depending on the materials, below which flaming combustion cannot be sustained. This means that the oxygen concentration in the drum after the deflagration must be above the LOL for combustion of contaminated waste. For hydrogen, the LOL is theoretically $5 \%$ by volume. This is obtained by taking the upper flammability limit of $75 \%$ by volume for hydrogen and figuring the oxygen concentration at the UFL for hydrogen $(0.25 \times 0.21)$. For complex hydrocarbons, e.g., plastics and cellulosic materials, the LOL is on the high side, e.g., $15 \%$ by volume. Assuming $10 \%$ as the LOL for the contaminated combustibles and ignoring the thermal consideration discussed above, the maximum hydrogen concentration for even a possibility of an ensuing fire involving contaminated waste is theoretically $17 \%$ by volume. However, it was shown above that the thermal consideration at stoichiometry of $29.6 \%$ does not support further reaction.

There is a period of venting, an outward flow of gases, in an explosion whether it is from a building or from a container like a 55-gal drum. During this, albeit short, period, there is no inward flow of fresh air as dictated by the Bernoulli equation. Thus, a fire following a hydrogen deflagration is not postulated consistent with the physical limitation.

According to vendor data for Type A drums, the typical hydrostatic pressures at failure range from $170 \mathrm{kPa}$ (24 psig) to $250 \mathrm{kPa}$ (36 psig) (Yang 2002). The computed AICC (adiabatic, isochoric complete combustion) pressure from a deflagration of hydrogen at the lower flammability limit (LFL) is 23 psig (HC/AB-B696-0202). Actual pressure measurements indicated that the deflagration is less than $90 \%$ of the predicted AICC pressure at low hydrogen concentrations up to $15 \%$ by volume. Therefore, a hydrogen deflagration at LFL is not likely to compromise the integrity of a container. While not likely to fail at LFL, the postulated deflagration is conservatively assumed to lead to failure of drum integrity.

The likely location for accumulation of radiolytic hydrogen is at or near the top of a container because of buoyancy. The exposed surface of contaminated waste would thus be limited. Based on the provision in DOE-HDBK-3010-94 to apply "only to the portion of waste surfaces that are actually exposed," only a nominal portion of waste surfaces would be exposed directly to a deflagration pressure. As discussed above, drum failure is not likely for a deflagration involving low hydrogen concentrations; thus, a DR of 0.2 is used. A LPF of unity is used for unmitigated analysis. 
The source term is then:

$$
\begin{aligned}
S T & =50 P E-C i \times\left(1 \times 10^{-3}\right) \times 1 \times 0.2 \times 1 \\
& =1.0 \times 10^{-2} P E-C i
\end{aligned}
$$

The most probable mechanism by which a radioactive release can occur subsequently from the facility is by entrainment in the exhaust ventilation flow, although a value of unity must be assumed for the leakpath factor for the unmitigated scenario consistent with Appendix $A$ of DOE-STD-3009-94 (DOE 2006). Gravitational settling and agglomeration would reduce the actual value for the $L P F$.

\subsection{Consequence Analysis}

This analysis was performed assuming the release occurs at B693 in order to bound the dose consequence results (see Section 3.4.1). The dose consequence result from MACCS2 is $22.1 \mathrm{rem} / \mathrm{PE}-\mathrm{Ci}$ at the nearest site boundary from B693 (WM/FS-WSF-0402). The radiation dose consequence to the $\mathrm{MOI}$ is then:

$$
\begin{aligned}
\text { TEDE } & =1.0 \times 10^{-2} \mathrm{PE}-\mathrm{Ci} \times 22.1 \mathrm{rem} / \mathrm{PE}-\mathrm{Ci} \\
& =0.2 \mathrm{rem}
\end{aligned}
$$

For estimating the potential dose consequence to the co-located worker, the dose consequence result from MACCS2 at $100 \mathrm{~m}$ from the release is $40.6 \mathrm{rem} / \mathrm{PE}-\mathrm{Ci}$ (WM/FS-WSF-0402). The radiation dose consequence to the co-located worker is then:

$$
\begin{aligned}
T E D E & =1.0 \times 10^{-2} \mathrm{PE}-\mathrm{Ci} \times 40.6 \mathrm{rem} / \mathrm{PE}-\mathrm{Ci} \\
& =0.4 \mathrm{rem}
\end{aligned}
$$

If the leakpath factor is reduced to less than unity because of agglomeration and gravitational settling as discussed in Section 3.4.2.1.2, the source term would be reduced linearly. For example, a $L P F$ of 0.5 will reduce the source term to $5 \times 10^{-3} \mathrm{PE}-\mathrm{Ci}$. The potential offsite dose consequences would be reduced to approximately 0.1 rem.

For the type of postulated accidents, sufficient energy is not available to change the particle size distribution already present in the container. The analysis implicitly assumed that the entire radioactive inventory is respirable even though respirable particulate may be minimal.

The dose consequence from the postulated deflagration bounds that of a single drum spill, which is a contamination event. This confirms that a spill inside the facility is a contamination event that does not pose a significant impact on the health and safety of the public. 


\subsection{Comparison to Guideline}

The conservative estimate of the radiation dose consequences to the public was $0.2 \mathrm{rem}$. This is well below, and does not "challenge," the evaluation guideline of 25 rem discussed in Appendix A of DOE-STD-3009-94 (DOE 2006).

\subsection{Summary of Safety-Class SSCs and TSR Controls}

No safety class structure, system, or component is identified from the analysis to prevent or to mitigate the consequences of the postulated deflagration, which bounds those of a single drum spill. The analysis shows that the potential unmitigated consequences for the postulated deflagration are "low" for the public and the workers. The risk associated with this scenario is also "low" to the public and the workers.

Approved TRU waste containers provide the means to packaging contaminated waste for transport and handling and provide defense in depth in postulated accidents. In addition, an inventory of $50 \mathrm{PE}-\mathrm{Ci}$ per container was assumed in the analysis. Approved TRU waste containers and inventory limits are captured in the TSR to ensure that the conclusion of the analysis remains valid.

Vented approved TRU waste containers and the approved TRU waste container maintenance program provide defense in depth to prevent or to mitigate the consequences of the postulated deflagration in the Waste Storage Facilities.

\subsubsection{Spill of Approved TRU Waste Containers in Yard}

Before containers are transported into facilities for storage, they are typically staged in the yard. An individual container or multiple containers can be transported at one time. Although the volume of the vehicle traffic in the Waste Storage Facilities is small and the speed of the vehicles is limited both spatially and by the facility speed limit, there is a potential for a collision involving vehicles that are used to transport containers from other facilities.

Based on the results of the hazard analysis in Section 3.3, a spill of an array of drums involved in a vehicle accident is identified as one of the scenarios to be analyzed in the accident analysis. Consequently, a bounding analysis involving an array of drums is performed in this section to ensure that the health and safety of the public and the workers are not adversely impacted by the postulated spill. The analysis of an impact of an array of drums bounds a spill of drums that are being hauled by a vehicle (e.g., TRUPACT-II cask).

\subsection{Scenario Development}

A typical approved TRU waste container is capable of sustaining a 4-ft drop. A container falling from typical operating heights is not likely to lose structural integrity. The potential exists for a truck to collide with pallets of staged drums, breaching the integrity of the drums, and releasing radioactive material. 
Container spills caused by vehicle accidents are estimated to be "anticipated" for a minor spill and "unlikely" for a significant spill. This accident analysis evaluates the bounding consequences from a significant spill of $200 \mathrm{PE}-\mathrm{Ci}$.

An array limit of drums containing $200 \mathrm{PE}-\mathrm{Ci}$ is staged outside B693. The total inventory at risk is, thus, $200 \mathrm{PE}-\mathrm{Ci}$. A high-speed truck is postulated to impact the array of staged drums. Although each drum is capable of sustaining a 4-ft drop, it is assumed that one-third of their contents are expelled. The expelled drum content is assumed strewn in the yard.

\subsection{Source Term Analysis}

An array limit containing a total of $200 \mathrm{PE}-\mathrm{Ci}$ is used as the MAR. The bounding airborne respirable fraction (ARF $\times \mathrm{RF}$ ) of $1 \times 10^{-3} \times 0.1$ is recommended in Section 5.1 of DOE-HDBK-3010-94 for "the situation where the combustible material is packaged in a relatively robust container (e.g., hard pail, drum) that is opened or fails due to impact with the floor or impaction by falling debris (shock-vibration induced by impact)." This is the value assumed in computing the source term for the scenario.

Typical approved TRU waste containers are designed to withstand a 4-ft drop. Container mishandling from impact or drop is not likely to lead to an uncontrolled radioactive release. A $D R$ of one-third is assumed to bound conditions in which drums are impacted and breached from a vehicle collision. A LPF of 1 is used for unmitigated analysis.

The source term is then:

$$
\begin{aligned}
S T & =200 P E-C i \times\left(1 \times 10^{-3}\right) \times 0.1 \times 1 / 3 \times 1 \\
& =6.7 \times 10^{-3} P E-C i
\end{aligned}
$$

\subsection{Consequence Analysis}

This analysis was performed assuming the release occurs at B693. The dose consequence for unit of radioactivity released to the environment from MACCS2 is $22.1 \mathrm{rem} / \mathrm{PE}-\mathrm{Ci}$ at B693 (WM/FS-WSF-0402). The radiation dose consequence to the $\mathrm{MOI}$ is then:

$$
\begin{aligned}
T E D E & =\left(6.7 \times 10^{-3} \mathrm{PE}-\mathrm{Ci}\right) \times 22.1 \mathrm{rem} / \mathrm{PE}-\mathrm{Ci} \\
& =0.1 \mathrm{rem}
\end{aligned}
$$


For estimating the potential dose consequence to the co-located worker, the dose consequence result from MACCS2 at $100 \mathrm{~m}$ from the release is $40.6 \mathrm{rem} / \mathrm{PE}-\mathrm{Ci}$ (WM/FS-WSF-0402). The radiation dose consequence to the co-located worker is then:

$$
\begin{aligned}
T E D E & =\left(6.7 \times 10^{-3} \mathrm{PE}-\mathrm{Ci}\right) \times 40.6 \mathrm{rem} / \mathrm{PE}-\mathrm{Ci} \\
& =0.3 \mathrm{rem}
\end{aligned}
$$

The dose consequence from the postulated spill bounds that of a single or multiple drum spill in the building.

\subsection{Comparison to Guideline}

The conservative estimate of the radiation dose consequences to the public was 0.1 rem TEDE. This is well below, and does not "challenge," the evaluation guideline of 25 rem discussed in Appendix A of DOE-STD-3009-94 (DOE 2006).

\subsection{Summary of Safety-Class SSCs and TSR Controls}

No safety class structure, system, or component is identified from the analysis to prevent or to mitigate the consequences of the postulated spill. The accident analysis shows that the potential unmitigated consequences for these postulated spills is "low" for the public and the workers. The risk associated with these scenarios is also "low."

Approved TRU waste containers provide the means to packaging contaminated waste for transport and handling and provide defense in depth in postulated accidents. In addition, an array limit is assumed in the analysis. These are captured in the TSR to ensure that the conclusion of the analysis remains valid.

\subsubsection{Fire Involving Stored Approved TRU Waste Containers in Building}

Based on the results of the hazard analysis in Section 3.3, a compartment fire involving TRU waste is identified as one of the scenarios to be analyzed in the accident analysis.

Consequently, this section provides a bounding analysis of a compartment fire involving stored approved TRU waste containers to ensure that the postulated fire does not adversely impact the health and safety of the public and the workers. The fire is postulated to occur in the B693 Room 1014. B693 Room 1014 is the smallest compartment in the closest building to the fence line $(130 \mathrm{~m})$. The fire severity is the worst due to the small compartment size and the dose consequence results are bounding as discussed in Section 3.4.1.

The quantity of incidental flammable liquids present in the facility is substantially below the exempt quantities for the occupancy type of the facility. Although the quantities of transient flammable liquids and combustible materials are typically minimal in the Waste Storage Facilities, this scenario assumes a spill of $10 \mathrm{gal}$ of incidental flammable liquid in the facility for conservatism. A spill and subsequent fire with 10-gal of flammable liquid bounds the dose consequences resulting from a compartment fire in the Waste Storage Facilities. 


\section{Documented Safety Analysis for the Waste Storage Facilities}

\subsection{Scenario Development}

TRU waste drums containing $50 \mathrm{PE}-\mathrm{Ci}$ each are assumed to be stored in B693. This analysis assumes that TRU waste drums are double-stacked on 4-ft $\times 4$-ft pallets, and each pallet holds four drums. The postulated accident involves a spill of a transient flammable liquid brought into B693 for maintenance or other activities incidental to the storage of waste. For conservatism, the flammable liquid is assumed to be gasoline. Gasoline is a Class I flammable liquid with a low flashpoint and high vapor density. Due to its combustion characteristics, including a high heat of combustion and mass burning rate, the fire severity from a gasoline pool bounds that from other incidental flammable liquids brought into the facilities. An ignition source (such as a spark, electrical equipment short, or hot works) ignites the pool, resulting in a fire engulfing six TRU waste drums (based on a ratio of the area of the pool fire to the area occupied by the stored drums). An additional four TRU waste drums outside the fire exposed to the critical heat flux are also assumed impacted by the fire. The computed magnitude of the postulated fire is 4.1 MW (WM/FS-WSF-0404).

Based on the concurrent conditional probabilities of a spill of a transient flammable liquid, an available ignition source igniting the pool, and the resulting fire engulfing approved TRU waste containers all containing the maximum inventory, this accident scenario is considered "extremely unlikely."

\subsection{Source Term Analysis}

One of the six drums engulfed in the fire is assumed to fail catastrophically (i.e., lid loss). While significant content expulsion from catastrophic drum failure caused by the engulfing fire was not observed in the large-scale drum fire test (WHC-SD-WM-TRP-246), it is conservatively assumed that $50 \%$ of the contaminated waste in the catastrophically failed drum is expelled by the engulfing fire. The remaining $50 \%$ is assumed to burn contained in the failed drum. For the ejected contents from the drum, the bounding ARF $\times$ RF of $1 \times 10^{-2} \times 1$ from Section 5.1 of DOE-HDBK-3010-94 for "burning of unpackaged, loosely strewn cellulosic materials" is assumed. For the waste that burns in the drum, the bounding ARF $\times$ RF of $5 \times 10^{-4} \times 1$ from Section 5.1 of DOE-HDBK-3010-94 for "contaminated combustible materials heated/burned in packages with largely non-contaminated exterior surfaces (e.g., packaged in bags, compact piles, pails, drums)" is assumed.

The remaining five drums in the fire are assumed to fail by lid seal failure, resulting in contained burning of the contents with an ARF $\times$ RF of $5 \times 10^{-4} \times 1$. An additional four TRU waste drums outside the fire exposed to the critical heat flux of $45 \mathrm{~kW} / \mathrm{m}^{2}$ or greater are conservatively also assumed to fail by lid seal failure resulting in contained burning. A DR of 0.6 is assumed for contained burning of waste in the nine drums that fail by lid seal failure (HC/AB-B696-0302).

Each drum is assumed to contain 50 PE-Ci. A LPF of unity is used for unmitigated analysis. 
Although the effect of the postulated fire is not expected to be as severe on drums located away from the fire, the temperature effect was evaluated to ensure all aspects of the failure criteria are addressed. A dynamic fire analysis was performed in WM/FS-WSF-0404 to demonstrate that the peak smoke layer temperature in the compartment remains below $600^{\circ} \mathrm{C}$, the temperatures above which catastrophic failure (i.e., lid loss) was observed in the Westinghouse large-scale drum fire test.

B693 Room 1014 was modeled in the dynamic fire analysis since it has the smallest compartment size, and will therefore result in the worst fire severity as measured by the predicted smoke layer temperature. The predicted maximum temperature in the compartment was below $400^{\circ} \mathrm{C}$ (WM/FS-WSF-0404). The Westinghouse large-scale drum fire test showed that the drum temperature at failure was greater than $600^{\circ} \mathrm{C}$ and that flame impingement appeared to be the main cause for drum failure. Therefore, given the computed maximum temperature was less than $400^{\circ} \mathrm{C}$ in the compartment, failure of drums not in the fire or exposed to the critical heat flux is not predicted.

The source term resulting from the postulated fire is, therefore, computed as follows (WM/FS-WSF-0404):

$$
S T=\sum\left[\begin{array}{l}
1 \text { drums } \times 50 \mathrm{PE}-\mathrm{Ci} / \mathrm{drum} \times 1 \times 10^{-2} \times 0.5 \times 1 \\
1 \text { drums } \times 50 \mathrm{PE}-\mathrm{Ci} / \mathrm{drum} \times 5 \times 10^{-4} \times 0.5 \times 1 \\
9 \text { drums } \times 50 \mathrm{PE}-\mathrm{Ci} / \text { drum } \times 5 \times 10^{-4} \times 0.6 \times 1
\end{array}\right]=0.40 \mathrm{PE}-\mathrm{Ci}
$$

The source term developed for this scenario is independent of the TRU waste storage location, and will therefore be bounded by the dose consequence results from B693 as discussed in Section 3.4.1.

\subsection{Consequence Analysis}

Ten gallons of gasoline is assumed to spill and form a liquid pool with a resulting diameter of $1.5 \mathrm{~m}$ surrounding the drums. The computed peak heat release rate of the postulated fire is 4.1 MW resulting in a plume sensible heat of $1 \mathrm{MW}$ (WM/FS-WSF-0404).

The potential dose consequence for unit of radioactivity released to the environment with a plume sensible heat of $1 \mathrm{MW}$ is $6.6 \mathrm{rem} / \mathrm{PE}-\mathrm{Ci}$ at the nearest site boundary from B693 (WM/FSWSF-0404). The radiation dose consequence to the $\mathrm{MOI}$ is then:

$$
\begin{aligned}
T E D E & =0.40 \mathrm{PE}-\mathrm{Ci} \times 6.6 \mathrm{rem} / \mathrm{PE}-\mathrm{Ci} \\
& =2.6 \mathrm{rem}
\end{aligned}
$$




\section{Documented Safety Analysis for the Waste Storage Facilities}

For estimating the potential dose consequence to the co-located worker, the worst-case dose consequence for unit of radioactivity released to the environment from WM/FS-WSF-0404 was selected. The potential dose consequence for unit of radioactivity released to the environment is $17.8 \mathrm{rem} / \mathrm{PE}-\mathrm{Ci}$ at $100 \mathrm{~m}$ as shown in Table 3-7. The radiation dose consequence to the colocated worker is then:

$$
\begin{aligned}
T E D E & =0.40 \mathrm{PE}-\mathrm{Ci} \times 17.8 \mathrm{rem} / \mathrm{PE}-\mathrm{Ci} \\
& =7.1 \mathrm{rem}
\end{aligned}
$$

\subsection{Comparison to Guideline}

The conservative estimate of the radiation dose consequences to the public was $2.6 \mathrm{rem}$. This is well below, and does not "challenge," the evaluation guideline of 25 rem discussed in Appendix A of DOE-STD-3009-94 (DOE 2006).

\subsection{Summary of Safety-Class SSCs and TSR Controls}

No safety class structure, system, or component is identified from the analysis to prevent or to mitigate the consequences of the postulated fire. However, programmatic provisions in the fire protection program provide defense in depth to mitigate the consequences of the postulated fire in the Waste Storage Facilities.

Approved TRU waste containers provide the means to packaging contaminated waste for storage and provide defense in depth in postulated accidents. In addition, an inventory of 50 PE-Ci per container is assumed. Approved TRU waste containers and inventory limits are captured in the TSR to ensure that the conclusion of the analysis remains valid.

\subsubsection{Fire Involving Stored Tritium Containers in Building}

Based on the results of the hazard analysis in Section 3.3, a impacting tritium (either tritium waste or tritium items) with subsequent release of radioactive material was identified as a unique scenario to be analyzed in the accident analysis. Consequently, this section provides a bounding analysis of a compartment fire involving stored tritium to ensure that the postulated fire does not adversely impact the health and safety of the public and the workers. Although the tritium containers may be stored in the Waste Storage Facilities yard area, the fire is postulated to occur in the B693 Room 1014. B693 Room 1014 is the smallest compartment in the closest building to the fence line. The fire severity is the worst due to the small compartment size that results in a more conservative plume sensible heat. Therefore, the dose consequence results is bounding for scenarios in other rooms and in the Waste Storage Facilities yard area.

The quantity of incidental flammable liquids present in the facility is substantially below the exempt quantities for the occupancy type of the facility. Although the quantities of transient flammable liquids and combustible materials are typically minimal in the Waste Storage Facilities, this scenario assumes a spill of $10 \mathrm{gal}$ of incidental flammable liquid in the facility for conservatism. A spill and subsequent fire with 10-gal of flammable liquid bounds the dose consequences resulting from a fire in the Waste Storage Facilities. 


\subsection{Scenario Development}

Typically, less than ten tritium containers are stored in a contiguous array in the WSF. For this scenario, it is assumed that an array of ten adjacent tritium containers with 2,000 Ci each of $\mathrm{H}^{3}$ is stored in B693. B693 is 140 meters from the fenceline. The fire scenario in the building bounds an uncontained (i.e., yard) fire closer to the fence line, as the plume rise will be significantly greater in an outside fire. Although tritium may be stored in a variety of types of containers (e.g., drums, boxes, transportainers, etc.), this analysis assumes the tritium is contained in drums on pallets (the containers with the smallest footprint).

The postulated accident involves a spill of a transient flammable liquid brought into a facility storing tritium. For conservatism, the flammable liquid is assumed to be gasoline. Gasoline is a Class I flammable liquid with a low flashpoint and high vapor density. Due to its combustion characteristics, including a high heat of combustion and mass burning rate, the fire severity from a gasoline pool bounds that from other transient flammable liquids brought into the facilities. The peak heat release rate of the postulated fire is $4.1 \mathrm{MW}$ (WM/FS-WSF-0404). An ignition source (such as a spark, electrical equipment short, or hot works) ignites the pool, resulting in a fire. The resulting fire affects will encompass approximately six containers based on the area of the fire. However, for conservatism an entire array of ten adjacent containers is assumed to be involved the fire.

Based on the concurrent conditional probabilities of a spill of a transient flammable liquid, an available ignition source igniting the pool, and the resulting fire impacting an array of ten adjacent containers all containing the maximum inventory, this accident scenario is considered "unlikely."

All of the containers engulfed in the fire are assumed to fail catastrophically (i.e., rapid heating of all contents). Additional information about the dynamic fire analysis of the compartment fire is provided in Section 3.4.2.3.2.

\subsection{Source Term Analysis}

Each container is assumed to contain the maximum allowable radioactive material content of $2,000 \mathrm{Ci}$. Ten containers of either waste or the non-waste tritiated materials are assumed to be exposed to fire environment. All of the containers are assumed to fail catastrophically (DR of unity) releasing all of their contents as tritiated water $\left(\mathrm{HTO}\right.$ or $\left.\mathrm{T}_{2} \mathrm{O}\right)$. A bounding $A R F \times R F$ of 1.0 from Section 2.2 of DOE-HDBK-3010-94 for "vapors (condensable gases)" is assumed. A LPF of unity is used for unmitigated analysis.

The source term resulting from the postulated fire is computed as follows:

$$
\mathrm{ST}=10 \text { container } \times 2,000 \mathrm{Ci} / \text { container } \times 1 \times 1 \times 1=20,000 \mathrm{Ci}
$$




\subsection{Consequence Analysis}

Ten gallons of gasoline is assumed to spill and form a liquid pool with a resulting diameter of $1.5 \mathrm{~m}$ surrounding the drums. The computed magnitude of the postulated fire is $4.1 \mathrm{MW}$ resulting in a plume sensible heat of $1 \mathrm{MW}$ when the fuel pool is ignited (WM/FS-WSF-0404).

This analysis was performed assuming the release occurs at B693 in order to bound the dose consequence results (see Section 3.4.1). As shown in calculation WM/FS-WSF-0401, the potential dose consequence for unit of radioactivity released from $\mathrm{B} 693$ to the fence line environment for a plume sensible heat of $1 \mathrm{MW}$ is $1.24 \times 10^{-5} \mathrm{rem} / \mathrm{Ci}$. (Note: calculation WM/FSWSF-0401 takes into consideration adjustment factors for dermal adsorption and for converting FGR 11 dose conversion factors into FGR 13 dose conversion factors.)

The predicted radiation dose consequence to the $\mathrm{MOI}$ from tritium is then:

$$
T E D E=20,000 \mathrm{Ci} \times 1.24 \times 10^{-5} \mathrm{rem} / \mathrm{Ci}=0.25 \mathrm{rem}
$$

The estimation of the potential dose consequence to the co-located worker 100 meters away is similar to the estimation of the potential dose to the MOI described above. As shown in calculation WM/FS-WSF-0401, the potential dose consequence for a unit of radioactivity released to the co-located worker 100 meters away for a plume sensible heat of $1 \mathrm{MW}$ is $1.65 \times 10^{-5} \mathrm{rem} / \mathrm{Ci}$. (Note: calculation WM/FS-WSF-0401 takes into consideration adjustment factors for dermal adsorption and for converting FGR 11 dose conversion factors into FGR 13 dose conversion factors.),

The predicted radiation dose consequence to the co-located worker from tritium is then:

$$
T E D E=20,000 \mathrm{Ci} \times 1.65 \times 10^{-5} \mathrm{rem} / \mathrm{Ci}=0.33 \mathrm{rem}
$$

\subsection{Comparison to Guideline}

The conservative estimate of the tritium radiation dose consequences to the public was $0.25 \mathrm{rem}$. This is well below, and does not "challenge," the evaluation guideline of $25 \mathrm{rem}$ discussed in Appendix A of DOE-STD-3009-94 (DOE 2006).

\subsection{Summary of Safety-Class SSCs and TSR Controls}

No safety class structure, system, or component is identified from the analysis to prevent or to mitigate the consequences of the postulated fire. However, programmatic provisions in the fire protection program provide defense in depth to mitigate the consequences of the postulated large fire in the Waste Storage Facilities.

The inventory limit of 2,000 tritium $\mathrm{Ci}$ per container is assumed. This is captured in the TSR to ensure that the conclusion of the analysis remains valid. 


\section{Documented Safety Analysis for the Waste Storage Facilities}

\subsubsection{A Large Fire involving Staged Approved TRU Waste Containers in Yard}

Before containers are transported into facilities for storage, they are typically staged in the yard. An individual container or multiple containers, for instance, a pallet of drums, can be transported at one time. Although the volume of vehicle traffic in the Waste Storage Facilities is small and the speed of the vehicles is limited both spatially and by the facility speed limit, there is a potential for a collision involving vehicles that are used to transport containers from other facilities.

Based on the results of the hazard analysis in Section 3.3, an array of drums involved in a vehicle accident with a fire involving the fuel from a truck is identified as one of the riskdominant scenarios analyzed in the accident analysis. Consequently, this section provides a bounding analysis involving the staged drums to ensure that the postulated fire does not adversely impact the health and safety of the public and the workers.

A parametric analysis on the size of the fire, which determines the plume buoyancy, and on the distance to the site boundary was performed assuming conservative diffusion parameters using MACCS2 (HC/AB-B696-0203).

\subsection{Scenario Development}

An array of drums containing $200 \mathrm{PE}-\mathrm{Ci}$ is staged outside B693. The total inventory at risk is, thus, $200 \mathrm{PE}-\mathrm{Ci}$ in one array. A high-speed truck is postulated to impact the array of staged drums. Of the staged drums in the array, one third of the drums is assumed directly impacted by the truck and assumed to lose their structural integrity from the impact, even though each drum is capable of sustaining a 4-ft drop. The content of the impacted drums is assumed to be strewn in the yard. Further, ten gallons of diesel fuel in the tank leak to form a fuel pool with a diameter of $8.9 \mathrm{ft}$ surrounding the drums and the scattered uncontained contaminated waste from the impacted drums. The fuel pool is subsequently ignited into a fire that engulfs the remaining drums and the scattered content of the impact-breached drums. The computed magnitude of the postulated fire was $8.9 \mathrm{MW}$ lasting 140 seconds (HC/AB-B696-0203).

Based on the population of approved TRU waste containers and on-going activities in other facilities at LLNL, staging an array of containers totaling 200 PE-Ci is considered "anticipated" to "unlikely." A collision with a vehicle that is out of control resulting in significant damage to the containers is considered "unlikely." The concurrent conditional probabilities of a spill of fuel from the vehicle resulting in a large fuel pool, an available ignition source igniting the pool, and the resulting fire engulfing approved TRU waste containers all containing the maximum inventory, this accident scenario is considered "extremely unlikely."

\subsection{Source Term Analysis}

The array limit of $200 \mathrm{PE}-\mathrm{Ci}$ is used as the MAR. The bounding airborne respirable fraction $(A R F \times R F)$ of $5 \times 10^{-4} \times 1$ from Section 5.1 of DOE-HDBK-3010-94 for "contaminated combustible materials heated/burned in packages with largely non-contaminated exterior surfaces (e.g., packaged in bags, compact piles, pails, drums)," is assumed in computing the source term for the waste that burns in the containers. 
For the scattered content of breached drums, the bounding ARF $\times$ RF of $1 \times 10^{-2} \times 1$ from Section 5.1 of DOE-HDBK-3010-94 for "uncontained cellulosics or largely cellulosic mixed waste" is assumed. The summary of assumptions in the analysis is as follows:

- The total inventory at risk in the array is $200 \mathrm{PE}-\mathrm{Ci}$

- One third of the contaminated waste is expelled upon impact and burns on the ground $(D R=1 / 3)$

- The two-thirds remaining in containers burns as packaged waste $(D R=2 / 3)$

A LPF of 1 is used for unmitigated analysis. The source term is a combination of releases from uncontained burning and burning packaged waste, as follows:

$$
\begin{aligned}
S T & =\sum\left[\begin{array}{l}
200 \mathrm{PE}-\mathrm{Ci} \times\left(1 \times 10^{-2}\right) \times 1 \times 1 / 3 \times 1 \\
200 \mathrm{PE}-\mathrm{Ci} \times\left(5 \times 10^{-4}\right) \times 1 \times 2 / 3 \times 1
\end{array}\right] \\
& =7.3 \times 10^{-1} \mathrm{PE}-\mathrm{Ci}
\end{aligned}
$$

\subsection{Consequence Analysis}

Ten gallons of diesel fuel is assumed to spill from the truck fuel tank and form a fuel pool with a resulting diameter of $8.9 \mathrm{ft}$ surrounding the drums and the scattered uncontained contaminated waste from the impacted drums. The computed magnitude of the postulated fire is $8.9 \mathrm{MW}$ lasting 140 seconds (HC/AB-B696-0203) resulting in a plume sensible heat of $5 \mathrm{MW}$ when the fuel pool is ignited.

This analysis was performed assuming the release occurs at B693. The potential dose consequence for unit of radioactivity released to the environment from MACCS2 for a plume sensible heat of $5 \mathrm{MW}$ is $3.9 \mathrm{rem} / \mathrm{PE}-\mathrm{Ci}$ at the nearest site boundary from B693 as shown in Table 3-7. The radiation dose consequence to the $\mathrm{MOI}$ is then:

$$
\begin{aligned}
T E D E & =7.3 \times 10^{-1} \mathrm{PE}-\mathrm{Ci} \times 3.9 \mathrm{rem} / \mathrm{PE}-\mathrm{Ci} \\
& =2.8 \mathrm{rem}
\end{aligned}
$$

For estimating the potential dose consequence to the co-located worker, the worst-case dose consequence for unit of radioactivity released to the environment from HC/AB-B696-0203 was selected. The potential dose consequence for unit of radioactivity released to the environment is $11 \mathrm{rem} / \mathrm{PE}-\mathrm{Ci}$ at $100 \mathrm{~m}$ as shown in Table 3-7. The radiation dose consequence to the colocated worker at $100 \mathrm{~m}$ is then:

$$
\begin{aligned}
T E D E & =7.3 \times 10^{-1} \mathrm{PE}-\mathrm{Ci} \times 11 \mathrm{rem} / \mathrm{PE}-\mathrm{Ci} \\
& =8.0 \mathrm{rem}
\end{aligned}
$$




\subsection{Comparison to Guideline}

The conservative estimate of the radiation dose consequences to the public was $2.8 \mathrm{rem}$. This is well below, and does not "challenge," the evaluation guideline of 25 rem discussed in Appendix A of DOE-STD-3009-94 (DOE 2006).

\subsection{Summary of Safety-Class SSCs and TSR Controls}

No safety class structure, system, or component is identified from the analysis to prevent or to mitigate the consequences of the postulated fire. However, programmatic provisions in the fire protection program and traffic controls to limit the potential for collisions provide defense in depth to mitigate the consequences of the postulated fire in the yard.

Approved TRU waste containers provide the means to packaging contaminated waste for storage, transport, and handling and provide defense in depth in postulated accidents. In addition, the inventory limit of 200 PE-Ci per array staged in the yard is assumed. These are captured in the TSR to ensure that the conclusion of the analysis remains valid.

\subsubsection{Airplane Crash with Fire In a TRU Waste Storage Building}

Based on the results of the aircraft crash frequency analysis in Appendix $B$, the hazard analysis in Section 3.3 identified a general aviation aircraft crashing into B625 resulting in an uncontrolled radioactive release as one of the scenarios to be analyzed in the accident analysis. Consequently, this section provides a bounding analysis for the stored approved TRU waste containers to ensure that the postulated spill and ensuing fire does not adversely impact the health and safety of the public.

\subsection{Scenario Development}

A general aviation aircraft with a single reciprocating engine carrying a full tank of gasoline is postulated to crash into B625. The direct impact leads to penetration of the engine through the wall or the roof and crushes four TRU waste drums. The crash is postulated to be followed by an 18.4-MW fire involving gasoline spilled from the aircraft (HC/AB-B696-0302). This leads to additional failure of drums from the engulfing fire in the building.

This analysis assumes that TRU waste drums are double-stacked on 4 - $\mathrm{ft} \times 4$ - $\mathrm{ft}$ pallets, each pallet holds four drums, and there is a 30 -in separation between aisles of stacked drums.

\subsection{Source Term Analysis}

The other accident analyses in this DSA assume an individual TRU waste drum inventory of 50 PE-Ci. However, the specific administrative control stipulating that limit in sections 4.5.1.1 and 5.5.1 also states that drum loading and configuration shall be controlled to remain consistent with NEPA bounding consequence calculations. Both of these limits are initial conditions of analysis, and an airplane crash is the one scenario specifically analyzed and constrained by the NEPA bounding consequence calculation. 
The material at risk for this scenario is derived from the bounding source term calculated in NEPA documentation. For B625, that source term is 1.4 PE-Ci (0.925 PE-Ci for B696R). The spectrum of potential drum loadings and configurations are therefore constrained so that the source term calculation does not exceed 1.4 PE-Ci.

The computational model used to assess against the 1.4 PE-Ci source term is defined in HC/AB-B696-0302. For the scenario postulating a fire ensuing the aircraft crash, a total of 25 drums are assumed engulfed in the postulated gasoline pool fire. Drums are assumed to fail through three mechanisms: direct impact from the aircraft engine, lid loss caused by the engulfing fire, and lid seal failure caused by the engulfing fire and exposure to a critical heat flux from the fire. The breakdown is as follows:

- Dimensions of a general aviation aircraft engine are approximately 36 in by $20 \mathrm{in}$. It is assumed that the initial direct impact leads to penetration through the structure of B625 and catastrophic failure of a total of four drums. The entire contents of these drums burn with an ARF $\times$ RF of $1 \times 10^{-2}$, the bounding ARF assigned in DOE HDBK-3010-94 for combustion of unpackaged waste.

- $\quad$ Five of the drums engulfed in the fire are assumed to fail by lid loss. While significant content expulsion due to this failure mechanism was not observed in the large-scale drum fire test (WHC-SD-WM-TRP-246), it is conservatively assumed that $50 \%$ of the contaminated waste in these failed drums is expelled by the engulfing fire and burns with an ARF $\times$ RF of $1 \times 10^{-2}$. The remaining $50 \%$ is assumed to burn contained in the failed drums with an ARF $\times$ RF of $5 \times 10^{-4}$.

- The remaining 16 drums in the fire are assumed to fail by lid seal failure, resulting in contained burning of portions of their contents with an ARF $\times$ RF of $5 \times 10^{-4}$.

- The fire impacts an additional 20 TRU waste drums outside the fire that are exposed to the critical heat flux. These drums are also assumed to fail by lid seal failure and have subsequent burning of portions of their contents with an ARF $\times \operatorname{RF}$ of $5 \times 10^{-4}$. A damage ratio of 0.6 is conservatively assumed for the drums that fail by lid seal failure.

The source term is computed as follows:

$$
S T=\sum\left[\begin{array}{c}
4 \text { drums } \times 18 \text { PE }-\mathrm{Ci} / \mathrm{drum}^{\times} \times 1 \times 10^{-2} \times 1 \times 1 \\
5 \text { drums } \times 18 \mathrm{PE}-\mathrm{Ci} / \mathrm{drum} \times 1 \times 10^{-2} \times 0.5 \times 1 \\
5 \text { drums } \times 18 \mathrm{PE}-\mathrm{Ci} / \mathrm{drum}^{\times} \times 5 \times 10^{-4} \times 0.5 \times 1 \\
36 \text { drums } \times 18 \mathrm{PE}-\mathrm{Ci} / \text { drum } \times 5 \times 10^{-4} \times 0.6 \times 1
\end{array}\right]=1.39 \mathrm{PE}-\mathrm{Ci}
$$


Note that this reference calculation assumes all drums are equally loaded at $18 \mathrm{PE}-\mathrm{Ci}$. However, individual drum loadings are variable based on the overall loading of any 45 contiguous drums (per the spacing defined in Section 3.4.2.6.1). As the individual loading of some drums goes down, the individual loading of other drums may go up. For example, if the loading of forty-one drums is only $1 \mathrm{PE}-\mathrm{Ci}$ each, the bounding four drums assumed to be impacted by the engine may be loaded to $33.5 \mathrm{PE}-\mathrm{Ci}$ each:

$$
S T=\sum\left[\begin{array}{c}
4 \text { drums } \times 33.5 \mathrm{PE}-\mathrm{Ci} / \mathrm{drum} \times 1 \times 10^{-2} \times 1 \times 1 \\
5 \text { drums } \times 1 \mathrm{PE}-\mathrm{Ci} / \text { drum } \times 1 \times 10^{-2} \times 0.5 \times 1 \\
5 \text { drums } \times 1 \mathrm{PE}-\mathrm{Ci} / \mathrm{drum} \times 5 \times 10^{-4} \times 0.5 \times 1 \\
36 \text { drums } \times 1 \mathrm{PE}-\mathrm{Ci} / \text { drum } \times 5 \times 10^{-4} \times 0.6 \times 1
\end{array}\right]=1.38 \mathrm{PE}-\mathrm{Ci}
$$

Per the above computational model, controlled positioning of drums may also be used to limit the number of high Curie content drums subject to the most severe accident stress. That remains consistent with the TSR specification that "drum loading and configuration shall be administratively controlled to remain consistent with the National Environmental Policy Act (NEPA) bounding consequences."

For a spill only scenario, the source term would be estimated assuming failure of four drums containing $50 \mathrm{PE}-\mathrm{Ci}$ each and utilizing the bounding impact ARF $\times \mathrm{RF}$ of $1 \times 10^{-3} \times 0.1$. The source term for the spill scenario is thus $0.02 \mathrm{PE}-\mathrm{Ci}$, which is far below the bounding NEPA source term.

\subsection{Consequence Analysis}

The potential dose consequence for unit of radioactivity released to the environment for an 18.4MW fire is $2.8 \mathrm{rem} / \mathrm{PE}-\mathrm{Ci}$ at the nearest site boundary from B625 (WM/FS-WSF-0403). The contribution to the plume buoyancy from burning of the contaminated waste is minimal and is ignored for conservatism in this analysis. The radiation dose consequence to the $\mathrm{MOI}$ is then:

$$
T E D E=1.39 \mathrm{PE} \mathrm{Ci} \times 2.8 \mathrm{rem} / \mathrm{PE} \mathrm{Ci}=3.9 \mathrm{rem}
$$

In estimating the potential dose consequence to the co-located worker, the maximum fire magnitude for unit of radioactivity released to the environment from HC/AB-B696-0203 was selected from Table 3-8. The potential dose consequence for unit of radioactivity released to the environment during a $9 \mathrm{MW}$ fire at $\mathrm{B} 625$ is $11 \mathrm{rem} / \mathrm{PE}-\mathrm{Ci}$ at $100 \mathrm{~m}$. The radiation dose consequence to the co-located worker at $100 \mathrm{~m}$ is then:

$$
\begin{aligned}
T E D E & =1.39 \mathrm{PE}-\mathrm{Ci} \times 11 \mathrm{rem} / \mathrm{PE}-\mathrm{Ci} \\
& =15.3 \mathrm{rem}
\end{aligned}
$$




\section{Documented Safety Analysis for the Waste Storage Facilities}

\subsection{Comparison to Guideline}

The conservative estimate of the radiation dose consequences to the public was $3.9 \mathrm{rem}$. This is well below, and does not "challenge," the evaluation guideline of 25 rem discussed in Appendix A of DOE-STD-3009-94 (DOE 2006).

\subsection{Summary of Safety-Class SSCs and TSR Controls}

No safety class structure, system, or component is identified from the analysis to prevent or to mitigate the consequences of the postulated air craft crash. No controls are considered necessary even if the consequences were to approach the Evaluation Guideline. This event is only marginally credible, physically cannot be mitigated if non-trivial quantities of TRU waste must be stored, and does not yield an overall dose risk that merits additional mitigation.

\subsubsection{BEYOND DESIGN BASIS ACCIDENTS}

The evaluation of accidents beyond the design basis (BDB) are required in DOE-STD-3009-94 (DOE 2006) to provide a perspective of the residual risk associated with the operation of the facility. These postulated events serve as bases for cost-benefit considerations if consequences exceeding Evaluation Guidelines are identified in the beyond DBA range. However, such costbenefit analysis would be performed outside the DSA with the concurrence of DOE. Two beyond design basis events are identified to provide a perspective of the residual risk associated with operation of the facility. This section provides a qualitative evaluation to obtain insight into the magnitude of consequences of beyond design basis accidents (i.e., provide perspective on potential facility vulnerabilities). These are beyond design basis wind, and a beyond design basis earthquake.

Operational beyond design basis accidents are not considered further in this section because the postulated events analyzed in Section 3.4.2 did not require any provisions to mitigate the consequences.

\subsubsection{Winds}

The consequences of BDB winds could include damage to the facility, typically short of facility collapse, resulting in direct damage to waste containers, and indirect damage to waste containers through the generation of missiles. TRU waste storage is limited to PC-2 buildings. Collapse of non-PC-2 facilities is evaluated in the PrHA. The consequences are bounded by the consequences for other scenarios identified in the PrHA. For operational accidents, analyses are performed using the $95^{\text {th }}$ percentile of the distribution of doses to the MOI. Meteorological conditions for the beyond design basis wind would likely occur at conditions other than those used in the analysis. The difference in X/Q between, for example, Stability Class $D$ with a wind speed of $72 \mathrm{mph}(32 \mathrm{~m} / \mathrm{s}$ ) - the design basis wind speed, and that used in the analysis is approximately a factor of 10 . In addition, the rubble covering the breached containers will reduce the ARF. Therefore, even if a pallet of approved TRU waste containers are breached by the beyond design basis wind, the consequences would be bounded by the operational spill scenarios and the Evaluation Guideline of 25 rem in Appendix A of DOE-STD-3009-94 (DOE 2006) is not challenged. 


\subsubsection{Earthquake}

The frequency of a beyond design basis earthquake is "unlikely" with a return period greater than 1,000 years. The consequences of a beyond DBE could range from minor damage to the structure to the complete collapse of the facility. Damage to the facility, excluding complete collapse, could result in damage to some waste containers inside the building that could result in consequences greater than that estimated for the design basis earthquake. Thus, complete collapse of the facility could result in consequences that challenge the Evaluation Guide of 25 rem in Appendix A of DOE-STD-3009-94 (DOE 2006).

\subsection{REFERENCES}

10CFR830, Code of Federal Regulations, Title 10, Energy, Part 830, "Nuclear Safety Management," Subpart B, "Safety Basis Requirements." Office of the Federal Register, Washington, D.C. (10 CFR 830).

10CFR835, Code of Federal Regulations, Title 10, Energy, Part 835, "Occupational Radiation Protection." Office of the Federal Register, Washington, D.C. (10 CFR 835).

29CFR1910, Code of Federal Regulations, Title 29, Labor, Part 1910.120, "Hazardous Waste Operations and Emergency Response," Appendix A, "List of Highly Hazardous Chemicals, Toxics, and Reactives." Office of the Federal Register, Washington, DC. (29 CFR 1910.119).

DOE (1994), Airborne Release Fractions/Rates and Respirable Fractions for Nonreactor Nuclear Facilities, DOE-HDBK-3010-94, U.S. Department of Energy, Washington, DC (December 1994).

DOE (1996a), Natural Phenomena Hazards Design and Evaluation Criteria for Department of Energy Facilities, DOE-STD-1020-94, Change Notice 1, U.S. Department of Energy, Washington, DC (January 1996).

DOE (1996b), Accident Analysis for Aircraft Crash into Hazardous Facilities, DOE-STD-301496, U.S. Department of Energy, Washington, DC (October 1996).

DOE (1997), Hazard Categorization and Accident Analysis Techniques for Compliance with DOE Order 5480.23, Nuclear Safety Analysis Reports, DOE-STD-1027-92, Change Notice 1, U.S. Department of Energy, Washington, DC (September 1997).

DOE (2006), Preparation Guide for U.S. Department of Energy Nonreactor Nuclear Facility Safety Analysis Reports, DOE-STD-3009-94, Change Notice 3, U.S. Department of Energy, Washington, DC (March 2006).

DOE (2009), http://www.hss.energy.gov/HealthSafety/WSHP/chem safety/teel.html, U.S. Department of Energy, Washington, DC (August 2009).

FGR 11, "Limiting Values of Radionuclide Intake and Air Concentration and Dose Conversion Factors for Inhalation, Submersion, and Ingestion," Federal Guidance Report No. 11, EPA 520/1-88-020, U.S. Environmental Protection Agency, September 1988. 


\section{Documented Safety Analysis for the Waste Storage Facilities}

FGR 13, "Cancer Risk Coefficients for Environmental Exposure to Radionuclides," Federal Guidance Report No. 13, EPA 402-R-99-001, CD Supplement, U.S. Environmental Protection Agency, September 1999.

HC/AB-B696-0202, “Radiolytic Hydrogen Deflagration," Joong M. Yang, Lawrence Livermore National Laboratory, Livermore, CA, June 2002.

HC/AB-B696-0203, "WMD Dose Consequence Analysis," Joong M. Yang, Lawrence Livermore National Laboratory, Livermore, CA, October 2002.

HC/AB-B696-0302, "Aircraft Crash Consequence Analysis," Joong M. Yang, Lawrence Livermore National Laboratory, Livermore, CA, May 2003.

ICRP 71/72, "Age-Dependent Doses to Members of the Public from Intake of Radionuclides," International Commission on Radiological Protection, 1996.

Lin, A. (1998), Flood Study for the Decontamination and Waste Treatment Facility, Parsons Infrastructure and Technology Group, Inc., May 3, 1998.

LLNL (latest revision). Environment, Safety, and Health Manual. Lawrence Livermore National Laboratory, Livermore, CA (UCRL-MA-133867).

LLNL (2006a), NMTP-06-089, Letter from Martinez to Yuan-Soo Hoo, Request for Change to the B332 Authorization Basis to Allow Deployment of Mobile Weapons Platform, dated July 14, 2006.

LLNL (2006b), Memo from Thom Kato to Jack Sims, "Modification to Individual Container Limits for Radioactive Waste Storage at Building 625 (B625)," Lawrence Livermore National Laboratory, Livermore, CA, July 10, 2006.

LLNL (2009a). Environment, Safety, and Health Manual. Document 3.1, "Nonnuclear Safety Basis Program," Lawrence Livermore National Laboratory, Livermore, CA (UCRL-AM133867). September 9, 2009.

LLNL (2009b), Documented Safety Analysis for the B695 Segment, Lawrence Livermore National Laboratory, Livermore, CA (UCRL-AR-407067).

LSO (2009), letter from Phillip E. Hill to Bruce T. Goodwin, "Approval of the Revised Safety Basis Amendment for Deployment of Mobile Weapons Platforms," NNSA Livermore Site Office, Livermore, CA, April 15, 2009.

Majumdar (2001), Building 231 Vault (B 231) Flood Hazard Analysis, Lawrence Livermore National Laboratory, Livermore, CA, UCRL-ID-146099, September 28, 2001.

Nelson (2003), Memo from Bob Nelson, Safety Basis Special Project Team, to Jorge Ferrer, et al., "Nuclear Safety Risk Ranking and Control Selection Guidelines," February 7, 2003.

NFPA (1997), Fire Protection Handbook, 18th Edition, National Fire Protection Association, Quincy, MA, 1997.

NNSA/LLNS (2009), Management and Operating Contract between The US Department of Energy/National Nuclear Security Administration and Lawrence Livermore National Security, No. DE-AC52-07NA27344, February 27, 2009. 
SAND97-0594, "Code Manual for MACCS2," Sandia National Laboratory, March 1997.

SFPE (1995), The SFPE Handbook of Fire Protection Engineering, $2^{\text {nd }}$ Edition, National Fire Protection Association, Quincy, Massachusetts, 1995.

WHC-SD-WM-TRP-246, "Solid Waste Drum Array Fire Performance," Rev. 0, Westinghouse Hanford Company, 1995.

WM/FS-WSF-0401, "Dose Consequence from Tritium Release," D. Crawford, Lawrence Livermore National Laboratory, Livermore, CA, February 2004.

WM/FS-WSF-0402, "Non-Buoyant Dose Consequence Analysis," R. Mailhot, Lawrence Livermore National Laboratory, Livermore, CA, February 2004.

WM/FS-WSF-0403, "Aircraft Crash Dose Consequence Analysis," R. Mailhot, Lawrence Livermore National Laboratory, Livermore, CA, February 2004.

WM/FS-WSF-0404, "Compartment Fire Dose Consequence Analysis," H. Larson, Lawrence Livermore National Laboratory, Livermore, CA, February 2004.

Yang (2002), E-Mail to Jack Sims, telephone conversation between Sean Reynolds of Myers and Joong M. Yang of LLNL, May 2002. 
This page intentionally left blank. 


\section{CHAPTER 4 \\ SAFETY STRUCTURES, SYSTEMS, AND COMPONENTS}

\subsection{INTRODUCTION}

This chapter provides details on those structures, systems, and components (SSCs) that were classified as safety-significant as a result of the hazard analysis in Chapter 3 . The structure and content of this chapter follow the outline provided in Chapter 4 of DOE-STD-3009-94, Change Notice 3 (DOE 2006). It establishes the adequacy of the controls by providing for each SSC, (1) its safety function(s) (as assumed in Chapter 3), (2) its functional requirements to support the safety function(s), (3) an evaluation with respect to its functional requirements, and (4) a brief description of the assumptions requiring control by TSR.

The following SSCs were identified in Chapter 3 as being the most significant to defense in depth and, hence, were designated safety-significant SSCs:

- $\quad$ Approved TRU waste containers

- B625 and B696R structural systems

- B696S/B696R partition

These SSCs are passive features that serve as initial conditions for many events evaluated by the PrHA. Their safety functions contribute substantially to the prevention or mitigation of the bounding accident scenarios evaluated in the accident analysis, provide important defense-indepth, or provide for worker safety in potentially life-threatening or disabling situations.

This chapter also provides the safety function(s), functional requirements, evaluation with respect to functional requirements, and a brief description of the assumptions requiring control by TSR for each of the Specific Administrative Controls (SACs).

\subsection{REQUIREMENTS}

This section contains the directives in effect as of February 2009 as implemented in the Lawrence Livermore National Security, LLC, Contract No. DE-AC52-07NA27344 (NNSA/LLNS 2009). Specific sections of these directives are relevant to the content of this chapter. This section also contains the codes, standards, regulations, and DOE orders specific to this chapter and required to establish the safety basis of the facility.

DOE Order 420.1B, Facility Safety (\$4.4 through 4.4.6 only) (DOE 2005a)

DOE-STD-1020-94, Change Notice 1, Natural Phenomena Hazard Design and Evaluation Criteria for Department of Energy Facilities (DOE 1996)

DOE-STD-1020-2002, Natural Phenomena Hazard Design and Evaluation Criteria for Department of Energy Facilities (DOE 2002b) 
DOE-STD-1186-2004, Specific Administrative Controls (DOE 2004)

DOE-STD-3009-94, Change Notice 3, Preparation Guide for U.S. Department of Energy Nonreactor Nuclear Facility Safety Analysis (DOE 2006)

49CFR173.465, Code of Federal Regulations, Title 49, Transportation, Part 173.465, "Type A Packaging Tests."

\subsection{SAFETY-CLASS STRUCTURES, SYSTEMS, AND COMPONENTS}

No safety-class SSCs were identified in the accident analysis in Chapter 3 for the Waste Storage Facilities. The accident analysis results did not challenge the Evaluation Guideline.

\subsection{SAFETY-SIGNIFICANT STRUCTURES, SYSTEMS, AND COMPONENTS}

Safety-significant SSCs protect workers against potentially life-threatening or disabling conditions. The safety-significant SSC designation can also apply to SSCs that protect against large releases of radioactive material. This section discusses each of the safety-significant SSCs identified in Chapter 3 and describes their safety functions, functional requirements, SSC evaluation, and the TSR controls. 


\subsubsection{APPROVED TRU WASTE CONTAINERS}

\subsubsection{Safety Function}

Approved TRU waste containers provide primary confinement for TRU waste material being handled or stored in the Waste Storage Facilities. The safety functions of approved TRU waste containers are to provide a barrier to significant releases and to mitigate releases in the event of mechanical impacts or thermal stresses.

\subsubsection{System Description}

Standard 55-gal drums, standard waste boxes (SWBs), TRU oversize boxes, and other steel containers meeting the definition of an approved TRU waste container (see Section 4.4.1.3) are used as packages for TRU waste in the Waste Storage Facilities. TRU oversize boxes are used primarily for large items that will not fit into standard containers.

The steel containers prevent loss of primary confinement for radioactive material being stored, staged or handled, thus preventing a significant release of radioactive material. Filter vents do not contribute to the overall structural integrity of a metal container; the removal of the filter vents does not affect the overall structural integrity of a metal container.

Approved TRU waste containers are vented, except for TRU oversize boxes and LLW/TRU conversions (i.e., LLW containers that have been converted to TRU waste after assay). The containers are vented through carbon composite filter vents to preclude container pressurization caused by gas generation from radiolytic decomposition of waste material and other reactions and to prevent particulate matter from escaping.

Carbon composite filter vents are installed in a threaded hole in most approved TRU waste containers (the exceptions are TRU oversize boxes and LLW/TRU conversions) to preclude container pressurization from gas generation and to prevent particulate matter from escaping. The filter itself serves a contamination control function and not a safety function for the purposes of this chapter.

The following is a description of the approved TRU waste containers used to store TRU waste in the Waste Storage Facilities:

- $\quad$ DOT 17C, 17H or UN1A2 steel drums with vents (except for LLW/TRU conversions see note).

- Standard waste boxes (SWBs) refers to oval-shaped steel containers with vents, roughly 3 -ft $\mathrm{H} \times 6$-ft $\mathrm{L} \times 4.5-\mathrm{ft} \mathrm{W}$, designed for efficient loading into TRUPACT II Type B shipping containers.

- TRU oversize boxes refers to unvented steel containers, rectangular in shape. Built to contain large pieces of contaminated equipment, the dimensions of each TRU oversize box are unique. Heights vary from approximately 53 inches to 101 inches, widths vary from approximately 47 inches to 70 inches, and lengths vary from approximately 78 inches to 138 inches. 
- Other steel containers with vents satisfying the free drop test performance criteria for Type A packaging (e.g., ten drum overpacks, 85-gal drums).

Note: LLW/TRU conversions are waste containers that have been assayed after acceptance and found to have greater than $100 \mathrm{nCi} / \mathrm{g}$ of alpha-emitting transuranic radionuclides (elements above uranium in the periodic table) with half-lives greater than 20 years, thereby meeting the definition of TRU waste. These containers have very low levels of TRU isotopes, on the order of $0.02 \mathrm{Ci}$ total. These drums are steel containers that meet the free drop test Type A performance criteria [49 CFR 173.465(c)(1)], but are not required to be vented.

\subsubsection{Functional Requirements}

Containers must provide a level of protection that supports the bases of the hazard and accident analyses. The functional requirements for approved TRU waste containers are as follows:

1. Containers must be vented (except for TRU oversize boxes and LLW/TRU conversions), and the vents must be designed to allow flammable gases that may be generated inside the waste container to be relieved. Removing and replacing filter vents is allowed for maintenance, non-intrusive inspection, and sampling activities. Only approved filters may be installed.

2. Containers must meet the free drop test performance criteria for Type A packaging. Requirements for these containers are found in 49 CFR 173.465(c)(1) for the applicable package mass.

\subsubsection{System Evaluation}

The approved steel containers used to package TRU waste meet the above functional requirements. The performance criteria for these containers are that they protect the waste from mechanical stresses and the elements of weather and provide confinement for the waste. To ensure that containers meet these criteria, weekly inspections will be performed.

\subsubsection{TSR Controls}

The steel containers including vents (where applicable) are passive design features. As part of the approved TRU Waste Container Maintenance Program, weekly inspections of waste container integrity will be conducted. 


\subsubsection{B625 AND B696R STRUCTURAL SYSTEMS}

The structural systems of B625 and B696R have been identified as safety significant SSCs based on the hazard analysis in Chapter 3.

\subsubsection{Safety Function}

The safety function of the structural systems of the Waste Storage Facilities buildings storing TRU waste is to not collapse in a PC-2 NPH event. Structural collapse could result in unacceptable damage to approved TRU waste containers.

\subsubsection{System Description}

The B625 and B696R structural systems consist of the following:

- Foundations

- Columns

- Beams directly connected to the columns

- Lateral bracing

- Roof deck

No relevant interfaces, other than the structures mentioned above, would impact the building structures. Descriptions of these buildings are provided in Section 2.4.

\subsubsection{Functional Requirements}

The functional requirements necessary to fulfill the safety functions stated above are as follows:

- Maintain structural integrity (not collapse) during a seismic event up to a PC-2 earthquake.

- Maintain structural integrity (not collapse) during a PC-2 wind event.

\subsubsection{System Evaluation}

The performance criteria for the building structures are those for PC-2 designed and constructed buildings. B625 was built prior to the establishment of the DOE PC-2 criteria, but met the Uniform Building Code (UBC) at the time of construction. For this structure, calculations have been performed (LLNL 2000) to confirm the structure meets the applicable PC-2 criteria. Every five years or less, the buildings will be assessed for their continued conformance with asbuilt structural design and for any conditions (e.g., damage or degradation) which may compromise their safety function.

\subsubsection{TSR Controls}

B625 and B696R structural systems are passive design features. A building inspection program is established, implemented, and maintained to ensure that the B625 and B696R structural systems meet their PC-2 requirements. This program includes inspections every five years or 
less by a qualified engineer (e.g., structural or civil) to verify that significant physical deterioration of or damage to the structures has not occurred. 


\subsubsection{B696S/B696R PARTITION}

The partition between B696R and B696S has been identified as a safety-significant SSC as it serves to support segmentation between the Waste Storage Facilities and the B695 Segment.

Segmentation takes into consideration several factors (e.g., aircraft crash, earthquake, fire, shared utilities). A justification for segmentation in regards to these factors is provided in Appendix C. The B696S/B696R partition specifically addresses fire. In order for the B696S/B696R partition to meet its safety function, the B696S/B696R partition functional requirements and environmental conditions (per DOE-STD-1020-2002) need to be met.

\subsubsection{Safety Function}

The safety function of the B696S/B696R partition is to isolate a fire in B696R from B696S.

\subsubsection{System Description}

The B696S/B696R partition is the wall assembly separating the low bay B696R and high bay B696S. The partition extends from true wall to true wall (inside of the exterior skin) in the north south direction and from the floor to the underside of the roof decks.

The cross-section of the partition between B696R and B696S consists of three layers of 5/8-in. Type $X$ gypsum board, on 4-in. deep 20 gage metal studs, R-13 insulation, an approximately 5.75-in. air gap, 4-in. deep 20 gage metal studs, and three layers of 5/8-in. Type X gypsum board.

\subsection{Drawings}

The B696S/B696R Partition construction is shown in the following drawings:

- PLZ96-696-016EB

- PLZ96-696-019EC

\subsubsection{Functional Requirements}

The minimum functional requirements for the system and the environmental conditions follow.

\section{Functional Requirements:}

- The B696S/B696R partition must prevent the propagation of a fire between B696R and B696S.

\section{Environmental Conditions:}

- In accordance with DOE-STD-1020-2002 (DOE 2002b), the B696S/B696R partition is designated as PC-2 equipment that must be able to withstand an evaluation basis earthquake (EBE) and an evaluation basis wind (EBW). 


\subsubsection{System Evaluation}

\section{Performance Criterion:}

- The B696S/B696R partition shall maintain a 2-hr fire-resistance rating.

A qualitative analysis of the B696S/B696R partition was performed by the Facility Engineer and reviewed by the Fire Protection Engineer in calculation WM/FS-B696-07-01. The conclusion of the evaluation was:

- In the event of a 2-hour equivalent fire in B696R Room 1010, the fire is not expected to propagate from B696R to B696S. The wall will perform its safety function of reducing the likelihood of fire propagation from B696R to B696S.

The partition wall is adequate to resist PC-2 seismic loading (WM-FS-696-0703). The PC-2 wind criteria are met since PC-2 seismic criteria bound the PC-2 wind criteria at LLNL and because the B696S/B696R partition is protected by the PC-2 B696R Structural System

Based on these analyses, the B696S/B696R partition can meet its safety function, functional requirements, environmental conditions, and performance criteria. The B696S/B696R partition's 2-hour fire resistivity supports segmentation.

\subsubsection{TSR Controls}

The B696S/B696R partition is a passive design feature. The partition between B696R and B696S is inspected monthly and also inspected every five years or less to verify that significant physical deterioration or damage to the partition has not occurred. 


\subsection{SPECIFIC ADMINISTRATIVE CONTROLS (SACS)}

SACs are those administrative controls that are selected to provide preventive and/or mitigative functions for specific potential accident scenarios, and which also have safety importance equivalent to engineered controls that would be classified as safety-class or safety-significant if the engineered controls were available and selected (DOE 2004).

\subsubsection{TRU WASTE INVENTORY LIMITS}

\subsubsection{Safety Function}

A maximum inventory per container of 50 PE-Ci was used as the MAR for most hazard and accident analyses involving TRU waste. Thus, the container inventory limit is an assumed initial condition for most scenarios in the hazard and accident analyses in Sections 3.3 and 3.4 of the Waste Storage Facilities DSA. The SAC protects this assumption and ensures that the consequences determined in the hazard and accident analyses remain bounding.

The Waste Storage Facilities are also required to comply with National Environmental Policy Act (NEPA) analysis in the current LLNL Environmental Impact Statement (DOE 2005b). The NEPA analysis establishes a bounding consequence based on overall facility inventory parameters. This SAC also requires that drum loading and configuration remain within the NEPA bounding consequence calculations. This limit was specifically used for all air craft crash with fire scenarios evaluated in the hazard and accident analysis.

\subsubsection{SAC Description}

This SAC ensures the following limit assumed in the hazard and accident analysis is maintained:

- $\quad$ For each approved TRU waste container in B696R or B625, the amount of radioactive material shall be no greater than $50 \mathrm{PE}-\mathrm{Ci}$ based on Acceptable Knowledge. Drum loading and configuration shall be administratively controlled to remain consistent with the National Environmental Policy Act (NEPA) bounding consequence calculations.

\subsubsection{Functional Requirements}

There are no SSCs or unique functional requirements associated with this SAC. The SAC shall ensure that the radioactive material inventory for each approved TRU waste container in B696R or $\mathrm{B} 625$ is less than or equal to $50 \mathrm{PE}-\mathrm{Ci}$. The radioactive material inventory limit requirement is met based on Acceptable Knowledge. Acceptable Knowledge characterization of TRU waste is based on an understanding of the materials and processes used to generate the waste, analytical data obtained from the process or waste stream, or both. Radionuclide quantification for individual radioactive waste containers will be performed. Written procedures will be followed to acquire, verify, and document Acceptable Knowledge.

Independent of the $50 \mathrm{PE}-\mathrm{Ci}$ limit, the Waste Storage Facilities are also required to comply with NEPA analysis in the current LLNL Environmental Impact Statement (DOE 2005b). 


\subsubsection{SAC Evaluation}

There are no SSCs or unique performance criteria associated with this SAC. RHWM operations personnel will complete the tasks needed to assure each approved TRU waste container is at or below the established inventory limits for B696R and B625 prior to the storage of the approved TRU waste container in B696R or B625 as assumed in the safety basis.

\subsubsection{Controls (TSRs)}

The following Directive Action SAC shall be established:

- For each approved TRU waste container in B696R or B625, the amount of radioactive material shall be no greater than $50 \mathrm{PE}-\mathrm{Ci}$ based on Acceptable Knowledge. Drum loading and configuration shall be administratively controlled to remain consistent with the National Environmental Policy Act (NEPA) bounding consequence calculations.

\subsubsection{FISSILE MATERIAL CONTAINER LIMIT}

\subsubsection{Safety Function}

200 Pu-239 FGE was identified as an assumed condition in the hazard analysis criticality event scenarios. This control serves to limit the quantity of fissile material in each approved TRU waste container. The material form, packaging and segregation required by the Criticality Safety Program preclude the possibility of an inadvertent criticality for 200 grams of Pu-239. CSM 1344 (LLNL 2003), "Criticality Safety Evaluation On the Use of 200-gram Pu Drum Mass Limit for RHWM Waste Storage Operations," provides the technical basis for the 200 Pu-239 FGE.

\subsubsection{SAC Description}

This SAC ensures the following limit assumed in the hazard and accident analysis is maintained:

- For each container, the fissile material inventory shall be no greater than 200 Pu-239 FGE.

\subsubsection{Functional Requirements}

There are no SSCs or unique functional requirements associated with this SAC. The SAC shall ensure that the fissile material in each container is less than or equal to $200 \mathrm{Pu}-239 \mathrm{FGE}$. The fissile material limit requirement for each waste container is met based on Acceptable Knowledge. Acceptable knowledge is based on an understanding of the materials and processes used to generate the waste, or analytical data obtained from the process or waste stream or both. Radionuclide quantification for individual radioactive waste containers will be performed. Written procedures will be followed to acquire, verify, and document Acceptable Knowledge. 


\subsubsection{SAC Evaluation}

There are no SSCs or unique performance criteria associated with this SAC. RHWM operations personnel will complete the procedural tasks needed to assure each waste container is at or below the fissile material inventory limit for each waste container prior to storage of the container as assumed in the safety basis.

\subsubsection{Controls (TSRs)}

The following Directive Action SAC shall be established:

- For each container, the fissile material inventory shall be no greater than 200 Pu-239 FGE.

\subsubsection{TRITIUM CONTAINER LIMIT}

\subsubsection{Safety Function}

A maximum inventory per container of 2,000 $\mathrm{Ci}$ of tritium was used as the MAR for the hazard and accident analyses. Thus, the container inventory limit for tritium is an assumed condition in the hazard and accident analyses in Sections 3.3 and 3.4 of the Waste Storage Facilities DSA, and serves to limit the quantity of tritium that can be impacted in accident scenarios. The SAC protects this assumption and ensures that the consequences determined in the hazard and accident analyses remain bounding.

\subsubsection{SAC Description}

This SAC ensures the following limit assumed in the hazard and accident analysis is maintained:

- The amount of tritium in a waste container shall be no greater than 2,000 Ci based on Acceptable Knowledge.

\subsubsection{Functional Requirements}

There are no SSCS or unique functional requirements associated with this SAC. The SAC shall ensure that the tritium inventory for each waste container is less than or equal to 2,000 $\mathrm{Ci}$. The tritium inventory limit requirement is met based on Acceptable Knowledge. Acceptable knowledge characterization of radioactive waste is based on an understanding of the materials and processes used to generate the waste, or analytical data obtained from the process or waste stream or both. Radionuclide quantification for individual radioactive waste containers will be performed. Written procedures will be followed to acquire, verify, and document Acceptable Knowledge.

\subsubsection{SAC Evaluation}

There are no SSCs or unique performance criteria associated with this SAC. RHWM operations personnel will complete the procedural tasks needed to assure each waste container is at or below the tritium material inventory limit prior to storage of the container as assumed in the safety basis. 


\subsubsection{Controls (TSRs)}

The following Directive Action SAC shall be established:

- The amount of tritium in a waste container shall be no greater than 2,000 Ci based on Acceptable Knowledge.

\subsubsection{TRU WASTE STAGING LIMITS}

\subsubsection{Safety Function}

The MAR of 200 PE-Ci was used in the hazard and accident analyses as the maximum inventory for an impacted array of staged waste containers in the yard. Thus, the outdoor array limit is an assumed condition in the hazard and accident analyses in Sections 3.3 and 3.4 of the Waste Storage Facilities DSA, and serves to limit the quantity of radioactive material that can be impacted in accident scenarios involving staged waste.

By separating arrays 10 feet (HC/AB B696-0301), drums in one array will not fail from exposure to the critical radiant heat flux of $45 \mathrm{~kW} / \mathrm{m} 2$ (identified in WHC-SD-WM-TRP-246, 1995) from a fire in another array.

\subsubsection{SAC Description}

This SAC ensures the following limit assumed in the hazard and accident analysis is maintained:

- $\quad$ TRU waste arrays staged outside the building shall be limited to a maximum inventory of $200 \mathrm{PE}-\mathrm{Ci}$ and separated by a minimum of 10 feet.

\subsubsection{Functional Requirements}

There are no SSCs or unique functional requirements associated with this SAC. The SAC shall ensure that approved TRU waste containers staged in the yard are:

- In arrays with no greater than 200 PE-Ci each

- Separated from other staged approved TRU waste container arrays by no less than 10 feet

Written procedures will be followed to provide instructions for tasks to be performed.

\subsubsection{SAC Evaluation}

There are no SSCS or unique performance criteria associated with this SAC. RHWM operations personnel will complete the procedural tasks needed to meet the staging array inventory limit and the staging array separation requirement as assumed in the safety basis. The duties to be performed by RHWM operations personnel to successfully perform the SAC are very simple. The RHWM operations personnel must simply verify that the inventory for each array of approved TRU waste containers to be staged in the yard is no greater than $200 \mathrm{PE}-\mathrm{Ci}$, will be separated from other approved TRU waste container arrays by no less than 10 feet 


\subsubsection{Controls (TSRs)}

The following Directive Action SAC shall be established:

- TRU waste arrays staged outside the building shall be limited to a maximum inventory of 200 PE-Ci and separated by a minimum of 10 feet.

\subsubsection{AUTHORIZED TRU WASTE STORAGE LOCATIONS}

\subsubsection{Safety Function}

The hazard analysis assumes that TRU waste is stored in building structures meeting PC-2 requirements. In addition, it assumes that TRU waste is not stored coincident with flammable liquid storage areas. This control serves to limit the locations that are authorized to store TRU waste to protect these assumptions.

\subsubsection{SAC Description}

This SAC ensures the following limit assumed in the hazard and accident analysis is maintained:

- $\quad$ TRU waste storage shall be limited to B696R and B625.

\subsubsection{Functional Requirements}

There are no SSCS or unique functional requirements associated with this SAC. This SAC shall ensure that TRU waste is only stored in B696R and B625. Written procedures will be followed to provide instructions for tasks to be performed.

\subsubsection{SAC Evaluation}

There are no SSCs or unique performance criteria associated with this SAC. RHWM operations personnel will complete the procedural tasks needed to ensure that TRU waste storage is limited to B696R and B625 as described in the safety basis. The duties to be performed by RHWM operations personnel to successfully perform the SAC are very simple. The RHWM operations personnel must simply verify that approved TRU waste containers are only stored in B696R or B625; TRU waste containers may be staged throughout the Waste Storage Facilities yard areas consistent with the staging limits described in Sections 4.5.5 and 4.5.10. There are no time restraints associated with performing the required operations.

\subsubsection{Controls (TSRs)}

The following Directive Action SAC shall be established:

- $\quad$ TRU waste storage shall be limited to B696R and B625. 


\subsubsection{STORAGE IN APPROVED TRU WASTE CONTAINERS}

\subsubsection{Safety Function}

Containers provide a confinement function limiting worker exposures and radioactive waste vulnerability in accident scenarios involving containerized TRU waste. Accordingly, TRU waste containers meeting specified criteria were an assumed condition in the hazard and accident analyses for scenarios involving TRU waste. TRU waste containers typically have carbon composite filter vents, which minimize the potential for buildup of gases.

\subsubsection{SAC Description}

This SAC ensures the following limit assumed in the hazard and accident analysis is maintained:

- $\quad$ All TRU waste shall be stored in approved TRU waste containers

\subsubsection{Functional Requirements}

There are no SSCs or unique functional requirements associated with this SAC. The SAC shall ensure that all TRU waste accepted into the RHWM nuclear facilities is in approved TRU waste containers, as described in Section 4.4.1. Written procedures will be followed to provide instructions for tasks to be performed.

\subsubsection{SAC Evaluation}

There are no SSCs or unique performance criteria associated with this SAC. RHWM operations personnel will complete the procedural tasks needed to ensure that TRU waste is stored in approved TRU waste containers as assumed in the safety basis. Prior to acceptance, Radiological Characterization Analysts (RCAs) review all waste packages to ensure they meet the RHWM waste acceptance criteria. As part of this process, the RCAs verify that all TRU waste is packaged in approved TRU waste containers.

\subsubsection{Controls (TSRs)}

The following Directive Action SAC shall be established:

- $\quad$ All TRU waste shall be stored in approved TRU waste containers

\subsubsection{APPROVED TRU WASTE CONTAINER STACKING LIMITS}

\subsubsection{Safety Function}

Stacking approved TRU waste containers no more than two levels high was identified in seismic hazard analysis scenarios as a credited control. Containers meeting the free drop test DOT Type A packaging performance criteria [49 CFR 173.465(c)(1)] are used to store TRU waste. These containers are designed to survive at least a 4-ft drop consistent with the performance criteria for Type A packaging. This SAC serves to ensure that stacked containers will not fall greater than 4 feet in the event of an earthquake, and hence will not breach. Ten drum overpacks are approximately 6 feet in height, and therefore, are not stacked. 


\subsubsection{SAC Description}

This SAC ensures the following limit assumed in the hazard and accident analysis is maintained:

- Approved TRU waste containers shall not be stacked more than two levels high. Ten drum overpacks and other approved TRU waste containers exceeding a nominal height of 4 feet shall not be stacked.

\subsubsection{Functional Requirements}

There are no SSCs or unique functional requirements associated with this SAC. The SAC shall ensure that approved TRU waste containers are stacked no more than two high and that approved TRU waste containers exceeding a nominal height of 4 feet are not stacked, consistent with the controls identified in the hazard analysis. Written procedures will be followed to provide instructions for tasks to be performed.

\subsubsection{SAC Evaluation}

There are no SSCs or unique performance criteria associated with this SAC. RHWM operations personnel will complete the procedural tasks needed to ensure that stacking of approved TRU waste containers is within the assumptions made in the safety basis. The duties to be performed by RHWM operations personnel to successfully perform the SAC are very simple. The RHWM operations personnel must simply verify that approved TRU waste containers are not stacked more than two high and that approved TRU waste containers exceeding a nominal height of 4 feet are not stacked.

\subsubsection{Controls (TSRs)}

The following Directive Action SAC shall be established:

- $\quad$ Approved TRU waste containers shall not be stacked more than two levels high. Ten drum overpacks and other approved TRU waste containers exceeding a nominal height of 4 feet shall not be stacked.

\subsubsection{APPROVED TRU WASTE CONTAINER LIDS}

\subsubsection{Safety Function}

Approved TRU waste containers provide primary confinement for TRU waste material being handled or stored in the Waste Storage Facilities. The safety functions of approved TRU waste containers are to provide a barrier to significant releases and to mitigate releases in the event of mechanical impacts or thermal stresses. Removing the lids of approved TRU waste containers is outside the scope of work at the Waste Storage Facilities. Removing and replacing filter vents is allowed for maintenance, non-intrusive inspection, and sampling activities. Filter vents do not contribute to the overall structural integrity of a metal container; the removal of filter vents does not affect the overall structural integrity of a metal container. 


\subsubsection{SAC Description}

This SAC ensures the following limit assumed in the hazard and accident analysis is maintained:

- The lids for approved TRU waste containers shall not be removed in the Waste Storage Facilities.

\subsubsection{Functional Requirements}

There are no SSCs or unique functional requirements associated with this SAC. The SAC shall ensure that all TRU waste in the Waste Storage Facilities is maintained in closed containers. Written procedures will be followed to provide instructions for tasks to be performed.

\subsubsection{SAC Evaluation}

There are no SSCs or unique performance criteria associated with this SAC. RHWM operations personnel will ensure that the lids for approved TRU waste containers are not removed in the Waste Storage Facilities.

\subsubsection{Controls (TSRs)}

The following Directive Action SAC shall be established:

- The lids for approved TRU waste containers shall not be removed in the Waste Storage Facilities.

\subsubsection{APPROVED TRU WASTE CONTAINER STAGING LOCATIONS}

\subsubsection{Safety Function}

The accident analysis in Section 3.4 of the Waste Storage Facilities DSA assumed that releases of TRU waste occurred no less than $130 \mathrm{~m}$ from the site boundary (Greenville Road fence line). Thus, this distance is an assumed condition in the accident analysis in Section 3.4 of the Waste Storage Facilities DSA, and serves to limit the consequences to the off-site public.

\subsubsection{SAC Description}

This SAC ensures the following limit assumed in the hazard and accident analysis is maintained:

- Approved TRU waste containers shall not be staged less than $130 \mathrm{~m}$ from the Greenville Road fence line (i.e., east of the B693 structure).

\subsubsection{Functional Requirements}

There are no SSCs or unique functional requirements associated with this SAC. The SAC shall ensure that approved TRU waste containers are not staged less than $130 \mathrm{~m}$ from the Greenville Road fence line (east of the B693 structure). This is an assumed condition in the accident 
analysis in Section 3.4 of the Waste Storage Facilities DSA. Written procedures will be followed to provide instructions for tasks to be performed.

\subsubsection{SAC Evaluation}

There are no SSCs or unique performance criteria associated with this SAC. RHWM operations personnel will complete the procedural tasks needed to ensure that staging of approved TRU waste containers is within the assumptions made in the safety basis.

The duties to be performed by RHWM operations personnel to successfully perform the SAC are very simple. The RHWM operations personnel must simply verify that approved TRU waste containers staged in the DWTF yard are not staged east of the B693 structure.

\subsubsection{Controls (TSRs)}

The following Directive Action SAC shall be established:

- Approved TRU waste containers shall not be staged less than $130 \mathrm{~m}$ from the Greenville Road fence line (i.e., east of the B693 structure).

\subsubsection{USE OF METAL CONTAINERS AND PALLETS FOR WASTE IN TRU WASTE STORAGE AREAS}

\subsubsection{Safety Function}

The use of metal containers and pallets for waste stored in TRU waste storage areas limits the potential for fire initiation and propagation during operational or other events in TRU waste storage areas by limiting available combustibles. This is a credited control for waste handling and natural phenomena hazard scenarios in the hazard analysis. This control serves to ensure that low-level, hazardous, and other wastes that can be stored coincident with TRU waste are in non-combustible packaging and on non-combustible pallets.

\subsubsection{SAC Description}

This SAC ensures the following limit assumed in the hazard and accident analysis is maintained:

- Only waste in metal containers and on metal pallets shall be allowed in TRU waste storage areas.

\subsubsection{Functional Requirements}

There are no SSCs or unique functional requirements associated with this SAC. The SAC shall ensure that only waste in metal containers and on metal pallets is stored in TRU waste storage areas (B696R and B625). Written procedures will be followed to provide instructions for tasks to be performed. 


\subsubsection{SAC Evaluation}

There are no SSCs or unique performance criteria associated with this SAC. RHWM operations personnel will complete the procedural tasks needed to ensure that only waste in metal containers and on metal pallets is stored in TRU waste storage areas.

The duties to be performed by RHWM operations personnel to successfully perform the SAC are very simple. The RHWM operations personnel must simply verify that waste containers stored in TRU waste storage areas are metal and that these containers are on metal pallets.

\subsubsection{Controls (TSRs)}

The following Directive Action SAC shall be established:

- Only waste in metal containers and on metal pallets shall be allowed in TRU waste storage areas.

\subsubsection{COMBUSTIBLE LOADING LIMIT}

This SAC is addressed below in five sections: (1) Safety Function, (2) System Description, (3) Functional Requirements, (4) System Evaluation, and (5) Controls (TSRs).

\subsubsection{Safety Function}

The safety function of the SAC is to limit combustible material in B625 and B696R.

\subsubsection{SAC Description}

This SAC ensures the following combustible material limit is maintained:

- Combustible loading shall be limited to an average of 7 pounds of equivalent ordinary combustibles per square foot, excluding waste containerized in metal packaging, in B625 and B696R.

\subsubsection{Functional Requirements}

This SAC shall ensure that the quantity of combustible material in B625 and B696R is limited to that the amount of combustible material assumed in the hazard analysis and accident analysis. Written procedures will be followed to provide instructions for tasks to be performed.

There are no SSCs or unique functional requirements associated with this SAC.

\subsubsection{SAC Evaluation}

There are no SSCs or unique performance criteria associated with this SAC. 


\section{Documented Safety Analysis for the Waste Storage Facilities}

\subsubsection{Controls (TSRs)}

The following Directive Action SAC shall be established:

- Combustible loading shall be limited to an average of 7 pounds of equivalent ordinary combustibles per square foot, excluding waste containerized in metal packaging, in B625 and B696R.

\subsection{REFERENCES}

49CFR173.465, Code of Federal Regulations, Title 49, Transportation, Part 173.465, "Type A Packaging Tests." Office of the Federal Register, Washington, DC. (49 CFR 173.465)

DOE (1996), Natural Phenomena Hazards Design and Evaluation Criteria for Department of Energy Facilities, DOE-STD-1020-94, Change Notice 1, U.S. Department of Energy, Washington, DC, June 1996.

DOE (1997), Hazard Categorization and Accident Analysis Techniques for Compliance with DOE Order 5480.23, Nuclear Safety Analysis Reports, DOE-STD-1027-92, Change Notice 1, U.S. Department of Energy, Washington, DC, September 1997.

DOE (2002b), Natural Phenomena Hazards Design and Evaluation Criteria for Department of Energy Facilities, DOE-STD-1020-2002, U.S. Department of Energy, Washington, DC, January 2002.

DOE (2004), Specific Administrative Controls, DOE-STD-1186-2004, U.S. Department of Energy, Washington, DC, August 2004.

DOE (2005a), Facility Safety. DOE Order 420.1B, U.S. Department of Energy, Washington DC, December 2005.

DOE (2005b), Final Site-wide Environmental Impact Statement for Continued Operation of Lawrence Livermore National Laboratory and Supplemental Stockpile Stewardship and Management Programmatic Environmental Impact Statement, DOE/EIS-0348, DOE/EIS-0236-S3, March 2005.

DOE (2006), Preparation Guide for U.S. Department of Energy Nonreactor Nuclear Facility Safety Analysis Reports. DOE-STD-3009-94, Change Notice 3, U.S. Department of Energy, Washington, DC, March 2006.

HC/AB-B696-0301, "Fire involving flammable liquids and separation distances," Joong M. Yang, Lawrence Livermore National Laboratory, Livermore, CA, March 2003.

LLNL (2000), Memo from Madhu Kamath, LLNL, to Erik Brown, LLNL, "Bldg. 625 Seismic/Wind Evaluation for PC-2 Criteria," Lawrence Livermore National Laboratory, Livermore, CA, June 30, 2000.

LLNL (2003), CSM 1344, "CRITICALITY SAFETY EVALUATION On the Use of 200-gram Pu Drum Mass Limit for RHWM Waste Storage Operations," Lawrence Livermore National Laboratory, August 2003. 
NNSA/LLNS (2009), Management and Operating Contract between The US Department of Energy/National Nuclear Security Administration and Lawrence Livermore National Security, No. DE-AC52-07NA27344, February 27, 2009.

RHWM Calculation WM/FS-B696-07-01 Rev. 1, "Impact of fire on wall in B696," May 18, 2007.

WHC-SD-WM-TRP-246, "Solid Waste Drum Array Fire Performance," Rev. 0, Westinghouse Hanford Company, 1995.

WM-FS-969-0703 "Evaluation of an Existing Partition Wall in Building 696, Room 1009," Derek Westphal, Lawrence Livermore National Laboratory, Livermore, CA, January 9, 2008. 


\section{CHAPTER 5 \\ DERIVATION OF TECHNICAL SAFETY REQUIREMENTS}

\section{$5.1 \quad$ INTRODUCTION}

The technical safety requirements (TSRs) were developed to ensure adequate protection for the off-site and on-site populations in the event of an uncontrolled release of radioactive material. Based on the information in DOE-STD-1027-92, Change Notice 1 (DOE 1997), the Waste Storage Facilities are Hazard Category 2 non-reactor nuclear facilities. The TSRs consist primarily of inventory limits and controls preserving the underlying assumptions in the hazard and accident analyses. Further, appropriate commitments to safety programs are presented in the administrative controls sections of this chapter.

\subsection{REQUIREMENTS}

This section contains the directives in effect as of February 2009 as implemented in the Lawrence Livermore National Security, LLC, Contract No. DE-AC52-07NA27344 (NNSA/LLNS 2009). Specific sections of these directives are relevant to the content of this chapter. This section also contains the codes, standards, regulations, and DOE orders specific to this chapter and required to establish the safety basis of the facility.

- 10 CFR 830, Nuclear Safety Management

- DOE-STD-3009-94, Change Notice 3, Preparation Guide for U.S. Department of Energy Nonreactor Nuclear Facility Safety Analysis Reports (DOE 2006)

\subsection{TSR COVERAGE}

This section lists the features identified in Chapters 3 and 4 that are needed to do the following:

- $\quad$ Provide important defense in depth;

- $\quad$ Assure worker safety; and

- Maintain consequences of facility operations at levels below the Evaluation Guideline.

The unmitigated estimate of the radiation dose consequence to the public from the bounding design basis accident from Section 3.4 .2 is less than 3 rem TEDE, which is well below, and does not "challenge," the Evaluation Guideline. No safety-class SSCs were identified based on the analyses, and the TSR controls discussed in the following sections provide important defense in depth and worker safety. 


\subsubsection{IMPORTANT DEFENSE IN DEPTH REQUIRING TSR COVERAGE}

Shown in Table 5-1 are the individual design features and their associated assumptions that require coverage in the Waste Storage Facilities TSRs. Table 5-2 shows the individual control features and their associated assumptions that require coverage in the Waste Storage Facilities TSRs. The details of these controls are discussed in Section 5.5.

Table 5-1. Design Features Requiring TSR Coverage

\begin{tabular}{|l|l|}
\hline \multicolumn{1}{|c|}{ Feature } & \multicolumn{1}{c|}{ Assumption } \\
\hline $\begin{array}{l}\text { Approved TRU waste } \\
\text { containers }\end{array}$ & $\begin{array}{l}\text { Reduces frequency of common spill and fire accidents during normal } \\
\text { waste-container operations and reduces probability of breaching of } \\
\text { containers stored on either the first or second level during a DBE or } \\
\text { DBW. Vents reduce frequency of buildup of flammable gases from } \\
\text { radiolysis. This subsequently reduces the probability of a deflagration. }\end{array}$ \\
\hline $\begin{array}{l}\text { B625 and B696R structural } \\
\text { systems }\end{array}$ & $\begin{array}{l}\text { The B625 and B696R structural systems will not collapse in PC-2 } \\
\text { earthquake and wind events. }\end{array}$ \\
\hline B696S/B696R partition & $\begin{array}{l}\text { The partition separates B696R from B696S for segmentation } \\
\text { purposes. }\end{array}$ \\
\hline
\end{tabular}

\subsubsection{WORKER SAFETY}

The design features and controls in Table 5-1 and Table 5-2 provide for worker safety. Additionally, the following programs provide for worker safety.

1. Criticality Safety Program

2. Radiation Protection Program

3. Hazardous Material Protection Program

4. In-service Inspection \& Test and Maintenance Programs

5. Fire Protection Program

6. Traffic Control Program

7. Training Program

8. Emergency Preparedness Program

9. Configuration Management Program

Additional details on these programs are provided in Section 5.5. 
Table 5-2. Control Features and Associated Assumptions

\begin{tabular}{|c|c|}
\hline Feature & Assumption \\
\hline $\begin{array}{l}\text { A limit of } 50 \text { PE-Ci of radioactive material } \\
\text { per container, with the exception of } \\
\text { tritium, which is limited to } 2,000 \mathrm{Ci} \text { per } \\
\text { container. Inventory configuration and } \\
\text { loading is administratively controlled } \\
\text { consistent with the NEPA limits. }\end{array}$ & $\begin{array}{l}\text { Limits the amount of radioactive material that can be impacted } \\
\text { by postulated accidents involving TRU waste or LLW } \\
\text { containing tritium in the Waste Storage Facilities. Maintains } \\
\text { consistency with NEPA radioactive inventory configuration and } \\
\text { loading limits. }\end{array}$ \\
\hline $\begin{array}{l}\text { The fissile material inventory per } \\
\text { container is limited to } 200 \text { Pu-239 fissile } \\
\text { gram equivalents (FGE). }\end{array}$ & $\begin{array}{l}\text { Limits the amount of fissile material to preclude an inadvertent } \\
\text { criticality. }\end{array}$ \\
\hline $\begin{array}{l}\text { TRU WASTE arrays staged outside the } \\
\text { building SHALL be limited to a maximum } \\
\text { inventory of } 200 \text { PE-Ci and separated by } \\
\text { a minimum of } 10 \text { feet. }\end{array}$ & $\begin{array}{l}\text { Limits the amount of radioactive material that can be impacted } \\
\text { by accidents in the yard. }\end{array}$ \\
\hline $\begin{array}{l}\text { A limit of two stacking levels for } \\
\text { approved TRU waste containers. } \\
\text { Approved TRU waste containers } \\
\text { exceeding nominal height of } 4 \text { feet will } \\
\text { not be stacked. }\end{array}$ & $\begin{array}{l}\text { Minimizes the potential for drum failure from toppling during a } \\
\text { DBE. Approved TRU waste containers are designed to } \\
\text { withstand a 4-ft drop. Ten drum overpacks are approximately } \\
6 \text { feet in height. }\end{array}$ \\
\hline $\begin{array}{l}\text { The lids for approved TRU waste } \\
\text { containers will not be removed. }\end{array}$ & $\begin{array}{l}\text { Ensures waste is confined in closed metal containers. } \\
\text { Removing the lids of approved TRU waste containers is outside } \\
\text { the scope of work at the Waste Storage Facilities. }\end{array}$ \\
\hline $\begin{array}{l}\text { Approved TRU waste containers will not } \\
\text { be staged less than } 130 \mathrm{~m} \text { from the } \\
\text { Greenville Road fence line (i.e., east of } \\
\text { B693 structure). }\end{array}$ & $\begin{array}{l}\text { Minimum distance to fence line assumed for postulated TRU } \\
\text { waste accidents involving staged waste in the hazard and } \\
\text { accident analyses. }\end{array}$ \\
\hline $\begin{array}{l}\text { TRU waste storage limited to B696R and } \\
\text { B625. }\end{array}$ & Limits the locations that are authorized for TRU waste storage. \\
\hline $\begin{array}{l}\text { Combustible loading shall be limited to } \\
\text { an average of } 7 \text { pounds of equivalent } \\
\text { ordinary combustibles per square foot, } \\
\text { excluding waste containerized in metal } \\
\text { packaging, in B625 and B696R. }\end{array}$ & $\begin{array}{l}\text { Ensures that the amount of combustible material allowed in } \\
\text { B625 and B696R is no more than assumed in the hazard } \\
\text { analysis and accident analysis. }\end{array}$ \\
\hline Traffic Control Program & $\begin{array}{l}\text { Protection from vehicular traffic is judged to provide significant } \\
\text { benefit in reducing the frequency of events impacting staged } \\
\text { containers in the Waste Storage Facilities yards. }\end{array}$ \\
\hline Criticality Safety Program & $\begin{array}{l}\text { Controls operations and storage of radioactive waste such that } \\
\text { an inadvertent criticality event is precluded. }\end{array}$ \\
\hline
\end{tabular}

Table continued on next page 
Table 5-2. Control Features and Associated Assumptions (continued)

\begin{tabular}{|l|l|}
\hline \multicolumn{1}{|c|}{ Feature } & \multicolumn{1}{c|}{ Assumption } \\
\hline $\begin{array}{l}\text { Single Container Inventory Limit } \\
\text { Program (SCIL) for chemical waste } \\
\text { (implemented as part of the Hazardous } \\
\text { Material Protection Program) }\end{array}$ & $\begin{array}{l}\text { Limits the amount of chemical waste that can be impacted by } \\
\text { postulated accidents involving hazardous, mixed, or combined } \\
\text { waste containers in the Waste Storage Facilities. }\end{array}$ \\
\hline $\begin{array}{l}\text { In-service Inspection \& Test (ISIT) } \\
\text { Program }\end{array}$ & $\begin{array}{l}\text { The building inspection program portion of the ISIT Program } \\
\text { ensures that the B625 and B696R structural systems maintain } \\
\text { structural integrity during PC-2 events and that the partition } \\
\text { between B696R and B696S is maintained consistent with the } \\
\text { functional requirements provided in Section 4.4.3.3. } \\
\text { The approved TRU waste container maintenance program } \\
\text { portion of the ISIT Program preserves approved TRU waste } \\
\text { container integrity and reduces the probability of buildup of } \\
\text { flammable gases from radiolysis. }\end{array}$ \\
\hline $\begin{array}{l}\text { Only waste in metal containers and on } \\
\text { metal pallets allowed in TRU waste } \\
\text { storage areas. Additional combustible } \\
\text { loading controls to minimize fire-loading } \\
\text { (implemented as part of the Fire } \\
\text { Protection Program). }\end{array}$ & $\begin{array}{l}\text { Limits the potential for fire initiation and propagation during } \\
\text { operational or other events in TRU waste storage areas to } \\
\text { mitigate consequences from fires involving TRU waste. }\end{array}$ \\
\hline $\begin{array}{l}\text { Keep Clear areas (implemented as part } \\
\text { of the Fire Protection Program) }\end{array}$ & $\begin{array}{l}\text { To maintain segmentation boundaries and protect the } \\
\text { assumption that an accident outside the segment will not } \\
\text { impact the TRU waste within the segment. }\end{array}$ \\
\hline $\begin{array}{l}\text { Certified crane operators (implemented } \\
\text { as part of the Training Program) }\end{array}$ & $\begin{array}{l}\text { Reduces the likelihood of crane accidents occurring as a result } \\
\text { of operator error. }\end{array}$ \\
\hline
\end{tabular}

\subsubsection{SAFETY-CLASS SSCS}

No safety-class SSCs were identified in the hazard and accident analyses.

\subsubsection{SAFETY-SIGNIFICANT SSCS}

Based on the analysis in Chapter 3, the following SSCs have been designated as safety significant:

- Approved TRU waste containers

- B625 and B696R structural systems

- B696S/B696R partition

Chapter 4 contains a discussion of the safety function for each of these safety significant SSCs. These SSCs are passive design features. 


\subsection{DERIVATION OF FACILITY MODES}

Facility modes are not required since there are no Limiting Conditions of Operation.

\section{$5.5 \quad$ TSR DERIVATION}

Based on the hazard and accident analyses, there are no Safety Limits, Limiting Control Settings, Limiting Conditions of Operation, or Surveillance Requirements. TSR coverage will be required for design features and $A C s$ that provide defense-in-depth. The design features are approved TRU waste containers; the PC-2 B625 and B696R structural systems; and the B696S/B696R partition. Programmatic ACs are discussed in further detail in the programmatic chapters. Specific Administrative Controls (SACs) are described below in Sections 5.5.2 and 5.5.3. There will be no sections that further describe Safety Limits, Limiting Control Settings, Limiting Conditions of Operation, or Surveillance Requirements.

\subsubsection{ADMINISTRATIVE PROGRAMS}

This section establishes programmatic administrative controls committed to in the Waste Storage Facilities DSA.

\subsubsection{Radiation Protection Program}

A radiation protection program shall be established, implemented, and maintained to ensure that radiation exposure to employees, subcontractors, visitors, and members of the general public is controlled at levels specified in applicable DOE regulations and standards (10 CFR 835) and adhere to the as-low-as-reasonably-achievable (ALARA) principle. The program includes the following key elements:

- As Low As Reasonably Achievable (ALARA) program.

- Dosimetry program.

- Radiological monitoring procedures.

\subsubsection{Criticality Safety Program}

A criticality safety program shall be established, implemented, and maintained to ensure that all Waste Storage Facilities operations and activities are reviewed, evaluated, and documented by LLNL criticality safety engineers in accordance with all contractor-applicable provisions of DOE Order 420.1B (DOE 2005b). This program includes the following key elements:

- Fissile material inventory control.

- Nuclear Criticality safety training. 


\subsubsection{Unreviewed Safety Question Process}

A process shall be established, implemented, and maintained to evaluate potential Unreviewed Safety Questions (USQS). Key elements of the process include the following:

- A USQ process that permits facility management to make physical and procedural changes and conduct tests and experiments without prior DOE approval as long as these changes and tests do not explicitly or implicitly affect the safety basis of the Waste Storage Facilities or result in a change to a TSR.

- A USQ process that ensures conditions or potential conditions outside the safety basis are identified.

Section 5.6.1 lists equipment important to safety.

\subsubsection{Configuration Management Program}

A configuration management program shall be established, implemented, and maintained in accordance with the NMTP Nuclear Facility Configuration Management Plan (LLNL latest revision-e). This program includes the following key elements:

- Program management.

- Design requirements.

- Document control.

- Change control.

- Assessments.

\subsubsection{Fire Protection Program}

A fire protection program shall be established, implemented, and maintained to reduce threats to the public, worker, and the environment resulting from a fire. This program is in accordance with DOE order 420.1B (DOE 2005b). This program includes the following key elements:

- A 20-ft exclusion zone marked in the DWTF yard between the Waste Storage Facilities and the B695 Segment.

- Routine fire protection assessments are conducted to identify fire hazards.

- Inspection, testing, and maintenance of fire protection systems (e.g., fire suppression, fire detection).

- $\quad$ No trucks allowed in TRU storage areas.

- No flammable fueled forklifts stored in TRU storage areas. 


\subsubsection{Emergency Preparedness Program}

An emergency preparedness program shall be established, implemented, and maintained to ensure that RHWM personnel are trained (in accordance with the RHWM Training Implementation Matrix) to react appropriately to emergencies, whether local or site-wide. This program is implemented by the applicable elements of Document 22.1, "Emergency Preparedness and Response," in the ES\&H Manual, in the RHWM Contingency Plan (LLNL latest revision-b), and in the FSPs. This program includes personnel response procedures and evacuation routes. The LLNL Emergency Plan (LLNL latest revision-c) describes the system's organizational elements, interfaces, authorities, responsibilities, resources, and actions to be taken in response to emergencies.

\subsubsection{In-service Inspection \& Test, and Maintenance Programs}

An in-service inspection \& test program and maintenance program shall be established, implemented, and maintained to ensure the integrity of the Design Features in Section 5.6. The In-service Inspection \& Test Program includes the approved TRU waste container maintenance program and building inspection program as described below. Inspections and tests shall be performed by qualified personnel.

An approved TRU waste container maintenance program shall be established, implemented, and maintained to preserve container integrity. This program includes:

- Initial acceptance, weekly, and off-normal event inspections of approved TRU waste container visually verifying vents are present on all approved TRU waste container, except TRU oversize boxes and LLW converted to TRU waste after assay as well as to evaluate the integrity, to include checks for rusting, corrosion, damage, denting, swelling, and damage to filter vents.

A building and partition inspection program shall be established, implemented, and maintained. This program includes:

- Inspections every five years or less by a qualified engineer (e.g., structural, civil, fire protection) to verify that significant physical deterioration or damage of the structural system has not occurred and the system meets applicable PC-2 requirements.

\subsubsection{Quality Assurance Program}

A quality assurance (QA) program shall be established, implemented, and maintained in accordance with 10 CFR 830, Subpart A, "Quality Assurance Requirements" and DOE Order 414.1C, Quality Assurance. This program ensures that the design, construction, modification, configuration and operation of safety-class and safety-significant SSCs meet applicable DOE and LLNL engineering and safety standards and is integrated into the Configuration Management Program. 


\subsubsection{Occurrence Reporting}

A program shall be established, implemented, and maintained for occurrence reporting of events and conditions that have safety, health, or environmental implications. This program ensures that both NNSA and LLNL management are informed of all events that could (1) impact the health and safety of the public, (2) seriously impact the intended purpose of NNSA facilities, (3) have a noticeably adverse effect on the environment; or (4) endanger the health and safety of workers. The program complies with DOE Order 231.1A, Change 1, including DOE Manual 231.1-2, Occurrence Reporting and Processing of Operations Information, and includes the following key elements:

- Preservation of the scene.

- DOE and management notification.

- Incident and causal analysis.

- Development of action items.

- Event or condition categorization.

\subsubsection{Hazardous Material Protection Program}

A hazardous material protection program shall be established, implemented, and maintained to ensure that exposure of employees, subcontractors, visitors, and members of the general public to hazardous materials is controlled to safe levels consistent with the ALARA principle. The program includes the following key elements:

- $\quad$ Single Container Inventory Limit (SCIL) limits the quantity of a chemical that can be stored in any one container.

\subsubsection{Traffic Control Program}

A traffic control program shall be established, implemented, and maintained to provide protection from vehicular traffic for TRU waste in the yard. The traffic control program is intended to limit the speed of vehicles while in the yard and includes speed limits (15 mph) posted in the yard and vehicles required to stop at the yard gate before entering. This program is implemented through the FSPs.

\subsubsection{Minimum Staffing Requirements}

RHWM Facilities normally operate on a single day shift, Monday through Friday. There are no minimum staffing requirements for passive operations such as storage. The Facility Manager determines the minimum staffing requirements for operation of the facility. 
Table 5-3. Minimum Staffing Requirements

\begin{tabular}{|l|c|c|}
\hline \multicolumn{1}{|c|}{ Required Staffing } & $\begin{array}{c}\text { During normal working } \\
\text { hours }\end{array}$ & $\begin{array}{c}\text { After normal working } \\
\text { hours }\end{array}$ \\
\hline \hline Health and safety (H\&S) technician & $1^{\mathrm{a}}$ & $1^{\mathrm{b}}$ \\
\hline Facility Manager (or designee) & $1^{\mathrm{b}}$ & $1^{\mathrm{c}}$ \\
\hline
\end{tabular}

a The H\&S technician or equivalent health and safety representative approved by the Facility manager.

b LLNL Onsite - not required to be in the Facility.

c On call.

\subsubsection{Operating Support}

ES\&H support organizations provide technical support for radiation safety, fire protection, industrial hygiene, industrial safety, and environmental analysis. The Nuclear Operations Directorate provides support to meet safety basis and criticality safety requirements. Health \& safety technicians shall be on site when work is being performed and shall be on call at all other times. For emergencies (in case of accidents involving radioactive material) after normal working hours, emergency response personnel can be contacted by calling 911 . In the event of an emergency, additional LLNL support can be provided as part of the Emergency Preparedness Program.

\subsubsection{Facility Staff Qualifications and Training}

A training program shall be established, implemented, and maintained to ensure that personnel responsible for RHWM operations are trained and qualified, as applicable, to perform their assigned responsibilities safely. This program includes forklift and crane operators who handle waste containers, or who operate a forklift or crane in the vicinity of waste containers; such personnel shall be trained and licensed in accordance with LLNL requirements, with specific reference to safe practices for lifting and handling waste containers. The Training Implementation Matrix for the Radioactive and Hazardous Waste Management Division (LLNL latest revision-d) addresses the requirements of DOE Order 5480.20A, Change Notice 1, Personnel Selection, Qualification, and Training Requirements for DOE Nuclear Facilities (DOE 2001). 


\subsubsection{Recordkeeping}

A records retention program shall be established, implemented, and maintained as described in LLNL records management policies and procedures. The program includes retention of the following documents:

- Records and logs of operations.

- Records and logs of principal maintenance activities, inspections, repairs, and replacement of principal equipment items related to safety-significant SSCs.

- All reportable events/occurrences.

- Records of training and qualifications of Waste Storage Facilities staff.

- $\quad$ Records of USQ documents.

\subsubsection{Reviews and Audits}

Reviews are performed by facility staff to ensure that day-to-day activities are conducted in accordance with the safety basis. Some of these reviews are described in the Inspection Schedule and Guidance (LLNL latest revision-d). Technical review, audit, and self-assessment of facility activities and programs that affect safety are performed independent of the facility staff by ES\&H personnel and Nuclear Operations Directorate analysts and engineers.

Written records of facility reviews, technical reviews, audits, and assessments shall be maintained in accordance with the Quality Assurance (QA) Program. In conjunction with the QA Program and the Integrated Safety Management System (ISMS), Configuration Management (CM) ensures the Laboratory achieves its safety goal. The CM Program (LLNL latest revision-f), including the Unreviewed Safety Question (USQ) process, and QA Program provide a systematic process for assuring the status of facility safety basis requirements, and maintaining the appropriate descriptive documentation. The CM Program implements a graded approach, applying greatest rigor to management of configuration items whose failure poses the greatest risks.

\subsubsection{Deviations From Technical Safety Requirements}

\subsection{General}

The TSR document shall be prepared, reviewed independently, and approved in accordance with 10 CFR 830, Subpart B.

\subsection{Compliance}

The TSRs shall be complied with, except for reasonable action taken in an emergency (see Section 5.5.17.6, below). RHWM management is responsible for ensuring that the requirements of these TSRs are met. Compliance shall be demonstrated by establishing, implementing, and maintaining the required Specific Administrative Controls (SACs) and Administrative Control (AC) Programs. 


\subsection{Violation of TSRs}

Violation of a TSR occurs as a result of failure to comply with an AC statement.

\subsection{Violation of an Administrative Control}

Failure to comply with the SACs in Section 5.5.2 and 5.5.3 constitutes a TSR violation. For the programmatic ACs listed in Section 5.5.1, violation occurs when the failure is of sufficient magnitude that the intent of the referenced program is not fulfilled. The U.S. Department of Energy (DOE) shall have the right, in consultation with RHWM facility management, to determine if a particular noncompliance will be considered a TSR violation.

\subsection{Response to a TSR violation of a Specific Administrative Control or Administrative Program}

If a Specific Administrative Control or Administrative Program has been violated, proceed as follows:

- Evaluate and, if necessary, place the facility in a safe condition.

- Notify DOE of the violation in accordance with applicable LLNL procedures and DOE orders and regulations.

- Prepare an Occurrence Report in accordance with applicable LLNL procedures and DOE orders and regulations.

- Carry out the corrective actions to comply with the Specific Administrative Control or Administrative Program.

\subsection{EMERGENCY ACTIONS}

Emergency actions may be taken that depart from a requirement in the TSR provided that:

- An emergency situation exists;

- These actions are needed immediately to protect the public health and safety; and

- No action consistent with the TSR can provide adequate or equivalent protection.

Such emergency actions will be authorized by the facility manager, designee or incident commander and performed by personnel trained and qualified for the equipment or systems needed to perform the actions. If an emergency action is taken, both verbal notification and a written report will be made within 24 hours to the DOE Livermore Site Office Manager or designee. 


\section{Documented Safety Analysis for the Waste Storage Facilities}

\subsubsection{SPECIFIC INVENTORY LIMITS}

1. For each approved TRU waste container in B696R or B625, the amount of radioactive material shall be no greater than 50 PE-Ci based on Acceptable Knowledge. Drum loading and configuration shall be administratively controlled to remain consistent with the National Environmental Policy Act (NEPA) bounding consequence calculations.

Safety Function: A maximum inventory per container of 50 PE-Ci was used as the MAR for most hazard and accident analyses involving TRU waste. Thus, the container inventory limit is an assumed initial condition in the hazard and accident analyses in Sections 3.3 and 3.4 of the Waste Storage Facilities DSA. The SAC protects this assumption and ensures that the consequences determined in the hazard and accident analyses remain bounding.

Waste Storage Facilities are also required to comply with NEPA analysis in the current LLNL Environmental Impact Statement (EIS) (DOE 2005b). The NEPA analysis establishes a bounding consequence based on overall facility inventory parameters. This SAC also requires that drum loading and configuration, remain within the NEPA bounding consequence calculations (LLNL 2006). This limit was specifically used for all air craft crash scenarios with fire evaluated in the hazard and accident analysis.

Basis: This SAC limits the amount of radioactive material that can be impacted by postulated accidents involving TRU waste in the Waste Storage Facilities and maintains consistency with the NEPA bounding consequence calculations.

2. For each container, the fissile material inventory shall be no greater than 200 Pu-239 FGE.

Safety Function: 200 Pu-239 FGE was identified as an assumed condition in the hazard analysis criticality event scenarios. This control serves to limit the quantity of fissile material in each approved TRU waste container. The material form, packaging and segregation required by the Criticality Safety Program preclude the possibility of an inadvertent criticality for 200 grams of Pu-239. CSM 1344 (LLNL 2003), "Criticality Safety Evaluation On the Use of 200-gram Pu Drum Mass Limit for RHWM Waste Storage Operations," provides the technical basis for the $200 \mathrm{Pu}-239$ FGE.

Basis: This SAC limits the amount of fissile material to preclude an inadvertent criticality.

3. The amount of tritium in a waste container shall be no greater than 2,000 Ci based on Acceptable Knowledge.

Safety Function: A maximum inventory per container of 2,000 Ci of tritium was used as the MAR for the hazard and accident analyses. Thus, the container inventory limit for tritium is an assumed condition in the hazard and accident analyses in Sections 3.3 and 3.4 of the Waste Storage Facilities DSA, and serves to limit the quantity of tritium that can be impacted in accident scenarios. The SAC protects this assumption and ensures that the consequences determined in the hazard and accident analyses remain bounding.

Basis: This SAC limits the amount of radioactive material that can be impacted by postulated accidents involving LLW containing tritium in the Waste Storage Facilities. 
4. TRU waste arrays staged outside the building shall be limited to a maximum inventory of 200 PE-Ci and separated by a minimum of 10 feet.

Safety Function: The MAR of 200 PE-Ci was used in the hazard and accident analyses as the maximum inventory for an impacted array of staged waste containers in the yard. Thus, the outdoor array limit is an assumed condition in the hazard and accident analyses in Sections 3.3 and 3.4 of the Waste Storage Facilities DSA, and serves to limit the quantity of radioactive material that can be impacted in accident scenarios involving staged waste.

By separating arrays 10 feet (HC/AB-B696-0301), drums in one array will not fail from exposure to the critical radiant heat flux of $45 \mathrm{~kW} / \mathrm{m}^{2}$ (identified in WHC-SD-WM-TRP-246, 1995) from a fire in another array.

Basis: This SAC limits the amount of radioactive material that can be impacted by accidents in the yard.

\subsubsection{SPECIFIC CONTAINER HANDLING AND STORAGE PROVISIONS}

The following requirements are specified as individual controls:

1. TRU waste storage shall be limited to B696R and B625.

Safety Function: The hazard analysis assumes that TRU waste is stored in building structures meeting PC-2 requirements. In addition, it assumes that TRU waste is not stored coincident with flammable liquid storage areas. This control serves to limit the locations that are authorized to store TRU waste to protect these assumptions.

Basis: This SAC limits the locations that are authorized for TRU waste storage.

2. All TRU waste shall be stored in approved TRU waste containers (i.e., steel containers that satisfy the criteria provided in Section 4.4.1).

Safety Function: Containers provide a confinement function limiting worker exposures and radioactive waste vulnerability in accident scenarios involving containerized TRU waste. Accordingly, approved TRU waste containers meeting specified criteria were an assumed condition in the hazard and accident analyses for scenarios involving TRU waste. Approved TRU waste containers typically have vents, which minimize the potential for buildup of gases.

Basis: This SAC reduces the frequency of common spill and fire accidents during normal waste-container operations and reduces the probability of breaching of containers stored on either the first or second level during a natural phenomena event. Vents reduce the frequency of buildup of flammable gases from radiolysis which reduces the probability of a deflagration. 


\section{Documented Safety Analysis for the Waste Storage Facilities}

3. Approved TRU waste containers shall not be stacked more than two levels high. Ten drum overpacks and other approved TRU waste containers exceeding a nominal height of 4 feet shall not be stacked.

Safety Function: Stacking approved TRU waste containers no more than two high was identified in seismic hazard analysis scenarios as a credited control. Containers meeting the free drop test DOT Type A packaging performance criteria [49 CFR 173.465(c)(1)] are used to store TRU waste. These containers are designed to survive at least a 4-ft drop consistent with the performance criteria for Type A packaging. This SAC serves to ensure that stacked containers will not fall greater than 4 feet in the event of an earthquake, and hence will not breach. Ten drum overpacks are approximately 6 feet in height, and therefore, are not stacked.

Basis: This SAC minimizes the potential for drum failure from toppling since approved TRU waste containers are designed to withstand a 4-ft drop.

4. The lids for approved TRU waste containers shall not be removed in the Waste Storage Facilities.

NOTE: Lids may be removed for LLW that has been converted to TRU WASTE following acceptance by RHWM in order to replace the lid with one that has a filter vent.

NOTE: Removal of a filter vent for maintenance, replacement or sampling is not lid removal.

Safety Function: The hazard and accident analyses assume that TRU waste in the Waste Storage Facilities is maintained in closed containers. The assumed condition in the Waste Storage Facilities DSA for all TRU waste scenarios is that the waste is confined in approved TRU waste containers. Removing the lids of approved TRU waste containers is outside the scope of work at the Waste Storage Facilities.

Basis: The hazard and accident analyses assume that waste is maintained in metal containers with closed lids. Removing the lids of Approved TRU waste containers is outside the scope of work at the Waste Storage Facilities. Removing and replacing filter vents is allowed for maintenance, non-intrusive inspection, and sampling activities. Filter vents do not contribute to the overall structural integrity of a metal container; the removal of the filter vents does not affect the overall structural integrity of a metal container.

5. Approved TRU waste containers shall not be staged less than $130 \mathrm{~m}$ from the Greenville Road fence line (i.e., east of the B693 structure).

Safety Function: The accident analysis in Section 3.4 of the Waste Storage Facilities DSA assumed that releases of TRU waste occurred no less than $130 \mathrm{~m}$ from the site boundary (Greenville Road fence line). Thus, this distance is an assumed condition in the accident analysis in Section 3.4 of the Waste Storage Facilities DSA, and serves to limit the consequences to the off-site public. 
Basis: This SAC provides assumptions in the DSA since $130 \mathrm{~m}$ is the minimum distance to the fence line assumed for postulated TRU waste accidents involving staged waste in the hazard and accident analyses.

6. Only waste in metal containers and on metal pallets shall be allowed in TRU waste storage areas.

Safety Function: The use of metal containers and pallets for waste stored in TRU waste storage areas limits the potential for fire initiation and propagation during operational or other events in TRU waste storage areas by limiting available combustibles. This is a credited control for waste handling and natural phenomena hazard scenarios in the hazard analysis. This control serves to ensure that low-level, hazardous, and other wastes that can be stored coincident with TRU waste are in non-combustible packaging and on noncombustible pallets.

Basis: This SAC limits the potential for fire initiation and propagation during operational or other events in TRU waste storage areas to mitigate consequences from fires involving TRU waste.

7. Combustible loading shall be limited to an average of 7 pounds of equivalent ordinary combustibles per square foot, excluding waste containerized in metal packaging, in B625 and B696R.

Safety Function: The safety function of the SAC is to limit the size of a fire in B625 and B696R.

Basis: The 7-lb/ft ${ }^{2}$ fire loading limit ensures that the amount of combustible material allowed in B625 and B696R is no more than assumed in the hazard analysis and accident analysis. The B696S/B696R fire-resistive partition is expected to maintain segmentation between B696S and B696R in the event of a $7-\mathrm{Ib} / \mathrm{ft}^{2}$ fire.

\subsection{DESIGN FEATURES}

The following are design features identified in Chapter 3 to be included in the TSRs: approved TRU waste containers; the B625 and B696R structural systems; and the B696S/B696R partition.

\subsubsection{EQUIPMENT IMPORTANT TO SAFETY}

The following are Equipment Important To Safety:

- B625 Structural System (Safety Significant SSC)

- B625 Fire Suppression System (Important Defense-In-Depth)

- B696R Structural System (Safety Significant SSC)

- B696S/B696R Partition (Safety Significant SSC)

- B696R Fire Suppression System (Important Defense-In-Depth)

- $\quad$ Approved TRU Waste Containers (Safety Significant SSC) 


\subsection{INTERFACE WITH TSRS FROM OTHER FACILITIES}

No TSRs from facilities located near the Waste Storage Facilities directly affect this safety basis. The partition between B696R of the Waste Storage Facilities and B696S of the B695 Segment of the DWTF is considered an interface because it is shared by both nuclear facilities. This wall is inspected at established intervals to ensure it maintains its function.

\subsection{REFERENCES}

DOE (1997), Hazard Categorization and Accident Analysis Techniques for Compliance with DOE Order 5480.23, Nuclear Safety Analysis Reports. DOE-STD-1027-92, Change Notice 1. U.S. Department of Energy, Washington, DC, September 1997.

DOE (2001), Personnel Selection, Qualification, and Training Requirements for DOE Nuclear Facilities. DOE Order 5480.20A, Department of Energy, Washington, DC (July 2001).

DOE (2004), Environment, Safety, and Health Reporting, DOE Order 231.1A, U.S. Department of Energy, Washington, DC (August 2003).

DOE (2005a), Facility Safety. DOE Order 420.1B, U.S. Department of Energy, Washington, DC, December 2005.

DOE (2005b). Final Site-wide Environmental Impact Statement for Continued Operation of Lawrence Livermore National Laboratory and Supplemental Stockpile Stewardship and Management Programmatic Environmental Impact Statement, DOE/EIS-0348, DOE/EIS0236-S3, March 2005.

DOE (2006), Preparation Guide for U.S. Department of Energy Nonreactor Nuclear Facility Safety Analysis Reports. DOE-STD-3009-94, Change Notice 3. U.S. Department of Energy, Washington, DC, March 2006.

HC/AB-B696-0301, "Fire involving flammable liquids and separation distances," Joong M. Yang, Lawrence Livermore National Laboratory, Livermore, CA, March 2003.

LLNL (2006), Memo from Thom Kato to Jack Sims, "Modification to Individual Container Limits for Radioactive Waste Storage at Building 625 (B625)," Lawrence Livermore National Laboratory, Livermore, CA, July 10, 2006.

LLNL (latest revision-a), Environment, Safety and Health Manual, Lawrence Livermore National Laboratory, Livermore, CA UCRL-AM-133867, latest revision.

LLNL (latest revision-b), Training Implementation Matrix for the Radioactive and Hazardous Waste Management Division, Lawrence Livermore National Laboratory, Livermore, CA UCRL-AR-116655, latest revision.

LLNL (latest revision-c), Contingency Plan for Radioactive and Hazardous Waste Management Facilities: Area 612, Area 514, Building 233 CSU, and the Decontamination and Waste Treatment Facility, Lawrence Livermore National Laboratory, Livermore, CA, UCRL-AR127066, latest revision.

LLNL (latest revision-d), Inspection Schedule and Guidance, Lawrence Livermore National Laboratory, Livermore, CA. 
NNSA/LLNS (2009), Management and Operating Contract between The US Department of Energy/National Nuclear Security Administration and Lawrence Livermore National Security, No. DE-AC52-07NA27344, February 27, 2009.

WHC-SD-WM-TRP-246 (1995), Solid Waste Drum Array Fire Performance, Westinghouse Hanford Company, 1995. 
This page intentionally left blank. 


\section{CHAPTER 6 \\ PREVENTION OF INADVERTENT CRITICALITY}

\section{$6.1 \quad$ INTRODUCTION}

The Waste Storage Facilities are Category 2 nuclear facilities for the storage of containerized radioactive waste. The radioactive waste stored in these facilities consists of low-level waste (LLW), transuranic (TRU) waste, mixed waste, and combined waste. The fissionable materials in LLW are mostly Nat-U/Dep-U and those in TRU waste are fissile materials, primarily Pu-239. Therefore, TRU waste is more of a criticality safety concern.

The Waste Storage Facilities are Category 2 nuclear facilities based on their total fissile materials inventories. The average fissile materials loading in individual approved TRU waste containers is approximately $10 \mathrm{~g} \mathrm{Pu}-239$ fissile gram equivalent (FGE). The potential for inadvertent criticality is predicated on the implementation of the LLNL criticality safety program and the scope of the facility operations. Criticality safety controls developed for these facilities are implemented in the Facility Safety Plans (FSPs). The double contingency principle and the defense-in-depth approach have been used in the development of the criticality safety controls to prevent inadvertent criticality for all operations.

This chapter describes the Criticality Safety Program for the Waste Storage Facilities and the means by which inadvertent criticality is prevented. This chapter includes the following:

6.2 Requirements - Lists the LLNL Criticality Safety standards in the NNSA/LLNS Contract Appendix G (NNSA/LLNS 2009) including the relevant DOE Orders required for establishing the safety basis of the facilities specific to this chapter.

6.3 Criticality Concerns - Discusses the probability of the occurrence of an inadvertent criticality accident in the facilities.

6.4 Criticality Safety Controls - Discusses the criticality safety controls in the facilities including a general discussion on the criticality safety basis and the approach used to ensure criticality safety. Also included in this section is the application of the double contingency principle in criticality safety.

6.5 Criticality Protection Program - Describes the Criticality Safety Program for the facilities and major elements of the criticality safety programmatic infrastructure needed to ensure that the criticality safety program is effective. Topics covered include Criticality Safety Plans and Procedures, Criticality Safety Training, and selfassessments.

6.6 Criticality Instrumentation - Justifies that a criticality accident alarm or detection system is not required in any of the Waste Storage Facilities. 


\subsection{REQUIREMENTS}

This section contains the directives in effect as of February 2009 as implemented in the Lawrence Livermore National Security, LLC, Contract No. DE-AC52-07NA27344

(NNSA/LLNS 2009). Specific sections of these directives are relevant to the content of this chapter. This section also contains the codes, standards, regulations, and DOE orders specific to this chapter and required to establish the safety basis of the facility.

\section{U.S. Department of Energy}

DOE O 420.1B , Facility Safety (DOE 2005).

\section{ANSI Standards}

ANSI/ANS-8.20-1991, Nuclear Criticality Safety Training

ANSI/ANS-8.22-1997, Nuclear Criticality Safety Based on Limiting and Controlling Moderators

ANSI/ANS-8.23-1997, Nuclear Criticality Accident Emergency Planning and Response

\subsection{CRITICALITY CONCERNS}

The Waste Storage Facilities deal with the storage of radioactive waste in containers. Many of these containers include fissionable materials. These fissionable materials are mostly in the form of Pu-239 in TRU waste and Nat/Dep-U in low-level waste. Pu-239 poses the main criticality concern. The average TRU container includes approximately 10 grams of Pu-239 FGE. Although the total fissionable material inventory of these facilities exceeds that of a critical mass, the material form, packaging and segregation preclude the possibility of an inadvertent criticality.

Criticality safety evaluations performed by the LLNL Criticality Safety Division indicate that all normal and credible upset conditions for these facilities are safe with respect to criticality safety (LLNL 2003). These evaluated optimized conditions with very conservative assumptions on the fissile drum contents, which are much higher than the average drum contents stored at this facility. O'Connell and Greybeck performed a probabilistic risk assessment (PRA) on RHWM storage operations in 2001 (O'Connell 2001). Their results show that inadvertent criticality is beyond extremely unlikely (or incredible). Based on the RHWM approved TRU waste container fissionable material contents and the scope of RHWM operations, their PRA work remains valid for 200 Pu-239 FGE containers and can be used as a demonstration of the incredibility of inadvertent criticality for current RHWM storage operations. 


\subsection{CRITICALITY SAFETY CONTROLS}

Criticality Safety in the Waste Storage Facilities is ensured by a combination of engineering and administrative controls on:

- Container sizes and types

- Quantities of fissionable materials

- Amount of moderators and reflectors, and

- Interaction between drums and arrays

Furthermore, a rigorous peer review process and a formal training program are in place to ensure effective implementation of the criticality safety controls.

Geometry, interaction, moderation, and mass are the primary criticality safety parameters that are important in developing criticality controls. For RHWM operations including storage operations at the Waste Storage Facilities, the principal defense against inadvertent criticality is to control the amount of fissionable materials so that the accumulation of a critical mass can be effectively prevented.

The overall approach in developing criticality controls for the Waste Storage Facilities operations emphasizes container controls and storage array controls. Criticality controls are developed based on a detailed understanding of operations including normal and credible upset conditions, system reactivity analysis, and formulation of defense-in-depth barriers to ensure subcritical configurations. Detailed neutronic evaluations were performed to assess the adequacy of the criticality controls for containers and arrays.

\subsubsection{ENGINEERING CONTROLS}

Since these are storage facilities, the engineering control used for waste handling and storage operations is the use of approved storage containers, such as steel drums and steel waste boxes for TRU waste storage. Containers are used to provide spacing and to isolate the fissionable materials in adjacent drums to minimize neutron interaction between drums.

\subsubsection{ADMINISTRATIVE CONTROLS}

All operations involving fissionable materials in the Waste Storage Facilities storage operations are subject to administrative criticality safety controls, which are applied to drums and arrays. The drum controls include fissionable material mass limits as well as moderator and reflector types and mass limits. The array controls include configuration (uniform or mixed-container), spacing, and drum-stacking. The fissile material inventory per container is limited to 200 Pu-239 FGE. 
Guidance to fire fighters is provided by the assignment of a Criticality Hazard Type for each operation in accordance with the definitions given in the LLNL ES\&H Manual, Document 20.6, "Criticality Safety." For the Waste Storage Facilities there are no restrictions on the use of water for fire suppression purposes.

\section{Evaluated Containers}

Programmatic controls are implemented in the various waste acceptance procedures as well as the FSPs to ensure that each container type used to store fissionable material contains no more than the authorized quantity of fissile material. These controls also incorporate limits on reflectors and moderators.

\section{Storage Array Configuration}

Programmatic controls are implemented in the FSPs to ensure that the storage configuration of the waste is safe. These controls include necessary configuration requirements for the various types of containers that may be stored in the Waste Storage Facilities.

\subsubsection{APPLICATION OF DOUBLE CONTINGENCY PRINCIPLE}

DOE Order 420.1B invokes ANSI/ANS-8.1-1983, R88 "Nuclear Criticality Safety in Operations with Fissionable Materials Outside Reactors" which defines the Double Contingency Principle.

For the Waste Storage Facilities operations, criticality safety is assured through the application of multiple (more than two) barriers exceeding the requirements of the Double Contingency Principle. For example, storage arrays will have the following barriers: fissionable materials mass limit, solid moderator limit, reflector limit, container size, and array spacing controls. A probabilistic risk assessment evaluation covering all credible external and internal events has concluded that there is no credible risk of a criticality accident.

In summary, the criticality safety controls in the FSPs ensure that a criticality accident is not possible for all normal and credible upset conditions. The double-contingency principle is strictly followed in the development of the criticality safety controls for the Waste Storage Facilities operations.

\subsection{CRITICALITY PROTECTION PROGRAM}

The LLNL Criticality Safety Program is defined in the LLNL ES\&H Manual, Document 20.6, "Criticality Safety." This program meets applicable regulatory requirements and applies to all LLNL nuclear facilities including the Waste Storage Facilities. Key areas covered in this program are discussed below.

\subsubsection{CRITICALITY SAFETY ORGANIZATION}

Specific responsibilities of the Waste Storage Facilities personnel and supporting organizations are described in the FSPs. Descriptions of roles and responsibilities for various line organizations and support organizations, such as the Criticality Safety Division, are described in detail in Document 20.6, "Criticality Safety," of the LLNL ES\&H Manual. 


\subsubsection{CRITICALITY SAFETY PLANS AND PROCEDURES}

Formal documented criticality safety evaluations (CSES) are required for all fissionable material operations in the Waste Storage Facilities. Criticality safety mass limits and controls are derived from the criticality safety evaluations. The LLNL Nuclear Criticality Safety Division is responsible for performing CSEs. All CSEs are performed by qualified criticality safety engineers. These CSEs meet the following minimum requirements:

- CSEs are performed to the LLNL criticality safety requirements found in Document 20.6, "Criticality Safety," in the ES\&H Manual.

- CSEs show that all normal and credible upset operating conditions are subcritical under the Double Contingency Principle.

- CSEs document the calculations and expert professional judgments used in determining that criticality safety is ensured.

- CSEs for new operations, not currently addressed by an approved CSE, are completed before any fissionable material is processed, stored, or relocated.

All CSEs are subject to a formal peer review process prior to their approval.

Criticality safety in the Waste Storage Facilities is governed by the FSPs. CSEs provide the technical bases for the criticality controls implemented in the FSPS.

\subsubsection{CRITICALITY SAFETY TRAINING}

Fundamentals of Criticality Safety or its equivalent is required for the Waste Storage Facilities personnel. The LLNL Nuclear Criticality Safety Division provides this training. On-the-job training is provided by the Facility Point of Contact with assistance provided by criticality safety engineers.

\subsubsection{DETERMINATION OF OPERATIONAL NUCLEAR CRITICALITY LIMITS}

The development of operational nuclear criticality limits is based upon assessment of the bounding conditions for normal operations and credible process upset conditions. Since the Waste Storage Facilities deal with storage of radioactive wastes, the process upset conditions for these facilities are primarily those associated with waste handling and storage operations.

The configurations of fissionable materials in normal operations are less reactive than upset conditions, such as loss of controls on fissionable materials mass. Therefore, the bounding scenarios for credible upset conditions bound the reactivities of normal operations.

All of the normal operations and credible upset conditions have been demonstrated to be subcritical. No safety-class or safety-significant SSCs have been identified related to criticality safety concerns. The LLNL Criticality Safety Program is a programmatic administrative control. A probabilistic risk assessment by O'Connell and Greybeck also independently showed that inadvertent criticality is not credible for RHWM waste storage operations (O'Connell 2001). 


\subsubsection{CRITICALITY SAFETY INSPECTIONSIAUDITS}

As an inadvertent criticality event is not credible in the Waste Storage Facilities, formal criticality safety audits are not required per LLNL ES\&H Manual, Document 20.6, "Criticality Safety." However, as a Category 2 facility, inspections, walkthroughs, or other assessments may be performed at the request of Facility Management or as deemed appropriate by criticality safety engineers to ensure effective implementation of criticality safety controls.

\subsubsection{CRITICALITY INFRACTION REPORTING AND FOLLOW-UP}

Infractions are deviations from criticality safety controls. The LLNL ES\&H Manual, Document 20.6, "Criticality Safety," specifies mandatory actions to be taken upon discovery of an actual or suspected infraction.

\subsection{CRITICALITY INSTRUMENTATION}

The Nuclear Criticality Safety Division has performed criticality safety evaluations to support the operations in these facilities and to ensure that a criticality accident is not possible under all normal and credible upset conditions. Since inadvertent criticality is not credible, a criticality accident detection or alarm system is not required for the RHWM waste storage operations per Paragraphs 4.3.3.b and 4.3.3.e of DOE Order 420.1B. Furthermore, there are no safety-class or safety-significant equipment or systems identified.

\subsection{REFERENCES}

DOE (2005), Facility Safety. DOE Order 420.1B, U.S. Department of Energy, Washington, DC, December 2005.

LLNL (latest revision). Environment, Safety, and Health Manual. Lawrence Livermore National Laboratory, Livermore, CA, UCRL-MA-133867, latest revision.

LLNL (2003), CSM 1344, "Criticality Safety Evaluation On the Use of 200-gram Pu Drum Mass Limit for RHWM Waste Storage Operations," Lawrence Livermore National Laboratory, August 2003.

NNSA/LLNS (2009), Management and Operating Contract between The US Department of Energy/National Nuclear Security Administration and Lawrence Livermore National Security, No. DE-AC52-07NA27344, February 27, 2009.

W.J. O' Connell and E.M. Greybeck (2001). Probability Analysis of Absence of Credible Criticality in Waste Storage in the HWM Facility. Lawrence Livermore National Laboratory, CA, UCRL-ID-143685, April 2001. 


\section{CHAPTER 7 RADIATION PROTECTION}

\subsection{INTRODUCTION}

This chapter addresses the Radioactive and Hazardous Waste Management (RHWM) Division's radiation protection program. In addressing occupational radiation protection for the Waste Storage Facilities, the facility safety plans (FSPs) for these facilities implement site requirements specified in the LLNL ES\&H Manual (LLNL latest revision-a).

\subsection{REQUIREMENTS}

This section contains the directives in effect as of February 2009 as implemented in the Lawrence Livermore National Security, LLC, Contract No. DE-AC52-07NA27344

(NNSA/LLNS 2009). Specific sections of these directives are relevant to the content of this chapter. This section also contains the codes, standards, regulations, and DOE orders specific to this chapter and required to establish the safety basis of the facility.

\section{U.S. Department of Energy (DOE)}

DOE Order 435.1, Change Notice 1, Radioactive Waste Management

DOE Order 5400.5, Change Notice 2, Radiation Protection of the Public and the Environment

\section{Code of Federal Regulations}

10 CFR 835, Occupational Radiation Protection

10 CFR 830, Nuclear Safety Management

\subsection{RADIATION PROTECTION PROGRAM AND ORGANIZATION}

A radiation protection program is established, implemented, and maintained to ensure that radiation exposure to employees, subcontractors, and visitors is controlled in accordance with requirements of 10 CFR 835, Occupational Radiation Protection (10 CFR 835), as implemented in ES\&H Manual Document 20.1, "Occupational Radiation Protection" and Document 20.2, "LLNL Radiological Safety Program for Radioactive Material."

The radiation protection program ensures that the Waste Storage Facilities are maintained and operated in accordance with 10 CFR 835. In particular, the radiation protection program assures that the occupational radiation exposures are maintained as-low-as-reasonably-achievable (ALARA) below 0.1 rem per year by design, radiation and contamination control, and procedures and training. 
The primary control for radiation protection is the container holding the waste and engineered controls in the design of the building that is storing the waste. The walls and roof provide a protective enclosure. Administrative controls and protective clothing provide secondary protection. ALARA concepts are applied to minimize exposures. Facility designs along with administrative requirements ensure that DOE stipulations for maximum dose are not exceeded. Radiation air monitoring devices are brought in, as required, for emergency situations or for monitoring requested by the health physicist.

The Hazard Control Department assigns ES\&H teams to oversee health and safety practices for each LLNL program. ES\&H Team 1, which includes a health physicist, oversees the safety of the Waste Storage Facilities. Additional organizational summary material is provided in Chapter 17, Management, Organization, and Institutional Safety Provisions.

\subsection{ALARA POLICY AND PROGRAM}

It is the policy of the DOE and LLNL that exposure of personnel to ionizing radiation associated with LLNL operations is to be maintained as low as reasonably achievable below regulatory limits. The ALARA objective is achieved by integrating the following factors:

- Management involvement.

- Education and training.

- Facility designs.

- Safety procedures.

- Radiation dosimetry.

- Workplace monitoring.

- Environmental monitoring.

- Emergency preparedness.

- Program evaluations.

- ALARA goal-setting.

\section{Benefit versus risk analyses.}

LLNL's detailed ALARA program is provided in ES\&H Manual Document 20.1, "LLNL Occupational Radiation Protection." The ALARA program is applicable to the Waste Storage Facilities activities. 


\section{Documented Safety Analysis for the Waste Storage Facilities}

\subsection{RADIOLOGICAL PROTECTION TRAINING}

Radiological protection training is required for all personnel appropriate to individual job assignments. General employees receive general radiation safety training prior to potential exposure. Allowance may be made for previous DOE training on generic radiation-safety topics (i.e., those not specific to a site or facility), provided the training had been received at another DOE site or facility within the past two years. General employees are instructed in radiation safety during new-employee orientation. Retraining is provided when there is a significant change to the radiological protection policies and procedures that affects general employees. Retraining is conducted at intervals not to exceed two years. Retraining can be accomplished by means of a self-study booklet that is sent to employees.

Radiological-worker training and retraining programs are in place for employees at LLNL who work on, with, or near ionizing-radiation-producing equipment or radioactive materials. Training or retraining is required prior to unescorted access into radiation areas and radiological buffer areas. Initial training is offered by the Hazard Control Department. Supervisors are required to identify workers who require training and ensure they attend the training. The Hazard Control Department provides the requisite training. In addition, on-the-job training (OJT) is provided by qualified instructors to customize the concepts of classroom training to a worker's actual work assignment.

Training programs for health and safety technicians are conducted at intervals not exceeding two years. The training familiarizes technicians with the fundamentals of radiation protection and procedures for maintaining exposures ALARA. The program includes classroom and applied training. The level of facility-specific training is commensurate with a technician's assignment.

Specialized radiological control courses are also available from the Hazard Control Department. The need for other courses is at the discretion of the supervisor or according to advice given by the health physicist responsible for the area. Direct supervisors and radiological-workers are required to complete training as specified in the Training Implementation Matrix for the Radioactive and Hazardous Waste Management Division (see Chapter 12).

\subsection{RADIATION EXPOSURE CONTROL}

This section summarizes the plans and procedures for controlling external occupational exposure to radiation, spread of contamination, and inhalation or ingestion of radioactive materials.

\subsubsection{ADMINISTRATIVE LIMITS}

The principal occupational radiation safety consideration in the Waste Storage Facilities is to minimize radiation exposure and assimilation of radioactive materials by employees. Activities in the Waste Storage Facilities comply with the intent of applicable DOE requirements as implemented by site policies and programs specified in ES\&H Manual Document 20.1, "Occupational Radiation Protection" and Document 20.2, "Radiological Safety Program for Radioactive Materials." 
The FSP and the ES\&H Manual provide information on isotope source handling and use, radiation safety systems, and safety procedures that provide administrative controls to prevent excessive radiation exposure. Each facility safety plan contains administrative limits on processes that are derived in accordance with the Radiation Protection Program to ensure that worker doses from normal operations and potential accidents remain ALARA.

Radioactive waste accepted by RHWM is limited to contact-handled waste. Therefore, the surface dose rate of a radioactive waste container may not exceed $200 \mathrm{mrem} / \mathrm{hr}$.

It is LLNL policy to comply with radiation protection standards given in 10 CFR 835, which specifies an annual radiation dose limit of 5 rem to the whole body, 50 rem to the skin and extremities, and 15 rem for the lens of the eye. When whole-body doses can exceed 100 mrem/yr, Administrative Control Limits (ACLs) will be established. The ES\&H Team health physicist determines, along with the Program, whether there is a need to establish any ACLs based on the most current dosimetry and bioassay results. Other ALARA reviews are conducted as described in ES\&H Manual Document 20.1.

\subsubsection{RADIOLOGICAL PRACTICES}

To prevent personnel contamination, LLNL provides protective apparel for individuals working with radioactive materials. All individuals working with dispersible radioactive materials are required to wear, at a minimum, a laboratory coat and gloves. Additional clothing and shoes may be specified, as needed. Radioactive contamination of surfaces outside work enclosures is maintained ALARA. Articles or equipment to be used in nonradioactive work areas or outside LLNL are decontaminated to levels that allow for unrestricted use, as required by the ES\&H Manual, Document 20.2, "LLNL Radiological Safety Program for Radioactive Materials." Waste containers are surveyed to verify external surfaces meet free release limits prior to being allowed in the Waste Storage Facilities.

Radiological areas are identified and maintained in accordance with ES\&H Manual Document 20.1. In general, all storage areas where radioactive materials are present are posted with warning signs containing applicable safety instructions and information for the radioactive materials present.

Access control to the Waste Storage Facilities is enforced. Only those personnel approved by the appropriate supervisors are authorized to work in these facilities. Such individuals are required to complete radiation worker training prior to working in an area where radioactive materials and waste are handled. Personnel not regularly assigned to the Waste Storage Facilities are required to prearrange access and be escorted while in the operational zones. 


\subsubsection{DOSIMETRY}

Personnel entering the Waste Storage Facilities are required to wear a dosimeter designed to measure radiation exposure to beta and gamma and neutron radiation as applicable. Personal alarming dosimeters are worn when deemed necessary by the health physicist. The health physicist determines the appropriate type of dosimeters needed for various types of radioactivematerial-handling activities. ES\&H Team 1 health physicists are responsible for promptly notifying RHWM management and the worker, as required by the ES\&H Manual or associated Dosimetry Program Manual, in the event of unexpected results from external or internal dosimetry. The health physicist is also responsible for investigating and evaluating the cause with priority given to preventing any further such exposures/intakes.

As stated in Chapter 6 of this report, a criticality accident is not a credible event in the Waste Storage Facilities. Thus, there are no criticality alarm systems, and nuclear accident dosimeters are not required.

\subsubsection{RESPIRATORY PROTECTION}

Respiratory protection devices are available for emergency response by trained personnel or for operations that the Industrial Hygienist and/or the Health Physicist determine respiratory protection is necessary. The devices are used when engineering controls (e.g., safety enclosures or proper ventilation) are not feasible or when emergency conditions develop. The need for respiratory protection for radiological purposes is determined by the health physicist.

\subsection{RADIOLOGICAL MONITORING}

The Hazard Control Department administers the program that meets 10 CFR 835 and ES\&H Manual Document 20.2, "LLNL Radiological Safety Program for Radioactive Materials," requirements. This program includes:

- $\quad$ Measuring ambient radiation fields.

- Monitoring for airborne contamination.

- Surveying for surface contamination.

Qualified individuals in the Hazard Control Department also select, obtain, calibrate, distribute, and maintain radiation-monitoring instruments, as needed. Radiation monitoring devices and sampling equipment (e.g., air, soil, and water) will be brought in, as required. Health physicists will evaluate on a case-by-case basis the use of CAMs and PASs, which will be used when operations requiring them are conducted in the Waste Storage Facilities.

\subsection{RADIOLOGICAL PROTECTION INSTRUMENTATION}

The health physicist supporting the RHWM Division prescribes a radiation monitoring program that meets requirements of ES\&H Manual Document 20.2. This program includes the type of monitoring (e.g., air, contamination surveys), the type of instrumentation needed, the type of detectors, sensitivities of instruments, and other information. 


\subsection{RADIOLOGICAL PROTECTION RECORD-KEEPING}

Dosimeter readings are obtained and recorded, and statements of accumulated external occupational radiation doses are provided annually to all employees, as required by $10 \mathrm{CFR}$ 835, Occupational Radiation Protection, per NNSA/LLNS Contract DE-AC52-07NA27344. Under existing programs, employees are notified of any positive radiation dose. Any radiation dose that exceeds the limits, as stated in ES\&H Manual Document 20.1, "LLNL Occupational Radiation Protection," is reported to the supervisor and to the person involved as soon as the information is available. The Hazard Control Department investigates the cause of such doses and maintains and stores all occupational radiation dose records for LLNL. Records and reports of dosimetry results and any other monitoring results are maintained per ES\&H Manual Document 20.1.

\subsection{OCCUPATIONAL RADIATION EXPOSURES}

The collective total effective dose (TED) for all RHWM workers between 2000 and 2005 ranged from 0.071 person-rem (2001) to 1.794 person-rem (2004) (Le 2005). Per 10 CFR 835, the maximum allowable exposure limit (TEDE) is $5 \mathrm{rem} / \mathrm{yr}$. The annual collective TEDE for all RHWM personnel based on historical data is less that the individual maximum allowable dose limit of 5 rem.

\subsection{REFERENCES}

CFR (10 CFR 835), Occupational Radiation Protection, U.S. Department of Energy, Code of Federal Regulations, Title 10, Office of the Federal Register, Washington, DC.

Le (2005), Email from Quang Le to Heather Larson, LLNL, December 2, 2005.

LLNL (latest revision-a), Environment, Safety, and Health Manual, Lawrence Livermore National Laboratory, Livermore, CA, UCRL-MA-133867, latest revision.

NNSA/LLNS (2009), Management and Operating Contract between The US Department of Energy/National Nuclear Security Administration and Lawrence Livermore National Security, No. DE-AC52-07NA27344, February 27, 2009. 


\section{CHAPTER 8 \\ HAZARDOUS MATERIAL PROTECTION}

\subsection{INTRODUCTION}

This chapter includes information on LLNL's Hazardous Material Protection Program, which is a part of the overall Health and Safety Program. The Health and Safety Program is devoted to identification, evaluation, and control of environmental factors found in the workplace as they apply to all facilities.

The objective of this chapter is to identify applicable aspects of the Hazardous Material Protection Program and to show how they protect against facility hazards and contribute to facility safety. The process for reducing occupational chemical exposures is also described in Section 8.11.

\subsection{REQUIREMENTS}

This section contains the directives in effect as of February 2009 as implemented in the Lawrence Livermore National Security, LLC, Contract No. DE-AC52-07NA27344 (NNSA/LLNS 2009). Specific sections of these directives are relevant to the content of this chapter. This section also contains the codes, standards, regulations, and DOE orders specific to this chapter and required to establish the safety basis of the facility.

\section{U.S. Department of Energy}

\section{Code of Federal Regulations}

10 CFR 830, Nuclear Safety Management

10 CFR 851, Worker Safety and Health Program

\subsection{HAZARDOUS MATERIAL PROTECTION PROGRAM AND ORGANIZATION}

The LLNL Health and Safety Policy, which includes requirements for hazardous material protection, is defined in the ES\&H Manual (LLNL latest revision-a). The policy is implemented through use of engineering and administrative controls and personal protective equipment (PPE). Procedures provide detailed requirements and responsibilities for implementing each part of the LLNL Health and Safety Policy. It is the policy of LLNL to implement DOE health and safety orders and to comply with prescribed standards and local, state, federal regulations, and Lawrence Livermore National Security, LLC policies. 
All management levels are responsible for developing and implementing procedures to protect workers against hazards in the workplace. LLNL also has the Hazard Control Department as one of its environment, safety, and health (ES\&H) organizations. By providing information on the radioactive and hazardous properties of materials and on relevant regulations, by recommending methods for control of hazardous materials, and by monitoring the work environment, this department, through its ES\&H teams, assists supervisors and employees in maintaining safe work areas. The head of the Hazard Control ES\&H Team (Team 1) assigned to the Radioactive and Hazardous Waste Management (RHWM) Division interacts directly with the Facility Manager.

The Waste Storage Facilities are monitored by ES\&H Team 1. This team consists of multidisciplinary specialists, including at least one industrial hygienist. Most LLNL industrial hygienists are certified by the American Board of Industrial Hygiene and/or have graduate degrees in industrial hygiene or a closely related field. The industrial hygienists provide the primary guidance for hazardous material protection and interface with facility staff and other ES\&H team members, including health and safety technicians, safety engineers, health physicists, fire protection engineers, safety analysis specialists, safety and health trainers, nuclear criticality safety specialists, Environmental Analysts, and Health Services Department personnel.

\subsection{ALARA POLICY AND PROGRAM}

Although there is no specific ALARA program for hazardous materials, a number of programs serve to maintain employee exposures to hazardous substances at levels below those of regulatory guidelines. The following documents from the ES\&H Manual establish policy and programs for hazardous materials:

Document 10.2, "LLNL Health Hazard Communication Program"

Document 11.1, "Personal Protective Equipment"

Document 14.1, "LLNL Chemical Safety Management Program"

These documents provide guidance and identify responsibilities for maintaining all exposures to hazardous materials well within DOE limits and federal and state regulations. All management levels of LLNL are responsible for developing and implementing controls and procedures to protect workers against hazards in the workplace. The facility safety plan (FSP) is the basic safety and health plan that must be followed by all personnel present within the building or area. Safety and health requirements specific to a hazardous waste operation are presented in the FSP or an Integration Work Sheet with a Safety Plan addendum (IWS/SP). 


\subsection{HAZARDOUS MATERIAL TRAINING}

The LLNL RHWM Training Program provides LLNL personnel with the necessary knowledge and skills to perform their duties safely and in an environmentally sound manner. RHWM personnel manage the Waste Storage Facilities. They are responsible for storing and treating waste and preparing shipment of LLNL's waste for offsite treatment and/or disposal. RHWM operations personnel working in the Waste Storage Facilities are trained in chemical safety. Training is provided for RHWM personnel as described in ES\&H Manual Document 40.1, "LLNL Training Program Manual" and the Training Implementation Matrix for the Radioactive and Hazardous Waste Management Division (LLNL latest revision-b). The ES\&H Team support for RHWM receive either general or occasional site worker training as described in 29 CFR 1910.120(e). Emergency response services beyond these training levels are provided by the LLNL/Alameda County Fire Department.

\subsection{HAZARDOUS MATERIAL EXPOSURE CONTROL}

\subsubsection{HAZARDOUS MATERIAL IDENTIFICATION PROGRAM}

All waste received at the Waste Storage Facilities is properly identified, prior to delivery, on a waste disposal requisition (WDR) form. Appropriate labels are affixed to waste containers in the waste accumulation area. The label is cross-referenced to the accompanying WDR form by its unique number. Potential radioactive (TRU and low-level), hazardous, mixed, and combined wastes are identified and documented through the following:

- Knowledge and assessment of the operations.

- Periodic walk-through surveys.

- Review of proposed projects and facilities.

- Maintenance of a hazardous material tracking system.

To assess potential hazards, all programs, facilities, and buildings are subject to review and evaluation by Hazards Control Department personnel. Results of the reviews are forwarded to the appropriate department so that any deficiencies can be corrected. Records of reviews are maintained by the Hazard Control Department. The program and activities that identify, analyze, and control potential hazardous material are described in the ES\&H Manual Document 14.1, "LLNL Chemical Safety Management Program," and the FSP.

\subsubsection{ADMINISTRATIVE LIMITS}

Several exposure limits are available. They are permissible exposure limits (PELs) established by the Occupational Safety and Health Administration (OSHA) or threshold limit values (TLVs) established by the American Conference of Governmental Industrial Hygienists (ACGIH). The lower of the two values for the same chemical is established as the administrative limit. DOE has established in 10 CFR 850 an "action level" for beryllium exposure. This action level triggers a series of additional controls if reached. LLNL implements this program in the ES\&H Manual Document 14.4, "Implementation of the Chronic Beryllium Disease Prevention Program Requirements." 
In order to limit exposures to co-located workers and to the public from accidents involving chemical waste, RHWM has established the Single Container Inventory Limit (SCIL) Program. An extensive list of toxic chemicals is maintained and updated, as required, listing the limit for each chemical in a container.

Although RHWM handles a large quantity of hazardous waste, the primary waste streams would be described as industrial hazardous waste such as dilute aqueous solutions, paint, oil, solvents, dilute corrosives, and fluorescent tubes. RHWM tracks the amount of chemical waste stored in a relational database. It is extremely difficult to maintain a meaningful real-time summarized inventory. The major difficulties in maintaining such an inventory are:

- Nomenclature - the same chemical can have multiple names

- Concentration - trace quantities in solution are far less toxic than the pure material

- Form - a fine powder is potentially more dangerous than a solid chunk

Because of the difficulty in maintaining a meaningful real-time chemical inventory, RHWM uses the SCIL Program. This program is based on the current Quantity value (Q value) chemical thresholds described in the LLNL ES\&H Manual Document 3.1, "Nonnuclear Safety Basis Program," revision September 9, 2009 (LLNL 2009). By using the Q values, the SCIL Program is designed to ensure that under a worst-case spill scenario, the concentration at 100 meters will be at a concentration that maintains the Waste Storage Facilities as Low Hazard facilities.

Before waste can be accepted into RHWM facilities, it goes through a series of reviews. One of these reviews is to verify if the waste meets the SCIL criteria. If it does not, then it is either repacked, shipped offsite from the field, or a calculation is performed to see if it can be safely accepted.

\subsubsection{OCCUPATIONAL MEDICAL PROGRAMS}

LLNL's Medical Monitoring Program, which is implemented by the Health Services Department, is described in ES\&H Manual Document 10.1, "Occupational Medical Program." This monitoring program includes physical examinations, medical evaluations and record-keeping of hazardous material exposures. Based on a hazard assessment of specific substances described in work control documents, the ES\&H Team industrial hygienist in consultation with supervisors and the Health Services Department determine the appropriate medical surveillance programs. Tailored medical surveillance programs for Hazardous Waste Workers, Beryllium Workers, and Respirator Users are common for hazardous waste technicians.

\subsubsection{RESPIRATORY PROTECTION}

LLNL's respiratory protection program is described in ES\&H Manual Document 11.1, "Personal Protective Equipment," and in Section 7.6.4 of this document. The process for reducing occupational chemical exposures is also described in Section 8.11. 


\subsection{HAZARDOUS MATERIAL MONITORING}

ES\&H Manual Document 14.1, "LLNL Chemical Safety Management Program" describes exposure monitoring for chemical hazards. Other sections of the ES\&H Manual for specific substances as well as procedures within the Hazards Control Department further detail how hazards are evaluated, monitored, and controlled.

ES\&H Manual Document 12.2, "Ventilation," and Document 12.3, "Evaluation and Control of Facility Airborne Effluents," provide the ventilation requirements and acceptance criteria for all new and modified facilities. This document provides the surveillance, maintenance, and systems-failure procedures for existing facilities. Area ES\&H teams conduct regular performance checks on all ventilation systems used for hazardous materials.

Monitoring for air and surface contamination is appropriate for initial evaluation of new waste handling procedures or after working conditions have been changed. Results will determine whether periodic monitoring is necessary.

The LLNL Site Annual Environmental Report (LLNL latest revision-c) provides information on the environmental monitoring activities conducted by the Environmental Protection Department. Activities include sampling and reporting results for air, sewage effluent, groundwater, surface water, soil, vegetation, and foodstuffs.

LLNL's environmental activities include radiological and nonradiological monitoring, effluentand compliance-monitoring, remediation, assessment of radiological releases and doses, and determination of the impact of LLNL operations on the environment and public health.

\subsection{HAZARDOUS MATERIAL PROTECTION INSTRUMENTATION}

The Hazard Control Department ES\&H Team 1 assists supervisors and employees in maintaining safe work areas by providing information on the hazardous properties of materials and relevant regulations, recommending methods for control, and monitoring the work environment. Instrumentation used for monitoring, sampling, and surveying is selected and placement determined by the appropriately qualified and trained member of the ES\&H team (e.g., IH, HP, IS). Information on the inventory and technical specifications of monitoring instruments are available in the Industrial Hygiene Instrument Laboratory.

\subsection{HAZARDOUS MATERIAL PROTECTION RECORD-KEEPING}

Results of hazardous material monitoring performed by the Hazard Control Department are documented in a report and provided to RHWM and the Health Services Department. Copies are maintained by Hazards Control according to department policies for authorized release only. Occupational exposure records are maintained per regulatory requirements. 


\section{Documented Safety Analysis for the Waste Storage Facilities}

\subsection{HAZARD COMMUNICATION PROGRAM}

In compliance with 29 CFR 1910.1200, the Hazard Control Department has a written Health Hazard Communication Program (ES\&H Manual Document 10.2, "LLNL Health Hazard Communication Program"). The purpose of the program is to ensure that hazardous materials have been evaluated and that this information is communicated to affected employers and employees. Other provisions of the Health Hazard Communication Program include:

- Identification and labeling of hazardous materials.

- Hazardous materials evaluation.

- Information and training.

RHWM implements the Health Hazard Communication Program for operations in the Waste Storage Facilities. Implementation of these provisions is discussed in ES\&H Manual Document 10.2, "LLNL Health Hazard Communication Program," and in the FSP.

\subsection{OCCUPATIONAL CHEMICAL EXPOSURES}

Potential for measurable or detectable levels of hazardous materials exists in the Waste Storage Facilities operations. Routine industrial hygiene surveillance of current RHWM operations in the Waste Storage Facilities have not shown exposures above LLNL adopted Occupational Exposure Limits (OELs). Although there have been previous operations with legacy waste materials that have exceeded OELs, none of those operations are currently performed. Controls (e.g., ventilation, respiratory protection) commensurate to the potential hazard shall be evaluated and recommended by the area ES\&H Team. A hazard assessment and analysis shall occur prior to the start of an operation. When operational parameters change (e.g., frequency, quantity, location), operations shall be reviewed to ensure adequacy of current control methodologies. Records of exposure assessments are available through the Industrial Hygiene Section.

\subsection{REFERENCES}

CFR (29 CFR 1910), Occupational Safety and Health Standards, U.S. Department of Labor, Code of Federal Regulations, Title 29. Office of the Federal Register, Washington, DC.

LLNL (latest revision-a), Environment, Safety, and Health Manual, Lawrence Livermore National Laboratory, Livermore, CA, UCRL-AM-133867, latest revision.

LLNL (latest revision-b), Training Implementation Matrix for the Radioactive and Hazardous Waste Management Division, Lawrence Livermore National Laboratory, Livermore, CA, UCRL-AR-116655, latest revision.

LLNL (latest revision-c), Environmental Report, Lawrence Livermore National Laboratory, Livermore, CA, UCRL-50027-96, latest revision. 
LLNL (2009). Environment, Safety, and Health Manual, Document 3.1, "Nonnuclear Safety Basis Program," Lawrence Livermore National Laboratory, Livermore, CA, UCRL-AM133867, September 9, 2009.

NNSA/LLNS (2009), Management and Operating Contract between The US Department of Energy/National Nuclear Security Administration and Lawrence Livermore National Security, No. DE-AC52-07NA27344, February 27, 2009. 
This page intentionally left blank. 


\section{CHAPTER 9 \\ RADIOACTIVE AND HAZARDOUS WASTE MANAGEMENT}

\section{$9.1 \quad$ INTRODUCTION}

The management of radioactive and hazardous waste is the overall mission and purpose of the Waste Storage Facilities. Although the purpose and operations are described in Chapter 2, this chapter is retained for completeness. The Waste Storage Facilities are Hazard Category 2 nonreactor nuclear facilities. Operations in these facilities are mainly those associated with storage of radioactive and hazardous waste, including TRU waste, LLW, mixed waste, California combined waste, and nonhazardous waste.

\subsection{REQUIREMENTS}

This section contains the directives in effect as of February 2009 as implemented in the Lawrence Livermore National Security, LLC, Contract No. DE-AC52-07NA27344 (NNSA/LLNS 2009). Specific sections of these directives are relevant to the content of this chapter. This section also contains the codes, standards, regulations, and DOE orders specific to this chapter and required to establish the safety basis of the facility.

\section{U.S. Department of Energy (DOE)}

DOE Order 435.1, Change Notice 1, Radioactive Waste Management

DOE Order 5400.5, Change Notice 2, Radiation Protection of the Public and the Environment

\section{Code of Federal Regulations}

10 CFR 830, Nuclear Safety Management

10 CFR 835, Occupational Radiation Protection

40 CFR 262, Standards Applicable to Generators of Hazardous Waste

40 CFR 264, Standards for Owners and Operators of Hazardous Waste Treatment, Storage, and Disposal Facilities

\section{California Code of Regulations}

22 CCR 66262, Standards Applicable to Generators of Hazardous Waste

22 CCR 66264, Standards for Owners and Operators of Hazardous Waste Transfer, Treatment, Storage, and Disposal Facilities 


\subsection{RADIOACTIVE AND HAZARDOUS WASTE MANAGEMENT PROGRAM AND ORGANIZATION}

This section summarizes the radioactive and hazardous waste management program and organization for the Waste Storage Facilities. Included in the discussion is an overview of safety management policies and philosophies used as the basis of the program.

\subsubsection{PROGRAM AND POLICIES}

The main operations within the Waste Storage Facilities is to accept, store, certify, and ship waste to disposal sites. See Chapter 2, "Facility Description," of this document for a description of the specific activities performed in the Waste Storage Facilities.

The Waste Storage Facilities include permitted waste treatment and storage facilities regulated under the Hazardous Waste Facility Permit for the LLNL Livermore Site. The permit was issued by the California Environmental Protection Agency Department of Toxic Substances Control (DTSC). LLNL manages hazardous and mixed waste in accordance with the conditions of this permit. The Operation Plan (LLNL latest revision-a) is a part of the Hazardous Waste Facility Permit issued by the DTSC.

In the area of radioactive waste management, LLNL's primary objective is to minimize potential impacts to the public and the environment, keeping all impacts ALARA below allowable limits. Waste management operations in the Waste Storage Facilities are also conducted in a manner that minimizes the potential impact to workers.

The Hazard Control Department provides assistance to RHWM supervisors and workers for both radiological and nonradiological occupational safety. The Environmental Protection Department is responsible for assisting RHWM personnel in protecting the environment from operations at the facility as well as providing guidance on pollution prevention.

\subsubsection{ORGANIZATIONAL STRUCTURE}

See Chapter 17, "Management, Organization, and Institutional Safety Provisions," of this document for a description of the Waste Management Program and Organization.

\subsubsection{TRAINING}

See Chapter 12, "Procedures and Training," of this document for a description of the RHWM Training Program. 


\subsubsection{PLANS AND PROCEDURES}

LLNL implements DOE's ES\&H policies and programs through site policies and programs specified in the LLNL ES\&H Manual (LLNL latest revision-b). RHWM safety management practices are in accord with the LLNL ES\&H Manual Document 20.2, "LLNL Radiological Safety Program for Radioactive Materials." Guidelines for safe management of waste are also covered in ES\&H Manual Document 36.1, "Hazardous, Radioactive, and Biological Waste Management Requirements" and Document 36.3, "Management of Satellite and Waste Accumulation Areas for Hazardous and Mixed Waste."

In addition, to perform operations within the Waste Storage Facilities efficiently and safely, controls specified within the facility safety plans (FSPs) are followed. All work in the Waste Storage Facilities beyond activities commonly performed by the public must be authorized according to the facilities work control process. RHWM procedures for specific activities are developed and maintained as described in Chapter 12, "Procedures and Training," of this document.

\subsection{RADIOACTIVE AND HAZARDOUS WASTE STREAMS OR SOURCES}

The waste types associated with the Waste Storage Facilities and the safety analyses of these materials are presented in Chapter 2, "Facility Description," and Chapter 3, "Hazard and Accident Analysis," of this document. RHWM wastes were identified from the 2005 LLNL EIS (DOE 2005). Appendices A and B of the EIS quantify waste generation for LLNL, and the reader is referred there for further detail. Specific information on the types of hazardous and mixed wastes managed in the Waste Storage Facilities can be found in the Operation Plan (LLNL latest revision-a).

\subsubsection{WASTE MANAGEMENT PROCESS}

This section summarizes the overall waste management plan, including the management policy or philosophy, at the Waste Storage Facilities. Included in the discussion is a summary of administrative practices important to effective management of waste. Operational practices are discussed in Chapter 2, "Facility Description" of this document. Note: Waste generated at the Waste Storage Facilities goes through the same administrative process as wastes entering from outside the Waste Storage Facilities.

When starting to fill a container during waste generation, Waste Generators and RHWM workers complete a waste disposal requisition (WDR). The WDR is used to document waste characterization, contain approvals, and identify chemical and radiological constituents. The WDR information is entered into a database management system that is maintained by RHWM for record keeping and retrieval. Each WDR is uniquely numbered to facilitate tracking through the computerized database. Subsequent management and treatment information is appended to the database to provide a complete disposition record of the waste stream. 
Characterization and identification data documented on Information Gathering Documents utilizes data from generator knowledge, fingerprint testing, sampling, swipes, and measurement with analytical equipment. The Information Gathering Documents are referenced on the WDR. Certifications are developed in accordance with their appropriate regulation. They are appended to the WDR.

Before waste is accepted into the Waste Storage Facilities, all WDR packages are reviewed to check that the waste is acceptable and to verify that the waste meets the acceptance criteria of the intended disposal site.

\subsubsection{WASTE SOURCES AND CHARACTERISTICS}

LLNL generates and manages both routine and non-routine wastes. Routine wastes are those generated during the normal operation of laboratories, test facilities, and research and development operations. Special, limited-duration projects, such as construction, that generate non-routine wastes are considered separately from facility operations. These types of projects can make a large contribution to the overall waste generation at LLNL and are difficult to reasonably forecast on an annual basis. Three types of projects are considered special operations: construction, decontamination and decommissioning, and environmental restoration. In addition to waste generated at LLNL, the Waste Storage Facilities will, on occasion, accept waste from other DOE Sites. The acceptance of waste into the Waste Storage Facilities is described in the sections above. Wastes may be generated at the Waste Storage Facilities as a result of sampling, handling containers, maintenance, cleanup of spills, and other activities. Waste generated within the Waste Storage Facilities are also reviewed for acceptance.

\subsubsection{WASTE-HANDLING OR WASTE-TREATMENT SYSTEMS}

Chapter 2, "Facility Description." and Chapter 3, "Hazard and Accident Analysis," of this document include discussions of operations and activities in the Waste Storage Facilities. These chapters include descriptions of waste handling and waste treatment in the Waste Storage Facilities.

\subsection{REFERENCES}

DOE (2005). Final Site-wide Environmental Impact Statement for Continued Operation of Lawrence Livermore National Laboratory and Supplemental Stockpile Stewardship and Management Programmatic Environmental Impact Statement, DOE/EIS-0348, DOE/EIS0236-S3, March 2005.

LLNL (latest revision-a), Operation Plan for Hazardous Waste Treatment and Storage Facilities, Livermore Site. Lawrence Livermore National Laboratory, Livermore, CA, latest revision.

LLNL (latest revision-b), Environment, Safety, and Health Manual, Lawrence Livermore National Laboratory, Livermore, CA, UCRL-AM-133867, latest revision.

NNSA/LLNS (2009), Management and Operating Contract between The US Department of Energy/National Nuclear Security Administration and Lawrence Livermore National Security, No. DE-AC52-07NA27344, February 27, 2009. 


\section{CHAPTER 10 \\ INITIAL TESTING, IN-SERVICE SURVEILLANCE, AND MAINTENANCE}

\section{$10.1 \quad$ INTRODUCTION}

This chapter discusses testing, surveillance, and maintenance programs as they relate to facility safety in the Waste Storage Facilities. Essential features of the in-service test and inspection program also are addressed.

\subsection{REQUIREMENTS}

This section contains the directives in effect as of February 2009 as implemented in the Lawrence Livermore National Security, LLC, Contract No. DE-AC52-07NA27344 (NNSA/LLNS 2009). Specific sections of these directives are relevant to the content of this chapter. This section also contains the codes, standards, regulations, and DOE orders specific to this chapter and required to establish the safety basis of the facility.

\section{U.S. Department of Energy}

DOE O 433.1A, Maintenance Management Program for DOE Nuclear Facilities (DOE 2001)

\subsection{INITIAL TESTING PROGRAM}

Initial testing or inspection on major repairs or modifications is performed under the In-service Inspection and Test Program. Initial testing or inspection for the Waste Storage Facilities consists of acceptance testing per design specifications and walkthroughs.

\subsection{IN-SERVICE INSPECTION \& TEST PROGRAM}

An in-service inspection \& test program is established, implemented, and maintained to ensure the integrity of the Design Features described in Section 5.6. Inspections and tests are performed by qualified personnel. The in-service inspection \& testing of safety significant SSCs (e.g., approved TRU waste containers, building structures) is discussed in Chapter 4.

Fire alarms, fire suppression systems, and fire extinguishers are inspected, tested, and maintained periodically for operational readiness. Emergency Management fire protection professionals, Emergency Management Alarms group, and Maintenance \& Utility Services Department also conduct periodic surveillances of fire suppression systems in accordance with applicable NFPA requirements. 


\section{Documented Safety Analysis for the Waste Storage Facilities}

\subsection{MAINTENANCE PROGRAM}

The RHWM maintenance program has been updated to meet DOE Order 433.1A. ES\&H Manual Document 52.1, "LLNL Maintenance Implementation Plan for Nonreactor Nuclear Facilities". Specific implementing details are found in RHWM-specific documents, such as the RHWM Maintenance Manual (LLNL latest revision-b). RHWM is responsible for maintaining SSCs and delineating requirements, including frequency of maintenance, calibration, and performance. The maintenance plan addresses the implementation of facility safety and operability and ensures that the capital investment in buildings and equipment is protected.

The graded approach to maintenance takes into account the potential for equipment failure on the following items, in order of importance: the public, laboratory workers, the environment, security and safeguards, and the Laboratory mission. A scale is used to rate anticipated results of the worst credible failure. Each structure, system, or component is assigned a risk rating. Areas and/or treatment units in the facilities are assigned a category (1 through 4) that corresponds to the highest risk rating for any structure, system, or component inside the area. The graded approach matches the category with the level of maintenance.

Category 1 is the most rigorous maintenance program, designed to emphasize reliability and minimize the probability of failure. Category 4 addresses maintenance limited to fixing broken items plus recurring activities, such as lubrication or cleaning. Safety-related systems in the Waste Storage Facilities have assigned risk categories, and the maintenance program is in accordance with the LLNL Maintenance Implementation Plan.

LLNL's overall real property and installed equipment are maintained by the Facilities and Infrastructure Directorate (F\&l). The Maintenance and Utilities Services Department (MUSD) Maintenance Implementation Plan for Non-reactor Nuclear Facilities provides the details to address requirements for the maintenance of real property and installed equipment in nuclear facilities. The maintenance of building structures, architectural systems, mechanical utility systems, electrical utility systems and other facility related systems are maintained by F\&l. Equipment and systems that are not part of a building's or facility's structures, utilities or operating systems are considered personal property or programmatic equipment and as such are the responsibility of the RHWM Division to indentify the service provider for maintenance. The RHWM Division maintenance program (which includes maintenance training, calibration, post-maintenance testing, and maintenance history) is detailed in the RHWM Maintenance Manual. Other LLNL organizations that assist RHWM in maintenance are the Emergency Management Department (EMD), Fleet Management Department, Information and Communication Services (ICS), the Hazards Control Department and private commercial vendors. RHWM maintenance procedures incorporate the Waste Storage Facilities designs and operations.

The MUSD and the EMD of the Facilities and Infrastructure Directorate provide the personnel for maintenance of the fire sprinklers and alarms. Journeyman pipefitters are trained in sprinkler piping and operations. Journeyman electricians are trained in alarm system operation and maintenance. 


\subsection{REFERENCES}

DOE (2001), Maintenance Management Program for DOE Nuclear Facilities, DOE Order 433.1A, U.S. Department of Energy, Washington, DC, June 1, 2001.

LLNL (latest revision-a), Environment, Safety, and Health Manual, Lawrence Livermore National Laboratory, Livermore, CA, UCRL-AM-133867, latest revision.

LLNL (latest revision-b), RHWM Maintenance Manual, Lawrence Livermore National Laboratory, Livermore, CA, latest revision.

NNSA/LLNS (2009), Management and Operating Contract between The US Department of Energy/National Nuclear Security Administration and Lawrence Livermore National Security, No. DE-AC52-07NA27344, February 27, 2009. 
This page intentionally left blank. 


\section{CHAPTER 11 OPERATIONAL SAFETY}

\subsection{INTRODUCTION}

This chapter describes the operational safety provisions, including the fire protection program, as they relate to the RHWM Waste Storage Facilities. Provisions in this information will satisfy the requirements of DOE-STD-3009-94, Change Notice 3. Operational safety and the fire protection program ensure that the Waste Storage Facilities can be operated without undue risk to the health and safety of facility workers, other onsite employees, or individuals at the site boundary. The general aspects of operational safety that are applicable to the facility are presented in Section 11.3, "Conduct of Operations." Conduct of operations for the Waste Storage Facilities follows the guidance specified by DOE Order 5480.19 , Change Notice 2 (DOE 2001), Conduct of Operations Requirements for DOE Facilities. Chapter 11 includes the basis for the conduct of operations program and the fire protection program.

\subsection{REQUIREMENTS}

This section contains the directives in effect as of February 2009 as implemented in the Lawrence Livermore National Security, LLC, Contract No. DE-AC52-07NA27344 (NNSA/LLNS 2009). Specific sections of these directives are relevant to the content of this chapter. This section also contains the codes, standards, regulations, and DOE orders specific to this chapter and required to establish the safety basis of the facility.

\section{U.S. Department of Energy}

DOE O 5480.19, Change Notice 2, Conduct of Operations Requirements for DOE Facilities

DOE Order 5480.20A, Personnel Selection, Qualification, and Training Requirements for DOE Nuclear Facilities

\section{Code of Federal Regulations}

10 CFR 830, Nuclear Safety Management

10 CFR 850, Chronic Beryllium Disease Prevention Program

10 CFR 851, Worker Safety and Health Program 


\subsection{CONDUCT OF OPERATIONS}

To ensure compliance with Chapter 1 of DOE Order 5480.19, Change Notice 2, the Waste Storage Facilities operate in accordance with ES\&H Manual Document 3.5, "Conduct of Operations for LLNL Facilities" (LLNL latest revision-a). Document 3.5 provides requirements and guidelines for the departmental elements to be used in developing directives, plans, and procedures relating to the conduct of operations at the Waste Storage Facilities. The practices and implementation of the programs described in this document provide consistent and auditable requirements, standards, and responsibilities for Waste Storage Facilities operations. Specific topical areas from DOE 5480.19 on conduct of operations that are considered in the Waste Storage Facilities are as follows:

- Operations Organization Administration. The RHWM facility manager, line manager, supervisors, and project leaders operating within the Waste Storage Facilities are responsible for ensuring the safety of operations and that an acceptable level of performance is achieved. The RHWM project leaders and group leaders are responsible for accomplishing division waste handling, processing and shipping goals, and the RHWM supervisors are responsible for directing day-to-day activities of employees and keeping management informed of operating problems and achievements. More information is provided in Chapter 17.

- Shift Routines and Operating Practices. Operations personnel adhere to the safety practices in the facility safety plans, conduct routine facility and equipment inspections and promptly notify supervisors of any unexpected situations. Personnel protection practices are followed to maintain personnel exposure as low as reasonable achievable to radiation, chemicals, toxic materials, or other personnel hazards. Through line management, the Waste Storage Facilities operations supervisor directs overall operations of the facility and ensures that only trained personnel are working in the facility.

- Communications. The Waste Storage Facilities provide adequate and reliable communication capabilities during routine and emergency conditions. The Waste Storage Facilities communication systems include telephones, emergency voice alarm (EVA) systems, personnel beepers, radios, and audible and visual alarms. Employees are instructed in the proper use of facility-specific communication devices. In addition, communications include fire pull stations that alert the onsite Fire Department Emergency Dispatch. A description of safety support systems is provided in Chapter 2.

- Control of On-Shift (On-the-Job) Training. Waste Storage Facilities employees who are new to an area may have a thorough technical background and a theoretical understanding of an operation, but on-the-job training (OJT) may still be required to ensure they understand specific details of an operation. Work conducted by personnel under instruction is carefully supervised to avoid errors that could have significant impact on safety or operations. OJT is conducted so that the trainee satisfactorily completes all of the required training objectives and receives maximum learning benefit from the experience. The training of workers meets the requirements of DOE Order 5480.20A. A description of training for workers is provided in Chapter 12, "Procedures and Training." 
- Investigation of Abnormal Events. Using the guidance provided in the ES\&H Manual Volume I, Part 4, "Feedback and Improvement," the RHWM facility manager is responsible for identifying abnormal events that require analysis. This document provides guidance for investigating abnormal events.

- Notifications. Employees or project leaders notify their line management of events that could affect the health and safety of the public or endanger the health and safety of employees. Line management is then responsible for notifying appropriate LLNL and DOE personnel, and other agencies, of these events. ES\&H Manual Document 4.5, "Incidents--Notification, Analysis, and Reporting," ensures the uniformity, efficiency, and thoroughness of such notifications consistent with DOE Order 231.1A.

- Controlling Equipment and System Status. The status of Waste Storage Facilities equipment is monitored. Systems or operations are controlled so that operations proceed according to specifications. Significant Waste Storage Facilities equipment is discussed in Chapter 2.

- Lockouts and Tagouts. Lockout and tagout is a proven procedure for ensuring that employees do not cause the unintentional release of energy, such as electrical or mechanical, to themselves or others, when working on or around equipment capable of causing harm. It is imperative that individuals working on or around potential stored energy sources at the Waste Storage Facilities observe LLNL's lockout and tagout policies and procedures. The Waste Storage Facilities operate in accordance with ES\&H Manual Document 12.6, "LLNL Lockout/Tagout Program," which provides guidance on this subject.

- Independent Verification. Independent verification is the act of checking to ensure that essential components such as valves, switches, circuit breakers, and other items are positioned to ensure proper functionality as established. Such verification recognizes the human element of component operation, that is, that any employee, no matter how proficient, can make a mistake and misposition valves, switches, circuit breakers, or other items. The concept of independent verification is incorporated into written procedures for the Waste Storage Facilities, as applicable.

- Logkeeping. Formal records or logbooks are maintained for those operations that can have significant impact on health, safety, or the environment, or significant impact to programs. The records contain enough information so they can be used to track the history of various situations or pieces of equipment, or to document occurrences within the facility.

- Operations Turnover. Shift personnel should be aware of the current conditions in the Waste Storage Facilities so that they can perform their duties in a safe manner. Therefore, it is important that employees report changes and other relevant information that occur during their shift. However, the Waste Storage Facilities operations typically operate only during the normal 8-to 10-hour day shift. Off-shift work is occasionally conducted and may include the performance of inspections. 
- Operations Aspects of Facility Chemistry and Unique Processes. The RHWM facility manager or group leaders are responsible for identifying and monitoring those operating parameters that, if out of range, could impact health, safety, or the environment. There are no operating parameters in the Waste Storage Facilities that require indirect monitoring.

- Required Reading. LLNL's safety policies and procedures are documented in a variety of manuals, including the ES\&H Manual, FSPs, Documented Safety Analyses, nonnuclear safety basis, Technical Safety Requirements, and IWS/SPS. The RHWM Required Reading Program Description references approved policies and procedures that define how RHWM administers the Required Reading Program.

- Timely Orders and Instructions to Operators/Workers. Instructions that are important to health, safety, or the environment are communicated to the Waste Storage Facilities employees. Instructions are provided in safety and operating procedures, employee instructions, operator aids, request forms, and LLNL notices. RHWM procedures provide personnel with the approved methods for issuing, reviewing, and cancelling shift orders and standing orders.

- Operating Procedures for Equipment and Systems. Waste Storage Facilities procedures are written instructions that give employees directions on how to conduct specific operations or operate specific systems or pieces of equipment during normal, postulated off-normal, and emergency conditions. The procedures are written for operations that could significantly impact health, safety, the environment, or the program. The procedures are outlined in Chapter 12, "Procedures and Training."

- Operator-Aid Postings. "Operator aids" are technical postings, other than formal procedures, rules, instructions, or the like, that assist employees in accomplishing specific tasks. Required postings (those that are not operator aids) include radiation area signs, material balance sheets, and evacuation assembly point postings. Operator aids provide an important function in the safe operation of a facility. Postings in the Waste Storage Facilities reflect the most current information available.

- Equipment and Piping Labeling. Equipment labeling is required by Occupational Safety and Health Administration (OSHA) regulations. Equipment and piping is consistently labeled in the Waste Storage Facilities so that maintenance and modifications can be safely conducted. 


\section{Documented Safety Analysis for the Waste Storage Facilities}

\subsection{FIRE PROTECTION}

\subsubsection{FIRE HAZARDS}

This section provides an overview of the Waste Storage Facilities fire hazards in terms of overall combustible loading in proximity to hazardous materials being stored at the Waste Storage Facilities. Explosive materials (e.g., those materials used in the fabrication of an explosive device) are not stored in the Waste Storage Facilities; thus, explosion criteria are not applicable. Fire hazards at the Waste Storage Facilities consist of fuel sources and ignition sources. The Fire Hazards Analyses (FHAs) for the Waste Storage Facilities (LLNL 2007a, LLNL 2007b, LLNL 2007c, LLNL 2007d, LLNL 2007e) provide more information on fire protection issues at the Waste Storage Facilities.

\section{Fuel Sources}

The primary fuel sources identified within the facilities and proximal to the hazardous material inventory are as follows:

- Combustible Contents of Non-Metal Waste Containers. Combustible waste within the waste inventory primarily consists of paper, cloth, plastic, and other ordinary combustible materials. Some of the combustible materials may also be cocontaminated with organic solvents or Class 1 oxidizers, e.g., nitrate salts or cellulosic materials. Class 1 oxidizers slightly increase the burning rate but do not cause spontaneous ignition when they come in contact with combustible materials according to NFPA 430, Code for the Storage of Liquid and Solid Oxidizers. Wastes may include flammable or combustible liquids stored in compatible closed containers.

- Combustible Packaging and Pallets. All TRU waste is packaged in steel containers. LLW and hazardous waste may be stored in a variety of containers including metal containers or combustible packaging such as plastic drums and bags, plastic tanks, wood crates, and fiber boxes. Waste other than TRU waste may be stored on combustible pallets. Combustible materials in Waste Storage Facilities that store TRU waste are limited by the combustible loading controls described in Section 11.4.3. High density polyethylene (HDPE) pallets that are designed to contain minor spills are used in the Waste Storage Facilities. While HDPE has a high heat of combustion, approximately $43 \mathrm{MJ} / \mathrm{kg}$, the $1 \%$ thermal decomposition temperature and flashpoint exceed $540^{\circ} \mathrm{K}\left(510^{\circ} \mathrm{F}\right)$, (SFPE 1995) and $616^{\circ} \mathrm{K}\left(650^{\circ} \mathrm{F}\right)$, respectively. The combustion characteristics of HDPE indicate that plastic pallets used for minor spill containment are difficult to ignite and, once ignited, difficult to sustain.

- Propane. Many of the forklifts used to convey waste containers inside and outside the facilities are powered by liquefied propane gas (LPG). Propane forklifts with 15to 35-lb fuel tanks represent a significant source of flammable gases. Refueling is performed outdoors by changing out the forklift LPG tank. Nevertheless, LPG inside a forklift fuel tank will flash to vapor if released to the atmosphere, and, therefore, represents a flammable gas hazard. 
- Liquid Fuels. The most common, significant fuel source is a flammable/combustible liquid spill from a vehicle (i.e., fuel or hydraulic fluid). Vehicles include cars, forklifts, and various sizes of trucks, ranging from small utility vehicles with 10 to 20 gal of gasoline or diesel fuel, up through trucks with supplemental fuel supplies or an occasional large tractor-trailer truck with up to $80 \mathrm{gal}$ of fuel. The fuel system on trucks and cars satisfies applicable Department of Transportation (DOT) requirements. Incidental quantities of liquid fuels may also be in the facilities for other activities. There is also drummed flammable liquid waste stored in designated locations.

- Hydraulic Fluid. The fluid used to power the hydraulic system of forklifts has a flash point greater than $200^{\circ} \mathrm{C}\left(390^{\circ} \mathrm{F}\right)$ with a limited volume of less than 90 liters (20 gal). This hydraulic fluid is a Class IIIB combustible liquid in accordance with NFPA 30 , Flammable and Combustible Liquids Code.

- Cleaning Solvents. Small amounts of cleaning solvents may be present, and are properly stored according to ES\&H Manual, Document 14.1, "LLNL Chemical Safety Management Program."

- Chemicals. Chemicals may be present and are properly stored according to ES\&H Manual, Document 14.1, "LLNL Chemical Safety Management Program."

- Combustible Building Construction Materials. The Waste Storage Facilities are generally constructed of noncombustible materials.

\section{Ignition Sources}

The following potential ignition sources that may exist inside or outside the Waste Storage Facilities were evaluated in the process hazard analysis (PrHA) and were found to be adequately controlled. The means to minimize or control these sources are discussed, as appropriate.

- Vehicles. Engine heat from trucks and vehicles operating near the Waste Storage Facilities presents a potential ignition source for the fuel sources described above. The PrHA considered several vehicle accidents, including forklift accidents, that result in a fire and waste burning.

- Forklifts. Engine heat from forklifts used during waste container handling operations presents a potential ignition source for the combustible waste being conveyed. However, container handling places waste containers away from the forklift engine, and because TRU waste is packaged within metal waste containers, engine heat is a highly unlikely ignition source for the combustible contents of approved TRU waste containers.

- Electrical Fault. Facility electrical systems were designed in accordance with NFPA 70, National Electric Code. Electrical wiring and devices in the vicinity of operations where fire or explosion hazards may exist due to flammable gases or vapors are rated as suitable in accordance with Chapter 5 of NFPA 70. All electrical wiring within the waste storage facilities is routed within conduit. In addition, major electrical equipment is installed according to PC-2 seismic criteria. 
- Lightning. The Livermore Valley rarely experiences severe weather. Thunderstorms typically occur fewer than 10 days per year and are not intense. Thus, the Waste Storage Facilities are not equipped with lightning protection air terminals. The buildings, however, are grounded.

- Refueling Fire. A fire associated with gasoline or diesel refueling operations, or during forklift LPG tank replacement, represents a potential ignition source for exposed combustibles. Similarly, refueling operations conducted proximal to the Waste Storage Facilities could expose the structures. Refueling operations are typically conducted at the motor pool away from the Waste Storage Facilities.

- Aircraft Crash. There is a probability of a small aircraft crash in the Waste Storage Facilities as discussed in Chapter 3. The onsite Fire Department will respond to such an event. Many of the Waste Storage Facilities have fire sprinklers that would activate, where the system is not damaged. Supplemental water can be provided from nearby hydrants (see Section 11.4.4).

- Welding. Occasional welding, using either electrical arc or hot flame (oxyacetylene or MAAP gas), may be required to maintain important building systems. The facility uses a hot work permit system as part of the facility's work control process. Before welding could be performed, a Hot Work Permit must be issued by the Emergency Management to ensure personnel who perform welding, soldering, and other hotwork operations with a high fire potential are aware of and protected from hazards.

- Wildfire. The area north of B696 is asphalt paving for about 20 feet. On the north side of the asphalt is a row of small trees, about 20 feet tall, beyond which is an open field buffer zone, owned by LLNL, and kept from accumulating weeds by seasonal mowing. Although wildfire could occur in open grassy areas near facilities or in forested areas further away, the area north of B696 is maintained free of excess weeds and grass. The exposure threat of a wildfire is minimal. Areas adjacent to all other Waste Storage Facilities are paved or lawn. Trees north of B696 and adjacent to Area 625 are periodically trimmed and maintained to reduce fire exposure to storage areas/buildings.

The estimated combustible loading in the various Waste Storage Facilities areas is low. Combustible materials are limited to the quantity required for current needs and are separated from ignition sources. Protection of the facilities is provided by automatic fire suppression systems, portable fire extinguishers, and fire-rated construction, as described in the FHAs. The hazard analysis documented in Chapter 3 addresses fire hazards particular to the Waste Storage Facilities.

\section{Fire Hazards Analyses}

FHAs have been prepared for Tent 6197, Tent 6198, B625, B693 and B693 Annex, and B696 of the Waste Storage Facilities (LLNL 2007a, LLNL 2007b, LLNL 2007c, LLNL 2007d, LLNL 2007e). The conclusion of each of these FHAs is that the facility meets the fire protection objectives and criteria outlined in Section 4.2 of DOE Order 420.1B (DOE 2005), qualifying it as an Improved Risk Facility. 


\subsubsection{FIRE PROTECTION PROGRAM AND ORGANIZATION}

In conformance with DOE Order 420.1B and the LLNL ES\&H Manual, the fire safety program at the Waste Storage Facilities includes provisions for:

- Minimizing the potential for occurrence of a fire or related event in the Waste Storage Facilities.

- Ensuring that fire does not cause an unacceptable onsite or offsite release of hazardous or radioactive material that will threaten the health and safety of employees, the public, or the environment.

- Providing an acceptable degree of life safety to LLNL and contractor personnel and the public from fire in the Waste Storage Facilities.

- Ensuring that the Waste Storage Facilities operations will not suffer unacceptable delays as a result of fire and related hazards.

Ensuring that property damage to the Waste Storage Facilities from fire and related events does not exceed defined limits in ES\&H Manual Document 22.5, "Fire."

LLNL maintains a large staff of emergency response personnel, including an onsite Fire Department (contracted to Alameda County), ambulance services (contracted to Alameda County), security services, and a fully staffed medical facility. In addition, a communications system is maintained specifically for emergency control purposes. Fire alarms at the Waste Storage Facilities annunciate at the Fire Dispatch Center (B313) (contracted to Alameda County), where personnel, in turn, transmit alarms over the EVA within the affected building.

The LLNL fire protection program is implemented through three organizations: Emergency Management Department (EMD), Maintenance \& Utilities Services Department (MUSD), and ES\&H Teams. The Fire Department (a division of EMD) -is responsible for initial response to and investigation of all life-threatening and property-loss emergencies on or adjacent to LLNL property. EMD's Alarms Group as well as Fire Protection Engineering's Fire Inspectors inspects and tests selected fire protection equipment. EMD also provides fire protection engineering leadership to ES\&H Team members. The subject matter expert (SME) for Fire Protection Engineering acts as the Fire Protection Program Manager and is also the LLNL Fire Marshal. Two ES\&H Teams provide environment, safety, and health support to the various LLNL programs. Each ES\&H team has at least one assigned, qualified fire protection engineer who provides fire protection engineering support. The fire protection engineer performs periodic facility walkthroughs to observe the physical conditions of the facilities and their fire protection features. Plans for new or revised fire protection systems and features for the Waste Storage Facilities must be reviewed and approved by the ES\&H Team 1 Fire Protection Engineer prior to start of work. Fire extinguishing system acceptance tests and inspections must be witnessed by the ES\&H Team 1 Fire Protection Engineer prior to occupancy. 


\section{Documented Safety Analysis for the Waste Storage Facilities}

The MUSD and EMD have the primary responsibility for testing and maintaining LLNL's fire protection and detection systems and utilities. EMD also have primary responsibility for portable fire extinguisher testing and maintenance.

The RHWM Self-Help Plan (LLNL latest revision-b) and the Contingency Plan for RHWM facilities (LLNL latest revision-c) outline the emergency program and actions to be taken by RHWM personnel responding to fires and other potential accidents at the Waste Storage Facilities.

\subsubsection{COMBUSTIBLE-LOADING CONTROL}

Combustible loading in the Waste Storage Facilities is controlled as a function of the LLNL fire protection program. RHWM implements measures to minimize and control the use of combustible materials at the Waste Storage Facilities and to prevent the accumulation of unnecessary combustibles. In addition, only waste in metal containers and on metal pallets is allowed in TRU waste storage areas.

Table 7-5A in the Fire Protection Handbook, 18th edition (NFPA 1997), limits allowable combustibles in accordance with the fire-resistive rating of the partitions of a compartment in a building. The combustible loading limit is established to preclude the potential for fire propagation. The allowable combustible loading is 5 psf per each half-hour fire-resistive rating of a partition or a wall that separates the compartments. For compartments separated by a one-hour fire-rated partition, such as B696R Room 1010 and 1011, the combustible loading allowed by Table 7-5A in the Fire Protection Handbook, 18th edition, is 10 psf. For conservatism in a TRU waste storage facility, a lower combustible loading limit of 7 psf is conservatively established, which is consistent with the definition of light fire loading discussed in NPFA 80A, Recommended Practice for Protection of Buildings from Exterior Fire Exposures. Waste containerized in metal packaging is excluded from the combustible loading control.

In addition, for B696, the combustible loading limit is a critical element for protection of the B696S/B696R partition in the event of a fire in B696R. The 7 psf combustible loading limit in B696R Room 1010 helps limit the severity of a fire such that the fire is not expected to challenge the partition or partition-roof interface in a manner that would allow the fire to circumvent the partition or propagate from B696R to B696S.

Implementation of the combustible-loading control measures includes, but is not limited to, the following activities:

- Housekeeping is inspected at least monthly by a trained staff member to ensure that equipment, materials, and stored wastes are orderly.

- Non-combustible or fire-retardant materials are used whenever practical.

- Only non-combustible pallets are used for storing TRU waste containers.

- Only waste in metal containers and on metal pallets is allowed to be stored in TRU waste storage areas.

- Combustible waste incidental to operations is collected in covered metal containers. 
- Allowance for only incidental quantities of flammable or combustible liquids (less than the exempt quantities for the occupancy type of the facility), except in designated flammable/combustible liquid storage areas. This does not prohibit the use of propane, diesel, gasoline, or electric powered forklifts.

- Grass and brush are clear-cut and removed from the vicinity of buildings and waste storage areas.

- A 20-ft exclusion zone is maintained between the DWTF Storage Area and the B695 Segment of DWTF, except between B696S and B696R, which are separated by a fire-resistive partition. In addition, the exclusion zone is expanded between adjacent roll-up doors in B696 near the segment boundary. This prevents fire from impacting both segments through adjacent roll-up doors.

\subsubsection{FIRE FIGHTING CAPABILITIES}

A detailed discussion of fire fighting capabilities at LLNL is provided in the Lawrence Livermore National Laboratory Emergency Plan (LLNL latest revision-d). The onsite Fire Department response schedule to emergencies is described in Emergency Management policy number 1200, Response Schedule. Fire Department response time for the main Livermore site is expected to be less than five minutes to any facility. Normal response to an automatic alarm is one engine with a crew of four; further equipment and/or personnel are available from the onsite Fire Department as necessary. Additional fire fighting support is available through mutual aid from outside fire agencies.

A detailed description of available firefighting equipment, fire response procedures, basic training, personnel qualifications for firefighters, and special precautions taken for fire fighting in radiological and hazardous chemical environments is provided in LLNL's Fire Protection Program Manual (LLNL latest revision-e).

The Contingency Plan developed for the RHWM facilities (LLNL latest revision-c) provides an overview of the fire protection available at the Waste Storage Facilities to detect fires, alert personnel to fire emergencies, suppress fire, and minimize fire spread. Portable fire extinguishers and fire hydrants are available at all Waste Storage Facilities.

\section{Automatic Fire-Suppression Systems}

B625 and B696R have fire sprinkler systems meeting NFPA 13 for Ordinary Hazard occupancies. All are wet pipe systems.

Building 693 has a fire sprinkler system meeting NFPA 13 for Ordinary Hazard Group 2, except that Room 1000 and 1014 which are Extra Hazard Group 1. B693 Room 1000 has an automatic high-expansion foam fire extinguishing system that is the primary fire protection provided for flammable waste storage. This system is triggered either by rate compensated heat detectors, or by manual pull stations, and should activate prior to the fire sprinklers, greatly reducing the quantity of water that might be discharged on a fire. 


\section{Documented Safety Analysis for the Waste Storage Facilities}

Sprinkler flows are monitored to automatically initiate a fire alarm at the Fire Dispatch Center. Each of these buildings has some capability to retain fire water discharged from the automatic sprinkler systems. Further details regarding the fire suppression systems and fire water retention are provided in the FHAs. If a fire suppression system is impaired, compensatory measures (in compliance with NFPA 25) will be put in place during hot work operations and forklift container movements in the facility when TRU waste is present in the fire area.

A general LLNL requirement mandates that contaminated liquid runoff from fire fighting operations should be prevented from leaving the site. firefighters are aware of the requirement and, when possible, they prevent fire fighting water from entering storm drains. The Sewer Diversion Facility is designed to prevent hazardous materials from being carried offsite from the Laboratory's sanitary sewer system, including fire fighting water entering the waste stream from a building's sewer system or floor drains.

\section{Fire Detection and Alarms}

$\mathrm{B} 625, \mathrm{~B} 696 \mathrm{R}$, and B693 are protected by presignal fire alarm systems. The fire alarm system is activated when water discharges from a fused sprinkler or when a manual fire alarm pull station (in selected locations) or heat detector (in selected locations) is activated. The fire alarm control panel transmits the alarm to the Fire Dispatch Center, automatically summoning the onsite Fire Department. The system does not automatically initiate audible and visual building EVAs. The emergency dispatcher must manually initiate building EVAs.

\section{Fire Extinguishers}

Appropriate types and sizes of fire extinguishers are placed throughout the Waste Storage Facilities and maintained in accordance with NFPA 10, Standard for Portable Fire Extinguishers. Additional fire extinguishers are located where specific fire hazards are present.

\section{Water Supply and Fire Hydrants}

Water is supplied to the main Livermore site from three, elevated, 500,000-gallon (each), steel tanks located on the Sandia National Laboratories Livermore site, approximately one mile south of the Laboratory. Fire protection and domestic water is supplied to the grid system at LLNL through one 14-in and one 16-in water main connected into a 14-in water main on the south side of the LLNL grid. The LLNL grid consists of mains of varying size, and the minimum main size is $8 \mathrm{in.} \mathrm{In} \mathrm{addition} \mathrm{to} \mathrm{primary} \mathrm{supply} \mathrm{reservoirs,} \mathrm{secondary} \mathrm{connections} \mathrm{are} \mathrm{provided} \mathrm{to} \mathrm{local}$ municipal water mains on both the west and north sides of the Laboratory. An additional connection to the 27-in, Zone 7 water main on the Laboratory's north side is pumped into the Laboratory's water distribution system through approved fire pumps, as needed. With all available water supplies considered, the total available water flow (to depletion) at LLNL is $8,900 \mathrm{gpm}$ for 5 hours and 7,476 gpm for 7 hours.

Multiple fire hydrants are located in the vicinity of the Waste Storage Facilities as part of the LLNL fire protection system. The flow capabilities of the hydrants protecting the Waste Storage Facilities are adequate to fight expected fires as detailed in the FHAs. Hydrant flow tests are conducted by the onsite Fire Department. Records of the tests and water flow information are available at the EMD office. Outage of fire protection water for non-routine maintenance complies with NFPA 25. 


\section{Documented Safety Analysis for the Waste Storage Facilities}

\section{Other Fire Controls}

Fire breaks, in the form of asphalt-paved open spaces or lawns, surround the Area 625 and DWTF facilities. Furthermore, a 20-ft firebreak between the DWTF Storage Area and the B695 Segment of DWTF has been established. The Waste Storage Facilities have marked fire lanes as required by LLNL. The locations of individual fire rated partitions within Waste Storage Facilities buildings are described in the FHAs and in Chapter 2, "Facility Description."

NFPA 704, Standard System for the Identification of the Hazards of Materials for Emergency Response, diamond-shaped placards are provided throughout RHWM facilities. The placards indicate the maximum hazard in each category (health, fire, reactivity, and special warnings) associated with the types of material in the facility and indicate the worst-case condition that an emergency responder can expect to encounter at the facility.

A variety of heavy equipment is available from Plant Engineering to assist in a fire emergency. The equipment includes compressors, cranes, cutting torches, forklifts, generators, pumps, scrapers, and bulldozers. Emergency equipment is maintained regularly to ensure that it is operational at all times.

\section{Fire Response Procedures}

The RHWM Self-Help Plan and the Contingency Plan identify personnel responsibilities, emergency equipment, and required actions necessary to mitigate fires within the Waste Storage Facilities. These plans also specifically define the types of emergencies that must be mitigated by the onsite Fire Department and those that may be remedied by RHWM personnel. The types of emergencies and responses are outlined in Chapter 15, "Emergency Preparedness Plan."

\section{Basic Training and Personnel Qualifications}

RHWM personnel are trained in appropriate responses to potential emergencies, such as fires, including calling the onsite Fire Department and evacuating as necessary. The training is outlined in the FSPs and in ES\&H Manual Document 40.1, "LLNL Training Program Manual." Basic training and qualifications are provided in Policy 1130, "Minimum Professional Standards for Fire Fighters, Fire Officers, and Chief Officers," of the LLNL Fire Department Policies and Procedures Manual.

The requirements for emergency responders, including the onsite Fire Department, to a fire or explosion at the Waste Storage Facilities are implemented through ES\&H Manual Document 40.1, "LLNL Training Program Manual."

\section{Special Precautions}

Special precautions are needed for fighting fires in radiological and hazardous chemical environments. Protection of firefighters at LLNL in radiological environments is outlined in $E S \& H$ Manual Document 22.6, "Exposure to Radiation in an Emergency." Special precautions are also described in documents and procedures provided in Policy 1130, "Minimum Professional Standards for Fire Fighters, Fire Officers, and Chief Officers," of the Official Action Guides. 


\section{Documented Safety Analysis for the Waste Storage Facilities}

\subsubsection{FIRE-FIGHTING-READINESS ASSURANCE}

The onsite Fire Department conducts periodic fire protection inspections of facilities. In addition, the RHWM Division has a combustible-loading control program that includes inspections of the Waste Storage Facilities to keep them free from unnecessary combustibles.

RHWM personnel participate in LLNL site-wide Self Help drills annually. LLNL conducts a coordinated program of these drills and exercises to provide emergency-response training and to establish a method for evaluating the response capability and readiness. Drills are designed to develop and maintain personnel emergency-response skills. They are conducted separately by each emergency response organization (ERO) and reflect the organization's specific training needs, which have been discovered during prior drills.

The Emergency Management Exercise Program is an annual, full-participation exercise based on rotating scenarios, such as a natural disaster, a security incident, or hazardous material incidents. The scenarios are designed to test the operational capability of individual organizations. The drills are evaluated for each exercise, and lessons learned are incorporated into emergency plans and procedures. Drills and exercises are discussed in the Lawrence Livermore National Laboratory Emergency Plan.

The process for classification and notification of accidents at the Waste Storage Facilities is outlined in the Lawrence Livermore National Laboratory Emergency Plan. Internal reporting at the Waste Storage Facilities requires employees to notify the Storage and Disposal Group Leader, or designee, of all release incidents (large or small), and the onsite Fire Department of all large incident releases, fires, or other emergencies. The Storage and Disposal Group Leader, or designee, gathers preliminary information and then must immediately notify the facility manager and the Hazard Control ES\&H Team. Records of fire protection system testing, inspection, and maintenance shall be prepared and retained based on the requirements of NFPA 25, Standard for the Inspection, Testing, and Maintenance of Water-Based Fire Protection Systems, and in accordance with LLNL procedures.

\subsection{REFERENCES}

DOE (2001), Conduct of Operations Requirements for DOE Facilities, DOE Order 5480.19, Change Notice 2, U.S. Department of Energy, Washington, DC, October 23, 2001.

DOE (2005), Facility Safety, DOE Order 420.1B, U.S. Department of Energy, Washington, DC, December 2005.

LLNL (2007a), Fire Hazards Analysis Building 6197, Lawrence Livermore National Laboratory, Livermore, CA, (September 2007).

LLNL (2007b), Fire Hazards Analysis B6198, Lawrence Livermore National Laboratory, Livermore, CA, (September 2007).

LLNL (2007c), Fire Hazards Analysis of B696, Lawrence Livermore National Laboratory, Livermore, CA, (February 2007). 
LLNL (2007d), Fire Hazards Analysis Building 625, Lawrence Livermore National Laboratory, Livermore, CA, (November 2007).

LLNL (2007e), Fire Hazards Analysis of the Lawrence Livermore National Laboratory Building 693 Waste Storage Facility, Livermore, CA, Lawrence Livermore National Laboratory, Livermore, CA, (June 2007).

LLNL (latest revision-a), Environment, Safety, and Health Manual, Lawrence Livermore National Laboratory, Livermore, CA, UCRL-AM-133867, latest revision.

LLNL (latest revision-b), Self-Help Plan Radioactive and Hazardous Waste Management Division, Lawrence Livermore National Laboratory, Livermore, CA.

LLNL (latest revision-c), Contingency Plan for Radioactive and Hazardous Waste Management Facilities: Area 612, Area 514, Building 233 CSU, and the Decontamination and Waste Treatment Facility, Lawrence Livermore National Laboratory, Livermore, CA, UCRL-AR127066, latest revision.

LLNL (latest revision-d), Lawrence Livermore National Laboratory Emergency Plan, Lawrence Livermore National Laboratory, Livermore, CA, UCRL-MA-113311, latest revision.

LLNL (latest revision-e), Fire Protection Program Manual, Lawrence Livermore National Laboratory, Livermore, CA, UCRL-MA-116646, latest revision.

NFPA (1997), Fire Protection Handbook, $18^{\text {th }}$ edition, National Fire Protection Association, Quincy, MA.

NNSA/LLNS (2009), Management and Operating Contract between The US Department of Energy/National Nuclear Security Administration and Lawrence Livermore National Security, No. DE-AC52-07NA27344, February 27, 2009.

SFPE (1995), The SFPE Handbook of Fire Protection Engineering, $2^{\text {nd }}$ Edition, National Fire Protection Association, Quincy, MA, 1995. 


\section{CHAPTER 12 \\ PROCEDURES AND TRAINING}

\subsection{INTRODUCTION}

This chapter addresses the processes by which the content of procedures and the training program are developed, verified, and validated at the Waste Storage Facilities.

\subsection{REQUIREMENTS}

This section contains the directives in effect as of February 2009 as implemented in the Lawrence Livermore National Security, LLC, Contract No. DE-AC52-07NA27344 (NNSA/LLNS 2009). Specific sections of these directives are relevant to the content of this chapter. This section also contains the codes, standards, regulations, and DOE orders specific to this chapter and required to establish the safety basis of the facility.

\section{U.S. Department of Energy}

DOE O 5480.19, Change Notice 2, Conduct of Operations Requirements for DOE Facilities

DOE O 5480.20A, Change Notice 1, Personnel Selection, Qualification, and Training Requirements for DOE Nuclear Facilities

Code of Federal Regulations

10 CFR 830, Nuclear Safety Management

40 CFR 264.16, Personnel Training

\section{California Code of Regulations}

22 CCR 66264.16, Personnel Training

\subsection{PROCEDURE PROGRAM}

DOE Order 5480.19, Change Notice 2 (DOE 2001b), requires that procedures be developed to provide specific direction for the operation of systems and equipment during normal, abnormal, and emergency conditions. The order includes technical-content development, verification, and validation requirements for procedures. The requirements of this order are implemented at the Waste Storage Facilities through the use of ES\&H Manual Document 3.5, "Conduct of Operations for LLNL Facilities." This document requires that safety plans and operating procedures be developed to ensure that workers are properly trained regarding identified hazards and associated controls, and to provide workers directions on how to conduct specific operations or operate specific systems or pieces of equipment during normal, postulated offnormal, and emergency conditions for operations that could significantly impact health, safety, the environment, or the program. 


\section{Documented Safety Analysis for the Waste Storage Facilities}

The Radioactive and Hazardous Waste Management (RHWM) Division implements its programs and controls through procedures. Procedures are developed by RHWM to ensure that waste is managed in a manner that will protect human health and the environment and that the procedure contents will comply with all applicable regulatory requirements.

ES\&H Manual Document 3.3, "Facility Safety Plans and Integration Work Sheets with Safety Plans," governs the development of FSPS and IWS/SPS. Each FSP provides general facility safety policies and rules, identifies hazards and environmental concerns, and specifies the ES\&H controls for long-term experiments, operations, and work performed in the facilities.

RHWM has a procedure that governs the development of RHWM administrative and standard operating procedures. This procedure meets the requirements of ES\&H Manual Document 3.4, "Preparation and Use of Work Procedures," Document 3.5, "Conduct of Operations for LLNL Facilities," and the Radioactive and Hazardous Waste Management Division Quality Assurance Plan (LLNL latest revision-a).

\subsubsection{DEVELOPMENT OF PROCEDURES}

Risk is the fundamental consideration in determining that procedures be developed for activities. Supervisors are responsible for making this determination and for directing the development of a procedure to ensure correct performance of an activity and to address safety concerns.

A technical subject-matter expert (or experts) is assigned to work with the technical writer/safety professional to provide input to the procedure. Procedures are written according to a standard format to ensure uniformity across the division.

The FSPs specify the responsibilities, hazards, policies, and controls for operations within the facilities. IWS/SPs contain the basic controls needed for safe operation beyond those contained in the ES\&H Manual and applicable FSPs. The RHWM procedures cover specific administrative and technical activities at a more detailed level. These documents contain safety advice for a given activity, preoperational requirements, the assignment of responsibilities, instructional steps on how to perform the activity in a safe manner, specific record-keeping requirements, and other miscellaneous information associated with the operation.

Procedures are formally reviewed, verified, and validated. Draft procedures are submitted for formal review to management, various subject-matter experts, and ES\&H safety professionals as applicable. All comments are resolved, and the documents are submitted for final signature review.

\subsubsection{MAINTENANCE OF PROCEDURES}

Supervisors are responsible for ensuring that their staff is familiar with the latest FSPs and procedures pertinent to their operation. This responsibility is implemented through the RHWM reading program, OJT, classroom training, and general supervisory oversight. The RHWM FSPS and procedures are available on RHWM's controlled document server. 
The FSPs and IWS/SPs are controlled as outlined in ES\&H Manual Document 3.3, "Facility Safety Plans and Integration Work Sheets with Safety Plans." RHWM's procedures are controlled in accordance with a RHWM document control procedure and are distributed by being posted on the controlled document server. Authorized versions of RHWM's procedures are available only from the controlled document server or the RHWM Document Control Office files.

Procedures undergo periodic review to ensure that their contents still reflect current operations and comply with any ES\&H regulations that may have been issued since the last review. FSPS are reviewed and updated at least triennially. If no changes are required, a memo to that effect is prepared and signed by the responsible individual. The memo is controlled and disseminated according to ES\&H Manual Document 3.3, "Facility Safety Plans and Integration Work Sheets with Safety Plans." If changes occur to an operation prior to the standard review time, it is the responsibility of the area supervisor to initiate the update of the procedure. The update may take place in the form of an addendum or a revision to the original FSP, an "immediate change implementation" to a procedure, or it may involve update and re-issuance of the actual document. Review, approval, and distribution requirements for issuing addenda and supplements are the same as those for the original procedure. During the next regular revision, addenda or supplements are incorporated, as necessary, into the original safety procedure. Changes to procedures are evaluated in accordance with Document 51.3, "LLNL Unreviewed Safety Question (USQ) Procedure," in the ES\&H Manual.

\subsection{TRAINING PROGRAM}

RHWM follows requirements in DOE Order 5480.20A (DOE 2001a), which specifies selection, qualification, and training requirements for personnel involved in the operation, maintenance, and technical support of DOE nuclear facilities. The training requirements are implemented at the Waste Storage Facilities through ES\&H Manual Document 40.1, "LLNL Training Program Manual." The training of personnel in hazardous waste management procedures is also required by 22 CCR 66264.16 and is implemented through ES\&H Manual Document 36.1, "Hazardous, Radioactive, and Biological Waste Management Requirements."

The main purpose of the RHWM training program is to provide appropriate instructional support that will enable RHWM workers to develop and maintain competencies for successfully executing work assignments. ES\&H Manual Document 40.1, "LLNL Training Program Manual," provides guidance for developing and managing individual directorate training programs. Guidance includes the following:

- Determining job categories, specific qualification requirements, and training requirements and responsibilities.

- Documenting training information.

- Qualifying course materials and instructors.

- Evaluating the training program. 


\section{Documented Safety Analysis for the Waste Storage Facilities}

The RHWM training program provides RHWM personnel with:

- Basic knowledge of regulatory requirements, hazards, and facility emergency response activities.

- Waste handling activities, including transportation of materials, tie-down methods, sampling activities, and general container handling.

- Instruction on specific duties and responsibilities relative to an individual's hazardous, radioactive, or mixed waste activities.

- Waste management unit-specific instruction for hazardous waste treatment, storage, and offsite shipment for those RHWM personnel who perform hands-on hazardous waste management facility operations.

- Presently, licenses are issued to forklift drivers.

RHWM personnel receive both broad and specific training in hazardous and mixed waste regulations relative to their job duties and responsibilities, including emergency response activities, to reduce the risk from accidents. Training is provided by several different methods depending on the type of information and skills required for performing the task. The first type is classroom instruction, provided by an instructor in a lecture and discussion format. The second type is training and evaluation implemented through On-the Job Training (OJT) for specific operations. A third type is self paced reading and review of safety and procedural documents. A fourth type is E-learning which is delivered through computers and other multi-media technologies. In some cases a combination of these methods will be used to convey the information and then provide the trainee practical experience in performing the activity.

The goal of the LLNL training program is to ensure that all employees have the skills and knowledge to carry out their work assignments safely and effectively. The objectives of the LLNL training program are to determine and document training requirements, to document and make available appropriate training-related information, to ensure that the program is structured to permit adequate review and analysis of its effectiveness, and to maintain documentation that provides guidance for implementing the program.

The format and content requirements for training program development, verification, and validation are provided in DOE Order 5480.20A. The requirements are implemented for RHWM facilities through the following ES\&H Manual Documents:

- 40.1, "LLNL Training Program Manual."

- 40.2, "Environment, Safety \& Health Training and Education."

- 50.1, "Personnel Selection, Qualification, Training, and Staffing at LLNL Nuclear Facilities."

Training may include OJT, classroom training, and/or computer-based training. The minimum training requirements for RHWM employees working in operational zones are identified in the FSPs. 


\section{Documented Safety Analysis for the Waste Storage Facilities}

\subsubsection{DEVELOPMENT OF TRAINING}

The RHWM Division's Training Implementation Matrix for the Radioactive and Hazardous Waste Management Division (LLNL latest revision-b), ES\&H Manual Document 40.2, "Environment, Safety \& Health Training and Education," and ES\&H Manual Document 40.1, "LLNL Training Program Manual," require that training content be such that employees can perform their responsibilities and apply their skills and knowledge to provide maximum protection for themselves, fellow employees, LLNL facilities, the public, and the environment. Detailed information on the technical content development of training program requirements is contained in Appendix A of ES\&H Manual Document 40.1, "LLNL Training Program Manual." The training program representative meets with RHWM management and subject-matter experts for input to course lesson plans. The draft course material is reviewed by management and subject-matter experts for accuracy before being finalized.

The RHWM's Training Implementation Matrix for the Radioactive and Hazardous Waste Management Division spells out the various training courses required for each RHWM job assignment. The training matrix is maintained online to allow for easy access to the most up-todate copy.

\subsubsection{MAINTENANCE OF TRAINING}

To keep RHWM training materials current, the RHWM training program representative reviews all RHWM procedures and changes to procedures and has access to the RHWM server that contains the latest procedures. The training representative meets periodically with the RHWM area supervisors to stay current on their operations and to determine any new training needs, or changes to existing courses, within their areas of responsibility. The training representative holds a monthly training meeting with RHWM management personnel. This enables the training program representative to stay current on changes occurring within RHWM facilities so training materials can be updated or new training materials developed, as needed.

Training records for RHWM facility workers are maintained on a computer database. The LLNL database is used by LLNL personnel, managers and training organizations throughout the Laboratory as a tool to monitor training and as the repository for course-completion information. The database is regularly updated as training is completed. Original records are maintained by the training organization.

\subsubsection{MODIFICATION OF TRAINING MATERIALS}

Procedures for identifying and correcting training program deficiencies are contained in Section 7.2 of ES\&H Manual Document 40.1, "LLNL Training Program Manual." Students are also asked to submit comments on their training via course evaluation forms. Supervisors and subject matter experts are asked to alert the training program representatives whenever operations or regulatory requirements change. Course material is periodically reviewed to determine if changes are necessary. Course lesson plans and materials are then updated accordingly. 


\subsection{REFERENCES}

DOE (2001a), Personnel Selection, Qualification, and Training Requirements for DOE Nuclear Facilities, DOE Order 5480.20A, Change Notice 1, Department of Energy, Washington, DC, July 12, 2001.

DOE (2001b), Conduct of Operations Requirements for DOE Facilities, DOE Order 5480.19, Change Notice 1, U.S. Department of Energy, Washington, DC, October 23, 2001.

LLNL (latest revision), Environment, Safety, and Health Manual, Lawrence Livermore National Laboratory, Livermore, CA, UCRL-AM-133867.

LLNL (latest revision-a), Radioactive and Hazardous Waste Management Division Quality Assurance Plan, Lawrence Livermore National Laboratory, Livermore, CA, M-078-92, latest revision.

LLNL (latest revision-b), Training Implementation Matrix for the Radioactive and Hazardous Waste Management Division, Lawrence Livermore National Laboratory, Livermore, CA, UCRL-AR-116655, latest revision.

NNSA/LLNS (2009), Management and Operating Contract between The US Department of Energy/National Nuclear Security Administration and Lawrence Livermore National Security, No. DE-AC52-07NA27344, February 27, 2009. 


\section{CHAPTER 13 \\ HUMAN FACTORS}

\section{$13.1 \quad$ INTRODUCTION}

This chapter discusses the human factors engineering that helped shape the design of the Waste Storage Facilities. Per DOE-STD-3009-94, Change Notice 3 (DOE 2006), the discussion of human factors is limited to human factors engineering. Human factors engineering focuses on designing facilities, systems, equipment, and tools so they are sensitive to the capabilities, limitations, and needs of humans. Human factors engineering supports, and is supported by, the hazard and accident analyses described in Chapter 3.

\subsection{REQUIREMENTS}

This section contains the directives in effect as of February 2009 as implemented in the Lawrence Livermore National Security, LLC, Contract No. DE-AC52-07NA27344 (NNSA/LLNS 2009). Specific sections of these directives are relevant to the content of this chapter. This section also contains the codes, standards, regulations, and DOE orders specific to this chapter and required to establish the safety basis of the facility.

\section{U.S. Department of Energy}

DOE O 5480.19, Change Notice 2, Conduct of Operations Requirements for DOE Facilities

DOE O 5480.20A, Change Notice 1, Personnel Selection, Qualification, and Training Requirements for DOE Nuclear Facilities

\section{Code of Federal Regulations}

10 CFR 830, Nuclear Safety Management

\subsection{HUMAN FACTORS PROCESS}

The human factors process considers the involvement of humans in potential operational accidents at the facilities and identifies the important human-machine interfaces for safety SSCs. Involvement may be with respect to prevention (e.g., inspection, analytic, and surveillance activities, or container handling or moving) and mitigation (e.g., shutdown of operations during off-normal or emergency situations) activities.

\subsection{IDENTIFICATION OF HUMAN-MACHINE INTERFACES}

Safety-significant SSCs were identified as a function of the hazard analysis as discussed in Chapters 3 and 4. The Process Hazard Analysis (PrHA) describes the accidents that are likely to involve workers. By focusing on worker aspects of the hazard analysis, the most important human-machine interfaces with the safety SSCs can be identified. The following human factors related controls are defense-in-depth: 


\section{Training}

The human-machine interface is operators driving vehicles to transport waste.

\section{Maintenance, testing, and inspection (MT\&l)}

- The human-machine interface is the maintenance and operation of test equipment to assure the integrity of the approved TRU waste container safety-significant SSCs.

- The human-machine interface is the maintenance and inspection of equipment used to transport waste.

\section{Approved TRU waste containers stacked no more than 2 high}

The human-machine interface is operation of the forklift used in stacking.

\subsection{OPTIMIZATION OF HUMAN-MACHINE INTERFACES}

Human factors elements in the facilities include allowances for spacing of approved TRU waste containers. Adequate lighting is supplied to ensure that operators can see when they are operating equipment and vehicles. Certain facilities are also equipped with emergency lighting to guide a worker to safety.

All work in the RHWM facilities is performed by personnel trained for that task or supervised by trained personnel. As part of their training, personnel are made cognizant of major pieces of equipment. A more detailed discussion of worker training is presented in Chapter 12.

Operating personnel wear protective equipment as required. When required, respirators and other specific personnel protection devices are used. The facilities are designed with eyewashes and showers available to workers in accordance with applicable codes.

RHWM Division personnel use procedures in their daily work. Where applicable, these procedures list the appropriate personal protective equipment required for each operation. In addition, LLNL's Hazard Control Department assigns safety professionals to support RHWM operations. Personnel include industrial hygienists, industrial safety specialists or experts, and health physicists. These professionals prepare hazard assessment and control forms for operations to assure respirators and other personal protective equipment are specified and appropriate for the work to be performed. The hazard assessment and control forms specify the safety equipment that must be in place and/or worn by RHWM personnel when performing an operation. The RHWM Division maintains these forms on file.

Forklifts used in RHWM facilities are designed with consideration given to human safety, comfort, and operational ease. Forklift operators are trained in the use of such equipment and are generally experienced in transporting waste containers at LLNL. Operators are licensed within the LLNL training system to operate forklifts; this training includes formal instruction, hands-on training, and a performance evaluation. 
At a minimum, two persons are required for movement of waste if self-rescue cannot be performed. Only one person is required for inspections and maintenance. However, no person shall perform an operation that might render them incapable of self-rescue without being in contact with another person.

\subsection{REFERENCES}

DOE (2006), Preparation Guide for U.S. Department of Energy Nonreactor Nuclear Facility Safety Analysis Reports, DOE-STD-3009-94, Change Notice 3, U.S. Department of Energy, Washington, DC, March 2006.

NNSA/LLNS (2009), Management and Operating Contract between The US Department of Energy/National Nuclear Security Administration and Lawrence Livermore National Security, No. DE-AC52-07NA27344, February 27, 2009. 
This page intentionally left blank. 


\section{CHAPTER 14 \\ QUALITY ASSURANCE}

\subsection{INTRODUCTION}

This chapter outlines the Quality Assurance (QA) Program and Organization, which integrates quality management with the appropriate requirements of environmental regulations and guidance documents. This chapter provides information regarding the management and assurance of quality in those activities that are applicable to the Radioactive and Hazardous Waste Management (RHWM) Division, specifically to the Waste Storage Facilities.

\subsection{REQUIREMENTS}

This section contains the directives in effect as of February 2009 as implemented in the Lawrence Livermore National Security, LLC, Contract No. DE-AC52-07NA27344 (NNSA/LLNS 2009). Specific sections of these directives are relevant to the content of this chapter. This section also contains the codes, standards, regulations, and DOE orders specific to this chapter and required to establish the safety basis of the facility.

\section{Code of Federal Regulations}

10 CFR 830, Subpart A, Quality Assurance Requirements

\subsection{QUALITY ASSURANCE PROGRAM AND ORGANIZATION}

LLNL endorses the application of quality management and recognizes the role of a coordinated quality assurance management program. The Waste Storage Facilities are nonreactor nuclear facilities that come under the jurisdiction of the LLNL Quality Assurance Plan (LLNL latest revision-a) and 10 CFR 830, Subpart A (10CFR830). RHWM addresses all requirements of 10 CFR 830, Subpart A, and the LLNL QA plan in the Radioactive and Hazardous Waste Management Division Quality Assurance Plan (RHWM QAP) (LLNL latest revision-b).

The purpose of the RHWM QAP is to ensure that RHWM management provides planning, organization, direction, control, and support to achieve the organization's objectives; that the line organizations achieve quality; and that overall performance is reviewed and evaluated using a thorough assessment process.

The RHWM QAP serves as the primary QA reference for personnel assigned to, or assisting in, performing work activities within the Waste Storage Facilities. This QAP also serves as the basis for audits and reviews, identifies formal controls and documentation requirements, and provides a means of feedback to verify the effectiveness of controls and achievement of quality goals. The QAP is implemented through procedures, instructions, and procurement documents established by the RHWM Division. Operations and maintenance in the Waste Storage Facilities are subject to the RHWM QAP. 
The RHWM QAP defines QA requirements for activities in the Waste Storage Facilities, including interfaces with the LLNL Radioactive Waste Program Certification and Quality Assurance Plan (LLNL latest revision-C). The Packaging and Transport Department Quality Assurance Plan interface requirements are also defined in the RHWM QAP.

The structure of RHWM and the relation of the line organization to the QA group are outlined in the RHWM QAP. The RHWM QA Manager is responsible for direction of the RHWM QA program and for developing, maintaining, and verifying the RHWM QA program. RHWM line management is responsible for ensuring that appropriate procedures and controls are developed and implemented for assigned tasks, that applicable standards have been identified, and that compliance with the standards is verified. All vendors, contractors, subcontractors, or other LLNL organizations must comply with applicable LLNL/RHWM QA program element requirements. Additional organizational summary material is provided in Chapter 17, Management, Organization, and Institutional Safety Provisions.

\subsection{QUALITY IMPROVEMENT}

The RHWM QAP describes control of nonconformances through the nonconformance and corrective action process. The process includes initiation of a nonconformance and corrective action report (NCAR). Implementing procedures, developed at the division level, further define the process for reporting on tracking, issuing, dispositioning, evaluating, and closing nonconformance reports. The LLNL Lessons Learned program also provides information to improve the quality and safety of operations and facilities.

\subsection{DOCUMENTS AND RECORDS}

Documents that specify QA requirements or prescribe quality-affecting activities are prepared, reviewed, and released for issuance and distribution in accordance with written procedures. Document control and records management requirements are identified in the RHWM QAP.

\subsection{QUALITY ASSURANCE PERFORMANCE}

\subsubsection{WORK PROCESSES}

Work processes are performed to established technical standards and administrative controls. Work is performed under controlled conditions using approved instructions, procedures, or other appropriate means. Adherence to established work processes is ensured through management oversight and periodic assessments.

\subsubsection{DESIGN}

Design activities for the RHWM Waste Storage Facilities, including modifications, are controlled in accordance with the RHWM QAP, which includes requirements for controlling design inputs, outputs, verification, technical review, alternate calculations and analyses, peer reviews, designchange control, interface control, and QA records. 


\section{Documented Safety Analysis for the Waste Storage Facilities}

\subsubsection{PROCUREMENT}

The requestor and RHWM Cost Account Manager are responsible for ensuring that procurement documents include appropriate technical, regulatory, LLNL Supply Chain Management Department, and QA requirements. The RHWM QA Manager reviews qualityaffecting procurement documents. These requirements are met through both internal RHWM procurement procedures and LLNL procurement department procedures. RHWM procedures ensure that procurement documents and their changes are reviewed and approved. Procurement activities are planned and documented.

Selection of vendors is based on an evaluation of the capability to provide items, services, and other products in accordance with requirements of the procurement documents. Qualified vendor performance is verified periodically through inspection, surveillance, audit, or test.

Containers that are used for packaging hazardous material or hazardous waste, including approved TRU waste containers, are procured through the Packaging and Transport Department in accordance with the Packaging and Transport Department Quality Assurance Plan.

\subsubsection{INSPECTING AND TESTING FOR ACCEPTANCE}

When it is necessary to ensure that required inspections and tests are performed, the status of inspection and test is identified either on the items or in documents traceable to the items. This approach ensures that items that have not passed the required inspections and tests are not inadvertently installed, used, or operated. Inspections are performed subject to the RHWM QAP.

\subsubsection{INDEPENDENT ASSESSMENT}

Audits, completed by LLNL staff , are the primary method for independent assessment and focus on improving items and processes. The emphasis is on achieving quality by departmentline organizations. Audits and surveillance are performed in accordance with written procedures or checklists. Activities are evaluated against specific criteria and objectives. Quality verification reports, where appropriate, detail corrective actions, identification of root causes, actions to prevent recurrence, lessons learned, and actions to be taken for improvement.

\subsection{REFERENCES}

CFR (10CFR830), Subpart A, "Quality Assurance Requirements," Nuclear Safety Management, U.S. Department of Energy, Code of Federal Regulations, Title 10, Office of the Federal Register, Washington, DC.

LLNL (latest revision-a), LLNL Quality Assurance Program, Lawrence Livermore National Laboratory, Livermore, CA, latest revision.

LLNL (latest revision-b), Radioactive and Hazardous Waste Management Division Quality Assurance Plan, Lawrence Livermore National Laboratory, Livermore, CA, M-079-92, latest revision. 
LLNL (latest revision-c), LLNL Radioactive Waste Program Certification and Quality Assurance Plan, Lawrence Livermore National Laboratory, Livermore, CA, UCRL-AM-148488, latest revision.

NNSA/LLNS (2009), Management and Operating Contract between The US Department of Energy/National Nuclear Security Administration and Lawrence Livermore National Security, No. DE-AC52-07NA27344, February 27, 2009. 


\section{CHAPTER 15 \\ EMERGENCY PREPAREDNESS PROGRAM}

\subsection{INTRODUCTION}

This chapter provides an overview of the emergency preparedness program for Radioactive and Hazardous Waste Management (RHWM) Division personnel at the Waste Storage Facilities.

\subsection{REQUIREMENTS}

This section contains the directives in effect as of February 2009 as implemented in the Lawrence Livermore National Security, LLC, Contract No. DE-AC52-07NA27344 (NNSA/LLNS 2009). Specific sections of these directives are relevant to the content of this chapter. This section also contains the codes, standards, regulations, and DOE orders specific to this chapter and required to establish the safety basis of the facility.

\section{U.S. Department of Energy}

DOE O 151.1, Change Notice 2, Comprehensive Emergency Management System

DOE O 231.1A, Change Notice 1, Environment, Safety, and Health Reporting

\subsection{SCOPE OF EMERGENCY PREPAREDNESS}

ES\&H Manual Document 22.1, "Emergency Management," describes the emergency management system and provides emergency planning procedures for operational emergencies, which are defined as significant accidents, incidents, events, or natural phenomena that could seriously impact the safety or security of LLNL's employees and facilities or the environment. The LLNL Emergency Plan (LLNL latest revision-a) provides additional information.

As a research facility, LLNL employs many energy sources, ranging from chemicals and explosives to radiation and microwaves, high-powered lasers, and high-voltage electricity that have the potential to pose serious hazards. The scope and extent of emergency planning and preparedness at LLNL address these hazards as well as hazards that have the potential for larger, more serious injuries, such as fires, earthquakes, or security-related incidents. LLNL uses an emergency management system (known as the Incident Command System) to respond to and mitigate the consequences of operational emergencies. The LLNL's emergency management system responds to and mitigates potential consequences of onsite and significant nearby emergencies that could threaten LLNL workers, the public, or the environment. 


\section{Documented Safety Analysis for the Waste Storage Facilities}

The degree of emergency planning and preparedness for a particular facility corresponds to the type and scope of hazards and the potential for harm. The Waste Storage Facilities handle, stage, treat, and store radioactive, mixed, and hazardous wastes. Emergency response for hazardous and radioactive materials is covered in ES\&H Manual Document 22.1, "Emergency Preparedness and Response," and Document 22.6, "Exposure to Radiation in an Emergency."

Facility hazards identified in the hazard analysis include vehicle accidents (spills and fires), electrical accidents (fire), deflagration, aircraft crash, high winds (spills), lightning (fire), flood (spill), and earthquakes (spills and fires). In general, emergencies at the Laboratory can be divided into three categories:

- Local emergencies that only involve a few people or a single location.

- Local emergencies with a potential to spread and become a large-scale incident.

- Large-scale or wide-spread emergencies that can affect multiple locations or facilities.

Emergency preparedness planning for large accidents (including an aircraft crash) is described in Section 15.4 and can involve offsite support organizations and hospitals. Smaller, local accidents could often be responded to by the onsite Fire Department and support organizations.

Because the Waste Storage Facilities may experience some flooding in the 2,000-year design basis flood, possibly leading to water 9 inches above the floor in the DWTF in the worst case, the following emergency provisions are established:

- Move waste to another part of the facility or another facility if enough notice of a flood is provided and if there is capacity.

- Sandbag the entrances to the facilities in the DWTF Storage Area if there is enough notice.

In any emergency, the Laboratory's onsite Fire Department and Protective Force Division can be supported by specialists in Hazard Control, the Environmental Protection Department, RHWM, and Health Services, if necessary. Fire protection at the Waste Storage Facilities is described in Chapter 11.4.

The Self-Help Plan (LLNL latest revision-b), RHWM Contingency Plan (RHWM 2008), and Facility Safety Plans (FSPs) are designed to be used with the LLNL Emergency Plan. Self-help organizations are needed because a large-scale emergency, such as an earthquake, may overburden the onsite Emergency Response Organization (ERO), and there may be significant delays to some requests for assistance because responses may have to be prioritized. Under such conditions, departments, divisions, or facilities will need to react locally to an emergency by using the self-help organizations for periods of eight hours or longer. The Self-Help Plan defines roles and responsibilities for facility personnel during emergency conditions. Responsibilities center on accounting for personnel, responding to injuries, and search-and-rescue operations, as follows:

- Ensuring that all personnel who should be in an assigned area are accounted for.

- Providing care and protection to personnel. 
- Providing first aid.

- Transporting injured personnel.

- Assessing and reporting emergency situations.

- $\quad$ Protecting facilities.

Following events that could significantly affect the building structure, an assessment will be performed prior to allowing re-entry of personnel into the building.

\subsection{EMERGENCY PREPAREDNESS PLANNING}

The LLNL Emergency Plan describes the system's organizational elements, interfaces, authorities, responsibilities, resources, and actions to be taken in response to emergencies.

\subsubsection{EMERGENCY RESPONSE ORGANIZATION}

The RHWM Division handles small incidents with the RHWM Storage and Disposal Group Leader or alternate as the emergency contact.

For a release to be determined a small incident, as described in the RHWM Contingency Plan (RHWM 2008), all of the following criteria must be met:

- The nature and potential hazards are known.

- The release presents no actual or potential threat to human health or the environment.

- Incident results in either no injury or injury requiring first aid only and no loss of work time due to injury. Note: For purposes of this plan, first aid is defined as care that can be provided by a non-medically trained person to treat minor injuries using typical first-aid kit supplies such as adhesive bandages and antiseptic.

For large incidents, personnel are to evacuate the immediate area to maintain their own safety, and the onsite Alameda County Fire Department is contacted. The first or senior Fire Department officer dispatched to or present at the incident site becomes the Incident Commander (IC) until relieved by the Battalion Chief; the Battalion Chief then becomes the IC. The IC is responsible for assessing the emergency conditions, initiating onsite response activities, collaborating with the Emergency Management Duty Officer (EMDO) on Operational Emergency categorization and classification determinations, and requesting support from offsite organizations.

The Emergency Management Department has an EMDO who is onsite or on-call at all times, and is responsible for categorizing emergency events as Operational Emergencies (OEs) and further classifying OEs as Alerts, Site Area Emergencies, and General Emergencies, if required. The EMDO is also responsible for consulting with the Laboratory Emergency Duty Officer (LEDO), making initial required off-site emergency notifications and activating the Emergency Operations Center (EOC) at LLNL. Subsequent to activation of the Emergency Response Organization as a result of an OE, the primary LEDO assumes the role of Emergency Director 
and the back-up LEDO assumes the role of Emergency Management Team Liaison Officer. The Emergency Director directs the efforts of the Emergency Response Organization (ERO) in the EOC and subordinate Department Operation Centers (DOCs) to support the IC in managing hazardous material and/or security-related emergencies.

The primary means of activating the Emergency Response Organization is through the Communicator NTX System, a digital call/paging system. For Operational Emergencies, the EMDO categorizes and classifies the incident and makes the initial notification to DOE Headquarters. Follow-up notification comes from the EOC under the direction of the Emergency Director.

Agreements with offsite emergency response organizations are discussed in the LLNL Emergency Plan. Response to fire, medical, and hazardous materials incidents on LLNL property is provided by the Alameda County Fire Department under contract to LLNL. The Alameda County Fire Department staffs both LLNL fire stations with security-cleared, trained fire fighters and fire fighter/paramedics. Both LLNL and the Alameda County Fire Department have ongoing contacts with local response agencies, mutual-aid agreements, and the response lead per California requirements. The State of California provides additional emergency assistance as described in the California Disaster and Civil Defense Master Mutual Aid Agreement. State agencies provide assistance at the direction of the Governor's Office of Emergency Services (OES). The Alameda County Sheriff's OES is the lead offsite response coordination agency for major emergency and disaster situations at or affecting the Livermore site. In addition, the Alameda County Fire Department is signatory to the State of California Master Mutual Aid Agreement for fire services and the Alameda County Mutual Aid Response Plan. Upon request, associated fire services will respond with personnel and equipment to support LLNL emergencies. The Livermore/Pleasanton Fire Department coordinates its activities with the Alameda County OES. If LLNL's primary communication links become unavailable, the ERO assists in activating the Amateur Radio Emergency Services (ARES). LLNL has a Memorandum of Understanding (MOU) in place with Valley Care Medical Center and Eden Medical Center to provide medical support for LLNL contaminated patients.

\subsubsection{ASSESSMENT ACTIONS}

The RHWM Storage and Disposal Group Leader or alternate decides the level of an emergency (small or large incident) and may consult with the Hazard Control Department ES\&H Team for help with this assessment. In case of a radioactive release, the Hazard Control Department ES\&H Team is called to monitor radioactivity levels. If personnel have any doubt about their ability to clean up a release properly and safely, or if the incident is determined to be a large incident, the LLNL onsite Fire Department is notified immediately.

The LLNL Emergency Plan defines and describes Operational Emergency classifications (i.e., "Not Requiring Further Classification," "Alert," "Site Area Emergency," and "General Emergency"). Upon arrival at the scene, the IC determines if the incident is an Operational Emergency. The classification is made using the applicable Emergency Action Levels, which provide guidance to classify under conditions of limited real-time availability of event-specific data, such as distance to the site boundary, and applicable Protective Action Guides or Emergency Response Planning Guidelines. 


\section{An Alert would be declared for:}

- An actual or potential substantial degradation in the level of control over hazardous materials (radiological and nonradiological) such that the radiation dose from any release of radioactive material or concentration in air from any release of other hazardous material is expected to exceed the applicable Protective Action Guide (PAG) value beyond 30 meters, but not greater than the facility boundary.

- An actual or potential substantial degradation in the level of safety of a facility or process that could, with further degradation, produce a Site Area Emergency or General Emergency.

\section{A Site Area Emergency would be declared for:}

- An actual or potential major failure of functions necessary for the protection of workers or the public. The radiation dose from any release of radioactive material or concentration in air from any release of other hazardous material is expected to exceed the applicable Protective Action Guide (PAG) or Emergency Response Planning Guideline (ERPG) values beyond the facility boundary or exclusion zone boundary. The PAG or ERPG value is not expected to be exceeded at or beyond the site boundary.

- Actual or potential major degradation in the level of safety of a facility or process that could, with further degradation, produce a General Emergency.

\section{A General Emergency would be declared for:}

- Actual or imminent catastrophic reduction of facility safety systems with potential for the release of large quantities of hazardous materials (radiological or nonradiological) to the environment.

- The radiation dose from any release of radioactive material or a concentration in air from any release of other hazardous material is expected to exceed the applicable PAG or ERPG value at or beyond the site boundary.

In the event of an accidental release to the environment, release response would be implemented and, if the incident were declared a large incident, the National Atmospheric Release Advisory Capability (NARAC) Center may be requested to advise the Emergency Management Team on implications of toxic or radiological releases. The NARAC center can estimate the effects and atmospheric dispersion of hazardous and radioactive waste releases within the immediate area surrounding a release or within Northern California. The NARAC center is equipped to perform detailed atmospheric dispersion calculations, allowing an accurate tracing of hazardous and radioactive waste dispersion. The capability of this system allows the various response teams to have information on any hazardous and mixed waste (radioactive material) concentrations resulting from an accidental release. Additional near-event dispersion calculations are available from the LLNL Hazard Control Industrial Hygiene Group. 


\subsubsection{NOTIFICATION}

Communications systems are in place for the prompt, initial notification of Laboratory emergency response personnel, onsite personnel, and emergency response personnel/organizations offsite, including NNSA, DOE Headquarters, and other federal, state, and local organizations. Communication systems are also in place to provide for continuing, effective communication among the emergency response organizations, both offsite and onsite, throughout an Operational Emergency.

Notification of emergency response personnel is done through the Communicator, as described earlier in the chapter. DOE and offsite agency notifications shall be made within 15 minutes of the actual declaration of an Alert, Site Area Emergency, or General Emergency, and within 30 minutes of the actual declaration of an Operational Emergency not requiring further classification.

Follow-up notifications are provided on an hourly basis or whenever classification of the emergency event changes. The Alameda County Office of Emergency Services notifies other appropriate State of California entities and can use the State of California's Emergency Broadcast System.

The External Relations and Communications is responsible for providing timely and accurate information to the community, news media, and Laboratory workforce on matters concerning health, safety, and operations during and following an Operational Emergency. During an emergency, the External Relations and Communications acts as the single point of contact for the news media, and as a principal source of information for Lab employees and community officials. It is also possible to coordinate the dissemination of information with outside agencies through the Joint Information Center.

LLNL employees are notified via the dedicated EVA system. Alternative emergency communication systems include Radio 1610, the Emergency Radio Paging System, the LLNL telephone system, emergency signals/alarms, and the emergency vehicle public address system.

\subsubsection{EMERGENCY FACILITIES AND EQUIPMENT}

This section briefly describes emergency equipment available to the Waste Storage Facilities. Such equipment includes emergency communication equipment, fire detection and suppression equipment, water supplies, emergency-response and spill-control equipment, and decontamination equipment.

\section{Emergency Communication Equipment}

Numerous methods for communicating emergency information are available, including:

- LLNL sitewide emergency paging system.

- Area emergency paging systems.

- Telephones. 
- Radio pagers and radio transceivers.

- Horns, sirens, and klaxons.

- Portable loudspeakers and megaphones.

\section{Fire Detection and Suppression Equipment}

The FSPs specify locations of fire extinguishers throughout the facilities. Fire extinguishers are typically located in areas of specific fire hazards.

Section 11.4.4 provides information regarding the fire detection and suppression equipment at the Waste Storage Facilities. Discharge of water through fire sprinkler(s) sends a signal to the fire alarm control panel (FACP), and the FACP will forward the signal to the onsite Emergency Dispatch.

Fire alarm pull stations are provided at emergency egress points in some facilities. Speakers and strobe lights, where applicable, of the EVA system are strategically located to warn people to evacuate the buildings.

\section{Water Supplies}

Water supplies for all purposes, including emergency responses, are provided to the Waste Storage Facilities as part of the site-wide utility infrastructure.

\section{Emergency-Response and Spill-Control Equipment}

Several categories of emergency-response equipment are available to the Waste Storage Facilities, including spill-control equipment, response vehicles and heavy equipment, site safety equipment, personal protective equipment, and emergency assembly-point kits. The RHWM Contingency Plan provides details on location, control, testing, and maintenance of emergency equipment and supplies. The LLNL Fire Protection Program (LLNL latest revision-c) describes emergency equipment available for larger incidences that require mitigation by the onsite Fire Department.

\subsubsection{PROTECTIVE ACTIONS}

Protective action criteria are levels of hazardous material that indicate action is needed to prevent or limit exposure to the hazard. The IC will direct protective actions of affected onsite personnel based on the initial assessment. If initial projections indicate that a hazardous material plume may extend beyond the site boundary, or that protective action criteria may be exceeded offsite, the IC will make protective action recommendations to offsite agencies.

The onsite Fire Department has available Protective Action Guides for hazardous materials. Protective actions include standby for further information, shelter, and evacuate. Criteria for determining the best protective action for onsite personnel and the public are described in the LLNL Emergency Plan. 


\section{Documented Safety Analysis for the Waste Storage Facilities}

Onsite protective actions will be modified or lifted at the direction of the IC, with concurrence of the Emergency Director. Shutdown of operations is the responsibility of operations personnel in the affected building or facility. Emergency response information and follow-up health and hygiene surveys are documented.

LLNL's Health Services Department is a professional medical staff that is responsible for maintaining a detailed medical emergency response plan for providing medical care, using both LLNL and offsite facilities, during emergencies. In addition, the Fire Department employs paramedics. The onsite medical facility includes a decontamination area that is designed for treatment of injured or noninjured radiologically or chemically contaminated personnel.

As described above under "Notifications," state and local response personnel and organizations are notified within 15 minutes of declaring an "Alert," "Site Area Emergency," or "General Emergency". Follow-up notifications are provided on an hourly basis or whenever classification of the emergency event changes. External Relations and Communications provides information to the public and news media during an Operational Emergency. The Alameda Office of Emergency Services notifies other appropriate State of California entities and can use the State of California's Emergency Broadcast System. The offsite agencies alert the public and provide guidance on what action to take.

\subsubsection{TRAINING AND EXERCISES}

Personnel at the Waste Storage Facilities participate in LLNL sitewide emergency drills and exercises. The LLNL Emergency Plan describes how emergency preparedness is maintained through use of training and exercises. LLNL conducts a coordinated program of drills and exercises to provide emergency-response training and to establish a method for evaluating response capability and readiness.

Drills are designed to develop and maintain personnel emergency-response skills. They are conducted separately by each ERO and reflect the organization's specific training needs, which have been discovered during prior drills. An integrated exercise is conducted annually to test communication and notification among organizations.

The Emergency Preparedness Section's Exercise Program includes an annual, full-participation exercise based on rotating scenarios, such as a natural disaster, security incident, or hazardous material incidents. The scenarios are designed to test the operational capability of individual organizations.

A Self Help drill is conducted annually. The Self Help program serves as a vehicle for training employees to help themselves during a catastrophic event, such as an earthquake, where professional first responders may be overwhelmed by calls for assistance. Personnel are trained to evacuate in accidents (e.g., large spill or fire) through an established training program described in Section 12.4, Training Program. 


\subsubsection{RECOVERY AND REENTRY}

Recovery includes incident assessments and investigation, recovery planning, scheduling, repair, restoration, and return or relocation. The LLNL Emergency Plan describes the provisions made for recovery from an Operational Emergency and reentry into the affected facility. The Emergency Director is responsible for terminating an operational emergency when applicable criteria are met. Such termination constitutes entry into the recovery phase.

Prior to emergency termination, a recovery organization will be established. The Emergency Director will appoint a Recovery Manager who designates a Recovery Team. The Team may include advisors from the Environmental Protection Department, Hazard Control Department, and Plant Engineering. The Recovery Manager will continue communications and coordination with offsite federal, state, and local officials, as needed.

The Recovery Plan indicates that emergency response personnel will be deployed to evaluate an emergency situation and determine when it is safe to return the facility to normal operations. Following such determination, the Recovery Manager notifies the Hazard Control Department ES\&H Team leader and transfers responsibility for the facility to the facility manager.

\subsection{REFERENCES}

LLNL (latest revision-a), LLNL Emergency Plan, Lawrence Livermore National Laboratory, Livermore, CA, UCRL-AM-113311, latest revision.

LLNL (latest revision-b), Self-Help Plan Radioactive and Hazardous Waste Management Division, Environmental Protection Department, Lawrence Livermore National Laboratory, Livermore, CA, latest revision.

LLNL (latest revision-c), LLNL Fire Protection Program, Lawrence Livermore National Laboratory, Livermore, CA, UCRL-MA-116646, latest revision.

NNSA/LLNS (2009), Management and Operating Contract between The US Department of Energy/National Nuclear Security Administration and Lawrence Livermore National Security, No. DE-AC52-07NA27344, February 27, 2009.

RHWM (2008), Contingency Plan for Radioactive and Hazardous Waste Management Facilities, UCRL-AR-127066-REV-3, January 2008. 
This page intentionally left blank. 


\section{CHAPTER 16 \\ PROVISIONS FOR DECONTAMINATION AND DECOMMISSIONING}

\subsection{INTRODUCTION}

This chapter provides a discussion of future decontamination and decommissioning (D\&D) activities, and it also provides a conceptual D\&D plan. Because of the similarity of Resource Conservation and Recovery Act (RCRA) requirements to those found in the DOE orders and guides pertaining to D\&D operations, this chapter summarizes information contained in the RCRA Closure Plan for these facilities (LLNL latest revision). The Waste Storage Facilities will be closed according to requirements of RCRA and the California Hazardous Waste Control Law (HWCL); the Federal Facility Compliance Act (FFCA), as agreed upon by the U.S. Environmental Protection Agency (EPA), the U.S. Department of Energy (DOE), the California Department of Toxic Substances Control (DTSC), and the California Regional Water Quality Control Board (RWQCB).

The good-practice guides (surveillance and maintenance, deactivation, and decommissioning) associated with DOE O 430.1B will be used as guidance for the disposition of this facility, following principles in the appropriate chapters of LLNL's ES\&H Manual. The integrated safety management concepts in DOE P 450.4 and DOE G 450.4-1 are reflected in the RCRA-required health and safety plan, which is an integral part of the RCRA Closure Plan. This plan also incorporates the ideas found in DOE-STD-1120-98, including work planning and identification, integrated hazard analysis, hazard controls and ES\&H documentation, and work performance.

\subsection{REQUIREMENTS}

This section contains the directives in effect as of February 2009 as implemented in the Lawrence Livermore National Security, LLC, Contract No. DE-AC52-07NA27344 (NNSA/LLNS 2009). Specific sections of these directives are relevant to the content of this chapter. This section also contains the codes, standards, regulations, and DOE orders specific to this chapter and required to establish the safety basis of the facility.

\section{U.S. Department of Energy}

DOE O 5400.5, Change Notice 2, Radiation Protection of the Public and the Environment DOE O 430.1B, Real Property Asset Management 


\section{Code of Federal Regulations}

10 CFR 830, Nuclear Safety Management

10 CFR 835, Occupational Radiation Protection

40 CFR 264, Subpart G, Standards for Owners and Operators of Hazardous Waste Treatment, Storage, and Disposal Facilities - Closure and Post-Closure

\section{California Code of Regulations}

22 CCR 66264, Article 7, Standards for Owners and Operators of Hazardous Waste Transfer, Treatment, Storage, and Disposal Facilities - Closure and Post-Closure

\subsection{DESCRIPTION OF CONCEPTUAL PLAN}

Prior to the start of D\&D activities, an Implementation Plan that describes the actual work to be performed in the facility and methods for complying with DOE orders and the ES\&H Manual will be developed. This plan will be based on an evaluation of all contamination sources identified within the facility. It will also include data from contamination files and detailed budgets and schedules. It is anticipated that the Implementation Plan will resemble the RCRA Closure Plan.

The waste inventory of the Waste Storage Facilities will be decreased significantly before D\&D activities begin. This means that the radioactive inventory will also decrease to well below Nuclear Hazard Category 3 limits stated in DOE-STD-1027-92, Change Notice 1.

Before decontamination, a pre-sampling survey may be conducted to determine where contamination exists within each unit or structure. Following the survey, sampling could be conducted, analytical results compared to the respective regulatory limits, and the appropriate decontamination activities undertaken. RHWM may elect to perform decontamination before sampling is undertaken. Sampling will be performed as required, and analytical results will be evaluated against established limits. If it is determined that further decontamination will not remove the identified contamination, decontamination activities will cease, and the item will be disposed of according to the level and type of contamination.

Sampling and analysis will be done with waste minimization as a goal, and with special emphasis on mixed waste minimization. Therefore, the first attempt to decontaminate equipment or a structure may be by washing the surface using pre-developed techniques. The floors of the Waste Storage Facilities are typically epoxy-coated to simplify decontamination activities.

Materials generated during D\&D activities will be evaluated against appropriate environmental requirements to ensure appropriate handling and disposal. 
The Closure Plan includes, but is not limited to, discussions of the following topics that will enable final closure certification at the end of the facility's operating life:

- General Facility Description: A general discussion of LLNL, its location, operations, and associated hazardous waste management activities.

- Waste Management Unit Information: An overview description of the specific waste-management units, including dimensions, location, construction materials, historical uses, potential historical contaminants, and containers and equipment used to manage waste at the unit.

- Closure Performance Standard: A discussion of several topics, including the sampling and analysis methodology, removal and disposal of contaminated equipment and structural components, and evaluation of wastes to regulatory definitions.

- Maximum Waste Inventory: A description of the maximum inventory of waste that could be in storage or treatment at any time during the operating life of the unit.

- Schedule for Closure: A discussion of the expected year of closure and a milestone chart showing the closure activities. The closure schedule provides a mechanism for tracking the progress of closure activities.

- Inventory Removal Procedures: A discussion of disposal options for waste generated during D\&D activities.

- Disposition of Equipment and Associated Structures: A discussion of disposal of equipment; decontamination of equipment and structures, debris waste, and equipment used for treatment of waste (if appropriate); and demolition and/or removal of contaminated structures for onsite treatment or offsite treatment or disposal.

- Closure Certification: A discussion of certification and analyses to be performed to verify clean closure and to certify closure.

- Site Safety and Health Plan: A discussion of site hazards and controls for LLNL or contractor personnel to perform assigned tasks safely.

\subsection{REFERENCES}

NNSA/LLNS (2009), Management and Operating Contract between The US Department of Energy/National Nuclear Security Administration and Lawrence Livermore National Security, No. DE-AC52-07NA27344, February 27, 2009. 
This page intentionally left blank. 


\section{CHAPTER 17 \\ MANAGEMENT, ORGANIZATION, AND INSTITUTIONAL SAFETY PROVISIONS}

\subsection{INTRODUCTION}

This chapter provides an overview of management, organization, and institutional safety provisions at the Waste Storage Facilities. LLNL has incorporated Integrated Safety Management (ISM) into all aspects of operations. The NNSA/LLNS Contract Appendix G (NNSA/LLNS 2009) has been used to select the most appropriate national consensus standards. Organizations and personnel with responsibilities for safety, and interfaces among the organizations, are described in this chapter. In addition, descriptions are provided of safety consciousness, safety culture, performance assessment, configuration and document control, occurrence reporting, and staffing and qualification for the Waste Storage Facilities.

\subsection{REQUIREMENTS}

This section contains the directives in effect as of February 2009 as implemented in the Lawrence Livermore National Security, LLC, Contract No. DE-AC52-07NA27344 (NNSA/LLNS 2009). Specific sections of these directives are relevant to the content of this chapter. This section also contains the codes, standards, regulations, and DOE orders specific to this chapter and required to establish the safety basis of the facility.

DOE Order 231.1A, Change 1, Environment, Safety, and Health Reporting, June 3, 2004.

DOE Order 414.1C, Quality Assurance, June 17, 2005.

DOE Order 433.1A, Maintenance Management Program for DOE Nuclear Facilities, February 13, 2007.

DOE Order 440.1A, Worker Protection Management for DOE Federal and Contractor Employees, March 27, 2000.

DOE Order 5480.19, Change 2, Conduct of Operations Requirements for DOE Facilities, October 23, 2001.

DOE Order 5480.20A, Change 1, Personnel Selection, Qualification, and Training Requirements for DOE Nuclear Facilities, July 12, 2001. 


\subsection{ORGANIZATIONAL STRUCTURE, RESPONSIBILITIES, AND INTERFACES}

The overall RHWM organizational structure is presented in this section. Included are safety provisions in the RHWM organizational structure that help ensure and enhance facility safety.

\subsubsection{ORGANIZATIONAL STRUCTURE}

LLNL is a multi-program laboratory operated for the DOE by the Lawrence Livermore National Security, LLC. To accomplish its mission, LLNL operates through a matrix system, with each major organization headed by a programmatic associate director or program leader. The nuclear facility managers are matrixed from Nuclear Operations into the Weapons and Complex Integration (WCI) principal directorate.

\subsubsection{ORGANIZATIONAL RESPONSIBILITIES}

Operational and management personnel responsibilities are outlined in this section. Included in the discussion are interfaces with other organizations, line operating organizations and safety organizations.

\section{Operational and Management Personnel}

ES\&H Manual Document 2.1, "Laboratory and ES\&H Policies, General Worker Responsibilities, and Integrated Safety Management," provides specific roles for personnel based on their position. RHWM personnel manage the Waste Storage Facilities. They are responsible for storing and preparing shipments of LLNL's radioactive, hazardous, and mixed waste for off-site treatment and/or disposal. Lines of authority, responsibility, and communications are established and defined for the highest, down to intermediate management levels, including all safety and operating organization positions.

$\mathrm{WCI}$ has line responsibility. They execute the scope, manage the budget and schedule, and provide day to day direction of the facility managers assigned to Nuclear Operations. The nuclear facility managers are matrixed from Nuclear Operations into the WCI principal directorate. In this role, they are accountable to the Nuclear Material Technology Deputy Principal Associate Director for the safe and compliant operation of the facility.

The RHWM Division Leader/Deputy Division Leader is responsible for overall facility operation and shall delegate, in writing, the succession to this responsibility during any absence.

Delegation shall be to a qualified individual. The RHWM Division Leader is responsible for safe operation within the Waste Storage Facilities. Safe operation includes interface requirements with other site organizations and facilities to ensure the availability of Hazard Control Department subject matter experts, fire protection, electric power, utilities, and related needs.

The Facility Manager is responsible for overall site safety and has control over those activities necessary for safe operation and maintenance of the Waste Storage Facilities. 
The RHWM Storage and Disposal Group Leader is responsible for the operational functions at the Waste Storage Facilities.

The Facility Point of Contact (FPOC) for the Waste Storage Facilities is the Storage and Disposal Nuclear Facilities Operations Supervisor. Some of the FPOC responsibilities include concurring that work can be performed within the safety envelope of the facility, identifying hazards associated with the work location and communicating them to the responsible work management chain, participating in pre-start review of work (when one is conducted), evaluating proposed operational or activity changes against the facility's existing ES\&H documentation (e.g., the authorization basis), and concurring that work may proceed in the building, prior to the onset of work.

The RHWM Safety Officer manages work control documentation.

Individuals who carry out health physics and QA functions, have independent safety review, audit, and compliance oversight. A health and safety technician, whose qualifications meet DOE Order 5480.20A (DOE 2001) requirements, shall be on call when radioactive material is present in the Waste Storage Facilities.

\section{Interfaces with Other Organizations}

Members of the Hazard Control ES\&H Team 1 may be called in to advise on planned and ongoing operations, conduct hazard assessments, and support RHWM at the Waste Storage Facilities during emergency incidents. The ES\&H Team is responsible for promptly notifying RHWM management in the event of any unexpected monitoring results (e.g., dosimetry). This team consists of specialists in industrial hygiene, industrial safety, health physics, environmental protection, explosives safety, fire protection engineering, and criticality safety.

An environmental analyst of the Environmental Stewardship and Planning Division of the EPD serves on the Hazard Control ES\&H Team.

The Fire Department is called in to handle major incidents. Details of emergency management at LLNL are found in the LLNL Emergency Plan (LLNL latest revision-c).

\section{Technical and Engineering Support, Maintenance, and Modifications}

Most large-scale design, construction, and maintenance efforts at LLNL are coordinated through Maintenance Utility Services Department (MUSD). Within the RHWM Division, the Waste Treatment Group Leader provides facility coordinators, fabrication technicians, and maintenance technicians to support smaller projects. 


\section{Safety Issue Discovery, Communication, Management, and Resolution}

Safety issue discovery takes place in a variety of ways, ranging from a worker's concern to a formal audit. Safety concerns from workers are transmitted to their supervisor who can act on them directly, often with input from the ES\&H Team, or they can be passed on to the group leader for action. Employees are aware that a variety of additional options are in place to raise safety issues. Audit results are typically forwarded to the division leader and corrective action plans developed by the appropriate group leader. For some issues, a nonconformance report can be issued in accordance with the RHWM Quality Assurance Plan (LLNL latest revision-d).

For safety issues that meet requirements found in the LLNL implementation of the Occurrence Reporting process, the institutional procedure is found in the ES\&H Manual Document 4.5, "Incidents-Notification, Analysis, and Reporting." Corrective actions from occurrence reports are tracked to closure in the LLNL ES\&H Issues Tracking System database as described in procedure PRO 0042, "Issues and Corrective Action Management." Issue owners ensure that the corrective action development and corrective action plan development are performed on a graded approach according to issue significance. Once completed, corrective actions addressing significant issues or issues from external or internal/independent assessments (or others) may require verification to determine closure.

LLNL has an active Lessons Learned program run by the Hazard Control Department. The RHWM Division submits issues of general usefulness to this program.

\section{Independent Safety Review, Audit, and Compliance Determination}

RHWM is subject to a variety of external (to LLNL) and internal audits. In addition to DOE audits, external audits include DNFSB, California Highway Patrol, Department of Transportation (DOT), and Department of Toxic Substance Control (DTSC) audits.

In terms of independent internal audits, LLNL staff carries out a variety of audits of RHWM activities, including those in areas such as criticality, nuclear facility authorization basis, and radiation worker protection. Findings from the audits are always tracked to closure in the LLNL ES\&H Issues Tracking System database.

\section{Safety Analysis Services, Including USQ Evaluation}

The Laboratory has a staff of trained safety analysts in the Safety Basis Division in Nuclear Operations Directorate. In addition, the RHWM Division maintains a staff of qualified personnel who perform USQ evaluations and develop DSAs and TSRs.

\section{Support Services Such As Utilities and Other Offsite Support}

The Plant Engineering Department provides telecommunications and utilities services. The Laboratory has backup sources for both electricity and water. 


\subsubsection{STAFFING AND QUALIFICATIONS}

This section summarizes the bases for staffing levels and the knowledge, skills, and abilities of personnel assigned to the Waste Storage Facilities. Included is a description of programs and provisions for monitoring safety performance of the staff.

The Training Implementation Matrix (TIM) for RHWM (LLNL latest revision-e) addresses the requirements of DOE Order 5480.20A, Personnel Selection, Qualification, and Training Requirements for DOE Nuclear Facilities. ES\&H Manual Document 40.1, "LLNL Training Program Manual," defines the LLNL training program. The FSPs list the minimum safety training requirements for employees who work in the Waste Storage Facilities operational zones.

The program associate director (AD) is responsible for carrying out the program's technical work and for ensuring that LLNL health and safety policies are integrated into the program's activities and plans. The program AD has the primary responsibility for ensuring:

- The safe conduct of all activities connected with program work.

- That program training responsibilities required by ES\&H Manual Document 40.1, "LLNL Training Program Manual," are carried out.

- The LLNL work force assigned is properly trained to carry out the work.

- That facilities and procedures used are appropriate for the work.

\subsection{SAFETY MANAGEMENT POLICIES AND PROGRAMS}

Facility safety is maintained at the Waste Storage Facilities through safety management policies and programs as described in the following sections. The safety management program is established to ensure that any hazardous activities are defined, evaluated, planned, performed, assessed, and improved in accordance with LLNL's Integrated Safety Management (ISM) policy and requirements.

\subsubsection{SAFETY REVIEW AND PERFORMANCE ASSESSMENT}

When any new activity, or a change to an existing activity, is planned, an IWS is developed. This work authorization control process requires hazardous work to be controlled by procedure, instruction, permit, or other such controlling documents and ensures that a careful review is performed both by ES\&H subject-matter experts and RHWM management.

The Hazard Control Department's ES\&H Team 1 provides independent safety oversight and support to RHWM facility operations. ES\&H Team 1 is composed of representatives from various safety disciplines, including health physics, industrial hygiene, fire safety, environmental protection, and industrial safety. The representatives also provide independent reviews of FSPS, IWS/SPS, and selected procedures. 


\subsubsection{CONFIGURATION MANAGEMENT AND DOCUMENT CONTROL}

The NMTP Nuclear Facility Configuration Management Plan (LLNL latest revision-f) is established in accordance with ES\&H Manual Document 41.2, "Configuration Management" and ensures consistency between the appropriate design requirements, physical configuration, and documentation of SSCs necessary to protect workers and the public. The USQ process is performed in accordance with Document 51.3, "LLNL Unreviewed Safety Question (USQ) Procedure," in the ES\&H Manual.

Maintenance activities and document control are discussed in Chapters 10 and 14, respectively. Any changes to documents or maintenance activities that may impact the safety basis are evaluated through the USQ process.

\subsubsection{OCCURRENCE REPORTING}

ES\&H Manual Document 4.3, "LLNL Implementation Procedure for Reporting Occurrences to DOE ," describes notifications to be made at LLNL following an incident, reports that must be prepared, the methodology of incident analysis, and actions required to minimize the frequency of a similar incident recurring. This conforms to the requirements of DOE Order 231.1A (DOE 2004).

Staff members of the Waste Storage Facilities are responsible for initial reporting and for writing occurrence reports. In addition, occurrences with application to others are written up for the LLNL Lessons Learned program that is operated by the Hazard Control Department.

\subsubsection{SAFETY CULTURE}

To ensure that the Waste Storage Facilities are operated in a safe manner, LLNL has established various programs for self-assessment, monitoring, enhancing operational personnel performance, and corrective action. Periodically, several levels of LLNL management review LLNL safety procedures and operations to ensure their continued effectiveness. The safe operation of the Waste Storage Facilities is monitored by Hazard Control Department ES\&H Team 1 to ensure that management is aware of risks and that necessary risks are minimized. Documents and procedures that help establish the safety culture at the Waste Storage Facilities are provided in the LLNL ES\&H Manual. Other safetyrelated programs that are applicable include:

- Integrated Safety Management, including the IWS process.

- Directorate and RHWM self-assessments.

- Management pre-start, readiness assessment, and operational readiness reviews.

- Responsible individual and supervisor monitoring.

- Periodic review and revision of safety procedures.

- Conduct of operations. 
- QA system monitoring.

- Nonconformance and corrective action reports.

- ALARA.

- Industrial safety and hygiene.

- Safety meetings.

\subsection{REFERENCES}

DOE (2001), Personnel Selection, Qualification, and Training Requirements for DOE Nuclear Facilities, DOE Order 5480.20A, Change Notice 1, Department of Energy, Washington, DC, July 12, 2001.

DOE (2004), Environment, Safety, and Health Reporting, DOE Order 231.1A, Change Notice 1, U.S. Department of Energy, Washington, DC, June 3, 2004.

LLNL (latest revision-a), Environment, Safety, and Health Manual, Lawrence Livermore National Laboratory, Livermore, CA, UCRL-AM-133867, latest revision.

LLNL (latest revision-c), LLNL Emergency Plan, Lawrence Livermore National Laboratory, Livermore, CA, UCRL-MA-113311, latest revision.

LLNL (latest revision-d), Radioactive and Hazardous Waste Management Division Quality Assurance Plan, Lawrence Livermore National Laboratory, Livermore, CA, M-078-92, latest revision.

LLNL (latest revision-e), Training Implementation Matrix for the Radioactive and Hazardous Waste Management Division, Lawrence Livermore National Laboratory, Livermore, CA, UCRL-AR-116655, latest revision.

LLNL (latest revision-f), NMTP Nuclear Facility Configuration Management Plan, Lawrence Livermore National Laboratory, Livermore, CA, latest revision.

NNSA/LLNS (2009), Management and Operating Contract between The US Department of Energy/National Nuclear Security Administration and Lawrence Livermore National Security, No. DE-AC52-07NA27344, February 27, 2009. 
This page intentionally left blank. 


\section{APPENDIX A PROCESS HAZARD ANALYSIS}

The process hazard analysis (PrHA) is derived from an evaluation of hazards in the RHWM Waste Storage Facilities. The following acronyms are used in the PrHA tables:

Process Hazard ID Numbers:

$\mathrm{WH}=$ Waste Handling and Operations

$\mathrm{FA}=$ Inadvertent Firearm Discharge

$\mathrm{EE}=$ External Event

$\mathrm{NPH}=$ Natural Phenomenon Hazard

Frequency:

$A=$ Anticipated

$\mathrm{U}=$ Unlikely

$\mathrm{EU}=$ Extremely Unlikely

$\mathrm{BEU}=$ Beyond Extremely Unlikely

Consequence:

$\mathrm{H}=$ High

$\mathrm{M}=$ Moderate

$\mathrm{L}=\mathrm{Low}$

Risk:

I = High

II = Moderate

III = Low

IV = Negligible 
Table A-1. Global Notes and Assumptions Related to Process Hazards Analysis

1. Throughout the PrHA tables, one * indicates an initial assumption; bold-font indicates that the control is a significant contributor in reducing the frequency or consequence. These initial assumptions and controls are considered candidates for designation as Administrative Controls in the TSR.

2. Unless otherwise specified, accident scenarios assume waste is TRU waste or mixed TRU waste. TRU waste contains alpha-emitting transuranic elements with half-lives of greater than 20 years and a combined activity of 100 nanocuries per gram of waste. LLW is any radioactive waste not classified as either TRU or high-level; thus, any releases of solid or liquid LLW are bounded by similar TRU waste scenarios. Activities relative to high-level waste are not performed at LLNL.

3. Mixed TRU waste contains RCRA hazardous material. The predominant hazard is radiological material.

4. The following radiological hazards are assumed to be present in the waste: contaminated material and radioactive material.

5. Non-radioactive hazardous materials may be present. Work requires Personal Protective Equipment and compliance with the requirements of the LLNL Hazardous Material Protection Program (ES\&H Manual). These are required controls and for all mitigated cases are assumed to be established and implemented in all activities.

6. Container inventories for hazardous waste chemicals are managed through the SCIL Program. Single container inventory limits are set at the ES\&H Manual Document 3.1 Q values that result in consequences of TEEL-2 at $100 \mathrm{~m}$. However, most containers have quantities well-below these limits. RHWM chemical inventory reviews have shown that releases from less than $1 \%$ of containers of hazardous waste chemicals could result in consequences >TEEL-1 and $\leq$ TEEL-2 at $100 \mathrm{~m}$; more than $99 \%$ would result in consequences $\leq$ TEEL-1. Typical releases result in small spills that do not release the entire contents of a container.

7. Per sections 4.5.1.1 and 5.5.1 of this DSA, the assumed container inventory for TRU waste is $50 \mathrm{PE}-\mathrm{Ci} \mathrm{Ci}$ if that limit does not yield consequences exceeding the NEPA bounding consequence calculations. The scenarios whose quantities are specifically constrained by NEPA calculations are aircraft crash scenarios with a fire. The fissile material inventory per container is also limited to 200 Pu-239 FGE.

8. Emergency response is assumed as a control for all radioactive material release scenarios.

9. Common mode failures are considered in this PrHA. Mitigation relies on human performance (e.g., training, evacuation) rather than SSCs. Interactions are considered and evaluated.

10. Impacts to the environment from the scenarios are considered less than impacts to the public. As such, controls identified in the PrHA are considered sufficient to address impacts to the environment. In addition, secondary containment for liquid waste provides control to protect the environment.

11. Storage of TRU waste no closer than $130 \mathrm{~m}$ from the site boundary was established as an initial condition for the hazard analysis.

12. Inventory Controls refers to the limits of $50 \mathrm{PE}-\mathrm{Ci}$ and $200 \mathrm{PE}-\mathrm{Ci}$ for TRU waste and 2,000 Ci for tritium. 


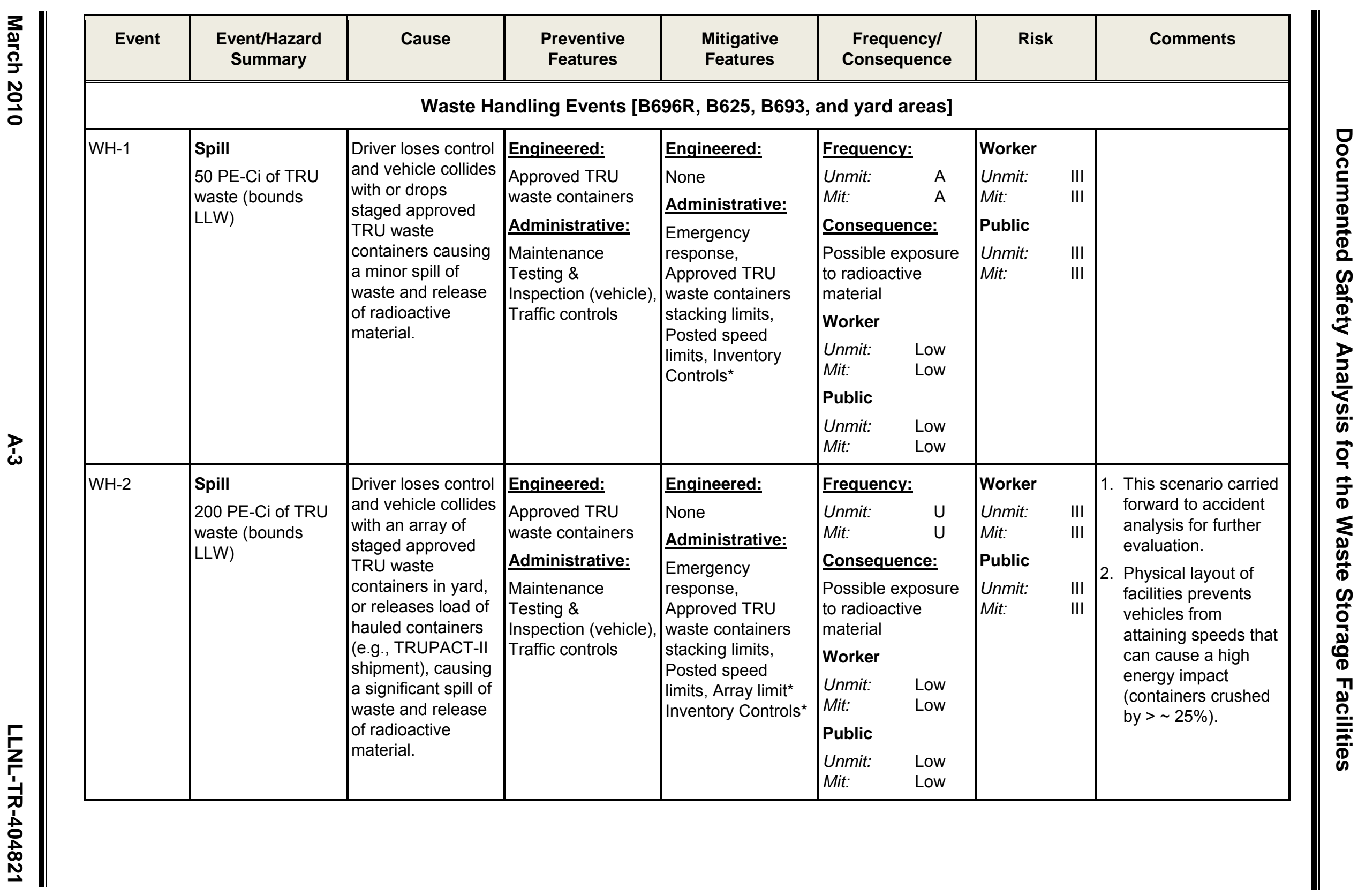




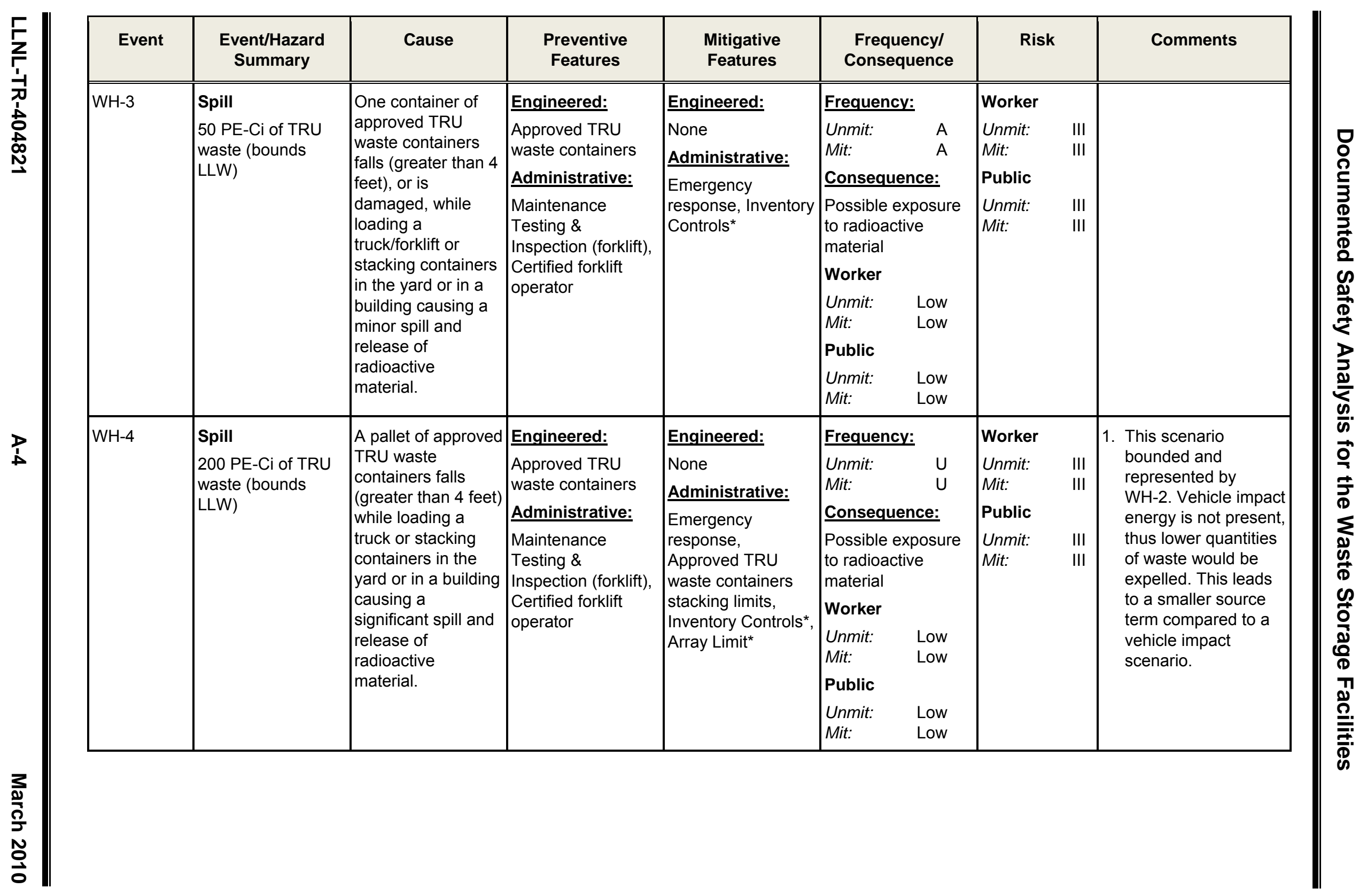




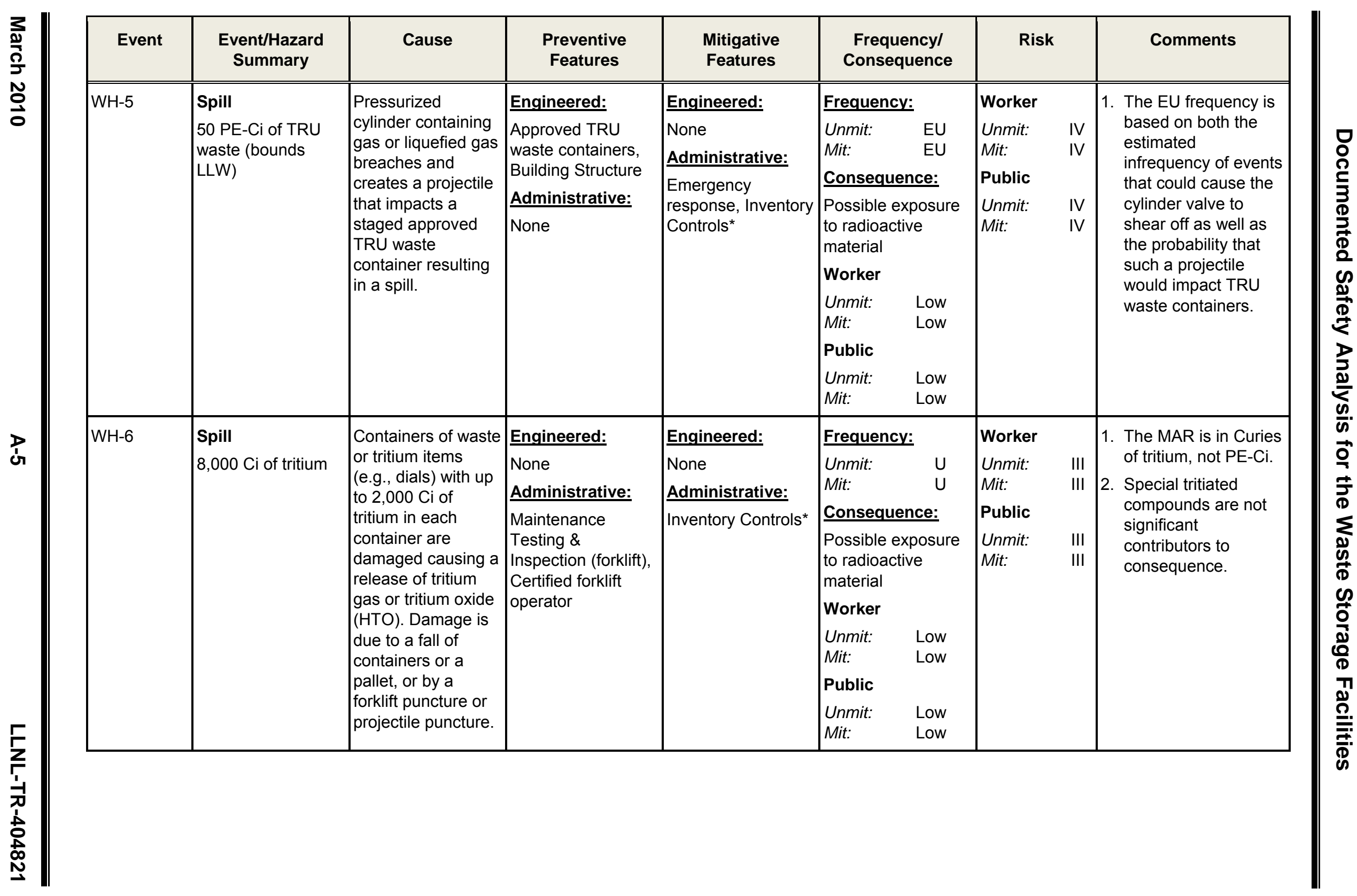




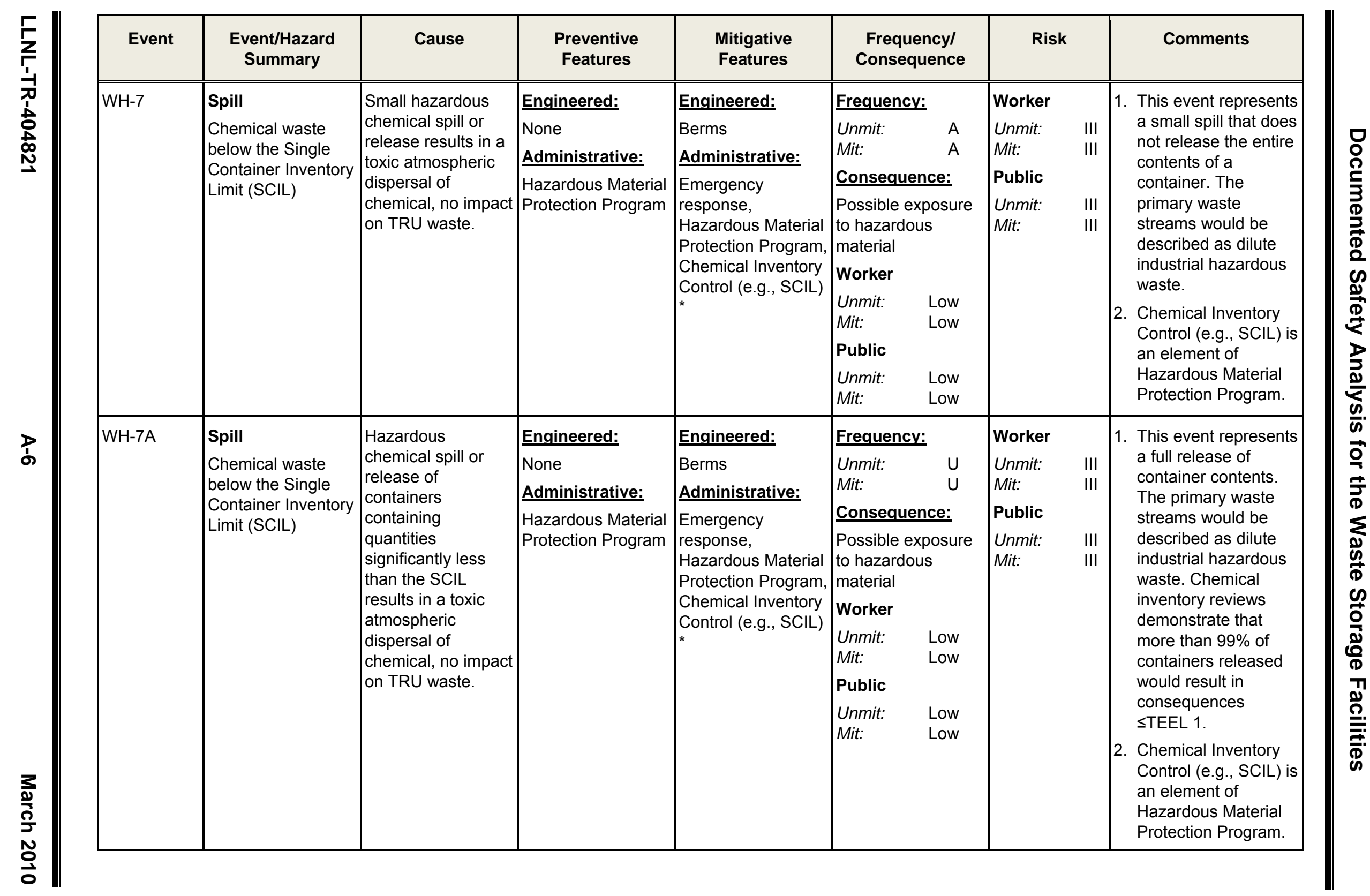




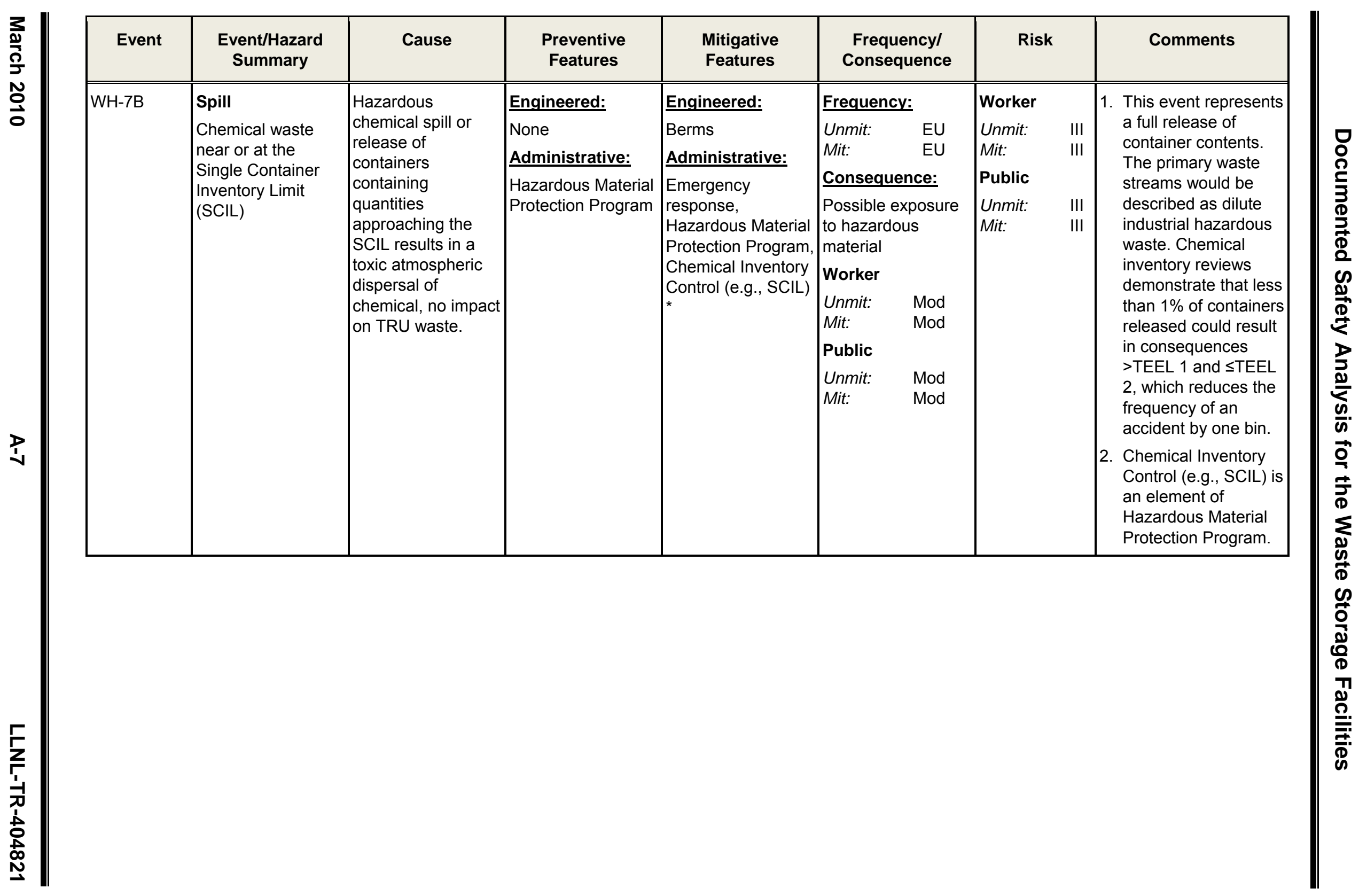




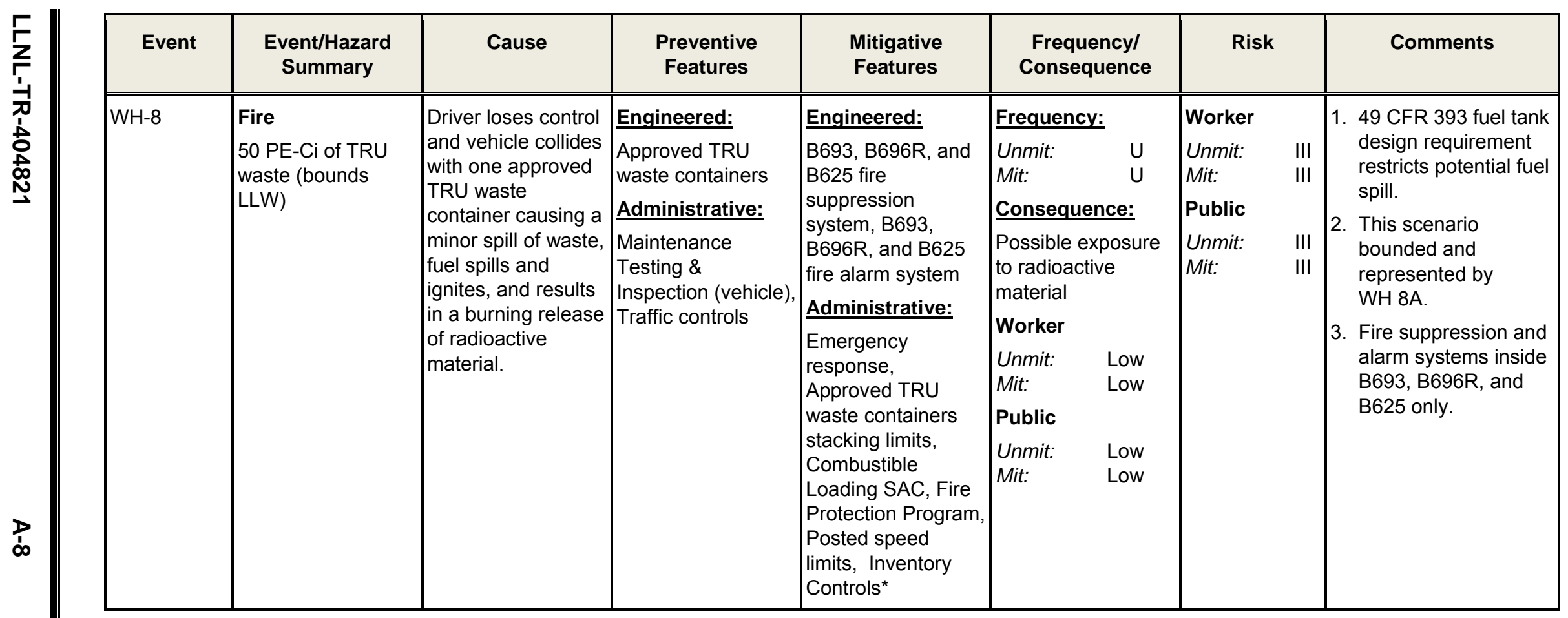




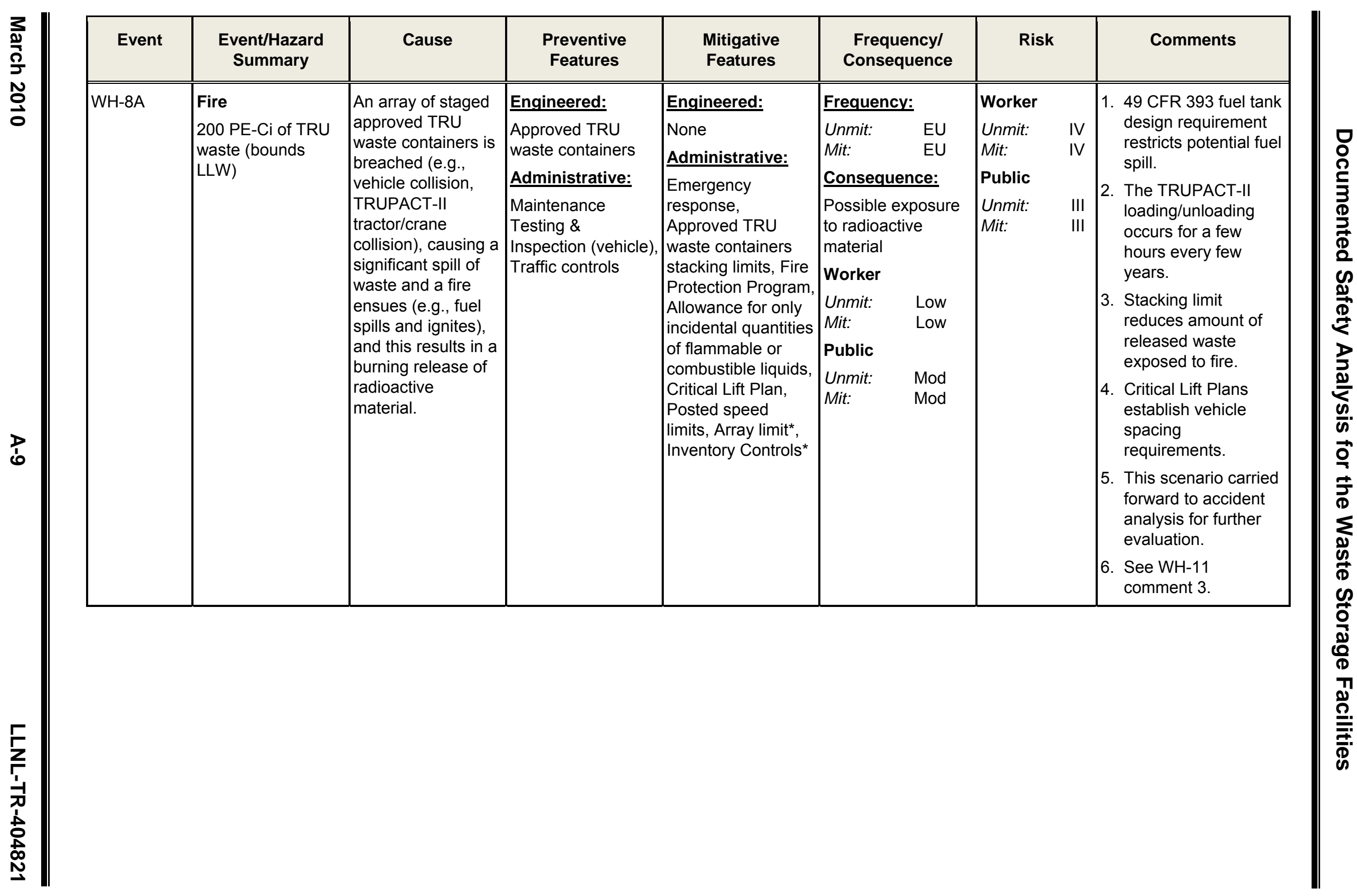




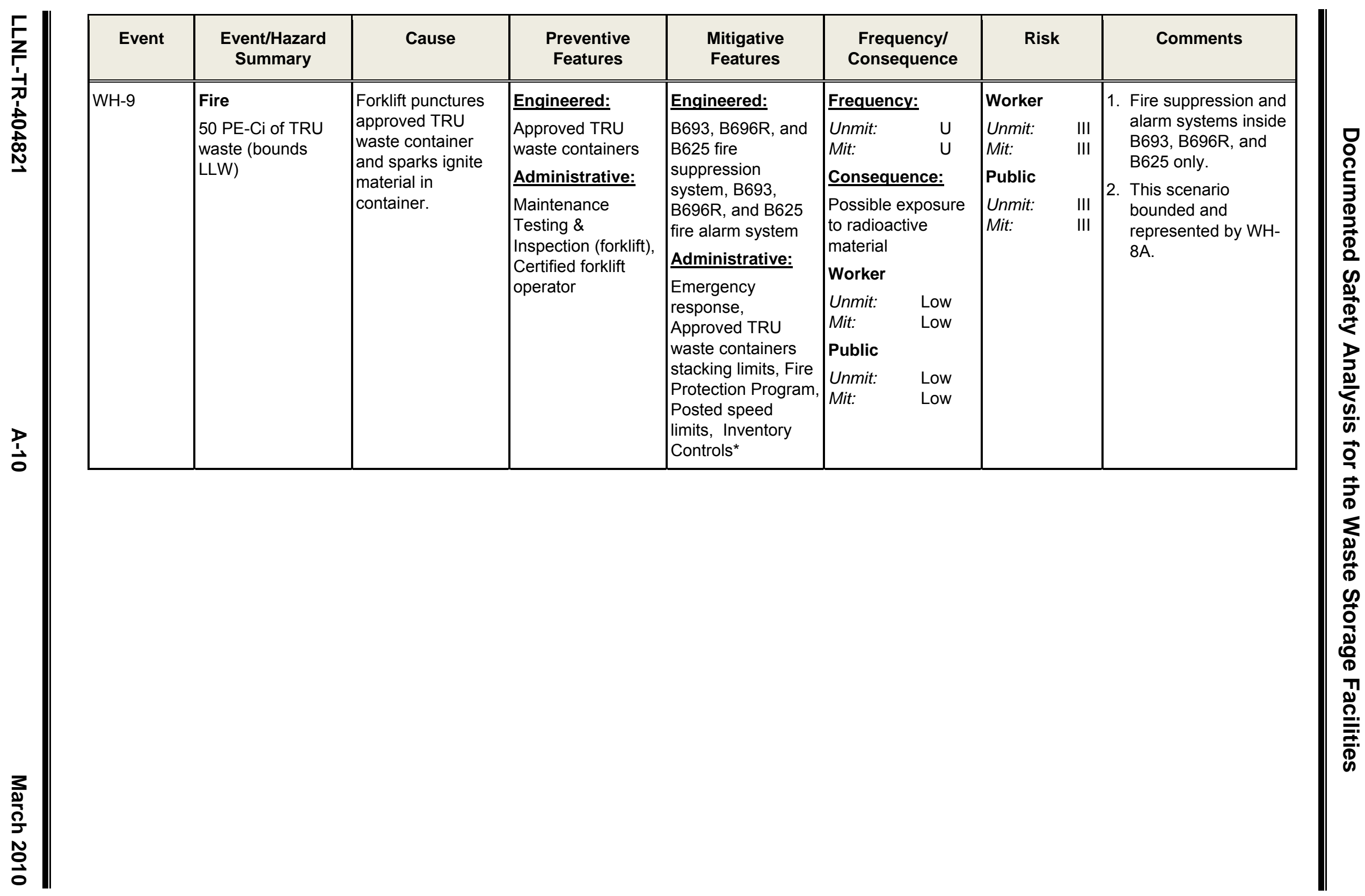




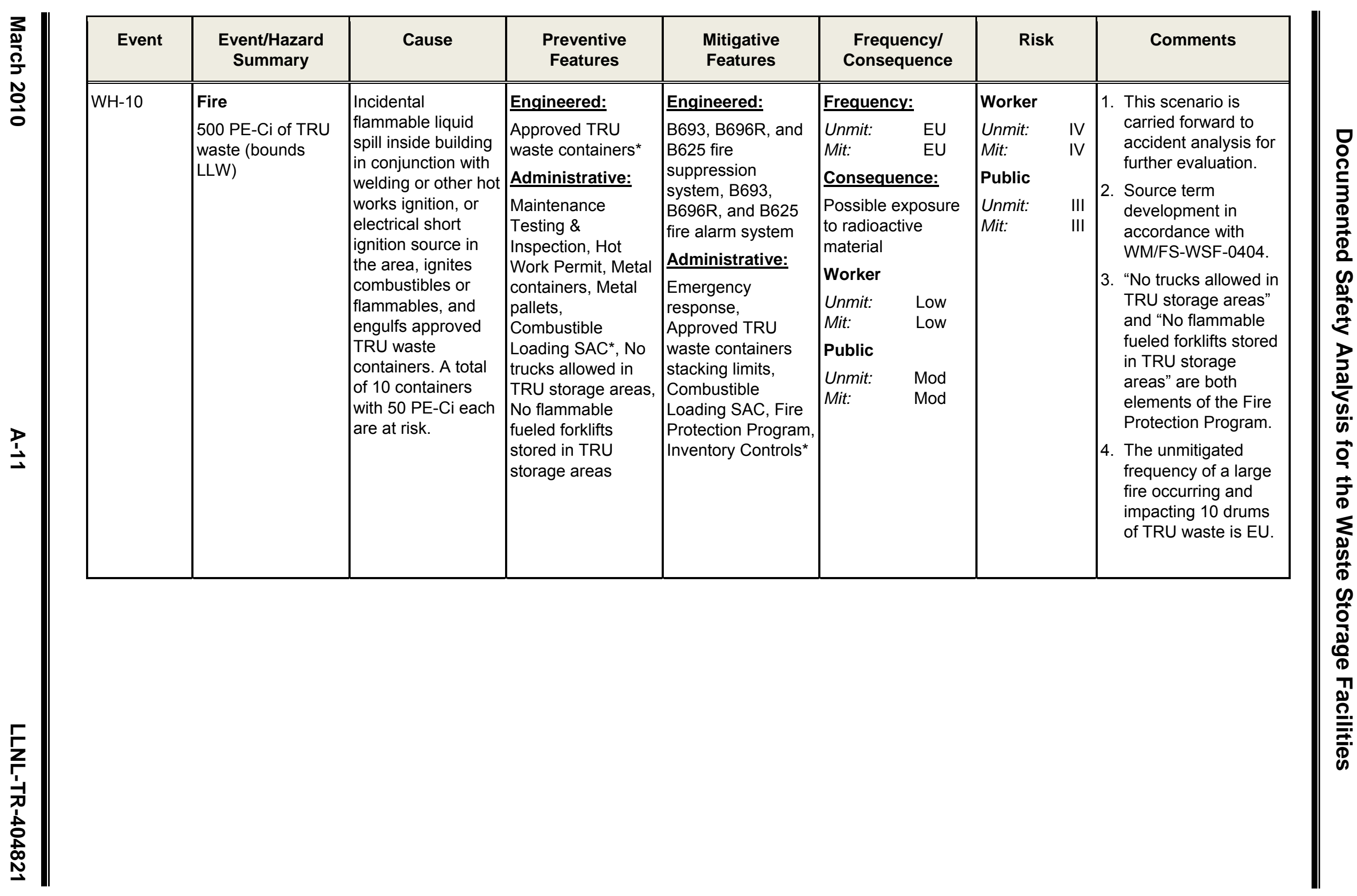




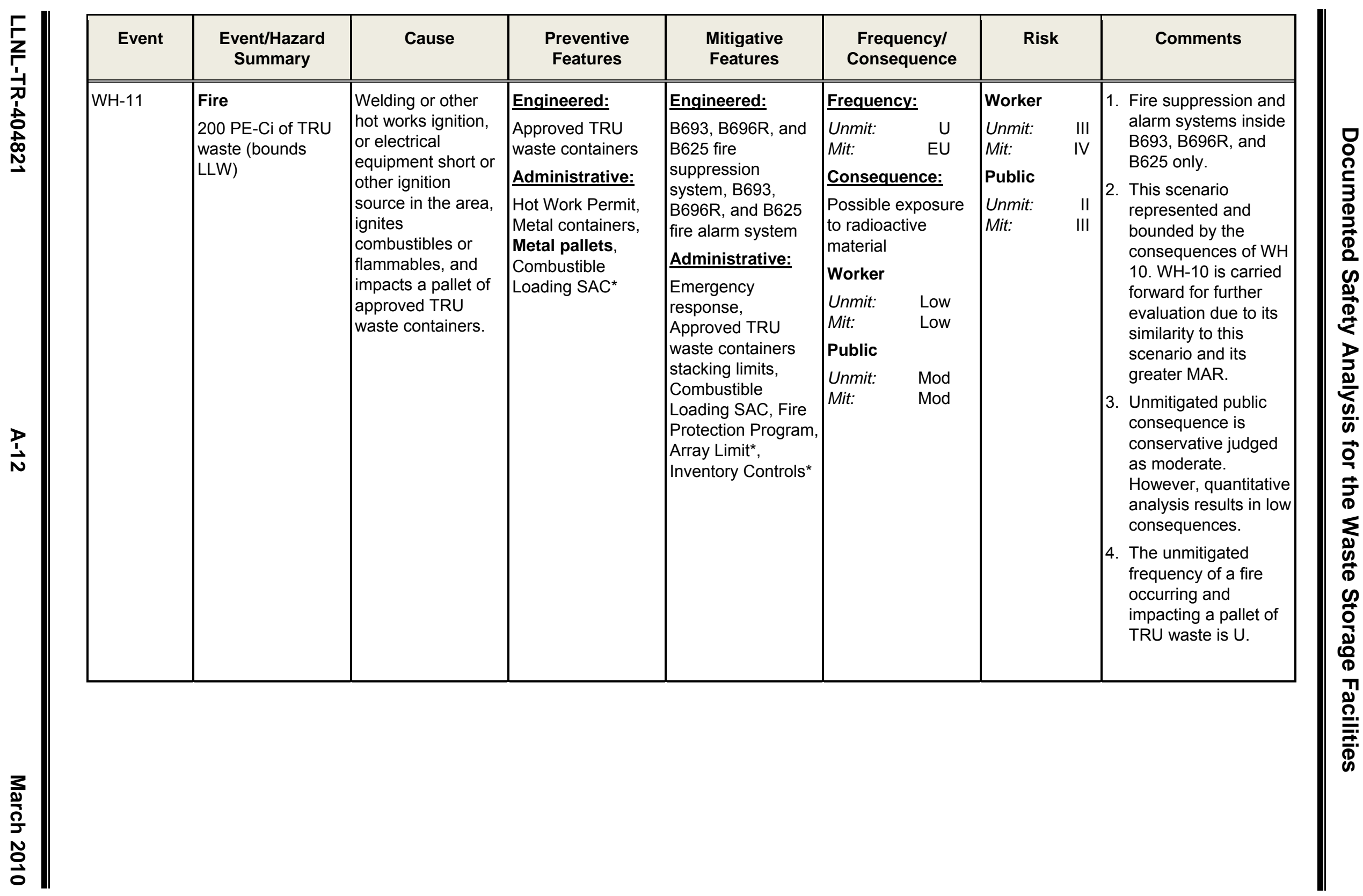




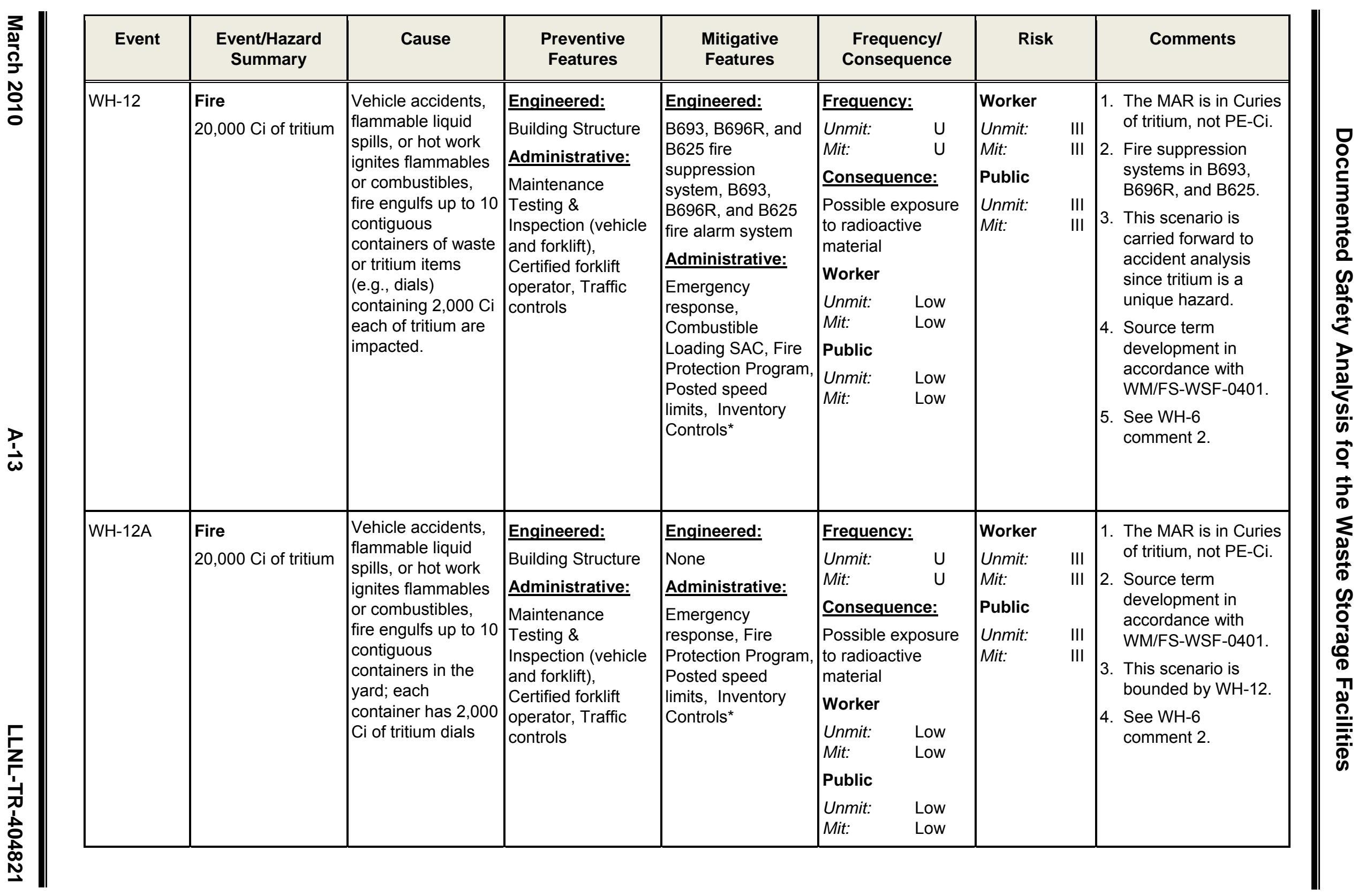




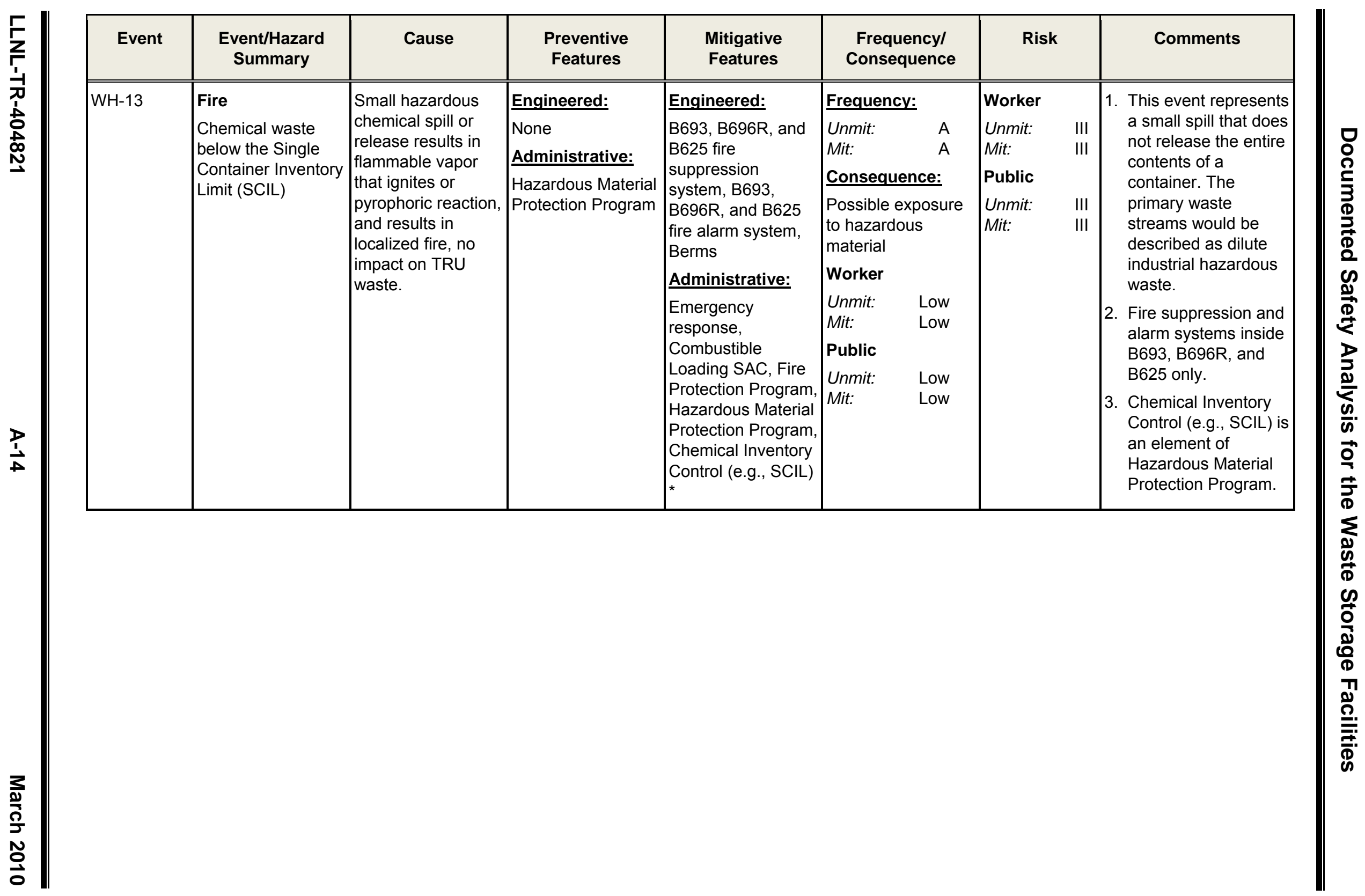




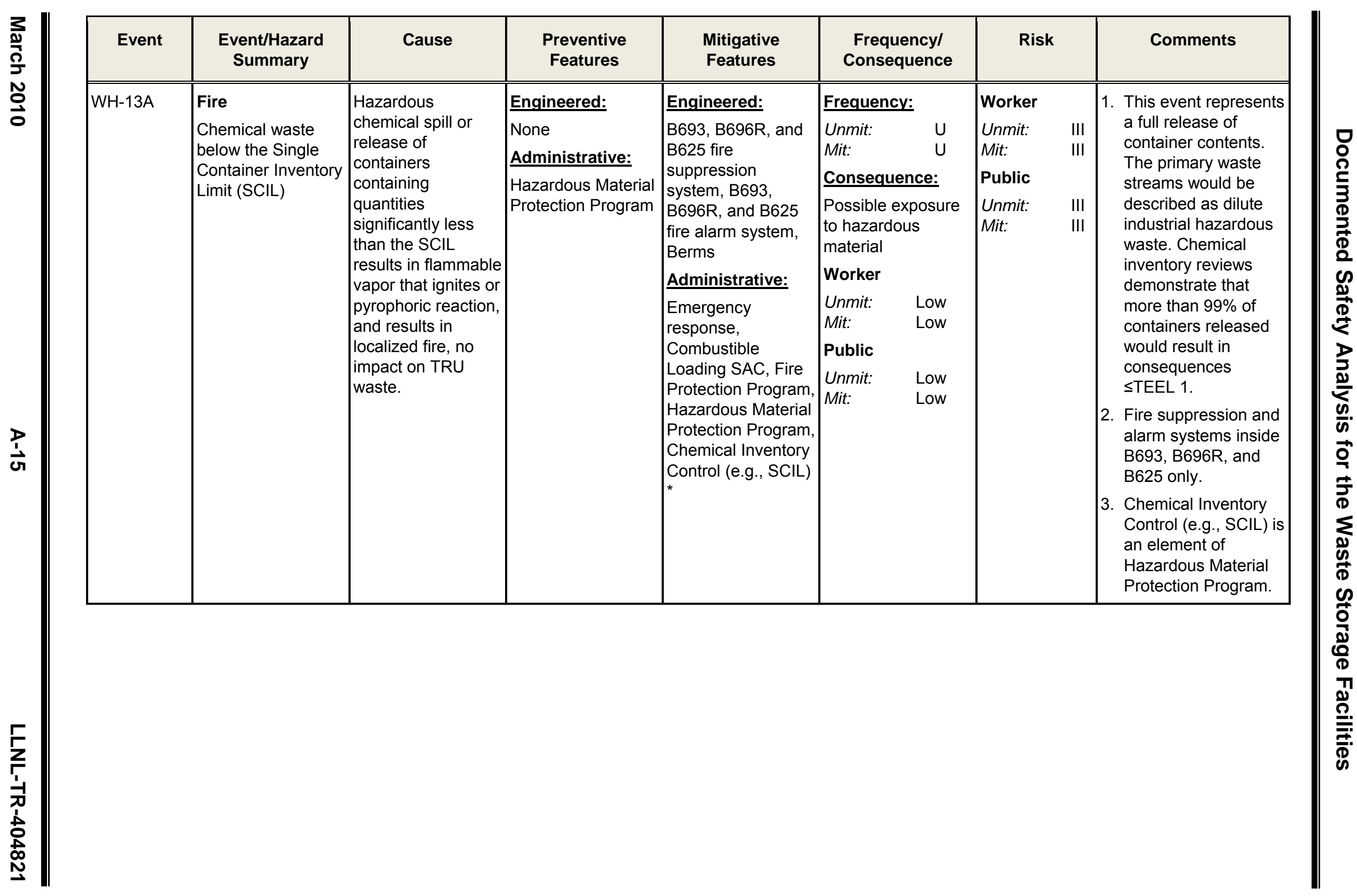




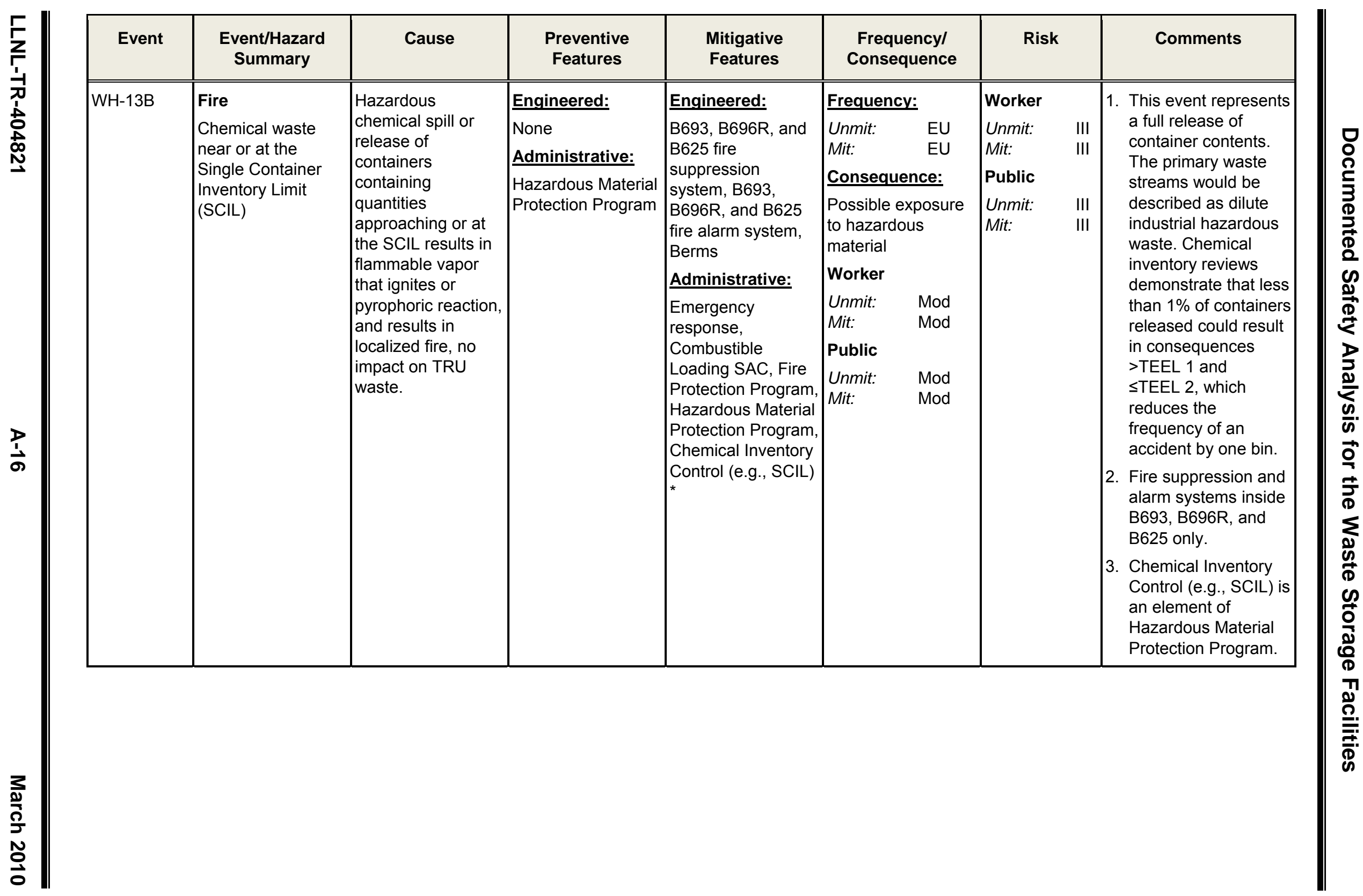




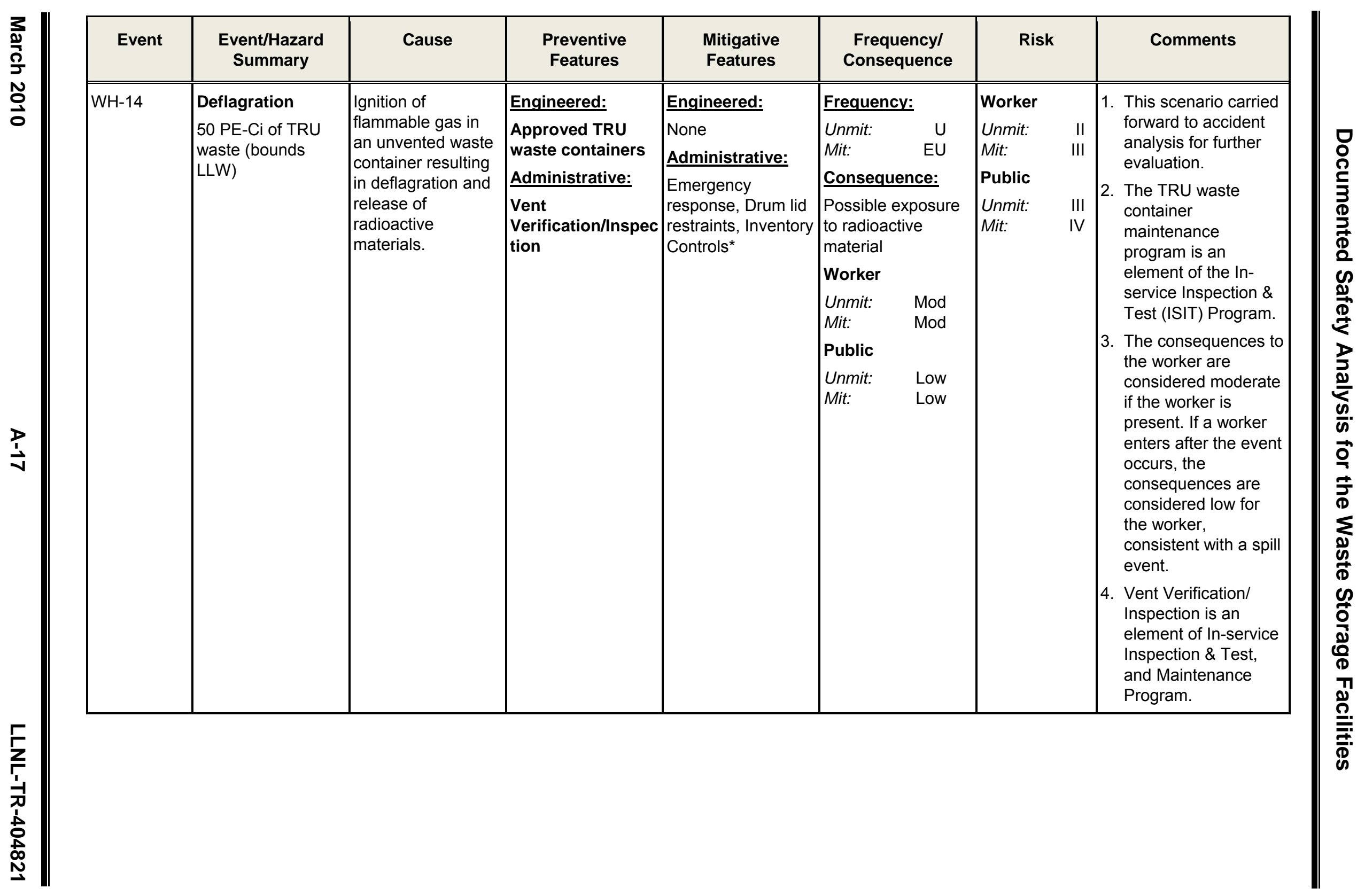




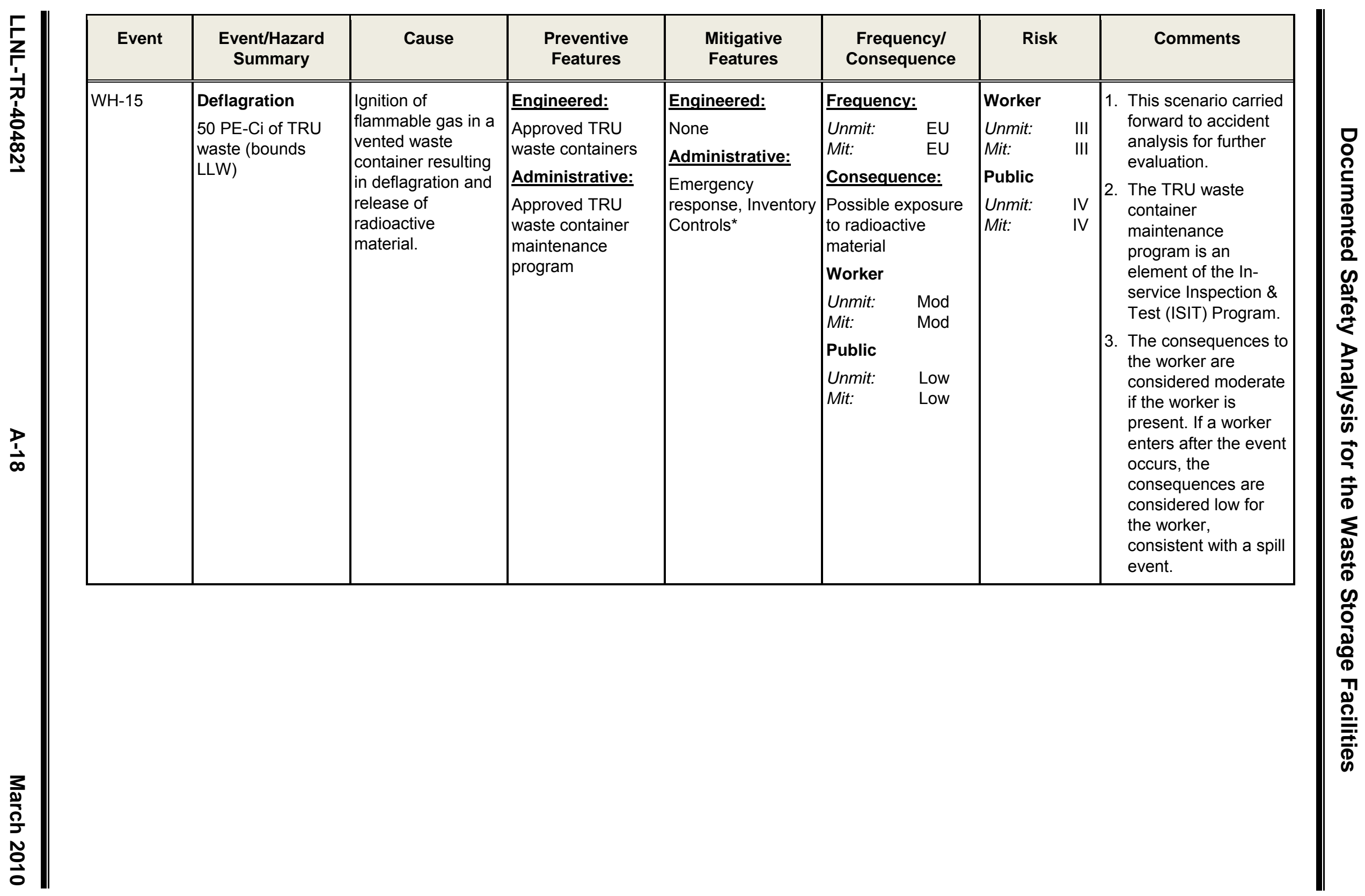




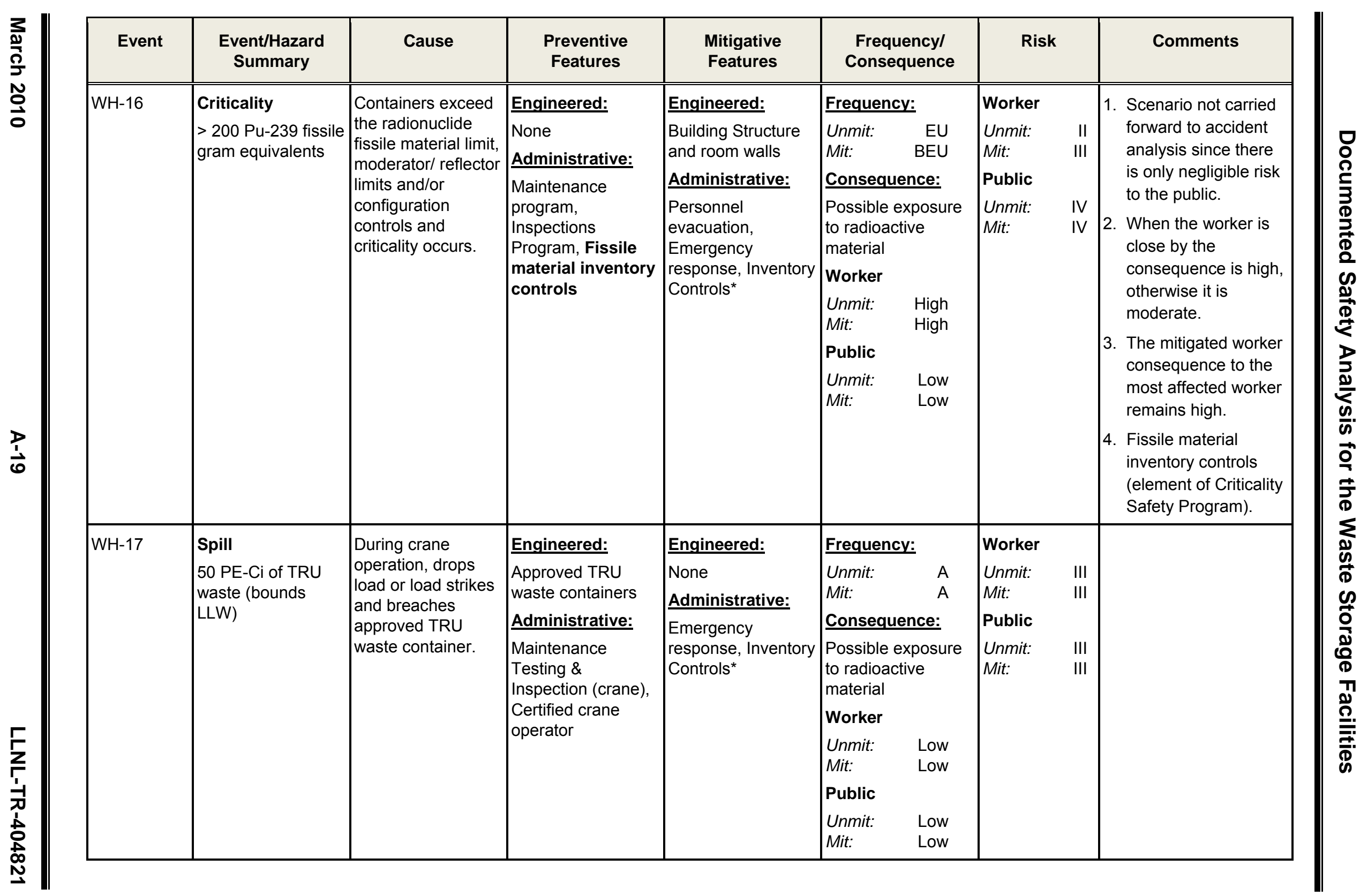




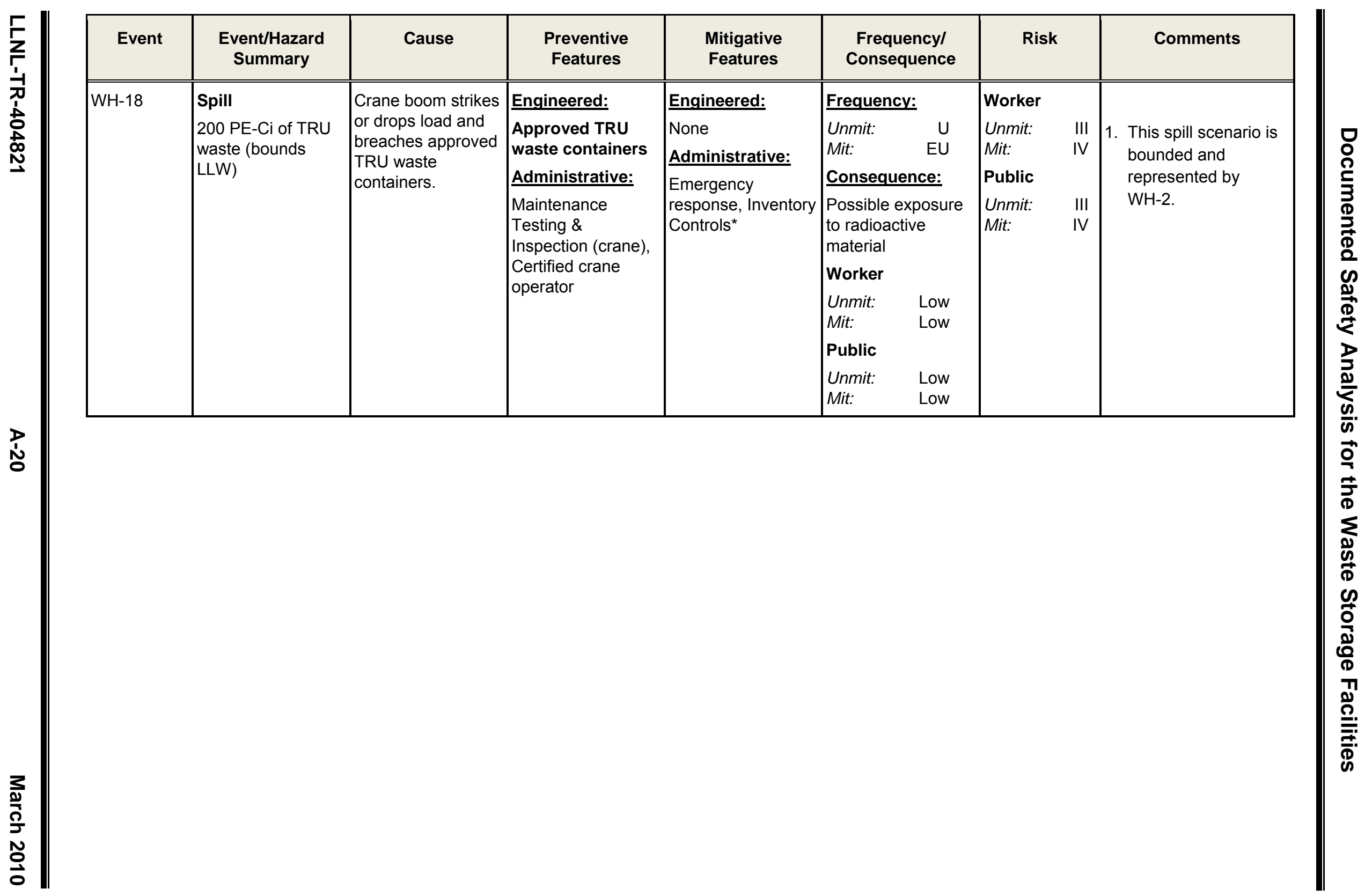




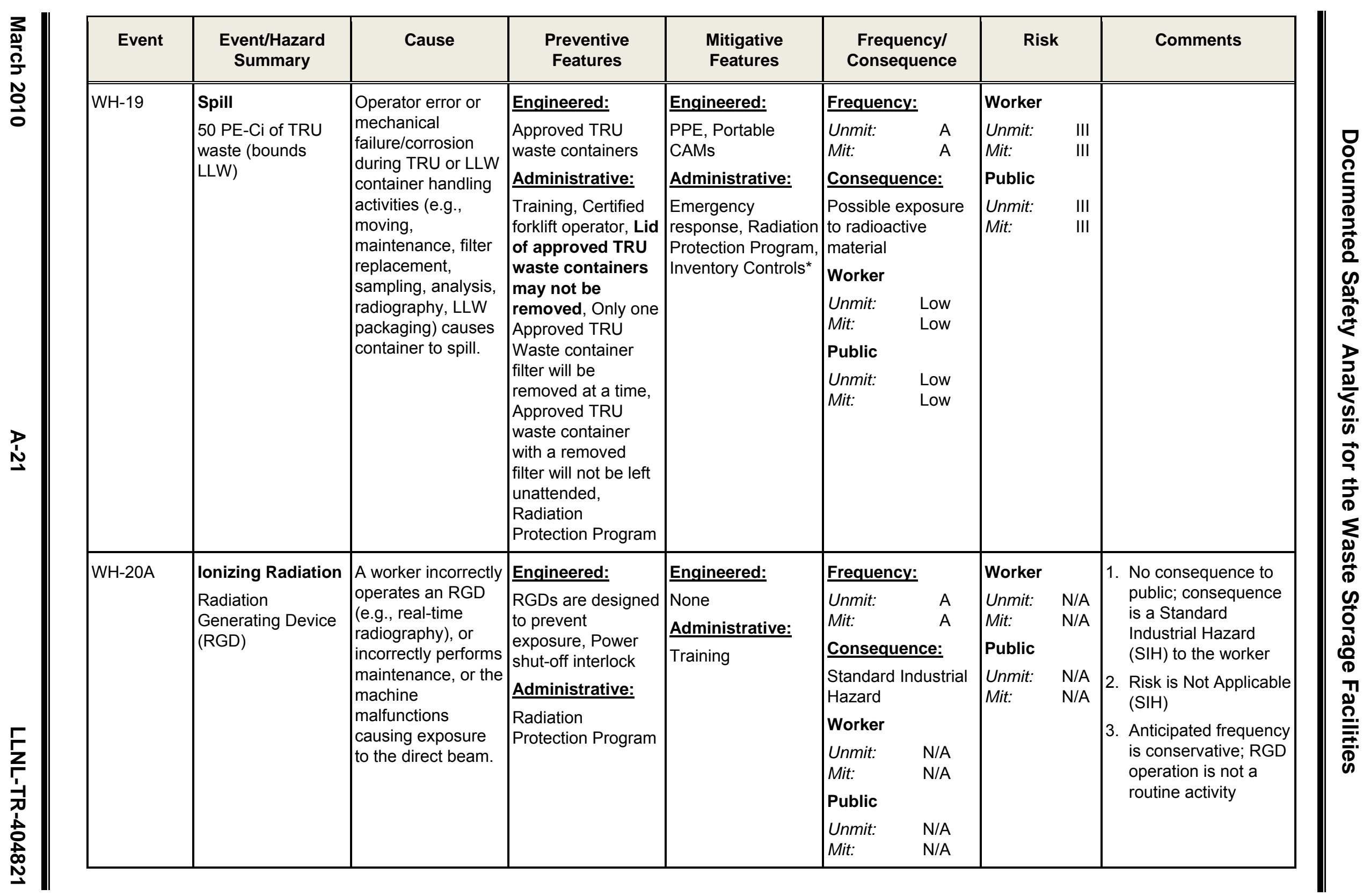




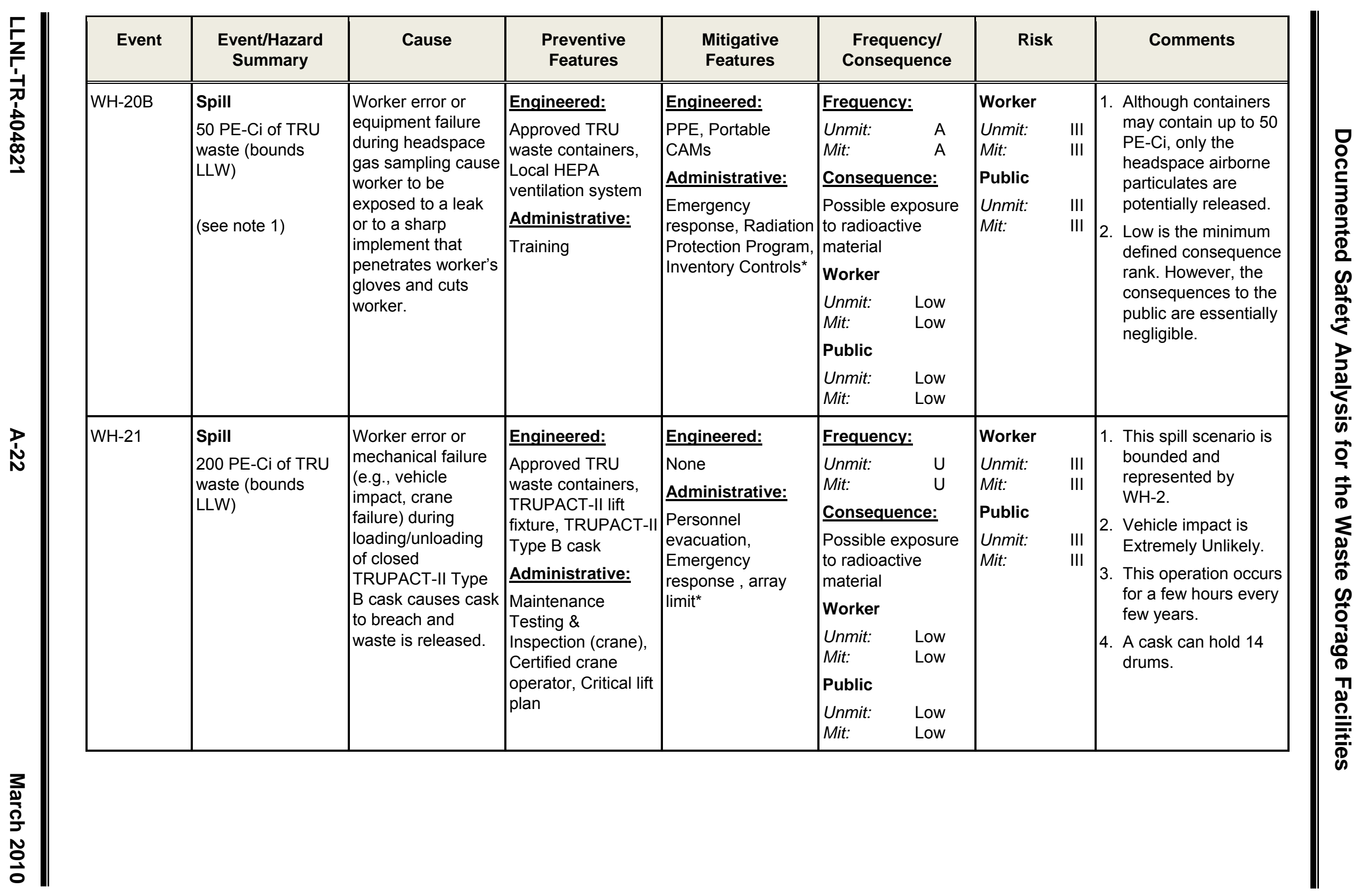




\begin{tabular}{|c|c|c|c|c|c|c|c|}
\hline Event & $\begin{array}{l}\text { Event/Hazard } \\
\text { Summary }\end{array}$ & Cause & $\begin{array}{l}\text { Preventive } \\
\text { Features }\end{array}$ & $\begin{array}{l}\text { Mitigative } \\
\text { Features }\end{array}$ & $\begin{array}{l}\text { Frequencyl } \\
\text { Consequence }\end{array}$ & Risk & Comments \\
\hline \multicolumn{8}{|c|}{ Security Events [B696R, B625, B693, and yard areas] } \\
\hline FA-1 & $\begin{array}{l}\text { Spill or Shrapnel } \\
50 \text { PE-Ci of TRU } \\
\text { waste (bounds } \\
\text { LLW) } \\
\text { or } \\
\text { Chemical waste } \\
\text { near or at the } \\
\text { Single Container } \\
\text { Inventory Limit } \\
\text { (SCIL) }\end{array}$ & \begin{tabular}{|l|} 
Damage with TRU \\
waste or chemical \\
waste from security \\
equipment. (e.g., \\
mobile weapons \\
platform, handguns, \\
rifles)
\end{tabular} & $\begin{array}{l}\text { Engineered: } \\
\text { See comment } 1 \\
\text { Administrative: } \\
\text { See comment } 1\end{array}$ & $\begin{array}{l}\text { Engineered: } \\
\text { Building Structure } \\
\text { Administrative: } \\
\text { Emergency } \\
\text { response }\end{array}$ & \begin{tabular}{|ll}
$|l|$ & Frequency: \\
Unmit: $\quad$ BEU \\
Mit: $\quad$ BEU \\
Consequence: \\
Potential for & severe \\
injury to & worker and \\
public as a & result of \\
bullet impact & \\
Worker & \\
Unmit: & High \\
Mit: & High \\
Public & \\
Unmit: & High \\
Mit: & High
\end{tabular} & $\begin{array}{ll}\text { Worker } & \\
\text { Unmit: } & \text { III } \\
\text { Mit: } & \text { III } \\
\text { Public } & \\
\text { Unmit: } & \text { III } \\
\text { Mit: } & \text { III }\end{array}$ & $\begin{array}{l}\text { 1. See LSO letter COR- } \\
\text { LSO-3/5/2009-68409 } \\
\text { from Phillip E. Hill to } \\
\text { Bruce T. Goodwin, } \\
\text { Approval of the } \\
\text { Revised Safety Basis } \\
\text { Amendment for } \\
\text { Deployment of Mobile } \\
\text { Weapons Platforms, } \\
\text { dated April 15, 2009. } \\
\text { 2. The toxic and } \\
\text { radiological } \\
\text { consequences to the } \\
\text { worker and public are } \\
\text { low. }\end{array}$ \\
\hline
\end{tabular}




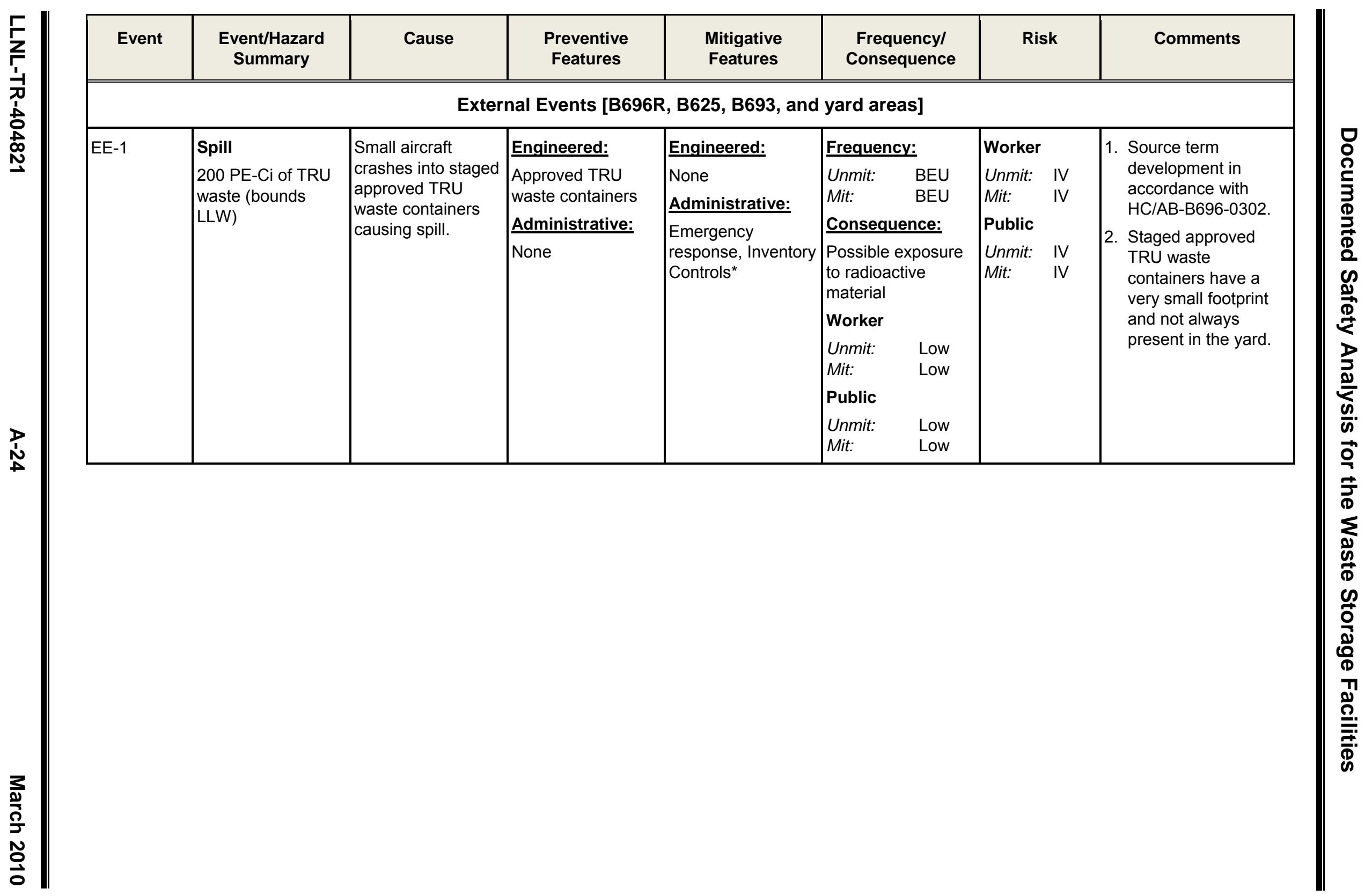




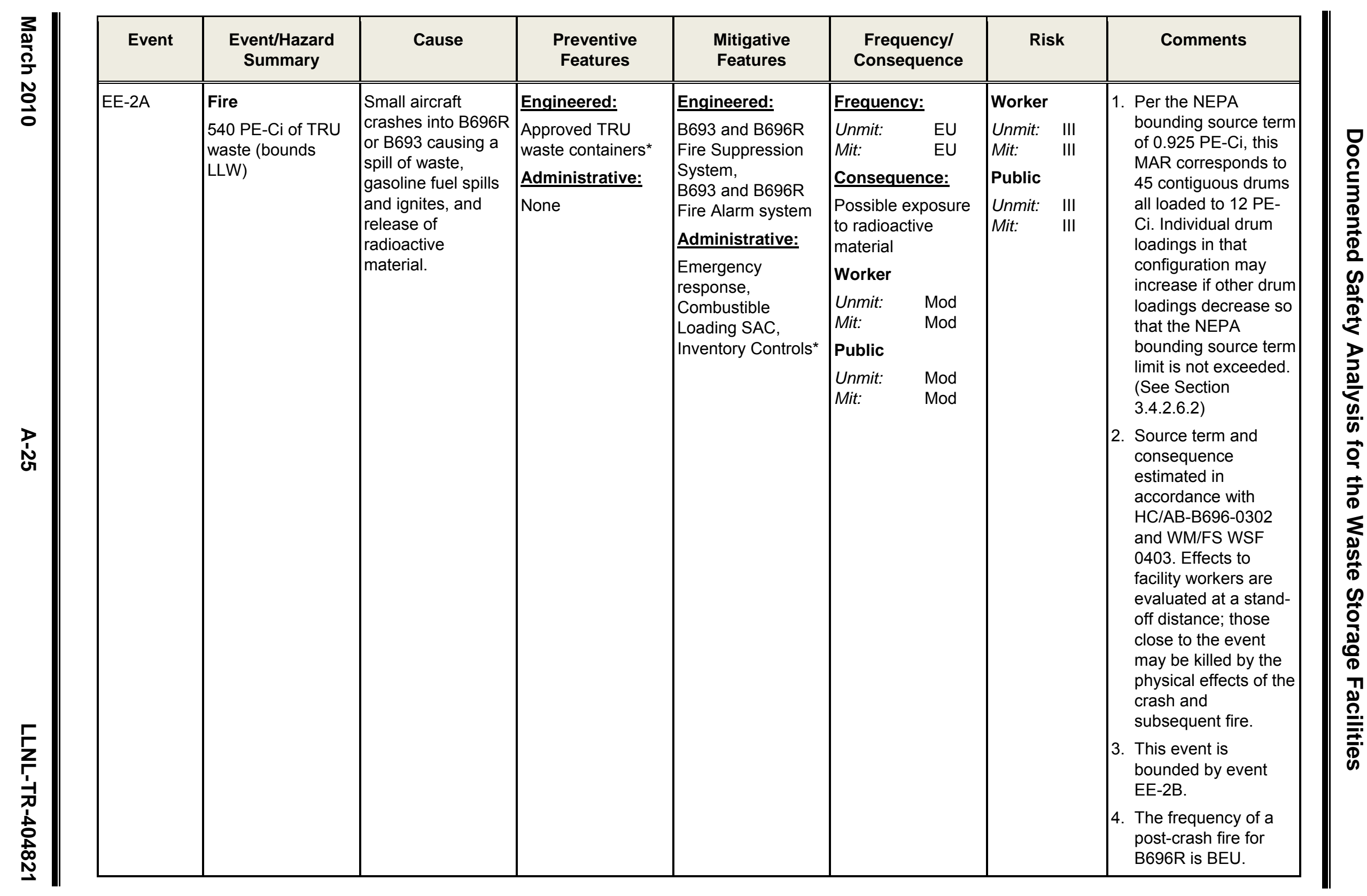




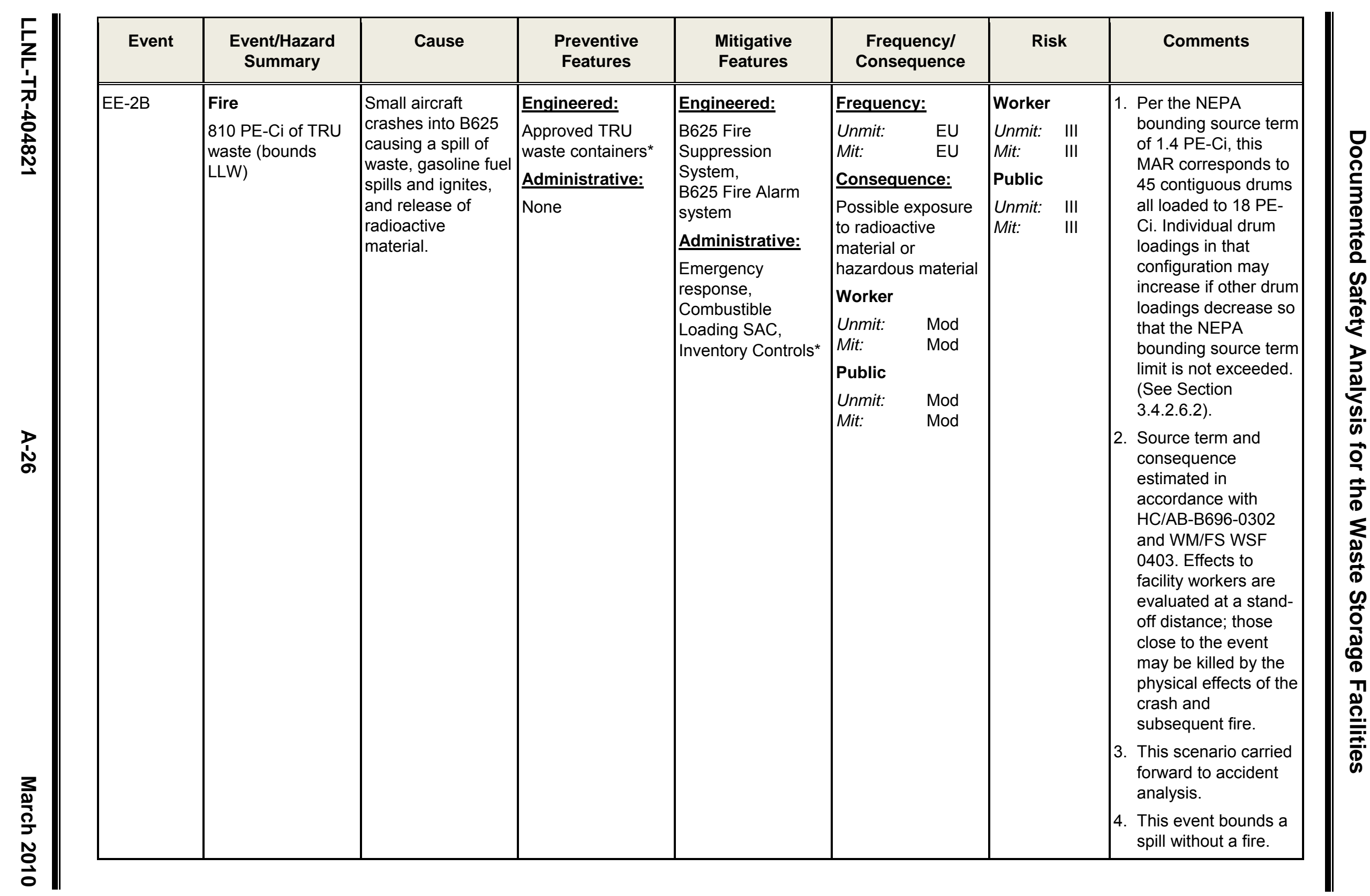




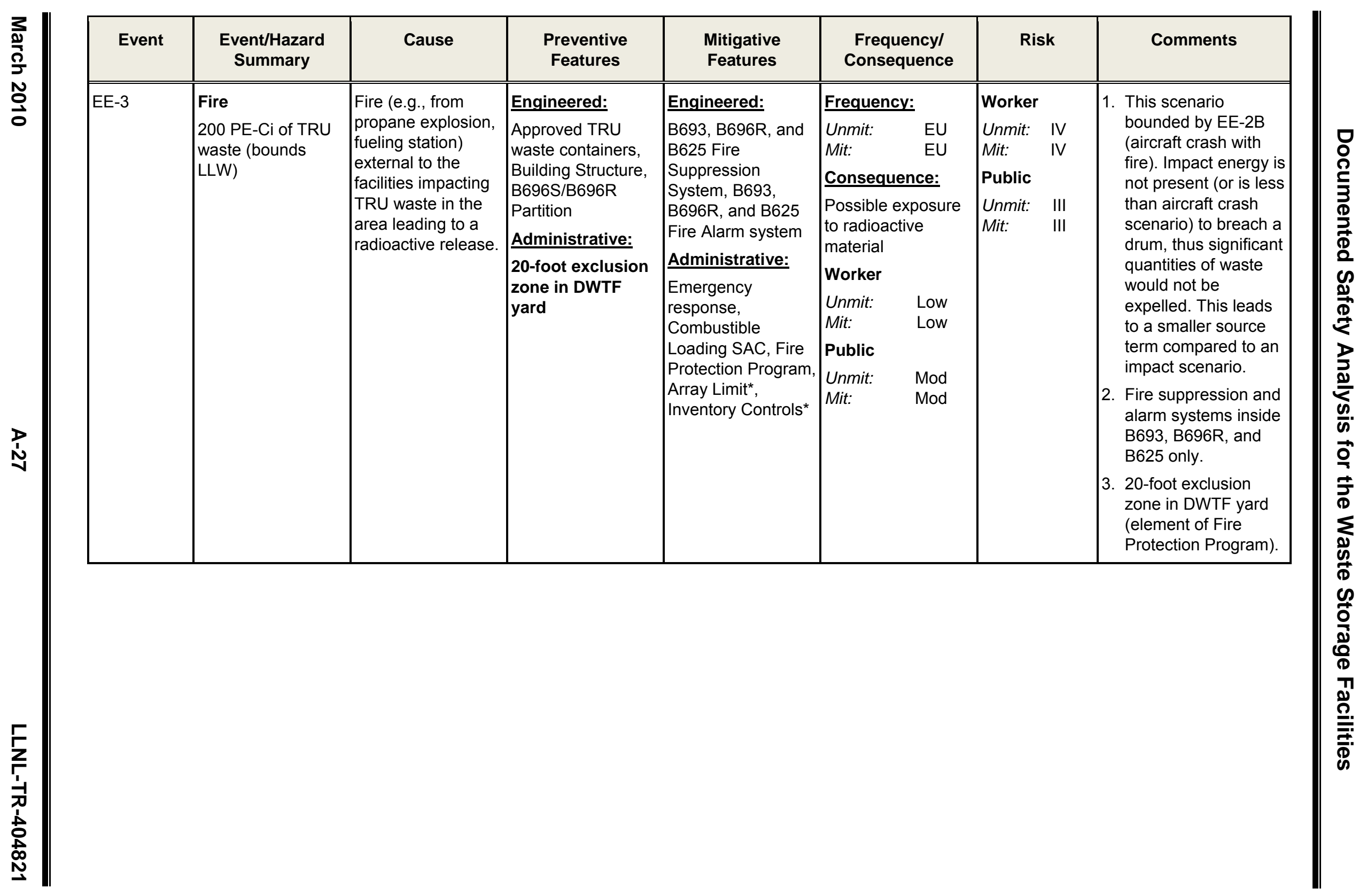




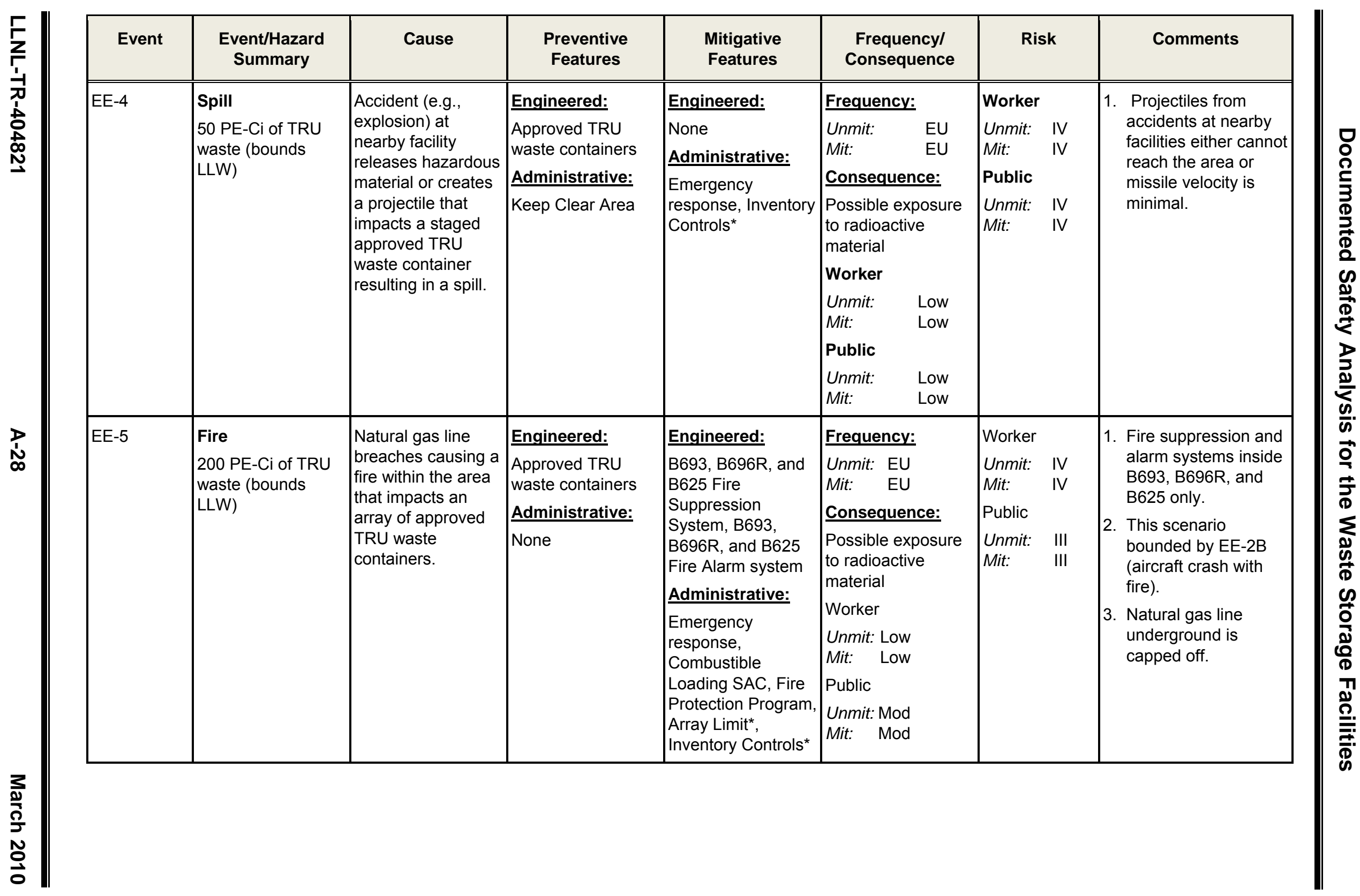




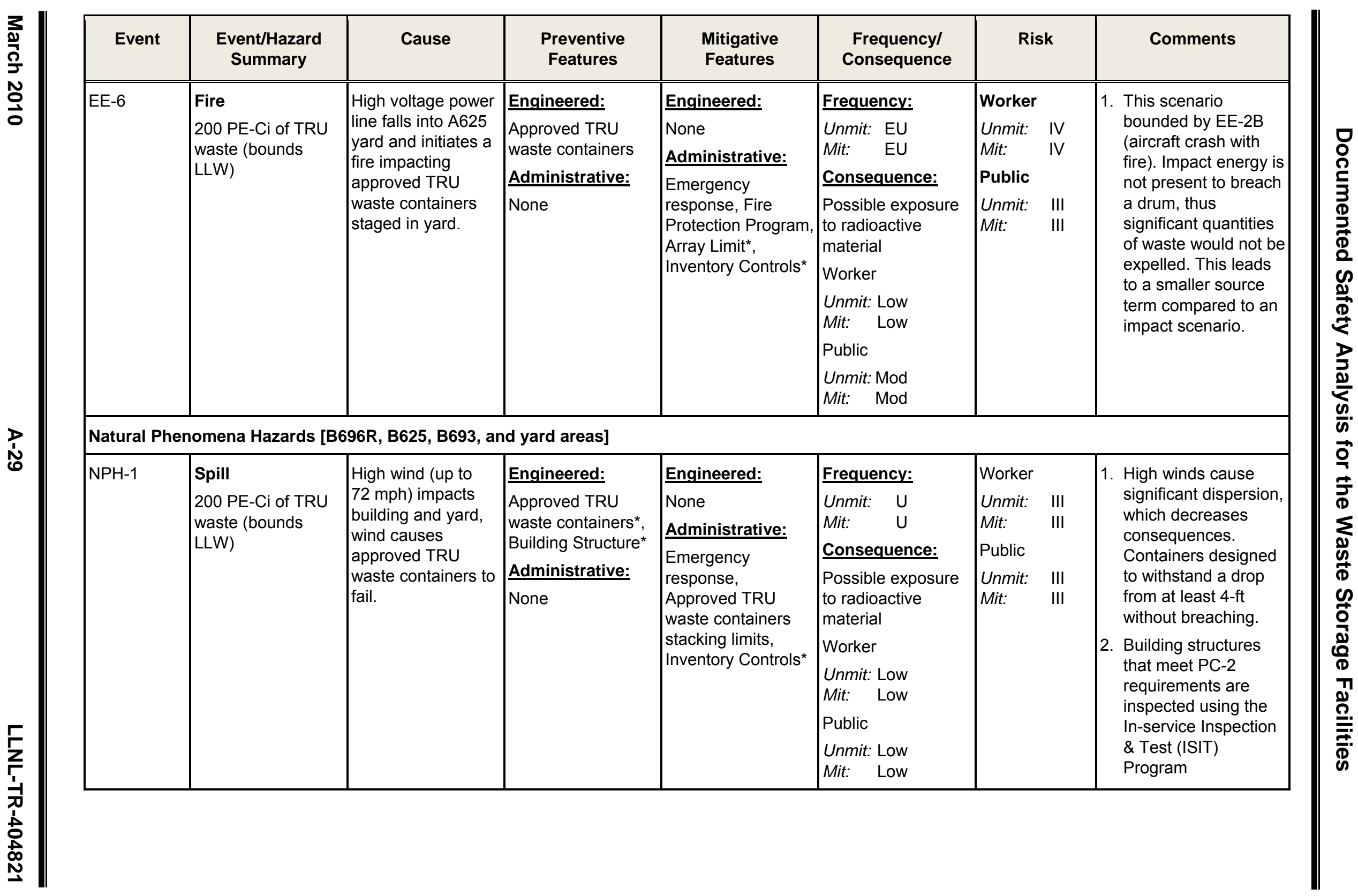




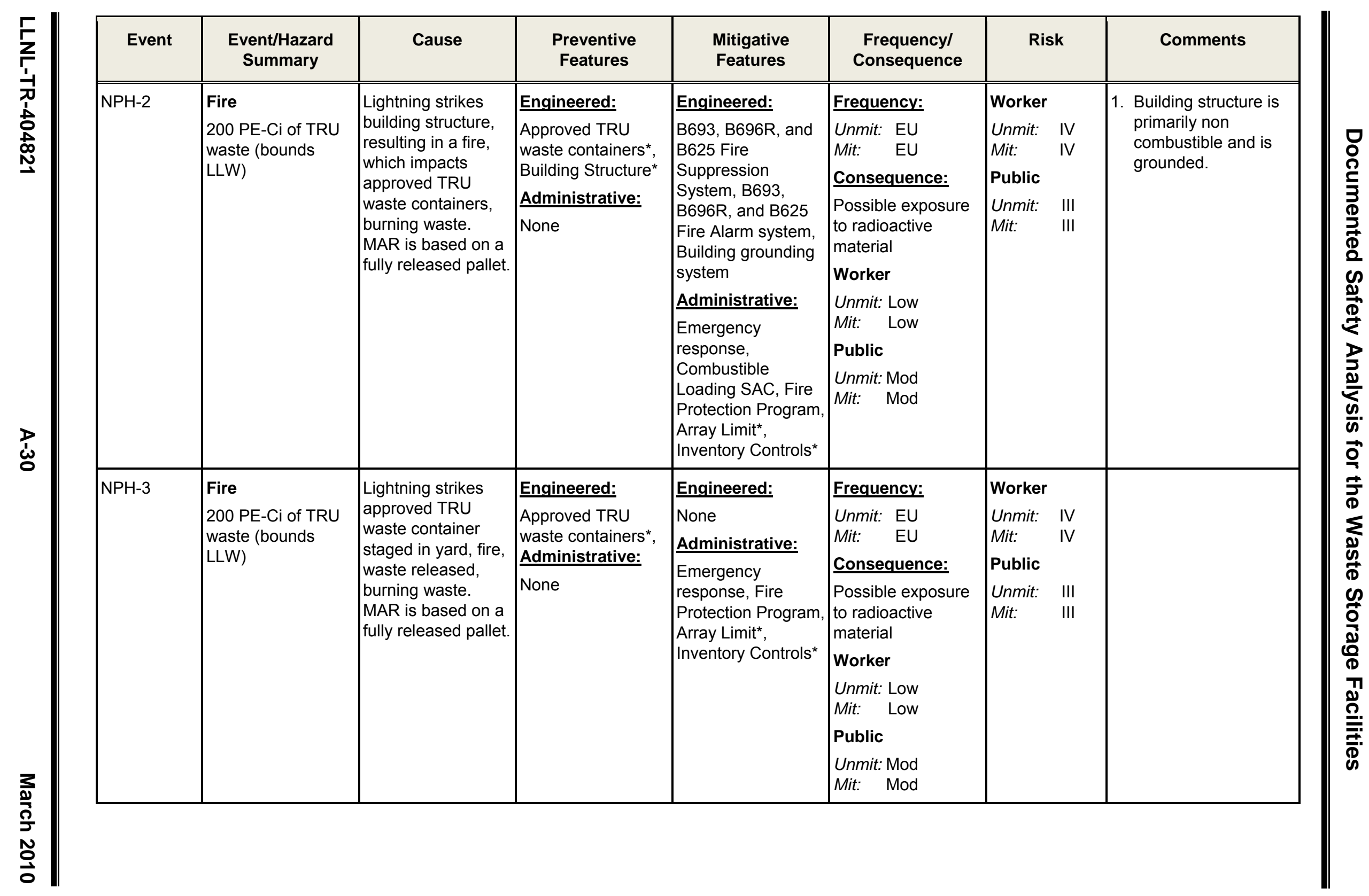




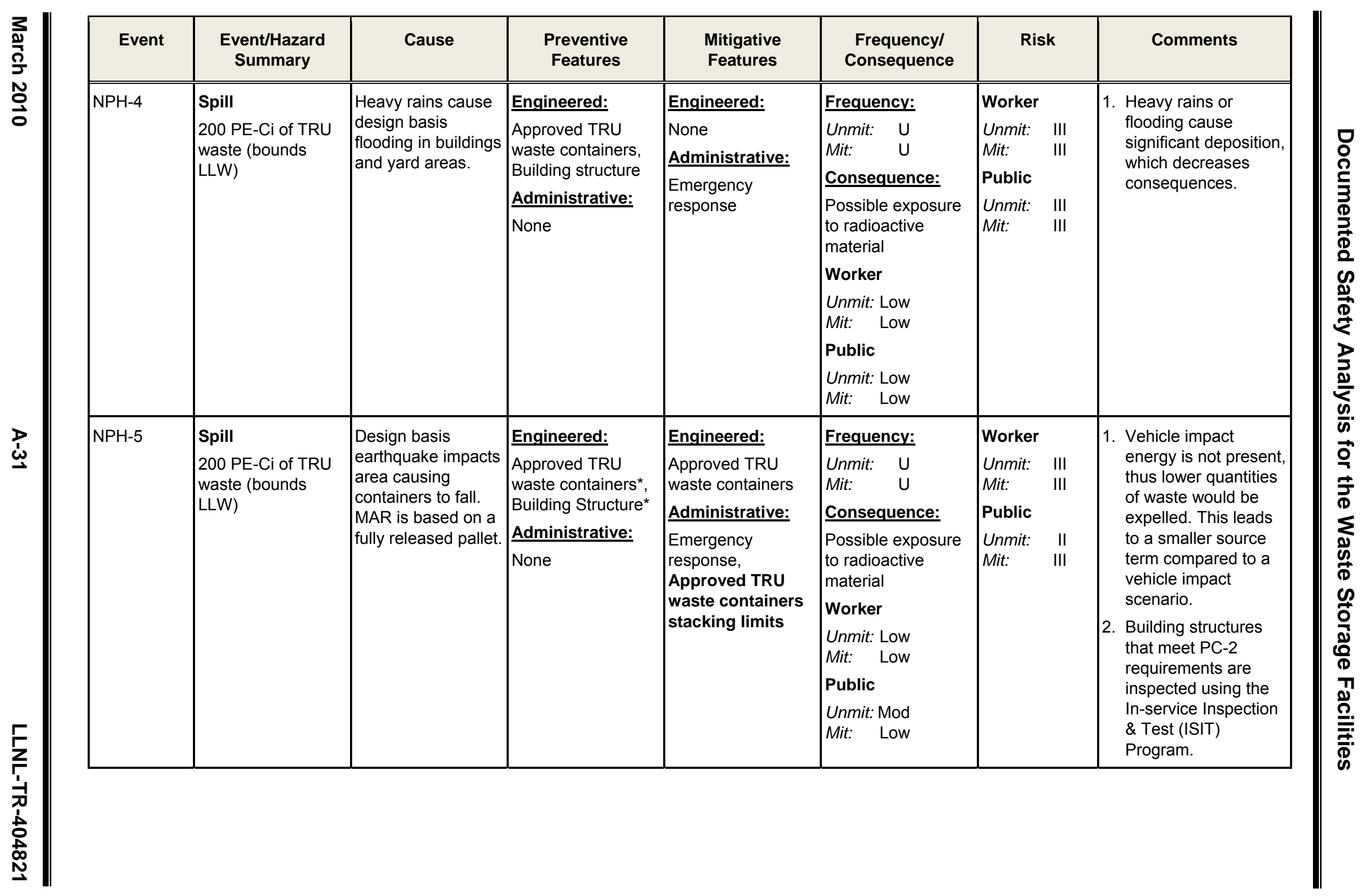




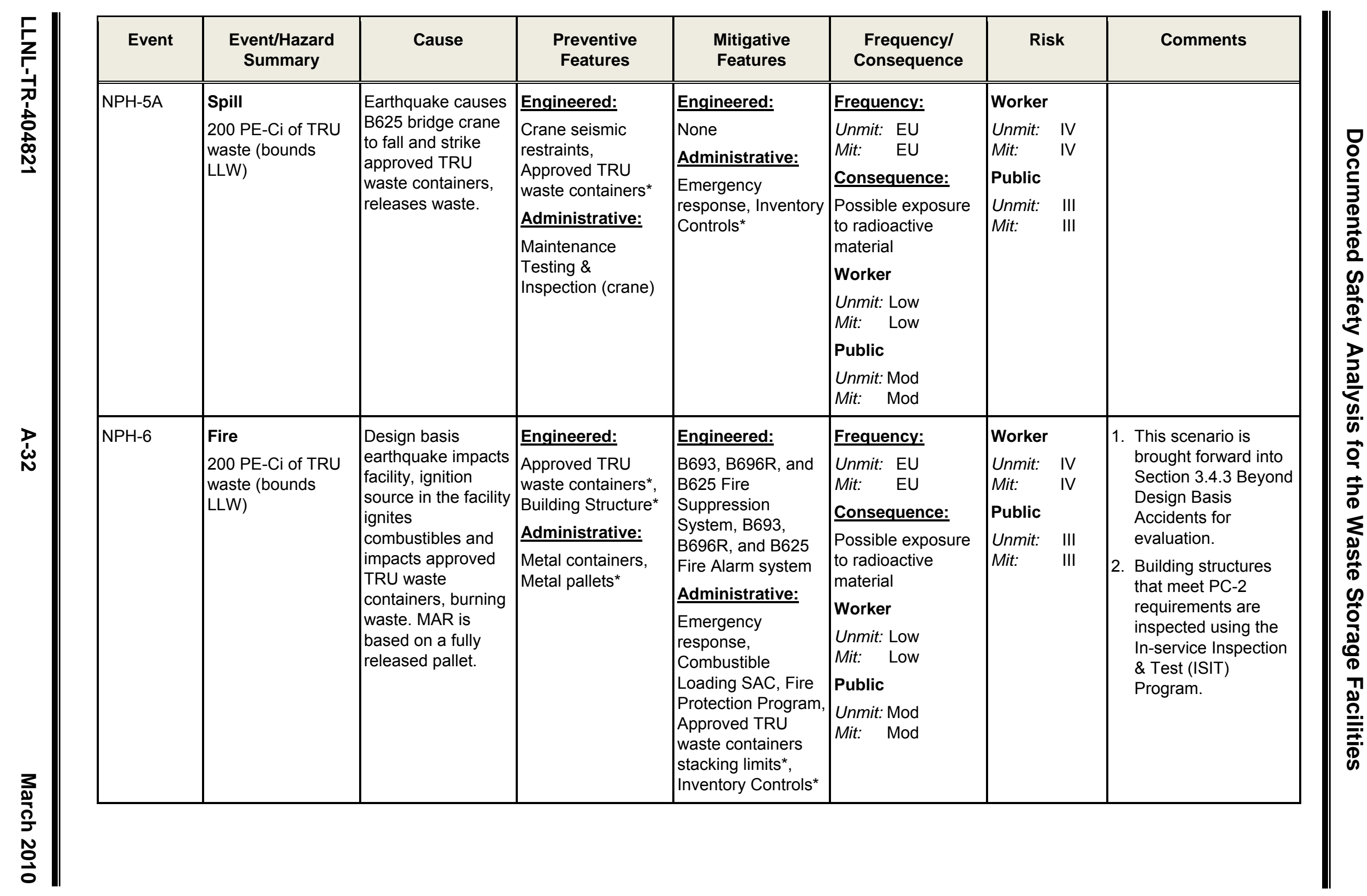




\section{APPENDIX B AIRCRAFT CRASH ANALYSIS}

The probability of an aircraft crashing into waste storage facilities was evaluated using the methods described in DOE-STD-3014-96. The probability of an aircraft crash is evaluated to bound the risk presented by surrounding airports and types of aircraft and operations in those airports. An assessment for Building 332 (Foote, 2002) showed that general aviation associated with the Livermore Municipal Airport (LVK) accounted for approximately $90 \%$ of the aircraft crash probability. Therefore, the operations of general aviation aircraft at the Livermore Municipal Airport dominate the risk of an aircraft crash to facilities at LLNL. Hence, the scope of this analysis is limited to quantification of the risk from general aviation at LVK.

\section{B.1 SCREENING AIRCRAFT CRASH PROBABILITY}

The analysis of the aircraft crash probability does not take into account the surrounding structures, and includes the probability that a wing tip of a light aircraft nicks a building (refer to Figure B-3 in DOE-STD-3014-96), which would not lead to uncontrolled radioactive release. Hence, the probability of an aircraft crash obtained by the analysis is conservative even without the adjustment for other types of aircrafts.

The formula below was used to calculate the frequency of an aircraft crash into the waste storage facilities:

$$
F=\sum_{i} N_{i} P_{i} f_{i}(x, y) A_{i}
$$

where $F$ is the estimated annual aircraft crash impact frequency for the facility, $N$ is annual number of aircraft operations, $P$ is the aircraft crash rate (crash/operations), $f(x, y)$ is the aircraft crash location conditional probability $\left(\mathrm{mi}^{-2}\right), A$ is the effective area of $\left(\mathrm{mi}^{2}\right)$, and $i$ is the flight phase, i.e., takeoff, in-flight, and landing.

The total number of aircraft operations is on the order of 240,000 per year from the latest posting on the Livermore Municipal Airport web site. The operations are all conservatively assumed to be general aviation of the fixed wing single engine reciprocating type. The distance from the middle of the runway to the nearest corner of a waste storage facility is approximately 6.6 miles. From Table B-1 of DOE-STD-3014-96, the generic crash rates are $1.1 \times 10^{-5}$ per takeoff and $2.0 \times 10^{-5}$ per landing, respectively. The crash location conditional probabilities, values of $f(x, y)$, for landings and take-offs in Tables B-4 and B-5 in DOE-STD-3014-96 are $2.9 \times 10^{-3}$ and 0 , respectively. In the opposite direction, associated crash location probabilities are $6.5 \times 10^{-4}$ and $1.5 \times 10^{-3}$, respectively. 
The effective target area presented is calculated using Equations B-3 to B-5 in DOE-STD-3014-96. Together, these equations yield the following:

$$
A_{e f f}=(W S+R)(S+H \cot \phi)+\left(\frac{2 \times W S}{R}+1\right) L \times W
$$

where WS is the aircraft wing span, $R$ is the length of facility diagonal, $S$ is the aircraft skid distance, $H$ is the facility height, cot $\varphi$ is the cotangent of aircraft impact angle, $L$ is the length of facility, and $W$ is the width of facility.

Dimensions of the buildings are provided in Table B-1. The wingspan of a general aviation aircraft is $50 \mathrm{ft}$ from Table B-16 of DOE-STD-3014-96. For general aviation, the value of $\cot \varphi$ is 8.2 from Table B-17 and the skid distance is $60 \mathrm{ft}$ from Table B-18 in DOE-STD-3014-96. The calculated effective target area is shown in Table B-1.

Table B-1. General Facility Dimensions and Effective Area.

\begin{tabular}{|l|c|c|c|c|c|}
\hline \multicolumn{1}{|c|}{ Facility } & Length (ft) & Width $(\mathbf{f t})$ & Height $(\mathbf{f t})$ & Diagonal (ft) & Effective Area $\left(\mathbf{m i}^{2}\right)$ \\
\hline \hline B625 & 120 & 40 & 24 & 126.5 & $1.9 \times 10^{-3}$ \\
\hline T6197 & 82 & 49 & 16 & 95.5 & $1.3 \times 10^{-3}$ \\
\hline T6198 & 98 & 30 & 16 & 102.5 & $1.3 \times 10^{-3}$ \\
\hline B693* & 150 & 80 & 16 & 170.0 & $2.2 \times 10^{-3}$ \\
\hline B696R & 120 & 80 & 23 & 144.2 & $2.3 \times 10^{-3}$ \\
\hline
\end{tabular}

* Historically calculated value, TRU waste is no longer authorized for B693 by this DSA.

LVK is a Class $D$ airport without the practice area. The traffic pattern extends approximately 4 miles from the runway at LVK. It is extended in a mile increment during periods of unusual air traffic congestion. Periods of unusually heavy congestion, when the traffic pattern is extended toward LLNL, occur infrequently. In those periods of congestion, aircraft are often required to (1) perform full stop landings, (2) exit the active runway and taxi back to the original departure position, and then (3) resume flight activities by requesting control tower access to the active runway prior to departure. When this happens, it changes the activity category from "touch and go" to the normal landing and takeoff. These are then included in the number of itinerant operations not associated with local operations within the traffic pattern. 
This is further supported by the FAA regulatory language that addresses airspace boundaries in the pattern around airports in FAA Order 7400.2E, "Procedures for Handling Airspace Matters," Change 1, July 7, 2001. In Section 10.3-2, "Airport Spacing Guidelines and Traffic Pattern Airspace Areas," a full pattern in the airspace around Livermore, which consists of eight to nine aircraft in the pattern, extends downwind about 3.75 miles from the center of Runway 25R only a portion of the time when the predominant wind direction is from the west. This puts the turn into the base leg about 2.75 miles away from the Building 696. Anecdotal reports from flight instructors at LVK indicate that the majority of the time they make this turn (downwind to base leg) over the Portola Avenue exit from Highway 580. Relative positions of LVK, LLNL, and the extended pattern are illustrated in Figure B-1.

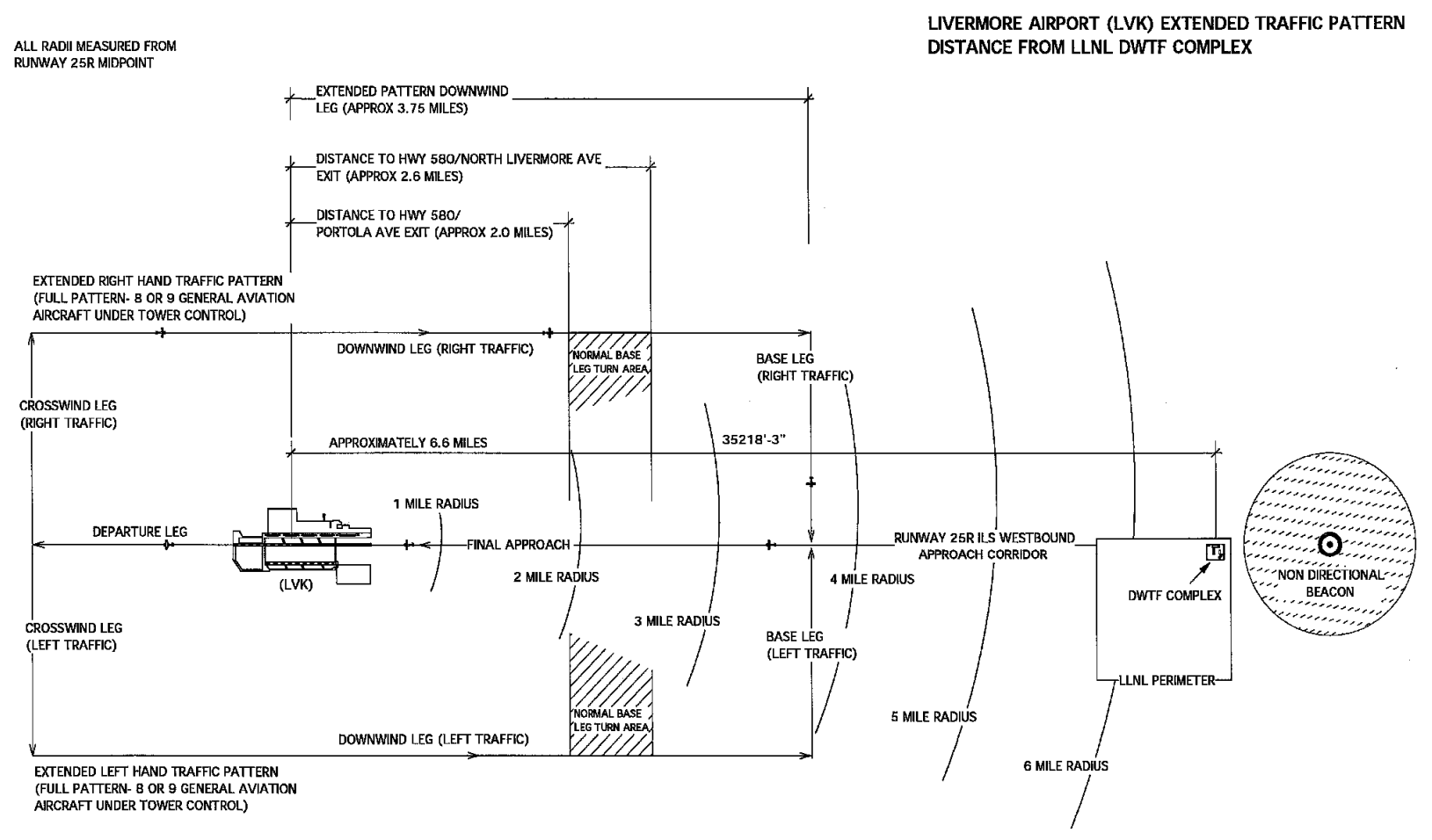

\section{Figure B-1. Extended Traffic Pattern for Livermore Airport (LVK)}

The estimate of effective area is made assuming the facility is a rectangle with the aircraft approaching perpendicular to the diagonal of the building. DOE-STD-3014 recognizes that these assumptions provide a conservative approximation to the true effective area.

A large portion of the operations is from local operations that include "touch and go" at the airport for flight training. Because local operations are typically confined to the 4-mi radius from the airport and do not go over or near the LLNL, these are excluded from the crash probability calculation. For conservatism, an additional $10 \%$ was assumed for non-counted general aviation operations that occur outside airport control tower operational times. 
Then, a total of 94,100 operations at the Livermore Municipal Airport are itinerant operations. Including a 10\% margin for non-counted general aviation operations, 104,000 operations are assumed for the crash probability analysis. For simplicity, operations in each direction are assumed to be divided evenly between takeoff and landing. Also, there is a directional dependence for landing and takeoff because of the prevailing wind at the Livermore Municipal Airport. Approximately $82 \%$ of the flights take off and land in the east-west direction. Based on DOE-STD-3014-96, the calculated annual probability of an itinerant aircraft crash into a waste storage facility is presented in Table B-2. For outdoor staging, a representative array of approved TRU waste containers that is two pallets wide (18ft, includes $10 \mathrm{ft}$ spacing), four pallets long (16 ft), and two pallets high (10.25 ft, conservatively assumed) would have an annual itinerant aircraft impact frequency of approximately $1.2 \times 10^{-6}$ for general aviation aircraft. Staged pallets have a lower aircraft impact frequency than a facility with an equivalent footprint because the height of the double-stacked containers is less than the height of a facility.

Table B-2. Annual Itinerant Aircraft Impact Frequencies for Waste Storage Facilities

\begin{tabular}{|c|c|}
\hline Facility & General Aviation \\
\hline \hline B625 & $5.3 \times 10^{-6}$ \\
\hline T6197 & $3.5 \times 10^{-6}$ \\
\hline T6198 & $3.4 \times 10^{-6}$ \\
\hline B693* & $6.0 \times 10^{-6}$ \\
\hline B696R & $6.3 \times 10^{-6}$ \\
\hline
\end{tabular}

* Historically calculated value, TRU waste is no longer authorized for B693 by this DSA.

\section{B.2 BETTER-ESTIMATE OF AIRCRAFT CRASH PROBABILITY LEADING TO UNCONTROLLED RELEASE OF RADIOACTIVITY FOR B696R}

The annual crash probability must also be limited to that which results in a direct impact on TRU waste drums in Building 696R. If the crash location is at the top or the roof of the building at a shallow angle, the engine is not expected to affect the TRU waste drums. For example, using the $7^{\circ}$ impact angle for general aviation aircrafts from DOE-STD-3014-96, if the general aviation aircraft hits the top corner of the building, it requires $189 \mathrm{ft}$ to reach the ground. A longer distance would be required for shallower impact angles. In comparison, the length of Building $696 \mathrm{R}$ is $120 \mathrm{ft}$. This indicates that the annual crash probability includes that which results in a damage to the building without any radioactive release. Therefore, the profile must be adjusted to that of the stored TRU waste drums for the potential radioactive release from TRU waste drums. For conservatism, the height of the stored drums is assumed to be $10.25 \mathrm{ft}$, which would exceed the height of stacked approved TRU waste containers. 
The integrity of structural members for Building 696R was evaluated in (WM/WT-B696-0201). These structural members are part of the safety-significant SSC, the B696R structure, as described in Section 4.4.2.2. The evaluation showed that a direct vertical impact by the engine of a general aviation aircraft on the most vulnerable roof beam at the point of maximum deflection in Building 696R would result in yielding, but not catastrophic failure leading to a collapse, of the roof beam. The same would apply to the structural columns of the walls of Building 696R. Structural columns are placed $20 \mathrm{ft}$ apart on the east wall and are $30 \mathrm{ft}$ apart on the north and south walls (see Figure 1, WM/WT-B696-0201). The potentially vulnerable area is then limited to the spacing between the structural members minus the width of the solid fragments.

Structural members are typically W18 $\times 35$. The width of column flanges are 8-in. A typical reciprocating piston engine has dimensions of 36 -in $\times 20$-in. The effective length and width of the building are adjusted to account for the structural robustness as follows:

$$
\begin{aligned}
W_{\text {eff }} & =83 \mathrm{ft} \times\left[1-\frac{3(24 / 12) \mathrm{ft}+2(16 / 12) \mathrm{ft}}{83 \mathrm{ft}}\right] \\
& =74 \mathrm{ft}
\end{aligned}
$$

The facility is 83-ft wide (east and west walls) with five 8-in wide structural columns that provide shielding capable of providing protection from debris or a missile. The effective width (Weff) was adjusted by considering that: the three columns distributed along the wall provided 24 -in of protection when considering the 8-in column and that the center of the engine could be 8-in off either side of the center line of the column and still provide adequate shielding from the 20 -in wide engine; and the two end columns would provide 16-in of protection since each is providing protection on one side of the column. This results in an adjusted effective width of 74- $\mathrm{ft}$, as shown in the previous equation.

$$
\begin{aligned}
L_{\text {eff }} & =120 \mathrm{ft} \times\left[1-\frac{3(24 / 12) \mathrm{ft}+2(16 / 12) \mathrm{ft}}{120 \mathrm{ft}}\right] \\
& =111 \mathrm{ft}
\end{aligned}
$$

The facility is 120 -ft wide (north and south walls) with five 8 -in wide structural columns that provide shielding capable of providing protection from debris or a missile. The effective width (Weff) was adjusted by considering that: the three columns in distributed along the wall provided 24-in of protection when considering the 8-in column and that the center of the engine could be 8-in off either side of the center line of the column and still provide adequate shielding from the 20 -in wide engine; and the two end columns would provide 16-in of protection since each is providing protection on one side of the column. This results in an adjusted effective width of $111-\mathrm{ft}$, as shown in the previous equation. 


\section{Documented Safety Analysis for the Waste Storage Facilities}

There are additional K-bracings, shear support structural beams, to prevent shear failure in the event of an earthquake. These provide further protection against a potential plane crash by limiting the effective target area for penetration through the roof and walls. Ignoring the K-bracings, however, vulnerable width and length of Building 696R are approximately 111-ft $\times 74-\mathrm{ft}$. As previously discussed, the wingspan is also reduced to $20 \mathrm{ft}$ for the engine and a significant portion of the wings that contain fuel to penetrate through the walls or the roof between the structural beams. Upon impact with the ground, the aircraft will sustain structural damage. The debris could impact and penetrate the facility; however, the fuel would spread outside the facility and only a small quantity would follow the debris into the facility. Any resulting fire is assumed to not be sufficient to involve multiple drums in a sustained fire. It is not considered viable for an impact with the ground, with debris penetrating the facility, puncturing multiple approved TRU waste containers, and having a sustained fire resulting in a release to the environment. Therefore, the skid length is reduced to zero when computing the net target area for a fire.

Then, the net target area is reduced to:

$$
\begin{aligned}
A_{\text {net }} & =\left[(20+134) \times(0+10.25 \times 8.2)+\left(\frac{2 \times 20}{134}+1\right) \times 111 \times 74\right] \times(5280)^{-2} \\
& =8.5 \times 10^{-4} \mathrm{mi}^{2}
\end{aligned}
$$

Also, the angle of direct impact has a significant effect on the annual crash probability. For simplicity, the impact angle of $7^{\circ}$, the standard value for general aviation, is used to estimate the annual crash probability.

B696R is shielded by surrounding buildings and trees. DOE-STD-3014 allows consideration of nearby barriers in the calculation of the effective target area. B696S is attached to B696R on the west and is 12-ft taller than B696R. This allows B696S to shield B696R on the west and partially on the roof. B695 is southwest of B696R and B693 is south of B696R. Both of these buildings provide partial shielding for B696R from the south. It is estimated that the total shielding attributes would reduce the effective target area by approximately $20 \%$. Thus, the annual crash probability is:

$$
\begin{aligned}
F & =\sum_{i} N_{i} P_{i} f_{i}(x, y) A_{i} \\
& =2.75 \times 10^{-3} \times 8.5 \times 10^{-4} \times(1-0.20) \\
& =1.9 \times 10^{-6}
\end{aligned}
$$

Note: The factor $2.75 \times 10^{-3}$ is the ratio of the crash probability computed in Table B-2 divided by the effective target area computed in Table B-1.

The annual probability of an aircraft crash leading to a direct impact with the TRU waste drum configuration required to produce the evaluated source term using the modified effective target area is $1.9 \times 10^{-6}$. The probability of an aircraft crash leading to a waste spill is therefore "extremely unlikely." 
The conditional probability of occurrence of a fire from a general aviation aircraft crash is approximately 0.3 (Wall 1974). The annual probability of an aircraft crash leading to a direct impact with the TRU waste drum configuration required to produce the evaluated source term with a fire involving the inventory of approved TRU waste containers is $6 \times 10^{-7}$. The conditional probability of a direct impact on the stacked drums all containing the maximum quantity of radioactivity is less than unity. Combining all factors together, the probability of the worst-case aircraft crash - a direct impact followed by a large fire involving drums, all of which contain the maximum radioactive inventory - leading to an uncontrolled release of a significant quantity of radioactivity is less than $6 \times 10^{-7}$, and is therefore "beyond extremely unlikely."

Further, only a portion of the aircraft represents material that could damage an approved TRU waste container after initial impact with the ground or facility. Nondeformable debris comprises the rigid and heavy components (e.g., engine), could have sufficient energy to damage an approved TRU waste container after initial impact. Deformable debris comprises relatively soft components that absorb energy during impact (e.g., wings, fuselage) and is not anticipated to have sufficient energy to damage an approved TRU waste container after initial impact. Using a representative aircraft (e.g., Piper Saratoga II HP) involved in an accident, the engine represents the primary nondeformable debris for a single engine fixed gear aircraft. The aircraft has a maximum takeoff weight of 3,600 pounds and an engine weight of approximately 450 pounds (WM/WT-B696-0201). Doubling the engine weight to account for any additional components that could act as nondeformable debris (DOE-STD-3014), results in $25 \%$ of the mass of the aircraft considered as potential nondeformable debris with the potential to damage approved approved TRU waste containers and $75 \%$ of the mass of the aircraft not anticipated to have sufficient energy to damage approved TRU waste containers after initial impact. Fuel is stored in the deformable aircraft wings that are anticipated to disassociate upon impact. Thus, resulting in a significant quantity of the fuel remaining outside of the facility, and reducing the potential size and duration of a fuel fire. Taking these issues into consideration would reduce the potential for an aircraft crash resulting in a fuel fire involving the inventory of approved TRU waste containers, thus providing additional conservatism to this analysis.

\section{B.3 BETTER-ESTIMATE OF AIRCRAFT CRASH PROBABILITY LEADING TO UNCONTROLLED RELEASE OF RADIOACTIVITY FOR B693}

As part of this evaluation, a structural analysis of B693 was performed to identify if the structural capacity of the building would withstand the impact from an aircraft crash. The conclusion of the analysis was that the B693 structural system is not capable of withstanding the crash impulse load from a general aviation aircraft impact (Kim 2004).

Section 3.4.3.3 provides an analysis of the consequences to the maximally exposed offsite individual (MOI) from a general aviation aircraft crash into B693 with an ensuing fire resulting in an uncontrolled radioactive release. The source term assumes that 45 TRU waste drums each containing $50 \mathrm{PE}-\mathrm{Ci}$ fail due to the impact or from the ensuing fire, resulting in both contained and uncontained burning of the contents. The radiation dose consequence to the $\mathrm{MOI}$ is estimated to be 15 rem TEDE. 
In the Building 696R (B696R) crash estimation for aircraft crash probability factors such as shielding from nearby buildings, reduced skid length and structural deflection were considered in a better-estimate of the crash probability. For B693, only shielding from nearby buildings is valid. The reduced skid distance in the B696R evaluation is based on a small quantity of debris and fuel penetrating the building and that they would not be sufficient to involve multiple drums in a sustained fire.

However, B693 contains flammable liquid waste, which, in the event of an aircraft impact, will likely lead to a fire. Moreover, unlike the structural member integrity of B696R, the structural integrity of B693 is not assured in an impact. Therefore, only shielding is taken into consideration consistent with the methodology in DOE-STD-3014-96.

Of the buildings surrounding B693, only Building 695 (B695) is high enough to shield B693. Taking the impact angle of $7^{\circ}$ for general aviation aircrafts from DOE-STD-3014-96, B695 shields the west side of B693 from an aircraft crash, as evaluated below.

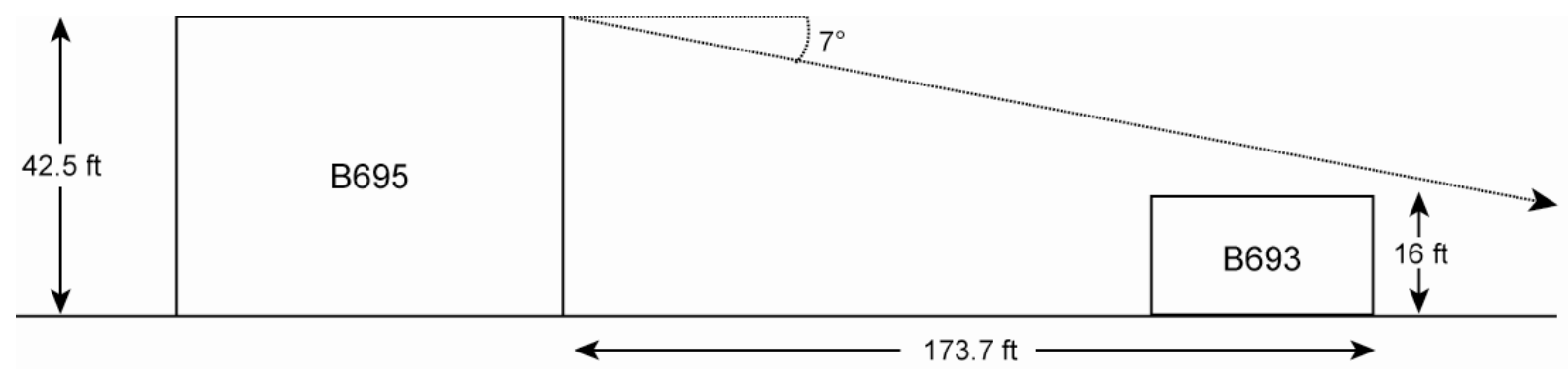

Only the west side of B693 is shielded by B695. Assuming a constant height for B693 and taking the ratio of the length of the west side of $B 693(150 \mathrm{~m})$ to the total building perimeter $(460 \mathrm{~m})$, it is estimated that approximately $33 \%$ of the building is shielded by B695. Therefore, the effective area of B693 is reduced by approximately $33 \%$ in the annual crash probability calculation.

Thus, the annual crash probability is:

$$
\begin{aligned}
F & =\sum_{i} N_{i} P_{i} f_{i}(x, y) A_{i} \\
& =6.0 \times 10^{-6} \times(1-0.33) \\
& =4.0 \times 10^{-6}
\end{aligned}
$$

The annual probability of an aircraft crash leading to an impact is $4.0 \times 10^{-6}$. Therefore, the probability of the worst-case aircraft crash - a direct impact followed by a large fire involving drums, all of which contain the maximum radioactive inventory - leading to an uncontrolled release of a significant quantity of radioactivity is "extremely unlikely."

Note again that this evaluation is of historical interest only as TRU waste is no longer authorized for $\mathrm{B} 693$ by this DSA. 


\section{B.4 REFERENCES}

Foote (2002), Transmittal of Detailed Aircraft Crash Probability Analysis for Building 332, PuFO-02-176, June 2002.

WM/WT-B696-0201, "Structural Response in Airplane Crash,” S.Y. Kim, October 2002.

Wall (1974), "Probabilistic Assessment of Aircraft Risk for Nuclear Power Plants," Ian B. Wall, Nuclear Safety, Vol. 15, No. 3, p. 276, June 1974.

Kim (2004), Personal communication from S.Y. Kim to H. Larson, regarding structural analysis of Building 693 under an accidental crash of a light airplane, October 19, 2004.

DOE (1996), Accident Analysis for Aircraft Crash into Hazardous Facilities, DOE-STD-3014-96, U.S. Department of Energy, Washington, DC (October 1996). 
This page intentionally left blank. 


\section{APPENDIX C SEGMENTATION JUSTIFICATION FROM THE B695 SEGMENT}

\section{C.1 INTRODUCTION}

DOE-STD-1027-92 provides guidance in establishing the hazard categorization for nuclear facilities. For Hazard Category 3 nuclear facilities with simple operations and inventories at levels within thresholds established in DOE-STD-1027-92, a graded approach is recommended in developing the safety basis documentation.

Facility segmentation is one step in the process of determining the hazard categorization of a facility. According to DOE-STD-1027-92, Attachment 1, the following considerations are made in facility segmentation:

"In facility categorization, flexibility must be allowed in the definition of facility segments. Many DOE facilities conduct a wide variety of activities in one facility, ranging from simple assay or lab experiments to complex fluid flow separations. It is necessary to avoid placing excessive requirements on simple or even trivial co-located operations. The concept of independent facility segments should be applied where facility features preclude bringing material together or causing harmful interaction from a common severe phenomenon.

It should be noted that DOE 5480.23 states that an analysis and categorization is to be performed on 'processes, operations, or activities' and not necessarily whole facilities. For the purposes of hazard categorization and estimating hazardous material inventory, the objective is to understand the available hazards that could interact and cause harm to individuals or the environment. It is not desirable to estimate the potential consequences from an inventory of hazardous materials when facility features would preclude bringing this material together. Therefore, the standard permits the concept of facility segmentation provided the hazardous material in one segment could not interact with hazardous materials in other segments. For example, independence of HVAC and piping must exist in order to demonstrate independence for facility segmentation purposes. This independence must be demonstrated and places the 'burden of proof' on the analyst." [Italics added for emphasis] 
LLNL has segmented Building 695, Building 696 SWPA, and their associated yard areas from other DWTF nuclear facilities, namely the Building 696 RWSA and Building 693 including yard area east of the Building 695 Segment (DWTF Storage Area), so that it may operate as a Hazard Category 3 nuclear facility. The purpose of the discussion is to demonstrate that the Building 695 Segment is adequately separated from nearby nuclear facilities to "preclude bringing material together or causing harmful interaction from a common severe phenomenon." A particular attention is paid to separation between Building 696 SWPA and Building 696 RWSA because the two are attached.

\section{C.2 FACILITY DESCRIPTION}

The Building 695 Segment is located in the northeast corner of the LLNL site between North Outer Loop Drive and the site boundary. The Building 695 Segment consists of Building 695, Building 696 SWPA, and adjacent yards to the west of Building 695, excluding the maintenance yard, trees to the north, DWTF rain water management area, loading dock, and the electrical utility yard, as shown in Figure C-1.

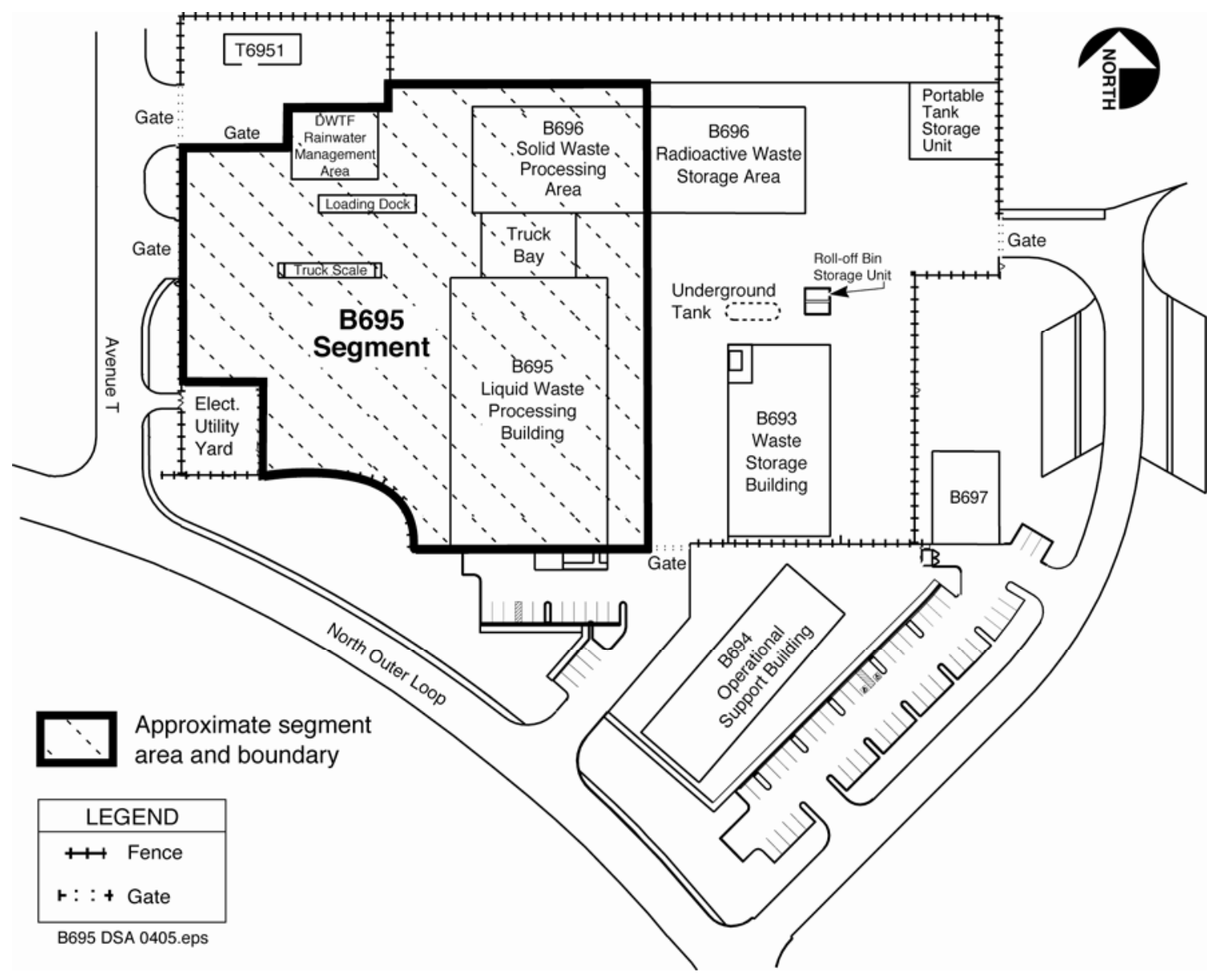

Figure C-1. Layout of the B695 Segment 


\section{Documented Safety Analysis for the Waste Storage Facilities}

Buildings 695 and 696 were designed and built to meet Performance Category 2 (PC-2) as defined in DOE-STD-1020-94 and DOE-STD-1021-92. These facilities will withstand structural loads exceeding the requirements of the 1994 Uniform Building Code.

The DWTF Storage Area includes Building 696 RWSA, Building 693, and associated yard areas. Building 693 and the DWTF Storage Area yard are separated from the Building 695 Segment by a distance exceeding 20 feet. There are no shared utilities between these areas and the Building 695 Segment.

Building 696 RWSA is separated from the Building 695 Segment, which includes Building 696 SWPA, by a fire-resistive partition. Building 696 RWSA is separated by a distance from Building 695 of approximately $45 \mathrm{ft}$. Additionally, a clear zone with a width of $20 \mathrm{ft}$ is defined as a part of the facility for both Building 696 SWPA and Building 696 RWSA.

Much of the utilities are shared between Building 696 RWSA and the Building 695 Segment. A discussion of utilities for Building 695 Segment is provided in Section C3.1.

\section{C.3 TECHNICAL BASIS FOR SEGMENTATION}

As discussed in DOE-STD-1027-92, in order to utilize the concept of facility segmentation, it must be shown that hazardous material in one segment could not interact with hazardous materials in other segments. Severe phenomena such as aircraft crash, earthquake, and fire may affect radioactive inventories in different segments. In addition, failure or malfunction of shared utilities must not allow interaction of inventories in different segments.

The analysis in this section is based on the data and documentation available at the time of the analysis. There is no new information that invalidates the analysis. It is shown that Building 695 Segment inventories and inventories from the Waste Storage Facilities will not interact in the event of severe phenomena. In addition, it is shown that failure or malfunction of shared utilities would not cause the interaction of radioactive inventories in different segments.

\section{C3.1 SHARED UTILITIES}

There are some common utilities shared between the Building 695 Segment and the Building 696 RWSA, including electrical systems, communication systems, hot and cold water supply, and the fire sprinkler system. Table E-1 summarizes the evaluation of shared utilities and when applicable the impact if the utility is lost.

No utilities were considered safety-significant or safety-class SSCs for the Building 696 RWSA [Reference 3]. The fire sprinkler system is defense-in-depth for Building 696 RWSA. It is anticipated that common systems will play a role of equal importance in Building 695 Segment to those in Building 696 RWSA.

It is concluded that there is no common severe phenomenon that would, by causing the loss any of these utilities, bring material together or cause harmful interaction. 
Table E-1. Evaluation of shared utilities

\begin{tabular}{|c|c|c|}
\hline Utility & $\begin{array}{l}\text { B695 segment } \\
\text { Utilities Shared } \\
\text { with } \\
\text { Building 696R? }\end{array}$ & Impact \\
\hline Shop Air & Yes & $\begin{array}{l}\text { Loss of pneumatic tool use in both segments. Operational issue } \\
\text { not directly impacting safety and health of the worker and public. }\end{array}$ \\
\hline Instrument Air & No & No interface effect. \\
\hline Breathing Air & No & No interface effect. \\
\hline Process Water & Yes & $\begin{array}{l}\text { Loss of Eyewash, limits decontamination and cleaning abilities } \\
\text { upon joint failure. Operational issue not directly impacting safety } \\
\text { and health of the worker in both segments and public. While loss } \\
\text { of eyewash may have an impact on the health and safety of } \\
\text { individual workers if an accident occurs, it is not relevant to } \\
\text { facility segmentation. }\end{array}$ \\
\hline $\begin{array}{l}\text { Tank and Floor } \\
\text { Drains }\end{array}$ & No & No interface effect. \\
\hline $\begin{array}{l}\text { Natural Gas } \\
\text { Distribution }\end{array}$ & No & No interface effect. \\
\hline Air Monitoring & No & No interface effect. \\
\hline $\begin{array}{l}\text { Utilities above and } \\
\text { hot water (supply and } \\
\text { return) }\end{array}$ & Yes & $\begin{array}{l}\text { Loss of space temperature control. Operational issue not directly } \\
\text { impacting safety and health of the worker and public. }\end{array}$ \\
\hline Fire Sprinkler System & Yes & $\begin{array}{l}\text { Loss of fire suppression abilities. This would be a concern if } \\
\text { there were a credible fire that would impact both segments. } \\
\text { However, no scenarios were identified that could impact both } \\
\text { segments given the presence of the partition and the } \\
\text { established combustible loading limits that would preclude } \\
\text { interaction between Building } 696 \text { SWPA and Building } 696 \\
\text { RWSA. See Section E3.4 for further discussion. }\end{array}$ \\
\hline Ventilation & No & No interface effect. \\
\hline Electrical Distribution & Yes & $\begin{array}{l}\text { Loss of non emergency lighting, loss of plug-in device use. } \\
\text { Operational issue not directly impacting safety and health of the } \\
\text { worker and public. }\end{array}$ \\
\hline $\begin{array}{l}\text { Signal and } \\
\text { communications }\end{array}$ & Yes & $\begin{array}{l}\text { Loss of phones, loss of fire panel supervision. Upon loss of this } \\
\text { device, however, notification to Fire Department is automatic. }\end{array}$ \\
\hline
\end{tabular}




\section{Documented Safety Analysis for the Waste Storage Facilities}

\section{C3.2 AIRCRAFT CRASH}

The probability of an aircraft crashing into the B695 Segment was evaluated using the method described in DOE-STD-3014-96. The probability of an aircraft crash into the B695 Segment must be evaluated to bound the risk presented by surrounding airports and types of aircraft and operations in those airports. The operations of general aviation aircraft at the Livermore Municipal Airport (LVK) dominate the risk of an aircraft crash to facilities at the LLNL. An assessment for Building 332 showed that general aviation associated with the LVK accounted for approximately $90 \%$ of the aircraft crash probability. Hence, the scope of the analysis is limited to quantification of the risk from general aviation at LVK.

The crash probability analysis does not take into account the surrounding structures, and includes the probability that a wing tip of a light aircraft nicks a building (refer to Figure B-3 in DOE-STD-3014-96), which would not lead to uncontrolled radioactive release. Hence, the probability of an aircraft crash obtained by the analysis is conservative even without the adjustment for other types of aircraft.

The following formula in DOE-STD-3014-96 is used to calculate the aircraft crash probability into Building 696 SWPA and Building 695:

$$
F=\sum_{i} N_{i} P_{i} f_{i}(x, y) A_{i}
$$

where $F$ is estimated annual aircraft crash impact frequency for the facility, $N$ is annual number of aircraft operations, $P$ is the aircraft crash rate (crash/operations), $f(x, y)$ is the aircraft crash location probability (mile ${ }^{-2}$ ), $A$ is the combined effective area of Building 696 SWPA and Building 695 (mile ${ }^{2}$ ), and $i$ is the flight phase, i.e., takeoff, in-flight, and landing.

The operations are all conservatively assumed to be general aviation of the fixed wing single engine reciprocating type. The distance from the middle of the runway to nearest corner of the B695 Segment is approximately 6.6 miles. From Table B-1 of DOE-STD-3014-96, the generic crash rates are $1.1 \times 10^{-5}$ per takeoff and $2.0 \times 10^{-5}$ per landing, respectively.

There is a directional dependence for landing and takeoff because of the prevailing wind at the Livermore Municipal Airport (LVK). Approximately $82 \%$ of the flights take off and land in the east-west direction. In this case, crash location probabilities, values of $f(x, y)$, for landings and take-offs in Tables B-4 and B-5 in DOE-STD-3014-96 are $2.9 \times 10^{-3}$ and 0 , respectively. In the opposite direction, associated crash location probabilities are $6.5 \times 10^{-4}$ and $1.5 \times 10^{-3}$, respectively.

According to the latest posting on the Federal Aviation Administration website [Reference 1], the total number of aircraft operations is bounded by 240,000 operations per year. A large portion of the operations is from local operations that include "touch and go" at the airport for flight training. Because local operations are typically confined to the 4-mi radius from the airport and do not go over or near the LLNL, these are excluded from the crash probability calculation. For conservatism, an additional $10 \%$ was assumed for non-counted general aviation operations that occur outside airport control tower operational times. 


\section{Documented Safety Analysis for the Waste Storage Facilities}

The normal traffic pattern extends approximately 4 miles from the runway. It is extended in a mile increment during periods of unusual air traffic congestion. Periods of unusually heavy congestion when the traffic pattern is extended toward the LLNL occur infrequently. In those periods of congestion, aircraft are often required to (1) perform full stop landings, (2) exit the active runway and taxi back to the original departure position, and then (3) resume flight activities by requesting control tower access to the active runway prior to departure. When this happens, it changes the activity category from "touch and go" to the normal landing and takeoff. These are then included in the number of itinerant operations not associated with local operations within the flight pattern. In addition, flights in an extended traffic pattern over LLNL would be re-categorized as "in-flight" because of the hilly terrain surrounding the site, i.e., Altamont Pass.

This is further supported by the FAA regulatory language that addresses airspace boundaries in the pattern around airports in FAA Order 7400.2E, "Procedures for Handling Airspace Matters," Change 1, July 7, 2001. In Section 10.3-2, "Airport Spacing Guidelines and Traffic Pattern Airspace Areas," a full pattern in the airspace around Livermore, which consists of eight to nine aircraft in the pattern, extends downwind about 3.75 miles from the center of Runway 25R only a portion of the time when the predominant wind direction is from the west. This puts the turn into the base leg about 2.75 miles away from the Building 696. Anecdotal reports from flight instructors at LVK indicate that the majority of the time they make this turn (downwind to base leg) over the Portola Avenue exit from Highway 580. Relative positions of LVK, LLNL, and the extended pattern are illustrated in Figure C-2.

Excluding local operations that do not go over or near the LLNL, a total of 94,100 operations at the Livermore Municipal Airport are itinerant operations. Including a 10\% margin for noncounted general aviation operations, 104,000 operations are assumed for the crash probability analysis. For simplicity, operations in each direction are assumed to be divided evenly between takeoff and landing.

The effective target area presented by the B695 Segment can be calculated using Equations B-3 to B-5 in DOE-STD-3014-96. Together, these equations yield the following:

$$
A_{e f f}=(W S+R)(S+H \cot \phi)+\frac{2 \cdot L \cdot W \cdot W S}{R}+L \cdot W
$$

where WS is the aircraft wing span, $R$ is the length of facility diagonal, $S$ is the aircraft skid distance, $H$ is the facility height, $\cot \varphi$ is the cotangent of aircraft impact angle, $L$ is the length of facility, and $W$ is the width of facility. 


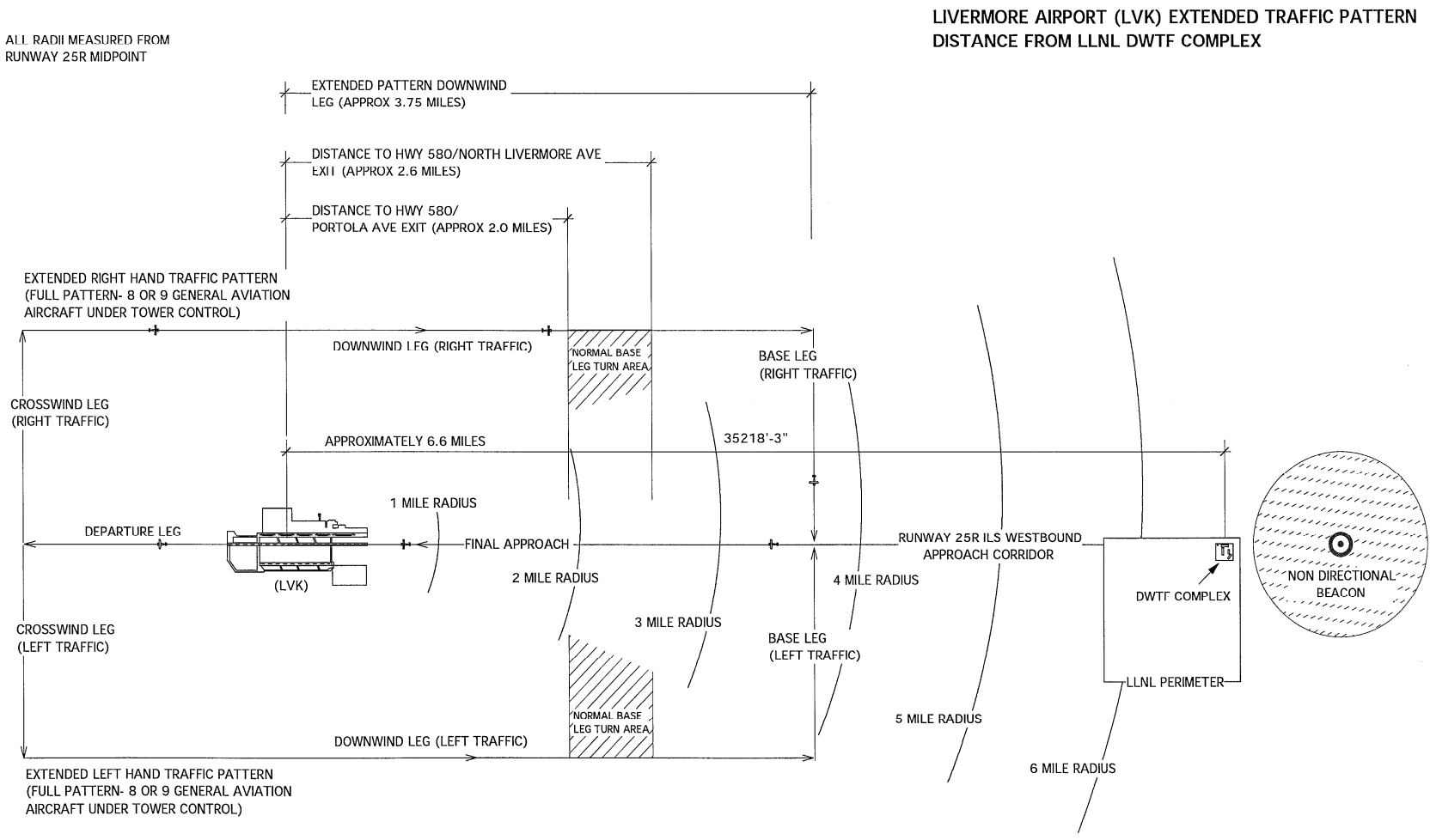

Figure C-2. Extended traffic pattern for Livermore Airport (LVK)

Dimensions of Building 695 are $213-\mathrm{ft} \times 123-\mathrm{ft} \times 42.5-\mathrm{ft}$ with a facility diagonal length of $246 \mathrm{ft}$. Dimensions of the Building 696 SWPA are $83-\mathrm{ft} \times 135-\mathrm{ft} \times 35-\mathrm{ft}$, with a facility diagonal length of $158.5 \mathrm{ft}$. The wingspan of a general aviation aircraft is $50 \mathrm{ft}$ from Table B-16 of DOE-STD-3014-96. For general aviation, the value of $\cot \varphi$ is 8.2-ft from Table B-17 and the skid distance is 60-ft from Table B-18 in DOE-STD-3014-96. Because the two buildings are not connected, two separate effective target area calculations are performed. The effective target area of the Building 695 is calculated as follows:

$$
A_{\text {eff }}=\left[(50+246) \times(60+42.5 \times 8.2)+\left(\frac{2 \times 50}{246}+1\right) \times 213 \times 123\right] \times(5,280 \mathrm{ft} / \mathrm{mi})^{-2}=5.7 \times 10^{-3} \mathrm{mi}^{2}
$$

Similarly, the effective target area of the Building 696 SWPA is calculated as follows:

$$
A_{\text {eff }}=\left[(50+158.5) \times(60+35 \times 8.2)+\left(\frac{2 \times 50}{158.5}+1\right) \times 83 \times 135\right] \times(5,280 \mathrm{ft} / \mathrm{mi})^{-2}=3.3 \times 10^{-3} \mathrm{mi}^{2}
$$

The combined effective target area of Building 695 and Building 696 SWPA is then $8.9 \times 10^{-3} \mathrm{mi}^{2}$. The crash probability is calculated by compiling the data in Table $\mathrm{E}-2$, shown below. 
Table C-2. Aircraft crash probability data and results for B695 Segment

\begin{tabular}{|l|c|c|c|c|c|c|c|}
\hline & $\begin{array}{c}\text { Number of } \\
\text { operations }\end{array}$ & $\boldsymbol{x}, \mathbf{m i}$ & $\boldsymbol{y}, \mathbf{m i}$ & $\boldsymbol{f}(\boldsymbol{x}, \boldsymbol{y})$ & $\boldsymbol{P}$ & $\boldsymbol{A}$ & $\begin{array}{c}\text { Impact } \\
\text { frequency }\end{array}$ \\
\hline $\begin{array}{l}\text { General aviation } \\
\text { takeoff (EW) }\end{array}$ & 42,640 & -6.6 & 0.036 & 0.0 & $1.1 \times 10^{-5}$ & $8.9 \times 10^{-3}$ & 0.0 \\
\hline $\begin{array}{l}\text { General aviation } \\
\text { landing (EW) }\end{array}$ & 42,640 & -6.6 & 0.036 & $2.9 \times 10^{-3}$ & $2.0 \times 10^{-5}$ & $8.9 \times 10^{-3}$ & $2.2 \times 10^{-5}$ \\
\hline $\begin{array}{l}\text { General aviation } \\
\text { takeoff (WE) }\end{array}$ & 9,360 & 6.6 & -0.036 & $1.5 \times 10^{-3}$ & $1.1 \times 10^{-5}$ & $8.9 \times 10^{-3}$ & $1.4 \times 10^{-6}$ \\
\hline $\begin{array}{l}\text { General aviation } \\
\text { landing (WE) }\end{array}$ & 9,360 & 6.6 & -0.036 & $6.5 \times 10^{-4}$ & $2.0 \times 10^{-5}$ & $8.9 \times 10^{-3}$ & $1.1 \times 10^{-6}$ \\
\hline Total & 104,000 & & & & & & $2.5 \times 10^{-5}$ \\
\hline
\end{tabular}

Given the calculated annual probability of $2.5 \times 10^{-5}$, an aircraft crash into the B695 Segment is credible.

\section{C3.2.1 Probability of plane crash on the segmenting wall}

As a part of the hazard categorization of Building 695 Segment, it was required by the DOE/OAK to establish segmentation of Building 696 SWPA and Building 696 RWSA. One of the considerations in determining segmentation is the structural integrity of individual segments in a postulated plane crash. The purpose of the analysis is to determine the probability of the plane crash onto the partition separating Building 696 SWPA and Building 696 RWSA. The potential impact on the segmenting wall, which is $20-\mathrm{ft}$ tall, is evaluated. For simplicity, only the contribution from general aviation from Livermore Airport is computed because it is the predominant factor in the overall crash probability.

The methodology in DOE-STD-3014-96 does not provide means to estimate the probability of breach of structural integrity of an inner wall that is protected by the surrounding structures of the building. The methodology in DOE-STD-3014-96 must be adopted in a way to allow estimation of the probability of a plane crash into the segmenting wall. The location and, thus, the crash frequency, for the plane would remain the same. The change related to the crash probability into the segmenting wall is the effective target area. 


\section{Documented Safety Analysis for the Waste Storage Facilities}

\section{C3.2.2 Assumptions}

The following assumptions were used in computing the probability of crash into the segmenting wall:

1. The probability of crash on four sides of the buildings is uniform, independent of the flight direction.

2. It is assumed that solid fragments that may damage the segmenting wall, i.e., the engine, propellers, main stringer, and landing gear, from the postulated plane crash travel in the same direction at the time of the impact.

3. Based on engineering judgment, a plane cannot traverse the entire length of the building after crashing in the absence of any intervening walls. Both Building 696 RWSA and Building 696 SWPA are divided into two compartments with load-bearing walls. Hence, solid fragments cannot penetrate more than two load-bearing walls. See Section C3.2.4 for further discussion on structural impact.

4. Because the solid fragments that may damage the structures are limited to the engine, propellers, main stringer, and landing gears, the effective wingspan of the general aviation aircraft is assumed to be $25 \mathrm{ft}$, one half of the wingspan specified in DOE-STD-3014-96 for general aviation. The wingspan of Cessna 210, for example, is less than $37 \mathrm{ft}$. Additionally, because the segmenting wall is an internal structure, only solid fragments that can penetrate the load-bearing walls can damage the segmenting wall. Therefore, the assumed wingspan is conservative.

5. The thickness of the segmenting wall is $1.5 \mathrm{ft}$.

6. The methodology in DOE-STD-3014-96 is adopted by treating the segmenting wall as a three-dimensional structure.

\section{C3.2.3 Analysis of total effective target area}

The total length of Building 696 RWSA is $120 \mathrm{ft}$. Building 696 RWSA is divided evenly into two $60-\mathrm{ft} \times 83-\mathrm{ft} \times 20-\mathrm{ft}$ compartments separated by a one-hour fire-rated partition. The total length of Building 696 SWPA is $135 \mathrm{ft}$. Building 696 SWPA is divided into one $90-\mathrm{ft} \times 83-\mathrm{ft} \times 35-\mathrm{ft}$ and one $45-\mathrm{ft} \times 83-\mathrm{ft} \times 35-\mathrm{ft}$ compartment separated by a one-hour fire-rated partition. Because of the difference in geometry, the effective target area will change depending on the impact angle. Consequently, target areas from four cardinal directions are addressed separately in order to determine the total effective target area. 


\section{Documented Safety Analysis for the Waste Storage Facilities}

\section{C3.2.3.1 Target area from West}

The skid impact from a plane crash would not reach the segmenting wall between Building 696 SWPA and Building 696 RWSA. Thus, it is not included in the effective target area calculation. The effective target area on the western end of the Building 696 SWPA is comprised solely of the shadow area cast by the 20 -ft high wall.

There are three potential outcomes from the impact through Building 696 SWPA depending on the angle of impact. First, if the impact angle is very low, the $20-\mathrm{ft}$ high segmenting wall would not be impacted because of the two loading bearing walls in Building 696 SWPA. The dividing impact angle is determined by the arctangent of the length of Building 696 SWPA (135 ft) and the remaining 15-ft section of segmenting wall. Second, for impact angles greater than the arctangent of the length of Building 696 SWPA (135 ft) and the total height of the segmenting wall (35 ft), the shadow area is the projected horizontal area of the $20-\mathrm{ft}$ high segmenting wall.

Last, for impact angles in between, the Building 696 SWPA roof provides shielding, which reduces the target area by the shadow area projected by the 15-ft high section above the segmenting wall. For steeper angles, the plane can penetrate the roof and impact the segmenting wall.

In summary, the effective target area from the west is summarized as follows:

$$
A_{W E S T}=(W+W S) \times\left\{\begin{array}{c}
0 \text { for } \phi \leq \tan ^{-1}\left(H_{1} / L_{S}\right) \\
L_{S}-H_{1} \times \cot \phi \text { for } \tan ^{-1}\left(H_{1} / L_{S}\right)<\phi \leq \tan ^{-1}\left(H / L_{S}\right) \\
H_{2} \times \cot \phi \text { for } \phi>\tan ^{-1}\left(H / L_{S}\right)
\end{array}\right.
$$

where $W$ is the width of Building 696 SWPA, WS is the wingspan, $L_{S}$ is the length of the compartment in Building 696 SWPA contiguous to the segmenting wall (90 ft), $H_{1}$ is the remaining height above the wall separating Building 696 SWPA and Building 696 RWSA (15 ft), $H$ is the total height of the wall separating Building 696 SWPA and Building 696 RWSA (35 ft), and $\phi$ is the impact angle. The two critical impact angles dividing the target area considerations in the equation above are $9.46^{\circ}$ and $21.3^{\circ}$.

\section{C3.2.3.2 Target area from East}

Likewise, the skid impact from a plane crash would not reach the wall separating Building 696 SWPA and Building 696 RWSA. Thus, it is not included in the effective target area calculation. Depending on the impact angle, the target area is either the area of the roof of Building 696 RWSA or the shadow area of the segmenting wall horizontally projected by the impact angle. Thus, the target area is calculated, as follows:

$$
A_{\text {EAST }}=\operatorname{MIN}\left[H_{2} \times \cot \phi, L_{R}\right] \times(W+W S)
$$

where $\mathrm{H}_{2}$ is the height of the wall separating Building 696 SWPA and Building 696 RWSA, and $L_{R}$ is the length of the compartment in Building 696 RWSA contiguous to the segmenting wall (60 ft). 


\section{C3.2.3.3 Target areas from North and South}

Unlike the potential impact on the east and west ends of Building 696, the skid impact from a plane crash can damage the segmenting wall between Building 696 SWPA and Building 696 RWSA. Thus, it must be included in the effective target area calculation. In addition, the target area presented in the two directions is symmetrical. Thus, the target area in either direction would be doubled in calculating the total effective target area.

As discussed, the skidding impact is plausible from north and south if surrounding structures, e.g., Building 693, are ignored. The area presented by the skidding plane is:

$$
A_{s k}=S \times(\delta+W S)
$$

where $S$ and $\delta$ are the skid length of the general aviation aircraft $(60 \mathrm{ft})$ and the thickness of the wall ( $1.5 \mathrm{ft}$ assumed), respectively.

In addition, the direct impact on the segmenting wall within the wingspan of general aviation aircraft, e.g., Cessna 210, is assumed to damage the structural integrity of the segmenting wall. Therefore, the area presented by the segmenting partition between Building 696 RWSA and Building 696 SWPA is calculated as follows:

$$
A_{\text {sh }}=\left(H_{2} \times \cot \phi+W\right) \times(\delta+W S)
$$

The target area consideration included the potential plane crash that would come to a full stop at the wall in the north-south direction without causing damage to the structure. In addition, results ignore the clear area north of the facility. Since the crash frequency includes all modes of failure, only a portion of which is incapacitation of the pilot, the outcome of the analysis would be very conservative.

\section{C3.2.3.4 Total effective target area}

Assuming a uniform probability of impact in all directions, the effective target area presented by the segmenting wall between Building 696 SWPA and Building 696 RWSA is integrated in all directions. In this case, it is the average of the four directional target area based on assumptions, as follows:

$$
A_{\text {TOTAL }}=\frac{1}{4} \times\left\{A_{\text {EAST }}+A_{\text {WEST }}+2 \times\left(W+H_{2} \times \cot \phi+S\right) \times(\delta+W S)\right\}
$$

Because of the dependence, the total effective target area must be evaluated for a range of impact angles. Results are shown in Table C-3. 
Table C-3. Total effective target area for various impact angles

\begin{tabular}{|c|c|c|c|c|c|c|}
\hline$\phi$ & $3^{\circ}$ & $7^{\circ}$ & $15^{\circ}$ & $30^{\circ}$ & $60^{\circ}$ & $85^{\circ}$ \\
\hline $\mathrm{S}, \mathrm{ft}$ & 60 & 60 & 60 & 60 & 60 & 60 \\
\hline $\mathrm{H}_{1}, \mathrm{ft}$ & 15 & 15 & 15 & 15 & 15 & 15 \\
\hline $\mathrm{H}_{2}$ & 20 & 20 & 20 & 20 & 20 & 20 \\
\hline $\mathrm{WS}, \mathrm{ft}$ & 25 & 25 & 25 & 25 & 25 & 25 \\
\hline $\mathrm{W}, \mathrm{ft}$ & 83 & 83 & 83 & 83 & 83 & 83 \\
\hline $\cot \phi$ & 19.1 & 8.2 & 3.9 & 2.1 & 1.2 & 1.0 \\
\hline $\mathrm{L}_{\mathrm{R}}, \mathrm{ft}$ & 60 & 60 & 60 & 60 & 60 & 60 \\
\hline $\mathrm{A}_{\mathrm{E}}, \mathrm{ft}^{2}$ & 6,480 & 6,480 & 6,480 & 3,781 & 1,247 & 189 \\
\hline $\mathrm{A}_{\mathrm{E}}, \mathrm{mi}^{2}$ & $2.32 \times 10^{-4}$ & $2.32 \times 10^{-4}$ & $2.32 \times 10^{-4}$ & $1.34 \times 10^{-4}$ & $4.47 \times 10^{-5}$ & $6.78 \times 10^{-5}$ \\
\hline $\mathrm{L}_{\mathrm{S}}$ & 90 & 90 & 90 & 90 & 90 & 90 \\
\hline $\mathrm{A}_{\mathrm{W}}, \mathrm{ft}^{2}$ & 0 & 0 & 3,674 & 3,741 & 1,247 & 189 \\
\hline $\mathrm{A}_{\mathrm{W}}, \mathrm{mi}^{2}$ & 0.0 & 0.0 & $1.32 \times 10^{-4}$ & $1.34 \times 10^{-4}$ & $4.47 \times 10^{-5}$ & $6.78 \times 10^{-5}$ \\
\hline $\mathrm{A}_{\mathrm{N} / \mathrm{s}}, \mathrm{ft}^{2}$ & 13,658 & 8,136 & 5,749 & 4,796 & 4,361 & 4,250 \\
\hline $\mathrm{A}_{\mathrm{N} / \mathrm{S}}, \mathrm{mi}^{2}$ & $4.89 \times 10^{-4}$ & $2.92 \times 10^{-4}$ & $2.03 \times 10^{-4}$ & $1.66 \times 10^{-4}$ & $1.44 \times 10^{-4}$ & $1.35 \times 10^{-4}$ \\
\hline $\mathrm{A}_{\mathrm{T}}, \mathrm{mi}^{2}$ & $3.03 \times 10^{-4}$ & $2.04 \times 10^{-4}$ & $1.93 \times 10^{-4}$ & $1.50 \times 10^{-4}$ & $9.44 \times 10^{-5}$ & $7.09 \times 10^{-5}$ \\
\hline
\end{tabular}

If the probability distribution function for the impact angle is conservatively ignored, a bounding probability can be obtained. As a bounding value, if it is assumed that the impact angle is always at $7^{\circ}$, chosen as the value for the general aviation aircraft crash angle in DOE-STD-3014-96, the effective target area for the wall separating Building 696 RWSA and Building 696 SWPA is $2.04 \times 10^{-4} \mathrm{mi}^{2}$. The annual plane crash probability is then $6 \times 10^{-7}$. The calculation for the impact angle of $7^{\circ}$ is shown in Table C-4. Even if an impact angle of $3^{\circ}$ is assumed, the effective target area is $3.03 \times 10^{-4} \mathrm{mi}^{2}$. Even then, the annual crash probability is less than $1.0 \times 10^{-6}$ at $9 \times 10^{-7}$. Again, hypothetical results ignored the range of probable impact angles and assumed that the crash angle had the probability of unity. This is extremely conservative. 
Table C-4. General aviation aircraft crash probability on segmenting wall of Building 696

\begin{tabular}{|l|c|c|c|c|c|c|c|}
\hline & $\begin{array}{c}\text { Number of } \\
\text { operations }\end{array}$ & $\boldsymbol{x}, \mathbf{m i}$ & $\boldsymbol{y}, \mathbf{m i}$ & $\boldsymbol{f}(\boldsymbol{x}, \boldsymbol{y})$ & $\boldsymbol{P}$ & $\boldsymbol{A}$ & $\begin{array}{c}\text { Impact } \\
\text { frequency }\end{array}$ \\
\hline $\begin{array}{l}\text { General aviation } \\
\text { takeoff (EW) }\end{array}$ & 42,640 & -6.6 & 0.036 & 0.0 & $1.1 \times 10^{-5}$ & $2.0 \times 10^{-4}$ & 0.0 \\
\hline $\begin{array}{l}\text { General aviation } \\
\text { landing (EW) }\end{array}$ & 42,640 & -6.6 & 0.036 & $2.9 \times 10^{-3}$ & $2.0 \times 10^{-5}$ & $2.0 \times 10^{-4}$ & $4.9 \times 10^{-7}$ \\
\hline $\begin{array}{l}\text { General aviation } \\
\text { takeoff (WE) }\end{array}$ & 9,360 & 6.6 & -0.036 & $1.5 \times 10^{-3}$ & $1.1 \times 10^{-5}$ & $2.0 \times 10^{-4}$ & $3.1 \times 10^{-8}$ \\
\hline $\begin{array}{l}\text { General aviation } \\
\text { landing (WE) }\end{array}$ & 9,360 & 6.6 & -0.036 & $6.5 \times 10^{-4}$ & $2.0 \times 10^{-5}$ & $2.0 \times 10^{-4}$ & $2.4 \times 10^{-8}$ \\
\hline Total & 104,000 & & & & & & $5.5 \times 10^{-7}$ \\
\hline
\end{tabular}

It is, thus, concluded that the annual crash probability of an aircraft onto the segmenting wall is not credible.

\section{C3.2.4 Conservatism in the plane crash probability analysis}

A structural evaluation of the potential aircraft crash on Building 696 RWSA was performed. The evaluation showed that a direct vertical impact by a 450-lb missile traveling at $87 \mathrm{mph}$ on the most vulnerable roof beam at the point of maximum deflection in Room 1010 in Building 696 RWSA would result in yielding, but not puncture, of the beam.

It is assumed that solid fragments, such as the engine, landing gears, etc., that penetrate the roof would damage the segmenting wall. A structural evaluation demonstrated that assuming penetration of the Building 696 RWSA roof is overly conservative. Structural beams in Building 696 SWPA are bigger; thus, the conclusion would remain unchanged.

The structural beams are placed $20 \mathrm{ft}$ apart. The potentially vulnerable roof area is then limited to the spacing between the structural beams minus the width of the solid fragments. There are additional K-bracings near the segmenting wall to prevent shear failure in the event of an earthquake. These provide further protection against a potential plane crash on the segmenting wall by limiting the effective target area for penetration through the roof. Thus, the computed total effective target area is bounding. The predicted crash probability of an aircraft impinging on the segmenting wall is conservative and bounding; therefore, the plane crash damaging the segmenting wall is not credible. 


\section{C3.3 NATURAL PHENOMENA}

Natural phenomena are design and siting issues that are not a part of the segmentation consideration for "processes, operations, or activities" in hazard categorization. However, they are typically evaluated in the hazards analysis in documented safety analyses. An evaluation of the natural phenomena, specifically, earthquakes and strong winds, is performed for completeness.

Seismic analyses were performed using the static force method detailed in DOE-STD-1020-94 for Performance Category 2 (PC-2) structures, systems and components. These analyses were performed using a peak ground acceleration (PGA) of $0.57 \mathrm{~g}$. The horizontal seismic force obtained was $0.189 \mathrm{~W}$, where "W" is the aggregate of the facility weight and includes roof, wall, and appurtenance weights contributing to the total seismic dead load at the facility roof line. Design and construction of the facility meets or exceeds requirements resulting from these calculations.

Assumed wind loads are based on a basic wind speed of $72 \mathrm{mph}$ coupled with a facility importance factor of 1.07 in accordance with ASCE 7-93, "Minimum Design Loads for Buildings and Other Structures." Steel bracings, support struts, and columns are designed to withstand the design basis wind with the parameters discussed previously.

When materials are out of doors and may be impacted by wind or flood, it is believed that the frequency of interaction is beyond extremely unlikely. These phenomena are generally not abrupt so that personnel can respond (e.g., move waste in doors). In addition, moving containers of material from one segment to the next and then breaching them so that they combine or have harmful interaction will not occur for these NPH (e.g., $72 \mathrm{mph}$ wind or 10" flooding) events.

It is concluded that there is no common severe natural phenomenon that would bring material together or cause harmful interaction.

\section{C3.4 FIRE}

Two potential vulnerabilities have been identified with respect to the impact of fire on the technical basis for segmentation of Building 696. This section evaluates these fire scenarios.

\section{C3.4.1 Impact of Building 696 RWSA Fire on Roof Beams}

The following potential vulnerability was identified in the November 2003 Building 696 Fire Hazards Analysis [Reference 2]:

"This partition is considered at least equivalent to 2-hr. fire-rated area separation partition. It would not, however, qualify as a 2-hr. fire-rated building separation wall, because exposed steel roof beams, on each side of the partition, are directly tied into this partition. In the event of a fire on one side of this partition that resulted in roof failure, the collapsing roof would pull this partition down with it, permitting the fire to spread to the other side of the partition." 


\section{Documented Safety Analysis for the Waste Storage Facilities}

The identified vulnerability presented an issue that would invalidate the technical basis for segmentation. Therefore, an evaluation was necessary to address the potential vulnerability identified in the November 2003 FHA.

The magnitude of the potential fire assumed in the FHA was not defined. A large fire postulated in the yard in the Waste Storage Facilities DSA, from a truck collision that subsequently spilled diesel fuel from its punctured fuel tank, was assumed in the building for the purpose of the evaluation. The magnitude of the postulated fire in the Waste Storage Facilities DSA [Reference 3] is an 8.9-MW fire involving a 2.7-m (8.9-ft) diesel fuel pool.

Exposed roof beams are located 20-ft above the floor in Building 696 RWSA and 35-ft above the floor in Building 696 SWPA. Using the data for the postulated fire, the flame height can be calculated based on the Heskestad flame height correlation [Reference 5], as follows:

$$
L_{f}=0.23 \dot{Q}_{c}^{2 / 5}-1.02 D_{e q}, \text { for } 7<\frac{\dot{Q}_{c}^{2 / 5}}{D_{e q}}<700 \frac{\mathrm{kW}^{2 / 5}}{\mathrm{~m}}
$$

where $Q_{c}$ is the magnitude of the fire in $\mathrm{kW}$ and $D_{e q}$ is the equivalent diameter of the postulated pool fire in $\mathrm{m}$. The magnitude of the postulated fire in the Waste Storage Facilities DSA is an 8.9-MW fire involving a spilled diesel fuel pool with a diameter of $2.7 \mathrm{~m}(8.9 \mathrm{ft})$. Based on the data, the flame height is as follows:

$$
L_{f}=0.23 \times(8,920)^{2 / 5}-1.02 \times(2.7)=6.0 \mathrm{~m}(20 \mathrm{ft})
$$

The flame impingement is not a concern for Building 696 SWPA; the roof beams are located $35 \mathrm{ft}$ from the floor.

For Building 696 RWSA, there is a potential for flame impingement and subsequent failure of the exposed roof beams. However, roof beams are placed $20 \mathrm{ft}$ apart and failure, if any, will be localized. Based on the qualitative structural evaluation, localized failure of a single roof beam is not a catastrophic failure of the roof in Building 696 RWSA, and will not lead to subsequent failure of the partition.

It is concluded that the partition separating Building 696 SWPA and Building 696 RWSA is not subject to a catastrophic failure as discussed in the November 2003 FHA.

\section{C3.4.2 Impact of Building 696 RWSA Fire on Partition-Roof Interface}

An additional vulnerability related to the B696R partition-roof interface was identified in a December 2006 assessment by an LLNL Fire Protection Engineer (FPE) (References 6 and 7). This assessment called into question an assumption associated with the adequacy of the partition between B696R and B696S. The fire rating of the partition between B696R and B696S from the true floor to the true ceiling was unquestioned; however, the adequacy of the B696R partition-roof interface was brought into question by the assessment. 
The assessment (Reference 6) stated, "The wall in question has construction similar to walls that are listed by a NRTL [Nationally Recognized Testing Laboratory] and have a 3 hour rating. However, the wall ceiling junction is the weak point that would let heat and fire into the interior of the wall that could damage the support structure of the wall to the point of failure."

As shown in Figure C-3, the exterior wall (an insulated metal panel) of the B696S high bay extends above the B696R low bay and has a slight overhang (approximately 8-in.) relative to B696R. The fire protection assessment identified that this construction creates a potential vulnerability such that in the event of a fire in B696R adjacent to the B696S/B696R partition, heat from the fire could burn through the uninsulated metal roof deck and allow heat and smoke to enter the cavity formed by the high bay wall in B696S Room 1009 and the exterior wall panel. This heat could potentially damage the B696S/B696R partition.

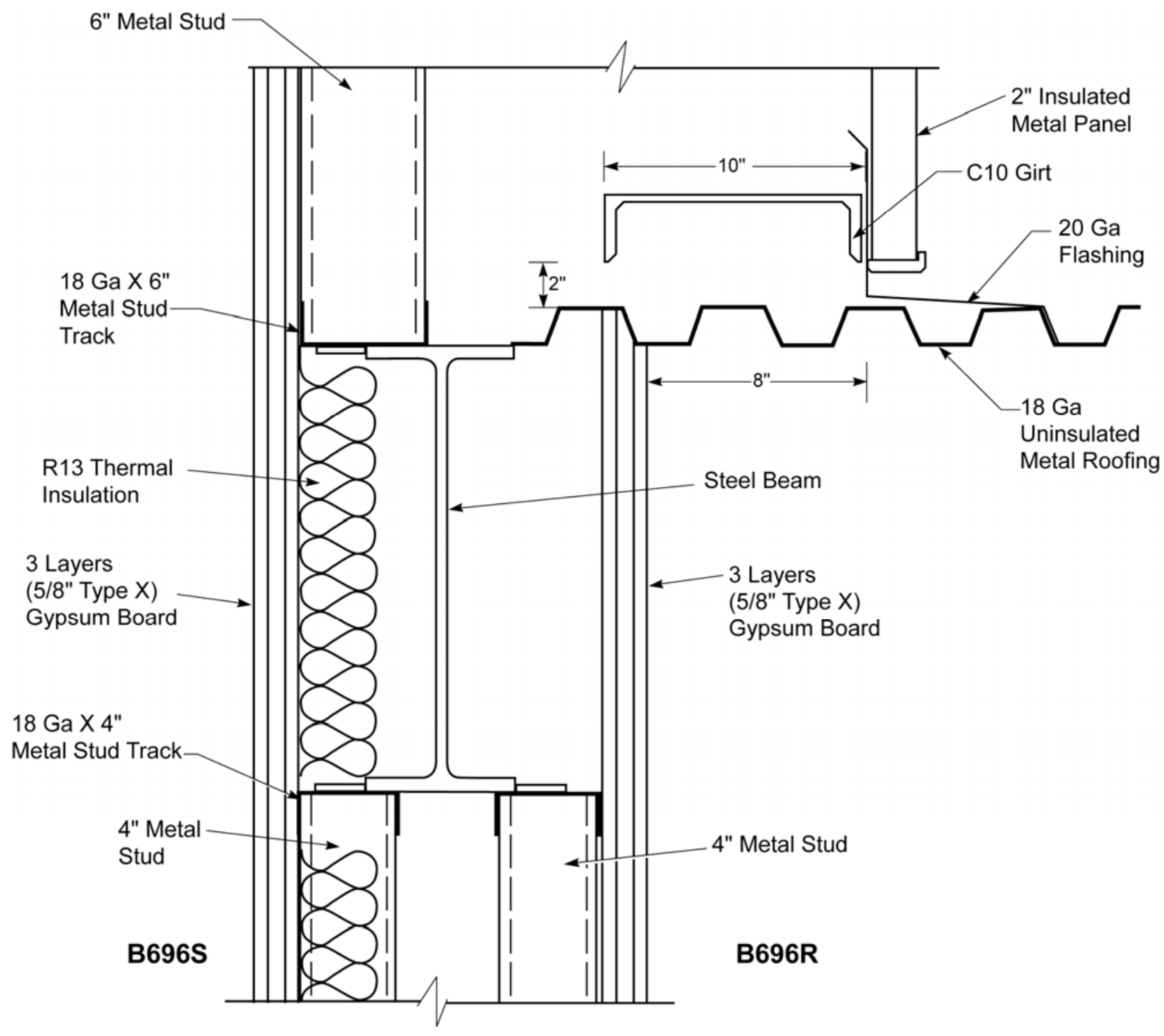

Figure C-3. Cross-section Showing B696R Wall-Ceiling Interface 


\section{Documented Safety Analysis for the Waste Storage Facilities}

Two engineering assessments were performed to evaluate the potential vulnerability raised by the fire protection assessment and to determine whether the basis for segmentation remains valid. These assessments are discussed below.

A qualitative analysis of the B696S/B696R partition's expected performance in the event of a fire was prepared to evaluate this potential vulnerability (Reference 8 ). The analysis evaluated the expected progression of a theoretical 2-hr equivalent fire and a fire limited by the TSR combustible loading control of $7 \mathrm{lb} / \mathrm{ft}^{2}$ and documented the expected impact on the B696S/B696R partition.

The analysis concluded that a 2-hr fire in B696R Room 1010 adjacent to the B696S/B696R partition will result in entry of heat into the interior of the upper B696S high bay wall (above the B696R roof deck), while obstructions (primarily a steel beam and metal stud tracks) in the wall will preclude any significant entry of heat into the lower portion separating B696S and B696R. The heat in the upper portion of the high bay wall is likely to result in cracking damage on the upper wall that will allow heat intrusion into the upper volume of the B696S high bay. However, fire is not expected to propagate as this area inherently has little, if any, combustible material. The lower portion of the wall that separates B696R from B696S will not be impacted by the heat entering the upper portion of the wall and will experience only the normal damage expected from a fire, consistent with the construction of the wall. The conclusion of the analysis of the theoretical 2-hr fire is as follows:

In the event of a 2-hr equivalent fire in B696R Room 1010, the fire is not expected to propagate from B696R to B696S. The wall will perform its safety function of reducing the likelihood of fire propagation from B696R to B696S.

The analysis concluded that in a $7 \mathrm{lb} / \mathrm{ft}^{2}$ equivalent fire, the potential failure mechanism at the partition-roof interface does not occur. The conclusion of the analysis of the $7 \mathrm{lb} / \mathrm{ft}^{2}$ equivalent fire is as follows:

In the event of a 7-lb/ft ${ }^{2}$ equivalent fire in B696R Room 1010, the fire is not expected to challenge the wall or wall-roof interface in a manner that would allow the fire to circumvent the wall or propagate from B696R to B696S. The wall will perform its safety function of reducing the likelihood of fire propagation from B696R to B696S.

Additionally, an evaluation of the B696S/B696R partition was performed by a registered fire protection engineer (subcontractor to LLNL) to provide an independent assessment of the wall performance (Reference 9). The conclusions of the independent evaluation were that based on the established use of the facility:

- The B696S/B696R partition meets the construction requirements for a 2-hr fire barrier as described in National Fire Protection Association (NFPA) 221, "Standard for High Challenge Fire Walls, Fire Walls, and Fire Barrier Walls."

- The fire barrier wall is adequate to prevent the transmission of heat and fire for the intended duration of 2 hours. 


\section{Documented Safety Analysis for the Waste Storage Facilities}

The aggregate information in these assessments demonstrates that the combination of the existing B696S/B696R partition and the TSR combustible loading limits precludes a fire from propagating from B696R to B696S. Therefore, this vulnerability has no impact on the basis for segmentation.

\section{C3.4.3 Use of Distance and Fire Loading in Segmentation}

Additional discussion was requested by NNSA personnel in DOE to justify the use of distance and fire loading as part of the technical basis for segmentation from Building 695 Segment. In past discussions of DSA development and facility segmentation, $20 \mathrm{ft}$ was assumed to be adequate for physical separation.

Spacing should be at least twice the height of the stacked materials to prevent the spread of fire from stack to stack or from stack to building. The largest material stacked outdoors will be the double-stacked 4-ft $\times 4$ - $\mathrm{ft} \times 7$-ft waste boxes. The height of the stacked boxes will be approximately eight feet, so twice this height is sixteen feet which is less than the proposed 20-ft fire break.

Additionally, the NFPA also provides guidance for protecting buildings from exposure to exterior fires. By determining the width-to-height ratio for the hypothetical fire, the minimum separation distance can be calculated using some parameters of the exposed building. The first step in this calculation is to determine the severity of the fire loading in the area. The NFPA classifies 7 $\mathrm{lbs} / \mathrm{ft}^{2}$ of combustible materials as a "light" severity of fire loading. A worst-case scenario would be for the double-stacked waste boxes to catch on fire. The stacked waste boxes have a widthto-height ratio of 0.875 , which will be rounded up to a value of 1.0. A conservative assumption would be to assume that the side of the building exposed to the fire is totally open so as to expose the contents of the building to the fire. Following the table provided by the NFPA, the minimum separation distance can be determined by multiplying the smaller dimension of the fire (either width or height) by 1.39 and adding five feet to the result:

$$
\text { Minimum Separation }=7^{\prime} \times 1.39+5^{\prime}=14.73 \text { feet }
$$

The minimum separation calculated is in relative agreement with the previous NFPA citation that recommended a sixteen-foot separation based on a "rule of thumb" determination. Though this calculative procedure is used primarily for determining distances between buildings, NFPA 231 recommended this procedure when storing commodities next to buildings.

Potential fires around Building 696 would not involve combined material at risk from either Building 696 RWSA or the Building 695 Segment because there is adequate separation.

The anticipated combustible loading in RHWM facilities, consisting of transient and fixed combustibles, is lower than $7 \mathrm{lb} / \mathrm{ft}^{2}$. The separation in a building containing this concentration of combustibles requires one-hour fire-rated partitions. The partition separating the SWPA from the RWSA in Building 696 is of equal construction to various listed 3 hour rated designs (Reference 7). Limiting the combustible material storage in B696S Room 1009 and in B696R to $7 \mathrm{lb} / \mathrm{ft}^{2}$ essentially limits the potential damage to the partition and ensures that the partition will not be breached due to a fire. 


\section{Documented Safety Analysis for the Waste Storage Facilities}

\section{C.4 CONCLUSION}

According to DOE-STD-1027-92, Attachment 1, the following considerations are made in facility segmentation:

"It is necessary to avoid placing excessive requirements on simple or even trivial colocated operations. The concept of independent facility segments should be applied where facility features preclude bringing material together or causing harmful interaction from a common severe phenomenon."

In order to satisfy the requirement in DOE-STD-1027-92, potential accidents that could invalidate the technical basis for segmentation were evaluated to ensure that "facility features" are adequate, as follows:

- Shared utilities

- Aircraft crash

- Natural phenomena

- $\quad$ Fire

It was shown in Section C3.1 that failure or malfunction of shared utilities for Building 696 RWSA and Building 695 Segment would lead to interruptions in operations. However, it was shown that failure or malfunction would not bring radioactive inventories together to pose undue risk to the public, workers or environment.

The potential for an aircraft crash into the partition separating Building 696 SWPA and Building 696 RWSA was evaluated in Section C3.2. A structural evaluation using conservative assumptions showed that a direct impact on the most vulnerable roof beam would result in yielding, but not puncture, of the beam. The probability estimate, however, assumed puncture upon impact for conservatism. Even then, the estimated annual probability of impact was determined to be less than $1 \times 10^{-6}$. A range of impact angles was evaluated in Section C3.2, results of which showed that the conclusion remains unchanged.

Natural phenomena were evaluated in Section C3.3. Building 696 and Building 695 are seismically qualified structures to preclude release of radioactivity in the event of natural phenomena, in particular, earthquakes and strong winds.

The potential for fire propagation that would adversely affect the radioactive inventories in the two segments was evaluated in Section C3.4. The evaluation addressed the vulnerabilities identified in the November 2003 FHA and December 2006 fire protection assessment with the potential for invalidating the segmentation of Building 696 SWPA and Building 696 RWSA. Based on the anticipated combustible loading and the magnitude of potential fires, it was shown that fire separation provided by the partition and the physical separation of $20 \mathrm{ft}$ around the Building 695 Segment were adequate to prevent fire propagation. 
It is concluded that there is no common severe phenomenon that would bring material together or cause harmful interaction. Therefore, the segmentation of the Waste Storage Facilities from B695 and B696S satisfies the requirement in DOE-STD-1027-92 for segmentation.

\section{C.5 REFERENCES}

1. Federal Aviation Administration, <http://aspm.faa.gov/main/atads.asp> (March 14, 2008).

2. "Fire Hazard Analysis of Building 696, Decontamination and Waste Treatment Facility, Solid Waste Processing \& Storage Building," Revision 2, November, 2003.

3. "Documented Safety Analysis for the Waste Storage Facilities," latest revision.

4. Introduction to Fire Dynamics, Douglas Drysdale, 2nd edition, Wiley \& Sons, 1998.

5. Fire Protection Handbook, Arthur E. Cote, et. al., 18th edition, National Fire Protection Association, 1997.

6. Memorandum from Michael L. Jones to Kerry Cadwell, "Clarification of Building 696 Fire Barrier Wall Hour Rating vs. Failure Time. (Question from E-mail dated 14 December 2006 from Kerry Cadwell)," December 21, 2006.

7. Memorandum from Michael L. Jones to Pat Epperson, "Bldg 696 Fire Partition Wall Between Room 1009 and 1010 Determination of Construction Fire Resistance Rating of Wall," December 6, 2006.

8. RHWM Calculation WM/FS B696-07-01, "Impact of fire on wall in B696," May 18, 2007, Rev. 1.

9. Letter from Patrick C. Ward, Schirmer Engineering Corporation, to David Larsen, LLNL, "Fire Barrier Wall, LLNL Building 696, Livermore, California, SEC Project No. 1607003-000," February 14, 2007. 